\title{
REVISÃO TAXONÔMICA E ANÁLISE FILOGENÉTICA DE ESPÉCIES DE APONYCHUS RIMANDO, PARAPONYCHUS GONZÁLEZ \& FLECHTMANN E STYLOPHORONYCHUS PRASAD (ACARI, EURYTETRANYCHINI)
}

\section{Fábio Akashi Hernandes}

Orientador: Prof. Dr. Reinaldo J.F. Feres

Tese apresentada ao Programa de Pós-graduação em Biologia Animal do Instituto de Biociências, Letras e Ciências Exatas de São José do Rio Preto, como parte dos requisitos para obtenção do título de Doutor em Biologia Animal. 
Hernandes, Fábio Akashi.

Revisão taxonômica e análise filogenética de espécies de Aponychus Rimando, Paraponychus González \& Flechtmann e Stylophoronychus Prasad (Acari, Eurytetranychini) / Fábio Akashi Hernandes. - São José do Rio Preto : [s.n.], 2010.

204 f. : il. ; $30 \mathrm{~cm}$.

Orientador: Reinaldo José Fazzio Feres

Tese (doutorado) - Universidade Estadual Paulista, Instituto de Biociências, Letras e Ciências Exatas

1. Acarologia. 2. Filogenia. 3. Ácaro - Filogenia. 3.Taxonomia zoológica. I. Feres, Reinaldo José Fazzio. II. Universidade Estadual Paulista, Instituto de Biociências, Letras e Ciências Exatas. III. Título.

CDU -595.42

Ficha catalográfica elaborada pela Biblioteca do IBILCE

Campus de São José do Rio Preto - UNESP 
Trabalho desenvolvido no Laboratório de Acarologia, Departamento de Zoologia e Botânica, Instituto de Biociências, Letras e Ciências Exatas de São José do Rio Preto, IBILCE/UNESP, e financiado pela Fundação de Amparo à Pesquisa do Estado de São Paulo - FAPESP (06/52893-5). 
Dedico este trabalho aos meus pais, José e Izaura, e à minha querida noiva, Flávia. 


\section{UNIVERSIDADE ESTADUAL PAULISTA \\ INSTITUTO DE BIOCIÊNCIAS, LETRAS E CIÊNCIAS EXATAS DE SÃO JOSÉ DO RIO PRETO}

1. Curso: Biologia Animal

2. Nível: Doutorado

3. Área de Concentração: Biologia Animal

4. Linha de pesquisa: Sistemática e Evolução

5. Projeto: Revisão taxonômica e análise filogenética de espécies de Aponychus Rimando, Paraponychus González \& Flechtmann e Stylophoronychus Prasad (Acari, Eurytetranychini).

6. Aluno: Fábio Akashi Hernandes

7. Matrícula: $34961-2$

8. Orientador: Reinaldo J.F. Feres

9. Data de matrícula: 20 de março de 2006

10. Data de defesa: 17 de março de 2010

11. Título da tese: Revisão taxonômica e análise filogenética de espécies de Aponychus Rimando, Paraponychus González \& Flechtmann e Stylophoronychus Prasad (Acari, Eurytetranychini).

12. Número de páginas: $204 p+X I V$. 
Meus agradecimentos ao Programa de Pós-Graduação em Biologia Animal do Instituto de Biociências, Letras e Ciências Exatas de São José do Rio Preto, IBILCE/UNESP pelo apoio e suporte no desenvolvimento do presente trabalho. 


\section{AGRADECIMENTOS}

Ao meu orientador, prof. Dr. Reinaldo J.F. Feres (UNESP, São José do Rio Preto) pela orientação, confiança e oportunidade oferecida para a realização do projeto. Espero ter correspondido à sua expectativa e desenvolvido da melhor forma o trabalho com os "seus bichos".

Aos diversos pesquisadores e curadores que gentilmente enviaram espécimes e tipos:

Dr. Anibal R. Oliveira (Universidade Estadual de Santa Cruz, Ilhéus, BA); Dr. Carlos H.W. Flechtmann (ESALQ - USP, Piracicaba), também pelas sugestões e revisão do resumo no idioma alemão; Dr. C-C Ho (Taiwan Agricultural Research Institute, Taiwan); Dr. Edward A. Ueckermann (ARC - Plant Protection Research Institute, Pretoria, África do Sul); Jeferson L.C. Mineiro (Instituto Biológico, Campinas, SP); Drs. Ronald A. Ochoa e Debra C. Creel (USDA - Beltsville, Maryland, EUA), também pela cordial hospitalidade durante visitas à coleção do Smithsonian Institution; Dr. Vikram Prasad (Indira Publishing House, West Bloomfield, Michigan, EUA); Dr. Jun Chen (Chinese Academy of Sciences, Beijing, China).

Aos pesquisadores (in memorian), pelo envio de espécimes tipo:

Dr. Shozo Ehara (Tottori University, Japão) e Magdalena K.P. Smith Meyer (ARC - Plant Protection Research Institute, Pretoria, África do Sul).

Aos pesquisadores e curadores pelo auxílio durante visitas às Coleções:

Drs. Ardis Baker Johnston e Adam Baldinger (MCZ - Museum of Comparative Zoology, Cambridge, Massachussetts, EUA); Drs. Ramakrishna Arkalgud, Asok Kanti Sanyal e Debabrata Battacharyya (ZSI - Zoological Survey of India, Calcutá, Índia).

Aos professores do Programa de Pós-graduação em Biologia Animal, pelas sugestões oferecidas:

Drs. Francisco Langeani Neto e Fernando B. Noll (UNESP, São José do Rio Preto), Dra. Vera C. Silva (UNESP, Jaboticabal), pelas sugestões oferecidas ao projeto e Exame de Qualificação.

A Hans Günther Rau, por gentilmente realizar a versão do resumo no idioma alemão.

Ao M.Sc. Luis Fernando Fracassi Gelin, pelo auxílio na utilização dos softwares de filogenética.

Ao amigo M.Sc. Michel P. Valim (Universidade Federal de Minas Gerais, Belo Horizonte, MG) pelas valiosas discussões, sugestões e parcerias, que muito contribuíram para meu entendimento sobre sistemática, taxonomia e ciência.

Aos companheiros de laboratório: Adriano Mendonça, Antônio C. Lofego, Eduardo R. Silva, Eliseu B. Castro, Felipe M. Nuvoloni, Fernanda Silva, José M. Rezende ("Zezão"), José C. Souza ("Zé"), Peterson R. Demite, Raquel G. Kishimoto, Renato Buosi, Rodrigo D. Daud, Rodrigo Verona, Vimael Russo e Viviane Mattos pelas prolíficas discussões e ótimo ambiente de trabalho. 
“(...) Nós nos importamos muito com quem se ramificou a partir de quem, porque nosso negócio é reconstituir a história da vida, e valorizamos nossas criaturas favoritas com o mesmo cuidado amoroso que muita gente dedica às suas famílias. Muitas pessoas ficariam bastante preocupadas se soubessem que seu primo era realmente seu pai - mesmo que essa descoberta trouxesse poucos esclarecimentos acerca de sua construção biológica."

Stephen Jay Gould (1941-2006)

trecho do ensaio O revelador "osso da sorte", do livro "O polegar do panda". 


\section{RESUMO}

Tetranychidae é uma importante família de ácaros exclusivamente fitófagos, atualmente com 1.257 espécies, sendo que algumas delas causam os mais severos danos à agricultura. Em decorrência disso, muita atenção tem sido dada aos seus aspectos biológicos, mas poucos trabalhos enfocam sua história evolutiva e relações de parentesco. Diversos gêneros já foram incluídos na tribo Eurytetranychini, entretanto, baseando-se em especulações, e não em estudos filogenéticos abrangentes que demonstrassem a evolução e homologia entre diferentes estados de caráter. Faz-se necessária, portanto, uma análise cladística para as espécies dessa tribo, de modo a se desvendar a importância dos diversos caracteres morfológicos utilizados na separação de táxons desse grupo, tentando reconstituir as relações de parentesco entre suas espécies.

Neste trabalho, apresentamos a primeira hipótese de relacionamento filogenético entre as espécies dos gêneros Aponychus, Paraponychus e Stylophoronychus. A análise forneceu apenas uma árvore mais parcimoniosa $(\mathrm{L}=135 ; \mathrm{IC}=45 ; \mathrm{IR}=82)$. Embora o monofiletismo do grupo interno tenha sido confirmado, os gêneros deste grupo revelaram-se parafiléticos quanto às suas relações internas. A presença de algumas politomias no cladograma foi constante, mesmo após pesagem de caracteres.

Com base nas análises morfológica, filogenética, de ocorrência geográfica e de hospedeiros, conclui-se que várias espécies desse grupo devem ser sinonimizadas: Aponychus aequilibris com A. corpuzae; Paraponychus incanus com P. corderoi; S. baghensis com S. nakaoi; A. bambusae e S. lalli com S. vannus. Outras espécies provavelmente devem ser sinonimizadas com A. rarus, mas isso não pôde ser confirmado porque a análise do material tipo de A. rarus não foi possível: A. expansus, A. grandidieri, A. lupus, A. parydrus e A. sulcatus.

Muitas espécies foram descritas a partir de poucos indivíduos, sendo suas diagnoses fundamentadas, na maioria das vezes, no que se mostrou serem diferenças individuais, como o comprimento relativo de algumas setas dorsais, e portanto, não específicas. Conclui-se, assim, que essas diferenças não mais devem ser utilizadas para a diagnose de espécies desse grupo, pelo menos até que se estude um número maior de indivíduos.

Algumas espécies não possuem material tipo disponível, ou possuem identidade duvidosa. Nestes casos, sugerimos que elas sejam consideradas como species inquirenda, até que novos exemplares sejam coletados nas localidades e hospedeiros tipo, e melhor analisadas: A. solimani e A. imperatus, que possivelmente constituem mais dois sinônimos júnior de A. rarus; $S$. insularis, descrita a partir de uma única fêmea, não apresenta seu espécime tipo disponível para estudo. Os resultados obtidos pela análise filogenética demonstraram que essa espécie não pertence ao gênero Stylophoronychus.

Palavras chave: acarologia, filogenia, sistemática, taxonomia, Tetranychidae. 


\begin{abstract}
Tetranychidae is an important family of strictly phytophagous mites, comprising currently of 1,257 species, some of which cause severe damage to crops. As a result, much attention has been paid to their biological aspects, meanwhile only a few papers emphasize their evolutionary history and relationships. Several genera have been included in the tribe Eurytetranychini, however, based on speculations rather than phylogenetical studies that depicted their evolution and homology between character states. Therefore, a thorough cladistic analysis is needed for the species of this tribe, throwing light into the evolution of morphological characters, and attempting to reconstruct the evolutionary history between these species.

We present here the first hypothesis of phylogenetic relationship for species of the genera Aponychus, Paraponychus and Stylophoronychus. The analysis returned only a single most parcimonious tree $(\mathrm{L}=135 ; \mathrm{CI}=45 ; \mathrm{RI}=82)$. Although the monophyly of the ingroup was confirmed, the genera within this group revealed paraphyletic for their internal relationships. Some polytomies were constantly found, even after character weighting.

Basing on the morphology, phylogeny, geographical occurence and host association, we concluded that several species must be put into synonymy: Aponychus aequilibris with A. corpuzae; Paraponychus incanus with P. corderoi; S. baghensis with S. nakaoi; A. bambusae and S. lalli with S. vannus. Other species that probably should also be synonymyzed with A. rarus are A. expansus, A. grandidieri, A. lupus, A. parydrus and A. sulcatus; this hypothesis could not be confirmed because the analysis of the types of $A$. rarus was not possible.

Several species were described based on a small number of specimens, and we concluded that their diagnosis merely reflects individual differences such as the relative length of some dorsal setae. Therefore, such differences should not be used to separate species of this group anymore, at least until a larger number of specimens are studied.

Some species do not have their types available, or have dubious status. In those cases, we suggest to regard them as species inquirenda, until more specimens are collected and analysed from the type host and localities: A. solimani and A. imperatus, which possibly are synonyms of $A$. rarus; $S$. insularis, described from a single female, does not have its type available either. The phylogeny suggests this species does not belong to the genus Stylophoronychus.
\end{abstract}

Keywords: acarology, phylogeny, systematics, taxonomy, Tetranychidae. 


\section{ZUSAMMENFASSUNG}

Tetranychidae ist eine wichtige Familie von ausschliesslich phytophagen Milben, zur Zeit mit 1257 Arten, von denen einige starke Schäden in der Landwirtschaft verursachen. Aus diesem Grund, werden ihre biologischen Aspekte stark beachtet, jedoch nur wenige Studien fokalisieren seine geschichtliche Evolution und ihre Verwandtschaftsbeziehungen. Verschiedene Unterarten wurden dem Stamm Eurytetranychini zugeordnet, jedoch auf Grund von Spekulationen und nicht auf Grund von phylogenetischen Studien welche die weitreichende Evolution und Homologie zwischen verschiedenen Karakter-stadien aufzeigen würde. Es ist daher notwendig für diese Art eine kladistische Analyse zu erstellen, um die tatsächliche Wichtigkeit der verschiedenen morfologischen Karaktere bei der Einteilung der Taxa dieser Gruppe, herauszufinden dieses als Rekonstruktion der richtigen Form der Verwandtschaftsbeziehungen zwischen den Arten.

Mit dieser Arbeit, stellen wir eine erste Hypotese vor, welche die phylogenetischen Beziehungen zwischen den Arten Aponychus, Paraponychus und Stylophoronychus beschreibt. Die Analyse ergab lediglich einen Stammbaum sparsam $(\mathrm{L}=135$; IC=45; IR=82). Der Monophyletismus der gesammten Gruppe wurde bestätigt, jedoch zeigte es sich dass sich Unterarten paraphyletisch zeigen in Bezug auf ihre internen Beziehungen. Die Anwesenheit einiger Polytomien im Kladogramm war konstant, auch nach dem abwiegen der Karaktere.

Basierend auf morphologischen und phylogenetischen Analysen sowie geografischer Präsenz und der Träger-arten resultiert, daß verschiedene Arten dieser Gruppe synonymisiert sind: Aponychus aequilibris mit A. corpuzae; Paraponychus incanus mit P. corderoi; S. baghensis mit S. nakaoi; A. bambusae und $S$. lalli mit $S$. vannus. Andere Arten sind vermutlich synonymisiert mit A. rarus, dies konnte jedoch nicht bestättigt werden ohne Analyse des Materials von den Arten: A. expansus, A. grandidieri, A. lupus, A. parydrus und A. sulcatus.

Viele Arten wurden beschrieben auf Grund von nur wenigen Exemplaren, so daß die Diagnose in der Mehrheit auf individuellen Differenzen basiert ist, wie zum Beispiel die Länge einiger Haare an der Rückenoberfläche welche daher nicht spezifisch sind. Es wird festgestellt, daß diese kleinen Unterschiede nicht mehr für die Diagnose der Arten dieser Gruppe verwendet werden sollen zumindest bis eine größere Gruppe dieser Arten untersucht wurde.

Für einige Arten steht kein typisches Material zur Verfügung, oder es bestehen Zweifel an ihrer Identität. Wir schlagen vor diese als species inquirendae zu bezeichnen bis neue Exemplare zur Analyse vorliegen aus deren geografischen Herkunft sowie der Wirtarten: A. solimani und A. imperatus welche vermutlich zwei Junior Synonyme von A. rarus; $S$. insularis, deren Beschreibung auf einem einzigen weiblichen Exemplar beruht hat keine typischen Merkmale für die Untersuchung. Das Ergebniß der phylogenetischen Analyse zeigt, daß diese Art nicht zur Gruppe der Stylophoronychus gehöhrt.

Stichworte: Acarologie, Phylogenetische, Systematik, Taxonomie, Tetranychidae. 


\section{LISTA DE FIGURAS}

Introdução Geral.

Figura 1 (pág. 3) - vistas dorsal e ventral do corpo de um ácaro da família Tetranychidae.

Figura 2 (pág. 4) - morfologia dos empódios.

Figura 3 (pág. 5) - setas das valvas anais da família Tetranychidae.

Figura 4 (pág. 6) - número de espécies das tribos da família Tetranychidae.

Figura 5 (pág. 9) - elementos tarsais de representantes da subfamília Tetranychinae.

Figura 6 (pág. 9) - classificações de Eurytetranychini.

\section{Capítulo I.}

Figura 7 (pág. 41) - cladograma com valores de Bremer, Boostrap e Jacknife.

Figura 8 (pág. 42) - cladograma com evolução de caracteres.

Figura 9 (pág. 45) - formato do idiossoma.

Figura 10 (pág. 45) - morfologia dos estilóforos.

Figura 11 (pág. 46) - detalhe de região dorsal de Aponychus parydrus.

Figura 12 (pág. 46) - detalhe de região dorsal de Stylophoronychus vannus.

Figura 13 (pág. 47) - setas da região posterior do corpo de Stylophoronychus lalli e S. vannus.

Figura 14 (pág. 47) - coxas das pernas I e II.

Figura 15 (pág. 48) - esquema de setas dorsais e de pernas de Aponychus corpuzae.

Figura 16 (pág. 49) - fêmures da perna I.

Figura 17 (pág. 50) - fêmures da perna II.

Figura 18 (pág. 51) - fêmures da perna III.

Figura 19 (pág. 52) - fêmures da perna IV.

Figura 20 (pág. 53) - gênus da perna I.

Figura 21 (pág. 54) - gênus da perna II.

Figura 22 (pág. 55) - gênus da perna III.

Figura 23 (pág. 56) - gênus da perna IV.

Figura 24 (pág. 57) - tíbias da perna I.

Figura 25 (pág. 58) - tíbias da perna II.

Figura 26 (pág. 59) - tíbias da perna III.

Figura 27 (pág. 60) - tíbias da perna IV.

Figura 28 (pág. 61) - tarsos da perna I.

Figura 29 (pág. 62) - tarsos da perna II.

Figura 30 (pág. 63) - tarsos da perna III.

Figura 31 (pág. 64) - tarsos da perna IV.

Capítulo II.

Figura 32 (pág. 72) - Stylophoronychus insularis.

Figura 33 (pág. 73) - Stylophoronychus insularis, artículos das pernas.

Figura 34 (pág. 77) - Aponychus schultzi, dorso.

Figura 35 (pág. 78) - Aponychus schultzi, artículos das pernas.

Figura 36 (pág. 81) - Aponychus pilipinus, dorso.

Figura 37 (pág. 82) - Aponychus pilipinus, artículos das pernas.

Figura 38 (pág. 85) - Aponychus firmianae, dorso.

Figura 39 (pág. 86) - Aponychus firmianae, artículos das pernas.

Figura 40 (pág. 88) - Aponychus spinosus, dorso.

Figura 41 (pág. 89) - Aponychus spinosus, artículos das pernas.

Figura 42 (pág. 91) - Aponychus taishanicus, dorso.

Figura 43 (pág. 93) - Aponychus mallotus, dorso.

Figura 44 (pág. 94) - Aponychus mallotus, artículos das pernas.

Figura 45 (pág. 96) - Paraponychus kodaikanalensis, dorso.

Figura 46 (pág. 99) - Paraponychus saundersi, dorso.

Figura 47 (pág. 100) - Paraponychus saundersi, artículos das pernas.

Figura 48 (pág. 103) - Aponychus chiavegatoi, dorso.

Figura 49 (pág. 104) - Aponychus chiavegatoi, artículos das pernas.

Figura 50 (pág. 108) - Paraponychus corderoi, dorso (holótipo). 
Figura 51 (pág. 109) - Paraponychus corderoi, dorso (parátipos) e P. incanus (parátipos).

Figura 52 (pág. 110) - Paraponychus corderoi, artículos das pernas.

Figura 53 (pág. 114) - Aponychus aequilibris e A. corpuzae.

Figura 54 (pág. 117) - Aponychus corpuzae, dorso.

Figura 55 (pág. 118) - Aponychus corpuzae, artículos das pernas.

Figura 56 (pág. 121) - Aponychus siamensis, dorso.

Figura 57 (pág. 122) - Aponychus siamensis, artículos das pernas.

Figura 58 (pág. 124) - Aponychus expansus, dorso e estilóforo.

Figura 59 (pág. 126) - Aponychus grandidieri, dorso.

Figura 60 (pág. 127) - Aponychus grandidieri, artículos das pernas.

Figura 61 (pág. 129) - Aponychus imperatus, dorso.

Figura 62 (pág. 131) - Aponychus lupus, dorso e estilóforo.

Figura 63 (pág. 133) - Aponychus parydrus, dorso e estilóforo.

Figura 64 (pág. 135) - Aponychus rarus, dorso.

Figura 65 (pág. 137) - Aponychus solimani, dorso.

Figura 66 (pág. 139) - Aponychus sulcatus, dorso e estilóforo.

Figura 67 (pág. 144) - Aponychus grandidieri, A. expansus, A. lupus, A. parydrus, A. rarus e A. sulcatus, dorsos.

Figura 68 (pág. 147) - Aponychus sarjui, dorso.

Figura 69 (pág. 148) - Aponychus sarjui, artículos das pernas.

Figura 70 (pág. 152) - Stylophoronychus nakaoi, dorso, tíbia e tarso I-II.

Figura 71 (pág. 154) - Stylophoronychus baghensis, dorso.

Figura 72 (pág. 155) - Stylophoronychus baghensis, artículos das pernas.

Figura 73 (pág. 160) - Stylophoronychus vannus, dorso.

Figura 74 (pág. 161) - Stylophoronychus vannus, artículos das pernas.

Figura 75 (pág. 163) - Stylophoronychus lalli, dorso (fotomicrografia em contraste de fases).

Figura 76 (pág. 165) - Stylophoronychus guangzhouensis, dorso.

Figura 77 (pág. 167) - Aponychus bambusae, dorso (fotomicrografia).

Figura 78 (pág. 171) - setas da região posterior do corpo de espécimes de Stylophoronychus.

Figura 79 (pág. 172) - espécimes tipo de Aponychus.

Figura 80 (pág. 173) - espécimes tipo de Aponychus.

Figura 81 (pág. 174) - espécimes tipo de Aponychus, Paraponychus e Stylophoronychus.

Figura 82 (pág. 175) - espécimes tipo de Aponychus e gêneros próximos.

\section{Capítulo III.}

Figura 83 (pág. 187) - domínios biogeográficos da flora mundial.

Figura 84 (pág. 188) - número de hospedeiros de cada espécie de Aponychus e gêneros próximos.

Figura 85 (pág. 189) - distribuição geográfica das espécies de Aponychus e gêneros próximos.

Figura 86 (pág. 190) - fillogenia e distribuição das espécies nas regiões Neotropical e Paleártica.

Figura 87 (pág. 193) - filogenia dos hospedeiros de Aponychus e gêneros próximos.

\section{LISTA DE TABELAS}

Tabela I (pág. 18) - espécies utilizadas na análise filogenética.

Tabela II (pág. 67) - espécies utilizadas na revisão taxonômica.

Tabela III (pág. 102) - medidas de espécimes de Aponychus chiavegatoi.

Tabela IV (pág. 107) - medidas de espécimes tipo de Paraponychus corderoi e P. incanus.

Tabela V (pág. 143) - medidas de espécimes tipo de Aponychus.

Tabela VI (pág. 157) - medidas de espécimes tipo de Stylophoronychus baghensis e S. nakaoi.

Tabela VII (pág. 170) - medidas de espécimes tipo de Stylophoronychus.

Tabela VIII (pág. 176) - quetotaxia das espécies de Aponychus, Paraponychus e Stylophoronychus.

APÊNDICE I (pág. 43) - matriz de caracteres e figuras.

APÊNDICE II (pág. 179) - plantas hospedeiras das espécies de Aponychus, Paraponychus e Stylophoronychus. 


\section{SUMÁRIO}

Resumo

Abstract.....

Zusammenfassung.

Lista de figuras

Lista de tabelas..

Introdução geral..

Objetivos

Formato da Tese.

CAPÍTULO I - Análise filogenética das espécies de Aponychus Rimando, Paraponychus González \& Flechtmann e Stylophoronychus Prasad.

Introdução

Material e métodos...

Resultados e discussão.

Apêndice I: matriz de caracteres, figuras e cladogramas.

\section{CAPÍTUlO II - Revisão taxonômica das espécies Aponychus, Paraponychus e Stylophoronychus..}

Introdução.

Objetivos.

Material e Métodos.

Resultados

Stylophoronychus insularis

Aponychus schultzi ....

Aponychus pilipinus.

Aponychus firmianae

Aponychus spinosus

Aponychus taishanicus

Aponychus mallotus ...

Paraponychus kodaikanalensis .....

Paraponychus saundersi

Aponychus chiavegatoi

Paraponychus corderoi

Paraponychus incanus

Aponychus aequilibris

Aponychus corpuzae

Aponychus siamensis

Aponychus expansus

Aponychus grandidieri

Aponychus imperatus

Aponychus lupus

Aponychus parydrus

Aponychus rarus

Aponychus solimani

Aponychus sulcatus

Aponychus sarjui

Stylophoronychus nakaoi

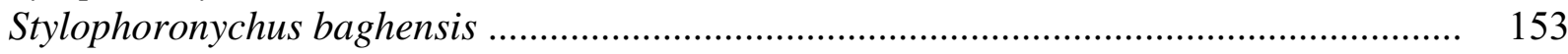

Stylophoronychus vannus 
Stylophoronychus lalli

Stylophoronychus guangzhouensis ...................................................................... 164

Aponychus bambusae ............................................................................................. 166

Chave para auxílio na identificação de fêmeas de Aponychus, Paraponychus e

Stylophoronychus.

Apêndice II: plantas hospedeiras das espécies de Aponychus, Paraponychus e

Stylophoronychus.

CAPÍTULO III -Biogeografia de Aponychus, Paraponychus e Stylophoronychus, e

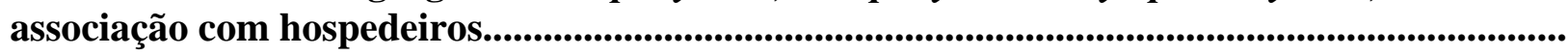

Introdução

Objetivo

Material e métodos

Resultados

Distribuição geográfica

Hospedeiros

Discussão

Origem e dispersão

Conclusões e considerações finais

Bibliografia. 


\section{INTRODUÇÃO GERAL}

Das diversas famílias de ácaros fitófagos, Tetranychidae Donnadieu, 1875 é a que apresenta espécies que causam os mais severos danos à agricultura (Lindquist 1985a). Em decorrência disso, muita atenção tem sido dada aos aspectos biológicos de seus representantes, com diversos trabalhos sobre ciclo de vida e testes de controle biológico das principais espécies de importância agrícola (Moraes \& Flechtmann, 2008). Entretanto, poucos trabalhos enfocaram a história evolutiva e relações de parentesco entre táxons dessa família (Lindquist 1985a, b, Gutierrez 1985, Rimando \& Corpuz-Raros 1996, Navajas \& Gutierrez, 1996).

\section{Aspectos biológicos e morfologia}

Tetraniquídeos têm sido referidos, na literatura nacional, como "ácaros-de-teia", e na literatura de língua inglesa, como "spider mites", devido à capacidade apresentada por algumas espécies de produzir teia. Apresentam, em sua maioria, desenvolvimento haplo-diplóide, com machos produzidos por arrenotoquia. Algumas poucas espécies reproduzem-se por telitoquia (Norton et al., 1994). Existem cinco estágios em seu ciclo vital: ovo, larva, protoninfa, deutoninfa e adulto.

O corpo dos tetraniquídeos pode ser didaticamente dividido em duas partes (Figura 1, p. 3): o gnatossoma, que inclui as quelíceras e os palpos, e o idiossoma, que contém a maioria dos órgãos internos, e onde se localizam os quatro pares de pernas. As quelíceras apresentam-se modificadas de um modo bastante peculiar, que prontamente permitem reconhecer os representantes dessa família: os dígitos móveis são modificados em longos e recurvados estiletes, em uma conformação que se assemelha a um cabo de guarda-chuva ou gancho, cujas extremidades anteriores são utilizadas para perfurar a superfície das folhas. Segundo Carmona \& Dias (1996), tetraniquídeos são capazes de perfurar a epiderme e atingir o parênquima das folhas, alimentandose do conteúdo celular extravasado. Os dois dígitos basais das quelíceras são fundidos, formando um estilóforo retrátil.

\section{Sistemática}

Tetranychidae é a família mais numerosa das cinco incluídas na superfamília Tetranychoidea, com cerca de 1.260 espécies conhecidas atualmente (Migeon \& Dorkeld, 2006). Outra família bastante numerosa, e que também apresenta espécies importantes para a agricultura é Tenuipalpidae Berlese, com 891 espécies (Mesa et al., 2009); outras famílias, menos numerosas, são Tuckerellidae Baker \& Pritchard (12 spp.), Linotetranidae Baker \& Pritchard (8 spp.) e Allochaetophoridae Reck (2 spp.). 
Atualmente, duas subfamílias de Tetranychidae são reconhecidas, Bryobiinae Berlese e Tetranychinae Berlese, diferenciadas principalmente pela estrutura dos empódios (Figura 2, p. 4) e pelo número de pares de setas pseudo-anais (Figura 3, p. 5). Seis tribos são reconhecidas (Figura 4, p. 6): Bryobiini, Hystrichonychini e Petrobiini para a subfamília Bryobiinae, e Eurytetranychini, Tenuipalpoidini e Tetranychini para Tetranychinae. Alguns representantes de Bryobiinae são considerados os tetraniquídeos mais primitivos, apresentando o número máximo de pares de setas prodorsais (4) e opistossomais (12 - o gênero Dasyobia Meyer apresenta 34 pares de setas opistossomais, devido à substituição de várias setas dorsais por grupos de 4 setas, por neotriquia [Gutierrez, 1985: 79]), pseudo-anais (3) e para-anais nas fêmeas (2); machos apresentam 4 pares de setas na região genitoanal. Desse modo, Gutierrez \& Helle (1985) consideraram que os grupos mais derivados seriam aqueles com maior redução no número dessas setas, aparentemente os Eurytetranychini. Entretanto, referiram-se a esses caracteres, tais como a redução no número de setas, como sendo "tendências evolutivas" na família, sendo essas inferências baseadas em análises de morfologia comparada, e não em estudos filogenéticos que forneçam um cenário das relações de parentesco, demonstrando a evolução e homologia entre esses estados de caráter.

Gutierrez \& Helle (1985: 106) aventaram a hipótese de que a subfamília Tetranychinae possa ter evoluído a partir de um ancestral tipo Petrobiini (Bryobiinae), baseando-se na estrutura do ambulacro e na capacidade de produção de seda. Nesse caso, a separação da família Tetranychidae em duas subfamílias, Tetranychinae e Bryobiinae, seria artificial, com esta última sendo parafilética. Entretanto, Lindquist (1985: 66) sugeriu o monofiletismo da subfamília Bryobiinae, baseando-se primariamente no aparecimento de setas nos artículos das pernas durante a ontogenia.

Cerca de 90 espécies compõem atualmente a tribo Eurytetranychini. Ao contrário dos demais tetraniquídeos, que apresentam dois conjuntos de setas dúplices no dorso dos tarsos I, e um nos tarsos II (Figura 5.1, p. 9), essa tribo foi caracterizada pela presença de setas fracamente associadas no dorso desses artículos, além de uma considerável redução no comprimento do elemento quimiossensorial distal (Figura 5.2, p. 9). As setas dúplices, que são uma característica distintiva da família Tetranychidae, são formadas por um elemento tátil proximal e um sensorial quimioreceptor distal, cujos alvéolos apresentam-se coalescentes. Acredita-se que a condição apresentada pelos Eurytetranychini tenha evoluído secundariamente (Lindquist, 1985b, Gutierrez \& Helle, 1985), com os alvéolos dos dois elementos (tátil e quimiorreceptor) separados entre si, ou fracamente associados e não coalescentes. Adicionalmente, o empódio nos representantes desta tribo apresenta-se em forma de garra ou é rudimentar, não ocorrendo pêlos associados como nos Bryobiinae (Figura 2.10-12, p. 4). 


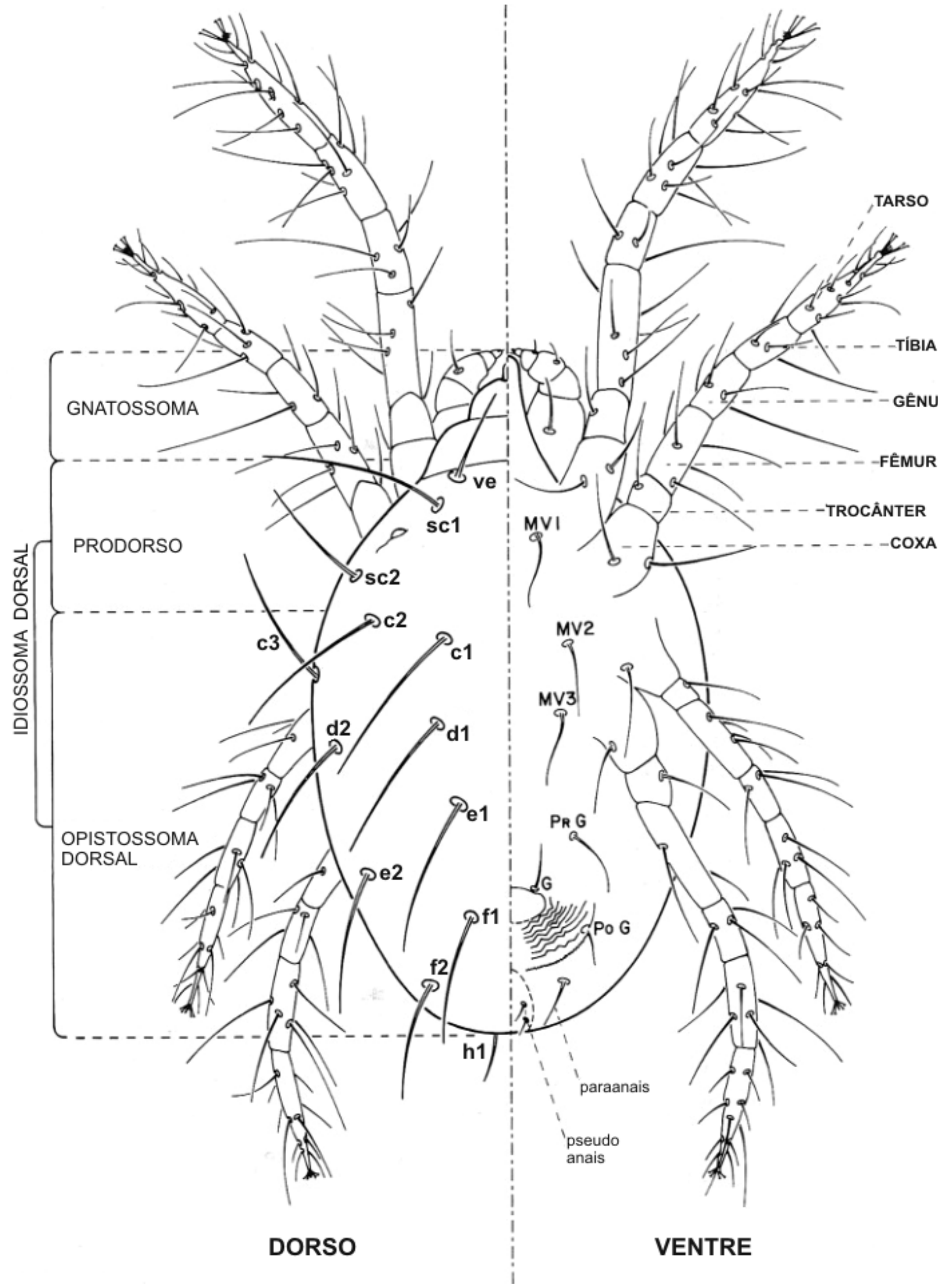

Figura 1. Esquema representativo do corpo de um ácaro da família Tetranychidae: vista dorsal à esquerda, ventral à direita (retirado de Gutierrez, 1985). 

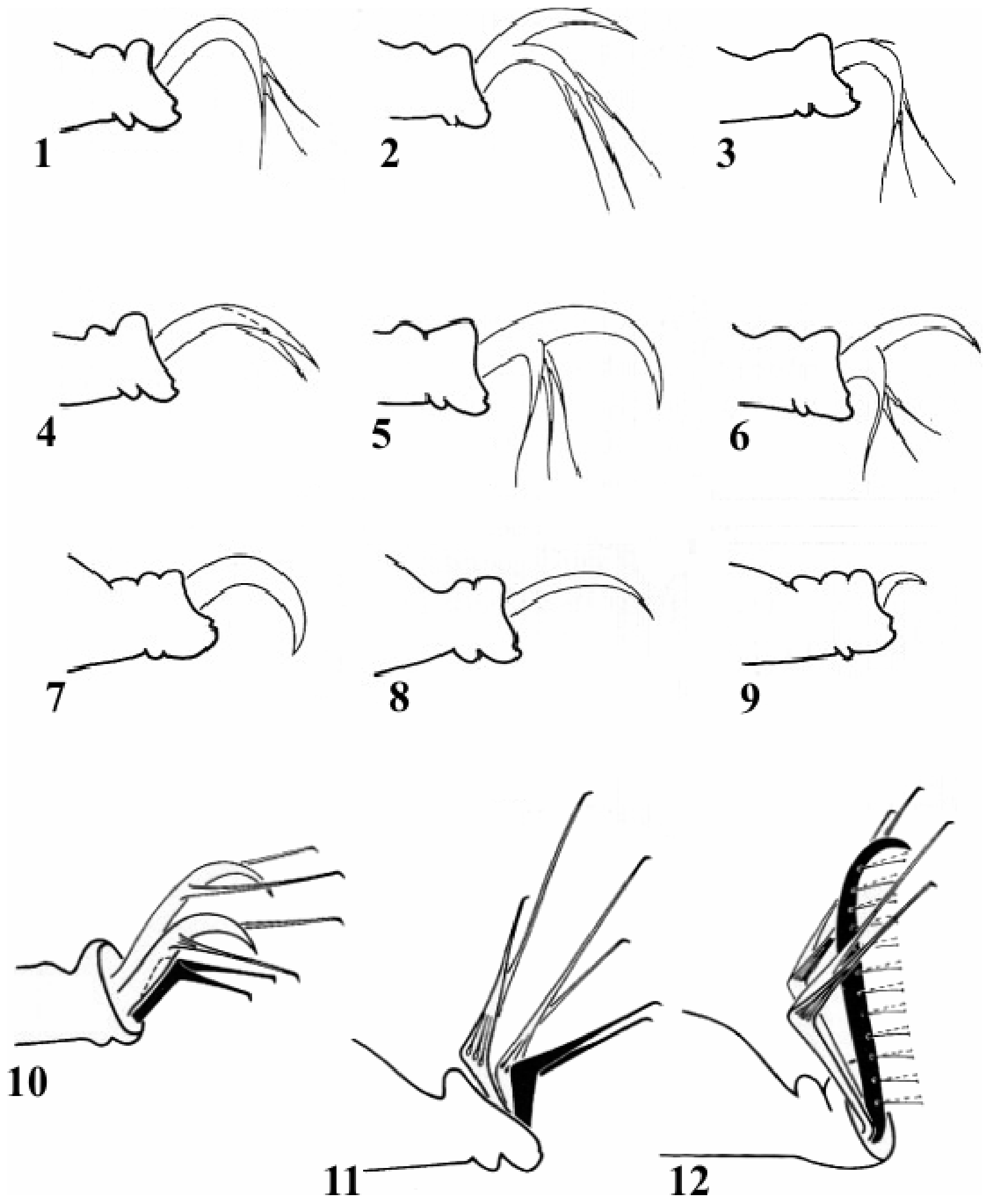

Figura 2. 1-12: empódios e estruturas do pretarso de representantes das subfamílias Tetranychinae (1-9) e Bryobiinae (10-12, empódios destacados em preto): Palmanychus, Eotetranychus, Platytetranychus, Mononychellus (1); Allonychus

(2); Atrichoproctus, Tetranychus (3); Yezonychus, Schizotetranychus (4); Panonychus (5); Oligonychus (6); Mixonychus (7); Sonotetranychus (8); Brevinychus (9); tribo Bryobiini (10); tribo Hystrichonychini (11); Petrobiini (12) (modificado de Gutierrez \& Helle, 1985). 
Com relação às setas dúplices e associadas nos tarsos, os Eurytetranychini formam o grupo mais heterogêneo dentre os Tetranychinae, mas em todos os gêneros dessa tribo ocorreu a perda das setas dúplices pelo menos nos tarsos da perna II. Rimando \& Corpuz-Raros (1996) propuseram uma nova tribo (Aponychini) para abrigar as espécies com um par de setas pseudo-anais (Aponychus e Paraponychus), mas esta proposição não foi aceita por Bolland et al. (1998).

A separação dos gêneros em Eurytetranychini é baseada na presença/ausência e forma do empódio; no número e comprimento dos pares de setas dorsais do opistossoma; na posição das setas do $4^{\mathrm{o}}$ par de dorsocentrais $(f 1)$; no número de setas em posição caudal no opistossoma; no número de setas presentes na coxa II ( 1 a 2); nas dimensões das projeções distais do estilóforo e no número de setas pseudo-anais (1 a 2 pares). Alguns desses caracteres são utilizados para a separação de gêneros, outros para espécies de um mesmo gênero. Ocorre ainda a utilização de vários desses caracteres na separação dos gêneros e espécies pertencentes às outras duas tribos de Tetranychinae (Tenuipalpoidini e Tetranychini).

Os gêneros da tribo Eurytetranychini Aponychus, Paraponychus e Stylophoronychus, que abrigam atualmente cerca de 30 espécies (Tabela I, p. 18) que apresentam somente um par de setas pseudo-anais, compõem o grupo de gêneros próximo de Aponychus, que é objeto deste estudo.
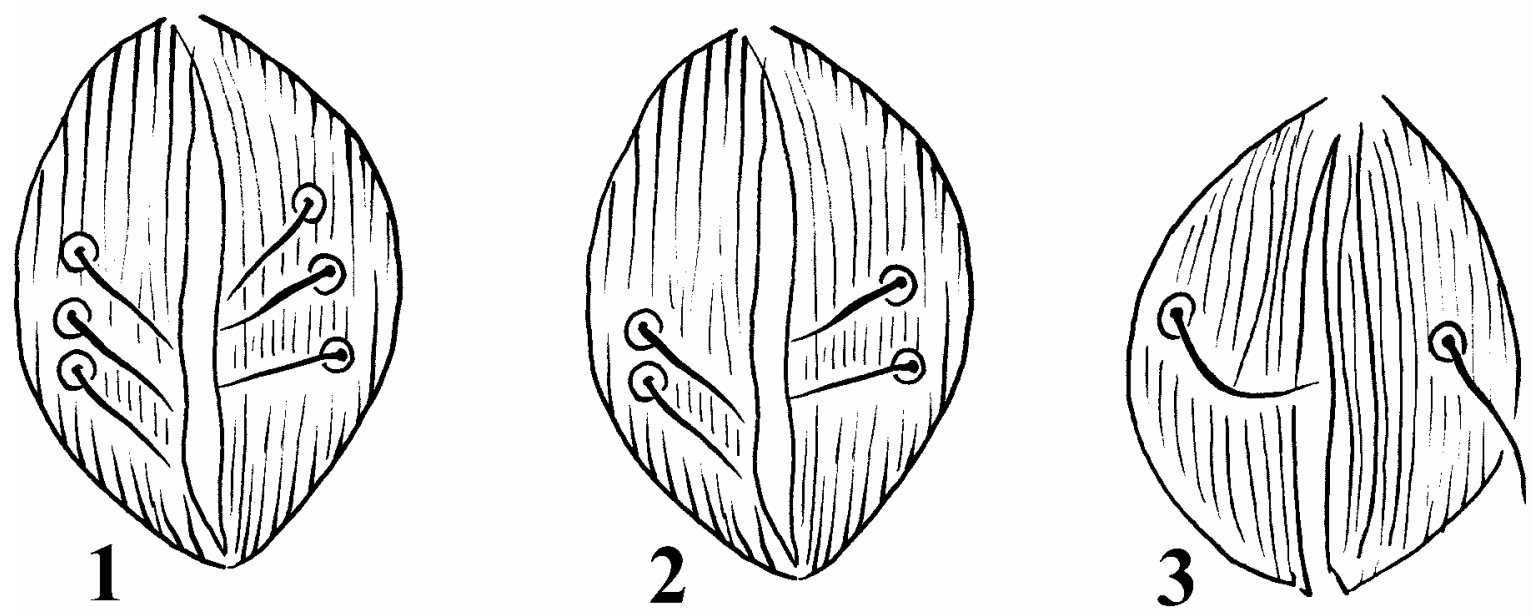

Figura 3. Região anal de fêmeas de representantes da subfamília Bryobiinae (1), e Tetranychinae $(2$ e 3$)$. 


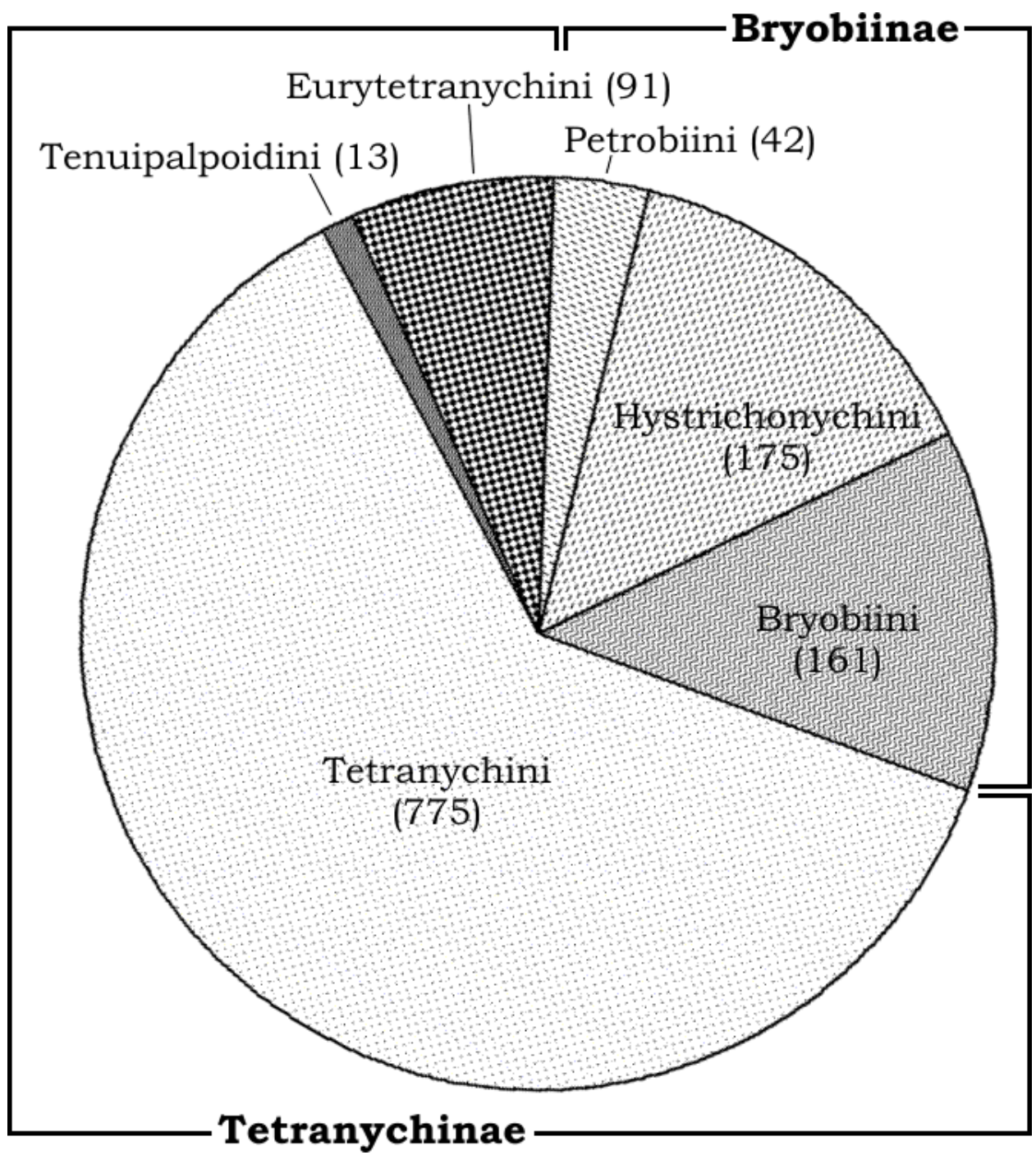

Figura 4. Número de espécies de cada tribo da família Tetranychidae, segundo classificação atual de Migeon \& Dorkeld (2006).

\section{Família Tetranychidae Donnadieu, 1875}

Assim como as demais famílias de Tetranychoidea (Allochaetophoridae, Linotetranidae, Tenuipalpidae e Tuckerellidae), os tetraniquídeos apresentam as bases das quelíceras fundidas formando um estilóforo e o dígito móvel das quelíceras é em forma de um longo e retrátil estilete. Uma das características diagnósticas da família Tetranychidae, dentre os Tetranychoidea, é a presença de setas dúplices no dorso dos tarsos I e II. As fêmeas são facilmente reconhecíveis pela presença de uma área da cutícula ao redor da abertura genital fortemente enrugada, que forma um ovipositor na ocasião da postura. Apesar de já terem sido atribuídos status de família para as subfamílias Bryobiinae e Tetranychinae (Reck 1952, 1959, Mitrofanov 1972, 1977 apud Lindquist, 1985), isso não foi aceito por Lindquist (1985), que as manteve como subfamílias, 
demonstrando que elas de fato formam um grupo monofilético, suportado por pelo menos 3 sinapomorfias: 1) presença de setas dúplices nos tarsos I e II; 2) seta $p v^{\prime}$ modificada em eupatídio ventral nos tarsos I e II; 3) seta trocanteral $l$ 'ausente.

\section{Subfamília Bryobiinae Berlese, 1913}

Os Bryobiinae apresentam 2 ou 3 pares de setas pseudo-anais ( $p s$ ) nas fêmeas, e cinco pares de setas genito-anais nos machos; o empódio apresenta pêlos conjuntos, que são processos setiformes com as extremidades distais achatadas (Figura 2.10-12, p. 4). Algumas espécies apresentam 4 pares de setas prodorsais e 12 histerossomais; raramente ocorrem apenas 6 (Marainobia Meyer) ou 34 (Dasyobia Strunkova) setas opistossomais.

\section{Subfamília Tetranychinae Berlese, 1913}

Representantes desta subfamília são caracterizados pela presença de 1 ou 2 pares de setas pseudo-anais (ps) nas fêmeas, e 4 pares de setas genito-anais nos machos; o empódio pode estar presente ou ausente, e quando presente não possui pêlos conjuntos. Quanto aos pares de setas dorsais, ocorrem apenas 3 prodorsais e no máximo 10 histerossomais (pares $d 3$ e e3 estão ausentes).

\section{Tribo Eurytetranychini Reck, 1950}

A presença de setas dúplices nos tarsos I e II é uma característica comum a quase todos os Tetranychidae, que os distinguem das demais famílias de Tetranychoidea. Na tribo Eurytetranychini ocorreu uma redução no número dessas setas, ou estas se apresentam fracamente associadas entre si, com os seus alvéolos aproximados mas não em contato. O empódio é reduzido e unciforme, ou ausente. Nas demais tribos de Tetranychinae, Tetranychini e Tenuipalpoidini, o arranjo de setas dúplices apresenta-se mais uniforme, com 2 pares de setas dúplices no tarso I e 1 par no tarso II, e o empódio pode ser em forma de garra ou fendido distalmente.

\section{Gênero Aponychus Rimando, 1966}

Tal como definido inicialmente por Rimando (1966), espécies deste gênero apresentam apenas um par de setas pseudo-anais ( $p s)$ nas fêmeas, empódio ausente, e 10 pares de setas histerossomais ( $c 2$ e $f 1$ presentes). As projeções anteriores no estilóforo podem estar presentes ou ausentes. Vinte espécies são atualmente incluídas neste gênero.

\section{Gênero Paraponychus González \& Flechtmann, 1977}

Espécies deste gênero assemelham-se às de Aponychus pela presença de apenas um par de 
setas pseudo-anais ( $p s)$ nas fêmeas, tarso I com um par de setas associadas e pelo empódio ausente, mas distinguem-se pela ausência do par de setas histerossomais $c 2$. $\mathrm{O}$ estilóforo não apresenta as fortes projeções anteriores, encontradas em algumas espécies de Aponychus e Stylophoronychus. Este gênero apresenta atualmente quatro espécies.

\section{Gênero Stylophoronychus Prasad, 1975}

Assim como em Aponychus e Paraponychus, espécies deste gênero apresentam apenas um par de setas pseudo-anais ( $p s$ ) nas fêmeas, tarso I com um par de setas associadas e empódio ausente, mas distinguem-se pela ausência do par de setas histerossomais $f 1$. Com exceção de $S$. insularis, as demais espécies apresentam duas grandes projeções anteriores no estilóforo. Seis espécies são atualmente incluídas em Stylophoronychus.

\section{A tribo Eurytetranychini Reck}

Diversas classificações já foram propostas para a tribo Eurytetranychini (Figura 6, p. 9). Na sua revisão monográfica sobre a família Tetranychidae, Pritchard \& Baker (1955) incluíram dois gêneros nesta tribo, Eutetranychus Banks e Eurytetranychus Oudemans, baseando-se no fato de que seus representantes não apresentam as setas dúplices nos tarsos das pernas I e II. Vainshtein (1958 apud Lindquist, 1985) considerou essa tribo como uma distinta subfamília. Meyer (1974) considerou mais quatro gêneros para essa tribo: Anatetranychus Womersley, Aponychus Rimando, Duplanychus Meyer e Synonychus Miller. Gutierrez (1985) adicionou a esse grupo os gêneros Atetranychus Tuttle, Baker \& Abatiello, Eurytetranychoides Reck, Meyernychus Mitrofanov e Paraponychus González \& Flechtmann. Meyer (1987) adicionou ainda três gêneros a essa tribo, Chinotetranychus Ma \& Yuan, Sinotetranychus Ma \& Yuan e Stylophoronychus Prasad, elevando esse último ao nível de gênero; considerou ainda os gêneros Anatetranychus, Atetranychus e Duplanychus na tribo Tetranychini. Baker \& Tuttle (1994) incluíram ainda Sonotetranychus Tuttle, Baker \& Abatiello na tribo Eurytetranychini.

Essas modificações e inclusões distanciaram essa a tribo de sua definição original (Pritchard \& Baker, 1955), que passou a ser considerada como um heterogêneo receptáculo de conveniência para abrigar os gêneros que não fossem adequadamente classificados nas outra tribos de Tetranychinae, levando, portanto, a uma classificação insatisfatória (Rimando \& Corpuz-Raros, 1996). Rimando \& Corpuz-Raros (1996) criaram duas novas tribos, Eutetranychini, abrigando os gêneros Eutetranychus e Meyernychus, e Aponychini, com Aponychus e Paraponychus, sinonimizando Stylophoronychus com Aponychus, e mantendo na tribo Eurytetranychini apenas os gêneros Eurytetranychus, Eurytetranychoides e Synonychus. 


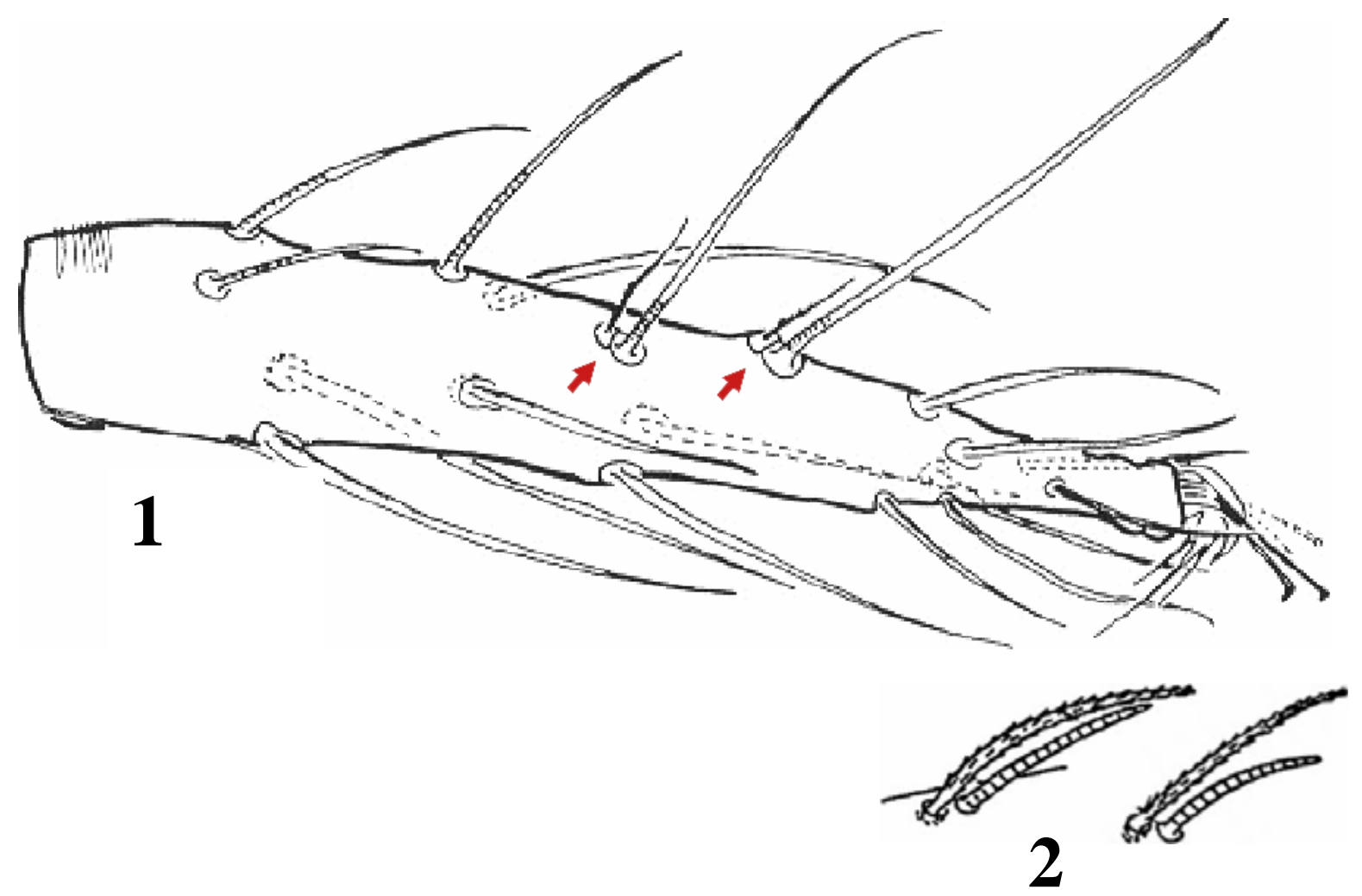

Figura 5. Tarso I, indicando os elementos tarsais de representantes da subfamília Tetranychinae: setas dúplices de Allonychus brevipenis Feres, 1992 (Tetranychini) (1) e setas associadas de Eutetranychus concertativus Meyer, 1974 (Eurytetranychini) (2).

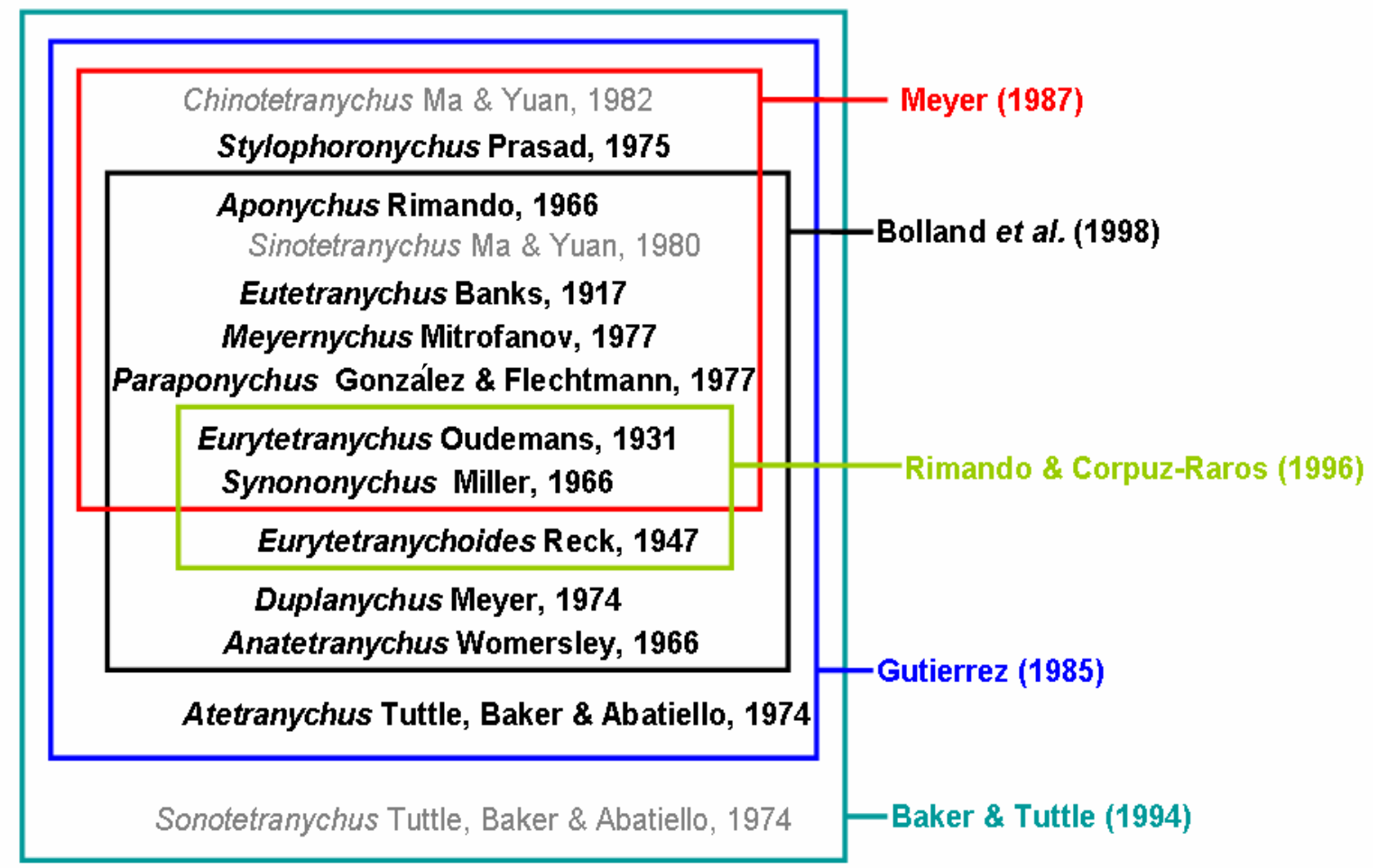

Figura 6. Diferentes classificações propostas para a tribo Eurytetranychini; classificação atual de Migeon \& Dorkeld (2006) em negrito. 
Essas alterações não foram aceitas no catálogo taxonômico da família Tetranychidae (Bolland et al. 1998), que considerou 11 gêneros nesta tribo: Anatetranychus, Aponychus, Atetranychus, Duplanychus, Eurytetranychoides, Eurytetranychus, Eutetranychus, Meyernychus, Paraponychus, Sinotetranychus e Synonychus. Apesar de Bolland et al. (1998) considerarem Stylophoronychus como sinônimo júnior de Sinotetranychus, Zhang et al. (2000a) revalidaram seu status genérico, transferindo para Stylophoronychus seis espécies previamente agrupadas em Aponychus e Sinotetranychus.

Entretanto, nenhuma dessas proposições tiveram como base a metodologia filogenética. Navajas \& Gutierrez (1996) investigaram o relacionamento filogenético de gêneros e espécies da família Tetranychidae, utilizando caracteres moleculares. Entretanto, nenhum membro da tribo Eurytetranychini foi incluído na análise.

\section{O gênero Aponychus e táxons próximos - algumas espécies, muitos nomes.}

O gênero Aponychus apresenta um histórico taxonômico bastante complexo, sendo que diversos táxons supra-genéricos já foram propostos para esse grupo. Rimando (1966) descreveu o gênero Aponychus, espécie tipo A. corpuzae, abrigando-o em uma nova subfamília, Aponychinae. Este gênero se assemelha a outros da tribo Eurytetranychini, principalmente a Eutetranychus, pela quetotaxia idiossomal e tarsal, pelo empódio vestigial/ausente e pela presença de dois pares de setas para-anais. Entretanto, a presença de apenas um par de setas pseudo-anais e o singular estilóforo bilobado, permitem prontamente distinguí-lo dos demais gêneros conhecidos de Eurytetranychini.

Prasad (1975a) propôs para o gênero Aponychus o subgênero Stylophoronychus, com espécies que apresentam duas fortes projeções anteriores no estilóforo, mantendo no subgênero Aponychus sensu strictu aquelas espécies que possuem o estilóforo convexo anteriormente, ou apenas fracamente recortado em lobos.

González \& Flechtmann (1977) criaram o gênero Paraponychus para abrigar P. incanus, por diferir de Aponychus no número de setas dorsais (12 pares ao invés de 13), e por faltarem as projeções distais do estilóforo. Estudando a quetotaxia histerossomal dos diferentes estágios de Aponychus sp. (= A. chiavegatoi Feres \& Flechtmann, 1988) Feres (1984) sugeriu que as setas ausentes em $P$. incanus deviam ser as do par $c 2(L 1)$, e não as do par $c 3(H)$, como indicado por aqueles autores. As setas $f 1$ seriam aquelas que possuem menor tamanho e situam-se entre as $e 2$ e $f 2$.

Ma \& Yuan (1980) criaram o gênero Sinotetranychus para abrigar S. guangzhouensis. 
Segundo esses autores, este gênero é bastante semelhante morfologicamente a Aponychus, mas três caracteres genéricos o diferenciam deste último: $\left.1^{\circ}\right)$ as setas dorso-centrais $(c l, d l, e l)$ são mais longas que os intervalos longitudinais entre suas bases; $2^{\circ}$ ) o tarso I possui um par de setas associadas; tarso II sem essas setas; $3^{\circ}$ ) coxa II possui somente uma seta tátil. Entretanto, nenhuma dessas três características observadas são exclusivas desse gênero. Em relação aos itens: $1^{\circ}, A$. schultzi e A. spinosus apresentam essa característica, e ambas já eram conhecidas como pertencentes ao gênero Aponychus pelo menos 10 anos antes da proposição desse novo gênero (Thewke \& Enns, 1969); 2 A. chiavegatoi, P. corderoi, P. incanus, P. saundersi e S. nakaoi apresentam essa característica; $3^{\circ}$, os desenhos de Chaudhri (1972) mostram apenas uma seta tátil na coxa II de A. lupus, A. expansus e A. sulcatus, e Meyer (1974) e Ehara (1980) reportaram, respectivamente, A. grandidieri (Gutierrez, 1966) e A. firmianae (Ma \& Yuan, 1965) com uma seta tátil na coxa II. Ao descreverem S. guangzhouensis, os autores citam que esta espécie possui 24 setas dorsais; as setas $e 2$ (dorsolaterais III) e "sacrais" $f 2$ (L4) são marginais. Setas deslocadas para a lateral do idiossoma são características do gênero Aponychus e a literatura mostra que é fato relativamente comum, no que diz respeito aos gêneros Eutetranychus e Aponychus, a redução de tamanho de algum dos pares de setas dorsais do idiossoma.

Ma \& Yuan (1982) propuseram o gênero Chinotetranychus, denominando Eutetranychus firmianae Ma \& Yuan, 1965 como espécie tipo, por ser semelhante a Aponychus, mas distinguindo-se deste por possuir as setas dorso-centrais e dorso-laterais de igual comprimento entre si e maiores que as "sacrais" $(f 1$ e $f 2)$ e "clunais" ( $e 2)$, e uma seta na coxa II, caráter este já usado pelos autores para caracterizarem Sinotetranychus.

Meyer (1987) transferiu A. corderoi Baker \& Pritchard para o gênero Paraponychus e elevou o subgênero Stylophoronychus ao status de gênero. Bolland et al. (1998) sinonimizaram Chinotetranychus com Aponychus, Stylophoronychus com Sinotetranychus e transferiram A. kodaikanalensis Gupta para o gênero Paraponychus. Zhang et al. (2000a) reestabeleceram Stylophoronychus como sinônimo sênior de Sinotetranychus, uma vez que Bolland et al. (1998) não observaram o princípio de prioridade do Código Internacional de Nomenclatura Zoológica (ICZN 1985: 47).

Segundo Feres (1984), os caracteres genéricos utilizados na criação destes gêneros são bastante variáveis e passíveis de discussão quanto à sua importância taxonômica. Desta forma, estes gêneros, na verdade, parecem constituir-se de espécies que apresentam pequenas variações dentro do que atualmente é definido como gênero Aponychus, cujas características genéricas definidas originalmente (Rimando, 1966) são: presença de 1 par de setas pseudo-anais, 1 par de setas fracamente associadas no dorso do tarso I e o par $f 1$ deslocado para a margem do corpo.

Meyer (1987:85) levantou dúvidas quanto a importância taxonômica de alguns caracteres 
atribuídos por diversos autores:

"In my opinion Prasad (1975), González \& Flechtmann (1977) and Ma \& Yuan (1980, 1982) assign subgeneric and generic value to slight morphological differences which result in an unsatisfactory classification. However, at present I feel that our knowledge of these genera does not allow us to comment on their taxonomic validity and that such a decision will have to be postponed until further knowledge of their species is gathered".

A tribo Eurytetranychini tem, portanto, sido objeto de opiniões divergentes acerca da classificação de alguns de seus gêneros e espécies. Faz-se necessária uma análise cladística para as espécies dessa tribo, de modo a melhor compreender a natureza dos diversos caracteres morfológicos utilizados na separação dos gêneros, numa tentativa de se reconstituir as relações de parentesco entre as espécies desse grupo.

Outro fator que deve ser destacado é que algumas espécies de Eurytetranychini, descritas logo após a proposição do gênero Aponychus Rimando (1966), não apresentam uma descrição detalhada e padronizada que possibilite uma análise sistemática robusta, o que aponta para a necessidade da redescrição dessas espécies.

\section{OBJETIVOS}

- Propor uma hipótese de relacionamento filogenético para as espécies de Aponychus, Paraponychus e Stylophoronychus.

- Realizar revisão taxonômica das espécies destes três gêneros, redescrevendo e reanalisando táxons, e abordando a literatura pertinente à taxonomia e ocorrência do grupo, com dados de distribuição geográfica, hospedeiros, tipologia e sinonímias.

- Propor uma chave dicotômica para auxiliar na separação das espécies desse grupo de Eurytetranychini.

\section{Formato}

A tese é apresentada sob a forma de três capítulos. No primeiro capítulo, é feita a análise cladística das espécies desse grupo, com base em caracteres morfológicos. Para a maioria das espécies, os caracteres foram levantados a partir de análise de material-tipo, e quando isso não foi possível, as informações foram obtidas de exemplares coletados e da literatura. 
O segundo capítulo contém a revisão taxonômica das espécies contidas nesse grupo. São apresentadas, para cada espécie, sua distribuição geográfica, hospedeiros sobre os quais já foram relatados, e redescrições das espécies para as quais foram analisados espécimes-tipo. Quando necessário, são sugeridas combinações novas e sinonímias para algumas espécies, que posteriormente deverão ser submetidas à publicação em periódicos científicos. Tais alterações foram corroboradas pelos resultados obtidos na análise cladística. As espécies foram organizadas seguindo a sequência de ramificações observadas no cladograma obtidos na análise filogenética (Figuras 7-8, p. 41-42)

No terceiro capítulo, analisamos os aspectos biogeográficos das 30 espécies desse grupo, abordando informações sobre distribuição geográfica e associação com hospedeiros. Ao final desse capítulo são apresentadas as conclusões e considerações finais do trabalho. Finalmente, são listadas as referências bibliográficas citadas nos três capítulos. 


\section{CAPÍTULO I}

\section{Análise filogenética das espécies de Aponychus Rimando, Paraponychus González \& Flechtmann e Stylophoronychus Prasad}




\section{INTRODUÇÃO}

Apesar de diversas classificações já terem sido propostas para gêneros da tribo Eurytetranychini (Acari: Tetranychidae) (Meyer, 1974, 1987, Rimando \& Corpuz-Raros, 1996, Bolland et al., 1998) (Figura 6, p. 9), pouco se conhece a respeito das relações de parentesco entre táxons desse grupo e sua história evolutiva. Alguns estudos investigaram a filogenia de táxons da superfamília Tetranychoidea: Beard \& Walter (2004), para a família Linotetranidae, e Navajas \& Gutierrez (1996) e Ros \& Breeuwer (2007) para táxons da família Tetranychiddae. Outros trabalhos enfocaram as relações intra-específicas em populações de espécies praga, como Tetranychus urticae Koch e T. cinnabarinus (Boisduval) (Navajas, 1998, Navajas et al., 1994, Hinomoto et al., 2001, Xie et al., 2006).

Espécies de Aponychus, Paraponychus e Stylophoronychus (Tetranychidae: Eurytetranychini) podem ser agrupadas por apresentarem, principalmente, duas características de grande valor taxonômico para a família Tetranychidae: ausência de empódio, ou estes resquiciais, e presença de apenas um par de setas na região das valvas anais nas fêmeas.

A tribo Eurytetranychini foi caracterizada por Rimando \& Corpuz-Raros (1996) como um heterogêneo agrupamento de conveniência para os gêneros que não fossem classificados nas outras tribos de Tetranychinae. Entretanto, previamente à escolha dos táxons a serem tratados foram realizados testes prévios de filogenia de gêneros de Eurytetranychini, sendo constatado que os três gêneros selecionados para o presente estudo foram sempre fortemente agrupados, demonstrando formar um grupo monofilético. Segundo Amorim (2002), a escolha de um grupo monofilético é um dos requisitos primários para se que se possa reconstruir sua história filogenética de modo adequado, adotando a parcimômia de evolução de caracteres. Espécies desses três gêneros são únicas entre os Eurytetranychini por apresentarem apenas um par de setas na região das valvas anais, caráter esse de grande importância para a sistemática e taxonomia da família Tetranychidae. Esta razão impulsionou a escolha desse grupo para a realização da análise filogenética.

\section{MATERIAL E MÉTODOS}

\subsection{Táxons e espécimes}

Os espécimes estudados foram montadas seguindo a técnica usual em acarologia, que consiste no uso do meio de Hoyer, sendo os ácaros montados em lâminas de microscopia seladas com gliptal ou verniz incolor (Krantz, 1970, Flechtmann, 1975), exceto Aponychus spinosus, montado em Bálsamo do Canadá. A classificação dos táxons foi utilizada de acordo com Migeon \& Dorkeld (2006).

O material utilizado foi obtido das coleções relacionadas a seguir, por meio de empréstimo, 
doação ou estudo realizado na própria coleção depositária. As espécies são listadas na Tabela 1 , p. 18. As coleções ou instituições depositárias de espécimes-tipo e demais espécimes analisados são referidas conforme os seguintes acrônimos:

CATIE - Colection of Centro Agronômica Tropical de Investigatión y Ensenanza, Unidad de Fitoprotección, Turrialba, Costa Rica.

DZSJRP - Coleção de Acari do Departamento de Zoologia e Botânica, Universidade Estadual Paulista - UNESP, câmpus de São José do Rio Preto, São Paulo, Brasil.

MZ-ESALQ - Museu de Zoologia, do Departamento de Zoologia, da Escola Superior de Agricultura “Luiz de Queiroz”, USP, Piracicaba, São Paulo, Brasil.

FAUC - Faculdade de Agricultura, Universidade do Cairo, Egito.

IZSA - Institute of Zoology, Academia Sinica, Beijing, China.

MCZ - Museum of Comparative Zoology, Harvard University, Cambridge, Massachusetts, E.U.A..

MHNS - Museu de História Natural de Shanghai, China.

MNHN - Muséum National d'Histoire Naturelle, Paris, França.

NCA - National Collection of Arachnida, ARC - Plant Protection Research Institute, Pretoria, África do Sul.

NCZSI - National Collection of the Zoological Survey of India, Calcutá, Índia.

NSMJ - Biological Institute, Faculty of Education, Tottori University, Japão, e National Science Museum, Tokyo, Japão.

OSU - Acarology Laboratory, Ohio State University, Columbus, Ohio, E.U.A..

SH - Coleção particular do Dr. Shôzô Ehara, Hamazaka, Tottori, Japão.

TARI - Taiwan Research Agriculture Institute, Taichung, Taiwan.

UAL - Department of Entomology, West Pakistan Agricultural University, Lyallpur, Paquistão.

UPLB - Departamento de Entomologia, University of the Philippines at Los Baños, Filipinas. USNM - United States National Museum of Natural History at Beltsville, Maryland, E.U.A.. 
Tabela I. Espécies utilizadas na análise filogenética $(*=$ espécies que tiveram exemplares tipo analisados; $\dagger=$ espécimes-tipo perdidos; entre parênteses as coleções depositária de cada espécie).

\section{Grupo externo}

1. Monoceronychus bambusicola Feres \& Flechtmann, 1995* (DZSJRP)

2. Eutetranychus banksi (McGregor, 1914) (DZSJRP)

3. Meyernychus emeticae (Meyer, 1974)* (DZSJRP)

\section{Grupo interno}

Aponychus Rimando, 1966

4. aequilibris Tseng, $1990 \dagger$

5. A. bambusae Gupta \& Gupta, $1990 *(\mathrm{NCZSI})$

6. A. chiavegatoi Feres \& Flechtmann, $1988 *(\mathrm{MZ}-\mathrm{ESALQ})$

7. A. corpuzae Rimando, $1966 *$ (USNM, DZSJRP)

8. A. expansus Chaudhri, $1972 *$ (USNM)

9. A. firmianae (Ma \& Yuan, 1965) * (SH)

10. A. grandidieri (Gutierrez, 1966) * (MZ-ESALQ)

11. A. imperatus Hafez \& El-Badry, $1980 \dagger$

12. A. lupus Chaudhri, $1972 *$ (USNM)

13. A. mallotus Ho, $2003 *$ (TARI)

14. A. parydrus (Meyer, 1987) * (NCA, DZSJRP)

15. A. pilipinus Corpuz-Raros, 1978 * (UPLB, DZSJRP)

16. A. rarus Rimando, 1966

17. A. sarjui Gupta, 1980 * (NCZSI)

18. A. schultzi (Blanchard, 1940) (MZ-ESALQ, DZSJRP)

19. A. siamensis Ehara \& Wongsiri, $1975 *(\mathrm{SH})$

20. A. solimani Zaher, Gomaa \& El-Enany, $1982 \dagger$

21. A. spinosus (Banks, 1909)* (MCZ)

22. A. sulcatus Chaudhri, $1972 *$ (USNM)

23. A. taishanicus Wang, $1980 *$ (IZSA)

Paraponychus González \& Flechtmann, 1977

24. P. corderoi (Baker \& Pritchard, 1962) * (USNM)

25. P. incanus González \& Flechtmann, 1977 * (MZ-ESALQ)

26. P. kodaikanalensis (Gupta, 1984)* (NCZSI)

27. P. saundersi Meyer \& Vargas, $1999 *$ (USNM)

Stylophoronychus Prasad, 1975

28. S. baghensis (Prasad, 1975)*(USNM)

29. S. guangzhouensis (Ma \& Yuan, 1980)

30. S. insularis (Flechtmann, 1981) $\dagger$

31. S. lalli (Prasad, 1975)* (USNM)

32. S. nakaoi (Ehara \& Wongsiri, 1975)*(SH)

33. S. vannus (Rimando, 1968) * (USNM, DZSJRP, OSU) 
Como grupos externos (Wathrous \& Wheeler, 1981), foram utilizadas as espécies da tribo Eurytetranychini Meyernychus emeticae (Meyer, 1974) e Eutetranychus banksi (McGregor, 1914), e da subfamília Bryobiinae, Monoceronychus bambusicola Feres \& Flechtmann, 1995.

\subsection{Caracteres}

A codificação e ordenação dos caracteres seguiram os diferentes métodos descritos na literatura (Kitching et al., 1998, Scotland \& Pennington, 2000). A polaridade dos caracteres foi determinada com o enraizamento através do método de comparação com grupos externos, como proposto por Nixon \& Carpenter (1993). Exceto quando informado de outro modo, os caracteres foram considerados como não aditivos, o que requer apenas um passo para transformação de caracteres com três ou mais estados. Por exemplo, para um caráter com estados 0 , 1 e 2 , qualquer transformação entre quaisquer estados requer apenas um passo.

Os caracteres analisados foram principalmente os atualmente utilizados no diagnóstico específico desse grupo, como o formato do estilóforo; comprimento, presença, disposição e formato das setas histerossomais; setas associadas nos tarsos I e II, entre outros. Outros caracteres que revelaram-se bastante constantes em algumas espécies também foram incluídos, como o número e disposição das setas em cada um dos artículos das pernas (caracteres 25 a 54).

Sempre que possível, foram evitados caracteres multi-estados, dando preferência a caracteres do tipo presença/ausência. Por exemplo, ao invés de considerarmos o número de setas no fêmur I como apenas um caráter, podendo apresentar 3 estados (7, 6, ou 5 setas), foram consideradas a presença ou ausência de cada seta individualmente (e.g. Figura 16, p. 49), o que resultou na obtenção de um maior número de caracteres. De acordo com Scotland \& Pennington (2000), a utilização desse método reduz o número de cladogramas mais parcimoniosos encontrados na análise filogenética, levando a uma análise mais apurada.

Algumas espécies tiveram um número extremamente pequeno de exemplares coletados: para algumas espécies, apenas o holótipo foi coletado (e.g. A. sarjui, S. insularis), enquanto outras apresentam apenas duas (e.g. S. guangzhouensis, S. lalli e P. kodaikanalensis) ou três (e.g. A. aequilibris, A. sulcatus e $S$. baghensis) fêmeas conhecidas, e nenhum indivíduo macho ou de estágios imaturos. Esse pequeno número de espécimes conhecidos contribuiu para que fossem utilizados principalmente caracteres morfológicos na análise filogenética, devido à dificuldade de obtenção de espécimes vivos ou preservados em álcool absoluto para análise de sequenciamento molecular. A maioria das espécies é conhecida apenas através dos trabalhos originais, sendo que somente nove das 30 espécies desse grupo tiveram exemplares coletados após sua descrição original.

Visto que em treze das trinta espécies do grupo interno o macho não é conhecido, os 
caracteres utilizados nas análises foram estudados e selecionados apenas em fêmeas. Caracteres de estágios imaturos também não foram incluídos, pois estes são conhecidos apenas para seis espécies do grupo estudado.

Para o estudo da quetotaxia das pernas foi utilizada, com poucas modificações, a nomenclatura padrão descrita para a família Tetranychidae (Robaux \& Gutierrez, 1973, Gutierrez, 1985). A nomenclatura utilizada por aqueles autores é aplicada para cada seta de acordo com a posição de inserção no artículo e também com o seu aparecimento nas diferentes fases de desenvolvimento, por exemplo, seta $l$ ” $N 2$ aparecendo pela primeira vez na ninfa 2 (deutoninfa) e v'lAd aparecendo somente no estágio adulto. Dada a dificuldade de se obter indivíduos de todos os estágios de desenvolvimento, juntamente com o fato das descrições de espécies raramente apresentarem descrições de estágios imaturos, essa nomenclatura é aplicada aqui de modo simplificado, não mencionando em quais estágios as setas surgem primeiramente.

\subsection{Análise filogenética}

Os dados obtidos foram combinados e analisados seguindo a metodologia desenvolvida por Hennig (1966), sintetizada em Scotland \& Pennington (2000), Schuh (2000) e Amorim (2002). A matriz de dados foi construída no programa Winclada 1.7 (Nixon, 1999-2002) e a análise filogenética realizada no programa NONA 2.0 (Goloboff, 1999), utilizando o programa Winclada como interface.

O mesmo peso foi inicialmente dado para todos os caracteres, e os seguintes comandos foram utilizados no programa NONA 2.0:

-rs0; (muda as sequências de adição dos táxons terminais, fazendo com que a primeira busca não seja aleatória);

-hold500; (para reter 500 árvores de todas as buscas);

- $h / 2$; (guarda na memória duas árvores de cada replicação);

-mult*400; (realiza 400 réplicas, adicionando táxons em ordens aleatórias);

-max*; (implementa o TBR - tree bissection reconnection).

O suporte dos ramos foi verificado através das análises de Bremer, Bootstrap e Jackknife, e foram consideradas árvores subótimas com até quatro passos adicionais. Para isto foram utilizados os comandos:

-hold1000;

-sub1;

-find*;

-bsupport; 
Após análise inicial da matriz, foi feita uma nova análise com pesagem $(\mathrm{k}=2,3,4$ e 5) dos caracteres 17 e 22 (presença/ausência das setas dorsais $c 2$ e $f 1$, respectivamente), que são os principais caracteres diagnósticos para os gêneros Paraponychus e Stylophoronychus, respectivamente.

\section{RESULTADOS E DISCUSSÃO}

\section{Caracteres morfológicos}

Os caracteres morfológicos utilizados na análise filogenética são apresentados e discutidos abaixo. Para cada um deles, são apresentados o número de passos obtidos, os índices de consistência (IC) e de retenção (IR).

1. setas pseudo-anais (ps) (Figura 3, p. 5): 3 pares (0); 2 pares (1); 1 par (2).

Número de passos $=2 ; \mathrm{IC}=100 ; \mathrm{IR}=100$.

O número de setas pseudo-anais é um dos caracteres mais importantes para a separação das subfamílias de Tetranychidae, sendo que os Bryobiinae, que apresentam o número máximo (3), são considerados os tetraniquídeos mais basais. Nesse sentido, a redução no número dessas setas é considerada uma tendência evolutiva (Gutierrez \& Helle, 1985), sendo que a maioria dos representantes da subfamília Tetranychinae apresentam 2 pares. Uma nova redução resultou em apenas 1 par de setas pseudo-anais em três generos da tribo Tetranychini (Acanthonychus Wang, Palmanychus Baker \& Pritchard e Atrichoproctus Flechtmann) e independentemente, nos gêneros de Eurytetranychini que compõem o foco do presente estudo, Aponychus, Paraponychus e Stylophoronychus.

Esse caráter foi considerado como aditivo (um passo para transformação 0 - 1; dois passos para transformação $0-1-2$ ).

2. empódio (Figura 2, p. 4): presente (0); vestigial ou ausente (1).

Número de passos $=1$; caráter não informativo.

O empódio é uma das características mais basais para separação das subfamílias e gêneros de Tetranychidae. Nos Bryobiinae apresenta pêlos associados, e nos Eurytetranychini o empódio é vestigial ou ausente.

3. forma do idiossoma (Figura 9, p. 45): circular (0); margem anterior menos curvada que a posterior (1). 
Número de passos $=2 ; \mathrm{IC}=50 ; \mathrm{IR}=88$.

O idiossoma em algumas espécies de Eurytetranychini, quando visualizado sob a preparação usual em acarologia, pode apresentar-se em formato ligeiramente circular ou oval, enquanto que em outras pode ser cordiforme, com a margem anterior do propodossoma menos curvado que a margem posterior do opistossoma.

4. projeções anteriores no estilóforo (Figura 10, p. 45): ausentes ou pouco desenvolvidas (0); presentes e bem desenvolvidas (1).

Número de passos $=1 ; \mathrm{IC}=100 ; \mathrm{IR}=100$.

Em algumas espécies o estilóforo pode apresentar-se com distintas projeções anteriores, como em S. vannus e A. corpuzae (Figuras 10.1-2, p. 45). Prasad (1975a) abrigou as espécies de Aponychus que apresentam esse caráter em um novo subgênero, Stylophoronychus, mantendo as demais espécies sem tais projeções no estilóforo no subgênero Aponychus. Visto que leves projeções anteriores no estilóforo também podem ser encontradas em espécies como A. solimani e P. corderoi e também em algumas espécies de Eutetranychus (Eurytetranychini) e Oligonychus (Tetranychini), é provável que este último estado possa ter surgido independentemente em diversas espécies de Tetranychidae.

Em A. aequilibris Tseng, apesar de não existir nenhuma ilustração desta estrutura, o autor descreve o estilóforo com tendo uma acentuada fissura na parte anteromediana, o que sugere a presença das projeções bem desenvolvidas. Além disso, segundo Tseng (1990: 33), esta espécie é muito semelhante a $A$. corpuzae, que também apresenta as marcadas projeções anteriores no estilóforo.

5. Grânulos no estilóforo: ausentes (0); presentes (1).

Número de passos $=1 ; \mathrm{IC}=100 ; \mathrm{IR}=100$.

Em algumas espécies de Stylophoronychus, grânulos estão presentes na porção ânterodorsal do estilóforo (Figura 10.1, p. 45).

6. Extremidade do peritrema: anastomosado (0); simples (1).

Número de passos $=1$. Caráter não informativo.

Apenas em uma espécie do grupo externo (M. bambusicola) esse caráter apresentou o estado plesiomórfico. 
7. Grânulos no tegumento dorsal (Figura 11, p. 46): presentes (0); ausentes (1).

Número de passos $=4 ; \mathrm{IC}=25 ; \mathrm{IR}=76$.

8. Enrugamento do tegumento dorsal (Figura 12, p. 46): ausente (0); presente (1).

Número de passos $=2 ; \mathrm{IC}=50 ; \mathrm{IR}=75$.

Conspícuas ornamentações podem estar presentes em praticamente todo o tegumento dorsal, resultando em um aspecto semelhante a um córtex cerebral (Figura 12, p. 46). Esse padrão é encontrado em algumas espécies de Stylophoronychus e em Aponychus firmianae.

9. Região central do prodorso (Figura 11, p. 46): lisa (0); tegumento enrugado (1).

Número de passos $=2 ; \mathrm{IC}=50 ; \mathrm{IR}=92$.

A região central do prodorso pode apresentar conspícuos enrugamentos, como nas espécies A. lupus e A. parydrus.

10. ocelos: 2 pares presentes (0); lente posterior vestigial ou ausente (1).

Número de passos $=4 ; \mathrm{IC}=25 ; \mathrm{IR}=72$.

A condição primitiva na família Tetranychidae é a presença de dois pares de ocelos no propodossoma, próximos as setas escapulares internas ( $s c 1)$; em algumas espécies o par posterior encontra-se em estado vestigial ou ausente.

\section{Quetotaxia dorsal (caracteres de 11 a 24)}

11. comprimento das setas dorsais: curtas, não ultrapassando a base do par subsequente (0); longas, ultrapassando a base do par subsequente (1).

Número de passos $=3 ; \mathrm{IC}=33 ; \mathrm{IR}=81$.

As setas dorsais dos Eurytetranychini geralmente são inseridas em fortes tubérculos e são robustas (e.g. Aponychus pilipinus, Figura 9.1, p. 45), ao invés de setiformes, e não apresentam as extremidades afiladas como, por exemplo, em Oligonychus spp.. Apesar de Gutierrez (1985) não considerar o comprimento das setas dorsais como um caráter taxonomicamente importante para separação de espécies de Eurytetranychini, é possível distinguir nas espécies de Aponychus e gêneros próximos, dois padrões distintos com relação ao seu comprimento: setas longas, 
ultrapassando as bases do par subsequente (e.g. A. pilipinus e S. insularis) ou curtas (e.g. P. saundersi). No grupo externo as setas dorsais seguem este último padrão, considerado aqui como o estado plesiomórfico deste caráter.

12. eixo central das setas dorsais (Figura 13, p. 47): não visível (0); visível (1).

Número de $\operatorname{passos}=1 ; \mathrm{IC}=100 ; \mathrm{IR}=100$.

13. setas da região central do idiossoma dorsal (sc1, $c 1, c 2, d 1, d 2, e 1)$ : normais (0); reduzidas (1).

Número de passos $=3 ; \mathrm{IC}=33 ; \mathrm{IR}=84$.

14. setas sc2: normais (0); reduzidas (1).

Número de passos $=3 ; \mathrm{IC}=33 ; \mathrm{IR}=50$.

Em algumas espécies que possuem setas dorsais longas, a seta sc2 pode apresentar-se reduzida em relação às demais setas dorsais (e.g. A. pilipinus, Figura 9.1, p. 45). Em outras espécies de setas longas, como A. mallotus, essa seta possui comprimento semelhante ao das demais setas dorsais.

15. disposição das setas dorsais sc2 e c3: extremidades não convergentes (0); extremidades convergentes (1).

Número de $\operatorname{passos}=2 ; \mathrm{IC}=50 ; \mathrm{IR}=88$.

Estas setas podem assumir nos exemplares fêmeas um padrão morfológico característico, com as extremidades distais de ambas em convergência (e.g. P. corderoi, Figura 9.2, p. 45). Apesar da ilustração original de $S$. lalli não representar essa configuração, a análise dos dois únicos espécimes-tipo dessa espécie revelou que essas setas possuem extremidades convergentes.

É importante notar que esse caráter foi observado apenas nas preparações semipermanentes, em lâminas de microscopia, não sendo possível inferir se ocorre também nos espécimes em vida, em conformação natural.

Em alguns machos das espécies em que as fêmeas apresentam essa disposição de setas, esse caráter não é observado (e.g. A. rarus, A. corpuzae, A. grandidieri). Em outros, ele está presente (S. vannus e A. imperatus). 
16. setas dorsocentrais $(\boldsymbol{c} 1, \boldsymbol{d} 1$ e $\boldsymbol{e} 1)$ : comprimentos equivalentes (0); redução gradual no comprimento $(c l>d l>e l)(1)$.

Número de passos $=2 ; \mathrm{IC}=50 ; \mathrm{IR}=50$.

Em algumas espécies, os três pares de setas dorso-centrais $(c l, d l$ e $e l)$ podem apresentar uma redução progressiva no seu comprimento $(c l>d l>e l)$ (e.g. P. corderoi, Figura 9.2, p. 45), sendo essa condição considerada apomórfica quando presente.

17. setas dorso-centrais inseridas em tubérculos (c1, d1 e e1): tubérculos ausentes (0); tubérculos presentes (1).

Número de passos $=2 ; \mathrm{IC}=50 ; \mathrm{IR}=85$.

Algumas espécies apresentam as setas dorso-centrais inseridas em proeminentes tubérculos (e.g. A. pilipinus, A. schultzi e A. spinosus). Em outras espécies (e.g. A. corpuzae, A. sarjui), esses tubérculos são ausentes ou pouco pronunciados nas bases dessas setas, apesar de presentes nas setas da região marginal do corpo (setas $s c 2, c 3, h 1, f 2$ e $e 2)$.

18. seta histerossomal $c 2$ : presente (0); ausente (1).

Número de passos $=4 ; \mathrm{IC}=50 ; \mathrm{IR}=25$.

A redução no número de setas dorsais é considerada uma tendência evolutiva na família, com algumas espécies de Bryobiinae apresentando o estado mais primitivo na família. Em Paraponychus ocorreu a perda das setas do par c2, e em Aponychus chiavegatoi as mesmas são consideravelmente reduzidas e ligeiramente deslocadas para o prossoma.

19. Comprimento das setas dorsais $\mathbf{c} 2$ em relação à $c 1$ : equivalentes (0); reduzidas (1).

Número de $\operatorname{passos}=2 ; \mathrm{IC}=50 ; \mathrm{IR}=83$.

As setas opistossomais $c 2$ podem ser de comprimentos equivalentes às $c 1$, como em $A$. corpuzae, A. sarjui e A. pilipinus, ou reduzidas em relação a estas setas, como em A. chiavegatoi e espécies de Stylophoronychus.

20. seta histerossomal $c 3$ : normal (0); reduzida (1).

Número de passos $=3 ; \mathrm{IC}=33 ; \mathrm{IR}=50$. 
Em algumas espécies que possuem setas dorsais longas, a seta c3 pode apresentar-se reduzida em relação às demais setas dorsais (e.g. A. pilipinus, Figura 9.1, p. 45). Em outras espécies de setas longas, como A. mallotus, essa seta possui comprimento semelhante ao das demais setas dorsais.

21. distância $\boldsymbol{d} 1$-d1 em relação a $\boldsymbol{c} 1$-c1: quase duas vezes (0); equivalente (1).

Número de passos $=3 ; \mathrm{IC}=33 ; \mathrm{IR}=80$.

22. Comprimento das setas dorsais $\boldsymbol{d} 2$ em relação às $\boldsymbol{d 1}$ : equivalentes (0); mais curtas (1); mais longas (2).

Número de passos $=2 ; \mathrm{IC}=100 ; \mathrm{IR}=100$.

23. seta histerossomal $f 1$ : presente (0); ausente (1).

Número de $\operatorname{passos}=2 ; \mathrm{IC}=50 ; \mathrm{IR}=83$.

Assim como na tribo Tenuipalpoidini, os elementos do par de setas $f l$ encontram-se deslocados lateralmente nas espécies de Aponychus e Paraponychus, sendo frequentemente reduzidos, e podendo estar ausentes em algumas espécies (e.g. S. vannus).

24. seta histerossomal $f 1$ : comprimento normal (0); reduzida (1).

Número de $\operatorname{passos}=2 ; \mathrm{IC}=50 ; \mathrm{IR}=90$.

Essa seta, quando presente, pode apresentar-se consideravelmente reduzida em relação às demais setas da região posterior do corpo $(e 2, h 1, f 2)$, como em A. sarjui e A. corpuzae.

\section{Quetotaxia das pernas (caracteres 25 a 39).}

Apesar de haver variação no formato e no comprimento, de modo geral as setas das pernas apresentam, nas espécies do grupo interno, um padrão relativamente constante na posição de inserção nos artículos, o que permite localizar e discriminar, com algumas exceções, cada uma dessas setas. À exceção das coxas (Figura 14, p. 47), que em decorrência de seu posicionamento no idiossoma, apresentam apenas setas em posição ventral, os demais artículos das pernas podem apresentar setas em posição variável: dorsal, dorso-lateral paraxial e antiaxial, e ventral (Figura 15, p. 48, Krantz \& Walter, 2009: 41). De modo geral, as setas dorsais paraxiais das pernas I e II e antiaxiais das pernas III e IV, apresentam aspecto mais robusto e piloso/escamoso, enquanto que as ventrais são quase sempre setiformes e delgadas. 
Nas espécies em que foram obtidas informações apenas acerca do número de setas nos artículos das pernas, sem a obtenção de desenhos que ilustrassem a disposição e local de inserção delas, a sua configuração foi inferida baseando-se em outras espécies que apresentam o mesmo número de setas naquele artículo. Este procedimento foi adotado apenas considerando as configurações que não apresentam mais do que uma possibilidade de distribuição das setas, sendo essas brevemente discutidas ao final da descrição de cada caráter.

Para algumas espécies não analisadas, a quetotaxia das pernas foi inferida com base em informação disponível na literatura. Segundo Tseng (1990), A. aequilibris apresenta a mesma quetotaxia encontradas nas pernas de A. corpuzae, e de acordo com Zhang et al. (2000a), S. guangzhouensis e S. lalli apresentam a mesma quetotaxia nas pernas.

25. seta $v 1$ na coxa II (Figura 14, p. 47): presente (2 setas) (0); ausente (1 seta) (1).

Número de $\operatorname{passos}=2 ; \mathrm{IC}=50 ; \mathrm{IR}=92$.

No grupo interno a quetoxaxia das coxas (I a IV) pode apresentar-se nas fórmulas 2-2-1-1 ou 2-1-1-1, havendo variação, portanto, apenas no número de setas presentes na coxa II. No grupo externo, e em algumas espécies do grupo interno, ocorrem 2 setas nesse artículo ( $v 1$ e $v 2$ ), sendo este estado considerado como plesiomórfico para a análise. Nas espécies que apresentam apenas uma seta, possivelmente ocorreu a perda da seta $v 1$.

O gênero Chinotetranychus Ma \& Yuan foi criado para abrigar as espécies com apenas uma seta na coxa II, sendo que Bolland et al. (1998) sinonimizaram este gênero com Aponychus. Apesar de Meyer \& Vargas (1999: 116) reportarem 3 setas na coxa I de Paraponychus saundersi, é possível concluir a partir da análise dos seus parátipos, que essa espécie apresenta, na realidade, 2 setas nesse artículo. Em alguns espécimes, a delimitação interna das coxas pode não ser nitidamente percebida, e conclui-se que aqueles autores consideraram o par de setas médio-ventral $1(M V 1)$, localizado entre as coxas I, como uma terceira seta coxal.

\section{Trocânter}

Apenas uma seta $(v)$, localizada em posição ventro-lateral anterior, insere-se no trocânter das pernas I a IV, conforme a fórmula 1-1-1-1. Este padrão é encontrado mesmo nas espécies do grupo externo, sendo que apenas em Stylophoronychus insularis ocorreu perda da seta v' no trocânter II, considerada aqui uma autapomorfia daquela espécie, não informativa para análise, sendo essa característica não incluída. 
Fêmur I (caracteres de 26 a 27) (Figura 16, p. 49)

Apresenta 6 ou 7 setas no grupo interno, em três disposições possíveis; no grupo externo esse número pode ser de 9 (Monoceronychus bambusicola), 8 (Meyernychus emeticae, Figura 16.1, p. 49) ou 6 setas (Eutetranychus banksi, Figura 16.26, p. 49). Nas espécies próximas de Aponychus, 5 setas estão sempre presentes nesse artículo: setas dorso-paraxiais 1 a 3 (d'1-3), dorso-lateral antiaxial $3(d " 3)$ e ventro-axial $1(v l)$. Nas espécies com 7 setas (Figuras 16.2-5, p. 49), além das já mencionadas podem ocorrer a dorso-antiaxial $1(d$ ” 1$)$ e a ventro-axial 3 ( $v 3)$. Nas espécies com 6 setas, duas disposições são possíveis, podendo haver a perda da seta $v 3$ (Figuras 16.6-25, p. 49) ou da $d " 1$ (Figuras 16.26-28, p. 49). Em M. emeticae, além das setas já mencionadas, há ainda a seta ventro-axial 2 (v2), mas encontra-se ausente a seta dorso-antiaxial 1 ( $d " 1)$, presente em algumas espécies do grupo interno.

Apesar de não haver na literatura desenhos que registrem a configuração das setas nos fêmures de A. aequilibris Tseng, essa espécie presumivelmente apresenta o mesmo padrão apresentado por A. corpuzae (Figura 16.2, p. 49), já que em sua descrição (Tseng, 1990: 33-34) consta a mesma quetotaxia nas pernas dessas duas espécies, à exceção do tarso II, que apresenta 13 setas (12 em A. corpuzae).

Do mesmo modo, é provável que $S$. guangzhouensis apresente a mesma configuração que S. vannus em todos os artículos das pernas. Segundo Zhang et al. (2000a: 42), essas duas espécies se assemelham em relação às setas idiossomais e das pernas, portanto será considerada aqui a mesma configuração para as duas espécies (Figura 16.25, p. 49).

26. seta dorso-antiaxial $\boldsymbol{d}$ "1 no fêmur I (Figura 16, p. 49): ausente (0); presente (1) Número de $\operatorname{passos}=2 ; \mathrm{IC}=50 ; \mathrm{IR}=66$.

27. seta ventro-axial $\boldsymbol{v} 3$ no fêmur I (Figura 16, p. 49): presente (0); ausente (1). Número de passos $=3 ; \mathrm{IC}=33 ; \mathrm{IR}=80$.

\section{Fêmur II (caracteres de 28 a 30) (Figura 17, p. 50)}

Apresenta de 4 a 6 setas nas espécies que compõem o grupo interno. No grupo externo, podem ocorrer 6 (Meyernychus emeticae, Figura 17.2, p. 50), 5 (Monoceronychus bambusicola) ou 4 (Eutetranychus banksi, Figura 17.17, p. 50) setas.

Pelo menos quatro setas encontram-se sempre presentes em ambos os grupos: setas dorsoparaxiais 1 e $3\left(d^{\prime} 1\right.$ e $\left.d^{\prime} 3\right)$, dorso-antiaxial $2\left(d^{\prime} 2\right)$ e ventro-axial 1 ( $\left.v l\right)$. Nas espécies que 
apresentam 6 setas (S. insularis e M. emeticae, Figuras 17.1-2, p. 50) ocorrem ainda a ventro-axial 3 (v3) e a látero-paraxial 2 ( $l$ '2); e nas espécies com 5 setas, houve a perda da v3 e da l’2, mas encontra-se presente a dorso-antiaxial $1\left(d{ }^{\prime \prime} 1\right)$.

Foi verificada assimetria nos fêmures da perna II esquerdo e direito (5 e 4 setas, respectivamente) em parátipo de Aponychus mallotus (Figuras 17.22-23, p. 50). Na descrição original dessa espécie (Ho, 2003: 346) são relatadas 4 setas. Portanto, é provável que o parátipo analisado apresente a duplicação da seta dorso-antiaxial 2 ( $d$ ”2) como uma anomalia.

Do mesmo modo que mencionado para o fêmur I, é considerada aqui a mesma disposição de setas no fêmur II para A. corpuzae e A. aequilibris, e para S. vannus e S. guangzhouensis. Na descrição de A. solimani, é reportada a presença de 5 setas no fêmur II (Zaher et al., 1982: 101). Como foi encontrada apenas uma configuração possível para as espécies que apresentam 5 setas nesse artículo, pode-se inferir que essa espécie apresenta essas setas como representado nas Figuras 17.3-16, p. 50.

28. seta látero-paraxial $l$ '2 no fêmur II: presente (0); ausente (1).

Número de passos $=2 ; \mathrm{IC}=50 ; \mathrm{IR}=50$.

29. seta dorso-antiaxial $d$ "1 no fêmur II: presente (0); ausente (1).

Número de passos $=3 ; \mathrm{IC}=33 ; \mathrm{IR}=83$.

30. seta ventro-axial $\boldsymbol{v} 3$ no fêmur II: presente (0); ausente (1).

Número de passos $=3 ; \mathrm{IC}=33 ; \mathrm{IR}=81$.

\section{Fêmur III (caracteres 31 a 32) (Figura 18, p. 51)}

Apresenta de 2 a 4 setas no grupo interno. Em Meyernychus emeticae ocorrem 3 setas (Figura 18.5, p. 51), e 2 em Eutetranychus banksi e em Monoceronychus bambusicola (Figura 18.26, p. 51).

Nas espécies com 2 setas, podem ocorrer duas disposições: a dorso-antiaxial 2 (d"2) e a ventro-axial 2 (v2) (E. banksi), ou as setas d"1 e d"2 (A. chiavegatoi, A. firmianae, P. corderoi e $P$. incanus). Nas espécies com 3 setas, em adição às duas últimas setas mencionadas, pode ocorrer a dorso-paraxial $2\left(d^{\prime} 2\right)$ ou a $v 2$; nas espécies com 4 setas, ocorre ainda a seta $v 2$. 
É considerada aqui a mesma disposição de setas no fêmur III de $A$. corpuzae e $A$. aequilibris. Em A. solimani e $S$. guangzhouensis, não foi possível determinar a disposição das setas nesse artículo, pois nas três espécies são reportadas 3 setas, e duas disposições com 3 setas são possíveis (Figuras 18.5-9 e 18.10-20, p. 51).

31. seta ventro-axial $\boldsymbol{v} 2$ no fêmur III: presente (0); ausente (1).

Número de passos $=5 ; \mathrm{IC}=20 ; \mathrm{IR}=55$.

32. seta dorso-paraxial d'2 no fêmur III: ausente (0); presente (1).

Número de passos $=2 ; \mathrm{IC}=50 ; \mathrm{IR}=90$.

\section{Fêmur IV (Figura 19, p. 52)}

33. seta $v 2$ no fêmur IV: ausente (0); presente (1).

Número de passos $=4 ; \mathrm{IC}=25 ; \mathrm{IR}=40$.

A seta dorso-antiaxial 3 (d”3) está presente no fêmur IV em todas as espécies dos grupos externo e interno, e é aqui considerada como estado plesiomórfico desse caráter. Nas espécies com duas setas, além da $d " 3$ ocorre também a ventro-axial 2 (v2).

Na descrição de Aponychus pilipinus Corpuz-Raros, é mencionada a presença de 2 setas no fêmur IV (Corpuz-Raros, 1978: 212). Entretanto, a análise de parátipos daquela espécie revelou a presença de apenas uma seta nesse artículo (Figura 19.20, p. 51).

É esperada a mesma disposição de setas no fêmur IV para A. corpuzae e A. aequilibris. Do mesmo modo, é provável que S. guangzhouensis apresente a configuração representada nas Figuras 19.5-28, p. 51. Esta última espécie é descrita como tendo uma seta no fêmur IV, e apenas uma disposição foi encontrada para espécies que apresentam uma seta ( $d$ "3). Além disso, Zhang et al. (2000a: 42) afirmaram que esta espécie se assemelha a $S$. lalli no que concerne as setas idiossomais e de pernas. Portanto, é provável que $S$. guangzhouensis também apresente a seta $d$ "3.

\section{Gênu I (caracteres 34 a 35) (Figura 20, p. 53)}

O gênu I pode apresentar de 1 a 3 setas nas espécies do grupo interno, em 3 disposições possíveis. Nas espécies nas quais ocorrem três setas, estão presentes a dorso-paraxial 2 (d'2), a 
ventro-axial $2(v 2)$ e a dorso-antiaxial $2(d$ ”2). Nas espécies com 2 setas, possivelmente houve a perda da $v 2$ (Figuras 20.19-24, p. 53), e nas espécies com uma seta apenas a dorso-paraxial (d’2) está presente (Figuras 20.25-27, p. 53).

A exemplo do que ocorre nos fêmures, é esperada a mesma disposição de setas nos gênus das pernas I a IV em A. corpuzae e A. aequilibris. Em A. solimani, é reportada a presença de 3 setas no gênu I (Zaher et al., 1982: 101). Como apenas uma disposição de setas foi observada para as espécies com 3 setas nesse artículo (v’2, d’2 e $d$ ”2), é presumível que essa espécie apresente essas setas como nas Figuras 20.3-18, p. 53.

Em S. guangzhouensis é esperado o mesmo padrão apresentado por S. lalli e S. vannus (Figuras 20.26-27, p. 53), com apenas a seta $d$ '2 presente.

34. seta ventro-axial $v$ '2 no gênu I: presente (0); ausente (1).

Número de passos $=4 ; \mathrm{IC}=25 ; \mathrm{IR}=66$.

35. seta dorso-antiaxial $d$ "2 no gênu I: presente (0); ausente (1).

Número de passos $=1 ; \mathrm{IC}=100 ; \mathrm{IR}=100$.

\section{Gênu II (caracteres 36 a 37) (Figura 21, p. 54)}

De uma a 3 setas estão presentes nas espécies do grupo interno; a seta dorso-paraxial (d'2) é sempre presente; nas espécies com 3 setas, estão presentes ainda a ventro-axial 2 ( $v$ ’2) e a dorsoantiaxial 2 ( $d$ ”2); nas espécies que apresentam 2 setas, houve a perda da seta v’2, e nas espécies com apenas uma seta, além desta última, também houve a perda da seta $d$ ”2.

Na descrição de Aponychus pilipinus, Corpuz-Raros (1978: 212) 4 setas são registradas no gênu II da fêmea. Entretanto, a análise de parátipos dessa espécie revelou a presença de apenas 3 setas. Na ilustração original da espécie é possível visualizar 2 setas dorsais nesse artículo (mas não a seta ventral), o que leva a hipótese de que a autora equivocou-se ao registrar 4 setas.

Em A. solimani, é reportada a presença de 3 setas no gênu II (Zaher et al., 1982: 101). Como apenas uma disposição de setas foi observada para as espécies com 3 setas nesse artículo (v’2, d’2 e d’2), é presumível que essa espécie apresente essas setas como nas Figuras 21.3-17, p. 54.

Em S. guangzhouensis é esperado o mesmo padrão apresentado por S. bambusae, S. lalli e S. vannus (Figuras 21.24-26, p. 54), com apenas a seta $d$ '2 presente. 
36. seta ventro-axial v'2 no gênu II: presente (0); ausente (1).

Número de passos $=4 ; \mathrm{IC}=25 ; \mathrm{IR}=66$.

37. seta dorso-antiaxial $d " 2$ no gênu II: presente (0); ausente (1).

Número de passos $=1 ; \mathrm{IC}=100 ; \mathrm{IR}=100$.

\section{Gênu III (caracteres 38 a 39) (Figura 22, p. 55)}

O gênu III pode apresentar de 0 a 2 setas nas espécies próximas de Aponychus. Nas espécies com duas setas, estão presentes a ventro-axial $2(v 2)$ e a dorso-antiaxial 2 ( $d$ ”2). Nas espécies com apenas uma seta presente, esta pode ser uma das duas setas acima mencionadas.

Em A. aequilibris e A. solimani é provável que a disposição das setas siga o padrão representado pelas Figuras 22.2-11, p. 55, pois para todas elas é relatada a presença de 2 setas, e apenas uma configuração deste tipo foi observada.

Em S. guangzhouensis, não foi possível determinar a disposição de setas nesse artículo, pois nessa espécie é reportada 1 seta, e duas disposições com 1 seta são possíveis (Figuras 22.1217 e 22.18-24, p. 55).

38. seta dorso-antiaxial $d$ " 2 no gênu III: presente (0); ausente (1).

Número de passos $=2 ; \mathrm{IC}=50 ; \mathrm{IR}=87$.

39. seta ventro-axial v2 no gênu III: presente (0); ausente (1).

Número de passos $=3 ; \mathrm{IC}=33 ; \mathrm{IR}=75$.

\section{Gênu IV (caracteres 40 a 41) (Figura 23, p. 56)}

O gênu IV pode apresentar de 0 a 2 setas nas espécies próximas de Aponychus. Nas espécies nas quais ocorrem duas setas, estão presentes a latero-paraxial ( $l$ ') e a latero-antiaxial ( $l$ ”), e nas espécies com apenas uma seta, esta pode ser uma das duas setas acima mencionadas.

Assim como no gênu III, é provável que em A. aequilibris e A. solimani a disposição das setas siga o padrão representado pelas Figuras 23.1-10, p. 56, pois para todas elas é relatada a presença de 2 setas, e apenas uma configuração deste tipo foi encontrada. 
40. seta dorso-antiaxial $d$ ”2 no gênu IV: presente (0); ausente (1).

Número de $\operatorname{passos}=2 ; \mathrm{IC}=50 ; \mathrm{IR}=88$.

41. seta ventro-axial $\boldsymbol{v} 2$ no gênu IV: presente (0); ausente (1).

Número de passos $=3 ; \mathrm{IC}=33 ; \mathrm{IR}=80$.

\section{Tíbia I (Figura 24, p. 57)}

Pode haver de 3 a 6 setas táteis na tíbia I das espécies de Aponychus e gêneros próximos. Não foi possível examinar exemplares de A. aequilibris, A. rarus e A. solimani em lâminas. Entretanto, pela informação apresentada nas descrições dessas espécies, é provável que apresentem o padrão de 5 setas táteis e uma sensorial representado nas Figuras 24.5-18, p. 57, pois apenas uma configuração foi encontrada em espécies que apresentam esse número de setas na tíbia I.

Do mesmo modo, é provável que $S$. guangzhouensis apresente três setas táteis e uma sensorial como representado pelas Figuras 24.23-27, p. 57, pois somente essa configuração foi encontrada para espécies que apresentam esse número de setas na tíbia I.

42. setas táteis na tíbia I: 9-8 (0); 6-5 (1); 4-3 (2).

Número de passos $=6 ; \mathrm{IC}=66 ; \mathrm{IR}=88$.

\section{Tíbia II (caracteres 43 a 45) (Figura 25, p. 58)}

Pode haver de 1 a 5 setas táteis na tíbia II nas espécies próximas de Aponychus, não ocorrendo nenhuma seta sensorial nesse artículo. Nas espécies com 5 setas nesse artículo, ocorrem as dorso-paraxial e antiaxial 2 (d'2 e $\left.d^{\prime \prime} 2\right)$, ventro-paraxial e antiaxial 2 ( $v^{\prime} 2$ e $\left.v^{\prime \prime} 2\right)$ e a ventroparaxial $1\left(v^{\prime} 1\right)$. A ocorrência de 4 setas, possivelmente se dá pela perda da seta $v^{\prime} 1$. Nas espécies que apresentam 3 setas, estas são as dorso-paraxial e antiaxial 2 (d'2 e d"2) e a ventro-paraxial 2 (v'2) e a ocorrência de duas setas se dá pela perda da seta v'2. Quando apenas uma seta está presente, esta é sempre a $d$ '2.

Não foi possível examinar exemplares de A. aequilibris, A. rarus e A. solimani. Entretanto, pelas informações apresentadas nas descrições daquelas espécies, é provável que apresentem o padrão de 3 setas táteis representado nas Figuras 25.9-18, p. 58.

É provável que $S$. guangzhouensis apresente apenas a seta d'2 na tíbia II, pois apenas essa configuração foi encontrada em espécies que apresentam uma seta nesse artículo. 
43. seta v'1 na tíbia II: presente (0); ausente (1).

Número de passos $=1 ; \mathrm{IC}=100 ; \mathrm{IR}=100$.

44. seta v'2 na tíbia II: presente (0); ausente (1).

Número de passos $=1 ; \mathrm{IC}=100 ; \mathrm{IR}=100$.

45. seta $d$ "2 na tíbia II: presente (0); ausente (1).

Número de passos $=1 ; \mathrm{IC}=100 ; \mathrm{IR}=100$.

Tíbia III (caracteres 46 a 48) (Figura 26, p. 59)

Pode ocorrer de 1 a 4 setas táteis nas espécies do grupo interno. A seta látero-dorsal antiaxial $d$ "2 encontra-se sempre presente, sendo a única seta presente nas espécies com apenas uma seta (Figura 26.19-23, p. 59); nas espécies com duas setas, além desta última, ocorre também a seta ventral paraxial v’2 (Figura 26.8-18, p. 59); nas espécies com 3 setas, ocorre ainda a seta dorso-paraxial d'2 (Figura 26.4-7, p. 59); no grupo interno, ocorrem 4 setas somente em $A$. schultzi e $S$. insularis (Figuras 26.2 e 26.3, respectivamente, p. 59), havendo nessas espécies, além das já mencionadas, a ventral paraxial v'1.

Não existem ilustrações desses artículos na descrição de A. aequilibris mas pode-se concluir pela informação apresentada no texto da descrição original, que ela provavelmente apresenta o padrão de 2 setas táteis ( $d^{\prime \prime} 2$ e v’2), representado nas Figuras 26.8-18, p. 59, pois somente uma configuração com duas setas presentes nesse artículo foi encontrada. Do mesmo modo, em S. guangzhouensis é provável que apenas a seta $d$ ”2 esteja presente na tíbia III, pois somente essa configuração foi encontrada nesse artículo, a exemplo de A. Bambusae, S. baghensis, S. lalli, S. nakaoi e S. vannus (Figuras 26.19-23, p. 59).

46. seta ventro-paraxial $v$ '1 na tíbia III: presente (0); ausente (1).

Número de passos $=1 ; \mathrm{IC}=100 ; \mathrm{IR}=100$.

47. seta dorso-paraxial $d$ '2 na tíbia III: presente (0); ausente (1).

Número de passos $=2 ; \mathrm{IC}=50 ; \mathrm{IR}=88$.

48. seta ventro-paraxial $v$ '2 na tíbia III: presente (0); ausente (1).

Número de passos $=1 ; \mathrm{IC}=100 ; \mathrm{IR}=100$. 


\section{Tíbia IV (caracteres 49 a 51) (Figura 27, p. 60)}

Na tíbia IV pode haver de 1 a 4 setas táteis nas espécies de Aponychus e de gêneros próximos. Assim como na tíbia III, a seta $d " 2$ ocorre em todas as espécies, sendo esta a única presente nas espécies com apenas uma seta (Figuras 27.20-24, p. 60). Nas espécies com duas setas, além desta última, ocorre também a seta v'2 (Figuras 27.9-19, p. 60), e nas espécies com 3 setas, há ainda a seta ventro-axial v’2 (Figuras 27.5-8, p. 60). No grupo interno, ocorrem 4 setas somente em $S$. insularis e $A$. schultzi, havendo nessas espécies, além das já mencionadas, a seta v'l (Figuras 27.3-4, p. 60).

Ho (2003: 346) descreveu A. mallotus como tendo 4 setas na tíbia IV. Entretanto, analisando-se um parátipo fêmea dessa espécie, foram observadas apenas 3 setas nesse artículo, não sendo possível concluir que se trata de uma variação apresentada pelo exemplar analisado.

Nas espécies analisadas que apresentam somente uma seta, esta é sempre a dorso-antiaxial 2 (d"2). É presumível que $S$. guangzhouensis também apresente esta seta, pois, segundo Zhang et al. (2000a: 42), essa espécie apresenta a mesma quetotaxia das pernas que S. lalli.

É provável que A. aequilibris apresente a configuração representada nas Figuras 27.9-19, p. 60, pois nessa espécie é relatada a presença de duas setas na tíbia IV, e somente uma configuração com duas setas nesse artículo foi encontrada.

49. seta ventro-paraxial v'1 na tíbia IV: presente (0); ausente (1).

Número de passos $=1 ; \mathrm{IC}=100 ; \mathrm{IR}=100$.

50. seta dorso-paraxial $d$ '2 na tíbia IV: presente (0); ausente (1).

Número de $\operatorname{passos}=1 ; \mathrm{IC}=100 ; \mathrm{IR}=100$.

51. seta ventro-paraxial $v^{\prime} 2$ na tíbia IV: presente (0); ausente (1).

Número de passos $=4 ; \mathrm{IC}=25 ; \mathrm{IR}=70$.

Tarsos (Figuras 28 a 31, p. 61-64)

Uma condição única da família Tetranychidae que a diferencia dos outros Tetranychoidea é a presença de setas dúplices no dorso dos tarsos I e II. Nos Eurytetranychini, com exceção do gênero Atetranychus Baker, Tuttle \& Abbatiello, que apresenta apenas um conjunto de setas 
dúplices nos tarsos I e II, essas setas encontram-se fracamente associadas entre si. Uma seta quimiossensorial pode estar presente na porção proximal dos tarsos III e IV.

Tarso I (Figura 28, p. 61)

52. seta associadas $f t^{\prime}$ e $\omega^{\prime} 2$ no tarso I: associadas (0); dissociadas (1).

Número de passos $=2 ; \mathrm{IC}=50 ; \mathrm{IR}=88$.

Tarso II (Figura 29, p. 62)

53. seta associadas $f t^{\prime \prime}$ e 1 no tarso II: associadas (0); dissociadas (1).

Número de passos $=4 ; \mathrm{IC}=25 ; \mathrm{IR}=76$.

Tarso III (Figura 30, p. 63)

Uma seta quimio-sensorial (solenídio) pode estar presente no tarso III em posição dorsoproximal.

54. seta quimiossensorial proximal no tarso III: presente (0); ausente (1).

Número de passos $=4 ; \mathrm{IC}=25 ; \mathrm{IR}=76$. 


\section{Reconstrução filogenética}

A análise filogenética retornou apenas uma árvore mais parcimoniosa (Figuras 7 e 8, p. 41-42), com número de passos 135, índice de consistência (IC) 45 e índice de retenção (IR) 82 . O monofiletismo do grupo interno foi suportado por nove sinapomorfias (caracteres 1, 11, 14, 17, 20, 26, 33, 40 e 42), presentes em representantes desses três gêneros. Entretanto, quanto às relações internas, os gêneros Aponychus, Paraponychus e Stylophoronychus revelaram-se parafiléticos.

Considerando a árvore subótima, com um passo adicional (136), foram encontradas mais 6 árvores, havendo variação apenas no posicionamento de três espécies: A. pilipinus, A. taishanicus e A. mallotus. O agrupamento de [A. firmianae + A. spinosus], posicionado em meio a essas espécies que tiveram variação, não foi alterado nas árvores subótimas.

O número de cladogramas obtidos após pesagem implícita de caracteres variou de acordo com o valor atribuído a $k$. Após pesagem diferenciada dos caracteres 18 e 23 (presença/ausência das setas dorsais $c 2$ e $f 1$, respectivamente), principais caracteres diagonósticos para diferenciação dos gêneros Paraponychus e Stylophoronychus, foram obtidos os seguintes resultados, utilizandose os diferentes valores de pesagem $(k)$ para esses caracteres:

$k=2 \rightarrow 1$ árvore de 141 passos;

$k=3 \rightarrow 1$ árvore de 147 passos;

$k=4 \rightarrow 1$ árvore de 153 passos;

$k=5 \rightarrow 7$ árvores de 159 passos;

$k=6 \rightarrow 1$ árvores de 163 passos;

Mesmo após pesagem destes caracteres, a presença de algumas politomias foi constante, o que indica a falta de caracteres suficientes encontrados e organizados na matriz para a separação dessas espécies.

A perda de uma seta na coxa da perna II (caráter 25; 2 passos; $C I=25 ; \mathrm{RI}=92$ ) foi utilizada por Meyer (1987) para fundamentar a proposição do gênero Chinotetranychus Meyer. Entretanto, a partir do resultado da análise filogenética foi possível constatar que esse caráter surgiu independentemente em espécies de Aponychus e Stylophoronychus, demonstrando que esse caráter não é adequado para o diagnóstico genérico desse grupo.

Alguns ramos basais tiveram pequenos valores de suporte de Bootstrap e Jackknife, o que mostra que tiveram baixo nível de resolução e congruência (Figura 7, p. 41). Os maiores valores foram encontrados nas espécies asiáticas de setas dorsais curtas, incluindo as do gênero Stylophoronychus. 


\section{Gênero Aponychus Rimando}

A análise revelou uma condição parafilética para este gênero, que abrigou também espécies atualmente incluídas em Paraponyhus e Stylophoronychus. Foi encontrada apenas uma sinapomorfia (caráter 38) para o grupo que inclui espécies de Aponychus, a ausência da seta dorsoantiaxial $d ” 2$ no genu III. O caráter 28 (ausência da seta látero-paraxial $l ’ 2$ no fêmur II), homoplástico, foi verificado nesse grupo, mas também em uma espécie do grupo externo, Eutetranychus banksi.

Algumas espécies foram agrupadas em politomias, o que reflete a dificuldade em se encontrar caracteres morfológicos suficientes para a diferenciação dessas espécies. Em alguns casos, é provável que algumas espécies devam ser consideradas em sinonímia (ver discussão taxonômica no capítulo II, páginas 106, 140, 156 e 168). O clado formado pelas espécies $A$. sulcatus, A. solimani, A. rarus, A. parydrus, A. lupus, A. imperatus, A. grandidieri e A. expansus foi suportado por grandes valores dos índices de Bootstrap e Jackknife (77 e 86, respectivamente). Esses dados apontam para uma grande dificuldade em se detectar caracteres morfológicos suficientes para a separação dessas espécies, o que pode ser indicativo de uma possível sinonímia entre elas. A estrutura dos palpos, principalmente dos fâneros presentes no tarso desse apêndice, é bastante utilizada na diagnose específica de tetraniquídeos, e deve ainda ser melhor averiguada nas espécies tratadas no presente estudo. Entretanto, na maioria dos espécimes estudados não foi possível visualizar claramente essas estruturas, pela posição do espécime na lâmina, interferência do meio de montagem e/ou pequeno número de exemplares montados de algumas espécies.

\section{Gênero Paraponychus González \& Flechtmann}

Esse gênero também mostrou-se parafilético, com Aponychus chiavegatoi sendo posicionado como grupo irmão do clado formado por Paraponychus corderoi e $P$. incanus. Essas duas últimas foram agrupadas em todas as análises realizadas, independente da pesagem dos caracteres utilizada, sendo possível que devam ser sinonimizadas com a espécie mais antiga delas, P. corderoi (ver discussão taxonômica na página 106). Os dados de ocorrência geográfica e de hospedeiros dessas duas espécies reforçam essa hipótese (capítulo II). O clado suportado por essas espécies foi também suportado por altos valores dos índices estatísticos (Bootstrap= 82; Jackknife= 87).

Paraponychus saundersi foi agrupada como grupo irmão do clado $[[P$. corderoi $+P$. incanus $]+$ A. chiavegatoi]. A inclusão de P. kodaikanalensis no clado do gênero Paraponychus somente foi obtida após pesagem do caráter 18 (ausência da seta histerossomal $c 2$ - principal 
caráter diagnóstico para o gênero), com valor de $k=5$. Entretanto, A. chiavegatoi, que apresenta essa seta, permaneceu agrupado como grupo irmão de $P$. corderoi $+P$. incanus mesmo após a pesagem desse caráter.

Entretanto, os ramos basais de espécies do gênero Paraponychus apresentaram pequenos valores dos índices estatísticos (Figura 7, p. 41), o que demonstra a necessidade de novos estudos filogenéticos e possível reavaliação dos caracteres utilizados para diagnose genérica desse grupo.

\section{Gênero Stylophoronychus Prasad}

As espécies deste gênero foram agrupadas no mesmo clado, suportado por cinco sinapomorfias (caracteres 12, 37, 42, 44 e 48), com exceção de apenas uma espécie, S. insularis. Essa espécie foi posicionada distante das demais espécies do gênero em todos os cladogramas obtidos, próxima à base do cladograma, independentemente do valor de $k$ utilizado para a análise. Isto reforça a sugestão de Zhang et al. (2000a) de que essa espécie não pertença a esse gênero. Portanto, sugere-se que o principal caráter utilizado taxonomicamente para diagnose de Stylophoronychus, i.e. ausência da seta dorsal $f 1$, tenha evoluído independentemente nesta e nas demais espécies do gênero. O alto valor de suporte dos índices estatísticos desse clado (Figura 7, p. 41, Bremer $=10$; Boostrap $=99$; Jackknife=100) corrobora seu monofiletismo, apresentando apenas espécies asiáticas, e demonstra que $S$. insularis deve ser removida desse gênero.

Quatro espécies, Aponychus bambusae, S. guangzhouensis, S. lalli e S. vannus, foram agrupadas na mesma politomia em todos os cladogramas obtidos, mesmo após pesagem dos caracteres 18 e 23 . O ramo que inclui essas quatro espécies foi suportado por quatro sinapomorfias (caracteres 5, 22, 35 e 45) e altos valores estatísticos $($ Bremer $=8$; Bootstrap=100; Jackknife= 100), sendo possível que elas representem sinônimos da espécie sênior, S. vannus (ver discussão taxonômica na página 168). Excetuando-se S. guangzhouensis, foram analisados espécimes-tipo das demais espécies desse clado.

Os grânulos presentes na região dorso-anterior do estilóforo (caráter 5) de algumas espécies de Stylophoronychus revelaram-se como uma sinapomorfia de S. vannus, S. lalli, S. guangzhouensis e A. bambusae. Esse caráter, encontrado somente nessas espécies, reforça a hipótese de sinonímia entre elas. 


\section{Caracteres}

Foi possível perceber algumas associações entre caracteres, de modo que a presença de um determinado caráter foi acompanhada pela presença de um ou mais caracteres aparentemente não relacionados entre si. Por exemplo, em algumas espécies as setas dorsais são longas e robustas (e.g. A. pilipinus, A. spinosus, S. insularis), suportadas por proeminentes tubérculos. Nessas espécies o estilóforo é sempre arredondado anteriormente, ou no máximo apresenta leves projeções, mas nunca com as fortes projeções bilobadas encontradas em algumas espécies de Aponychus e Stylophoronychus (e.g. A. sarjui, S. vannus). Nestas últimas, as setas dorsais são sempre curtas, no máximo atingido as bases do par subsequente.

Outra associação encontrada entre espécies que possuem setas curtas foi a conformação das setas escapulares externas $(s c 2)$ e humerais (c3), que assumem nessas espécies uma disposição com as suas extremidades convergentes entre si. 


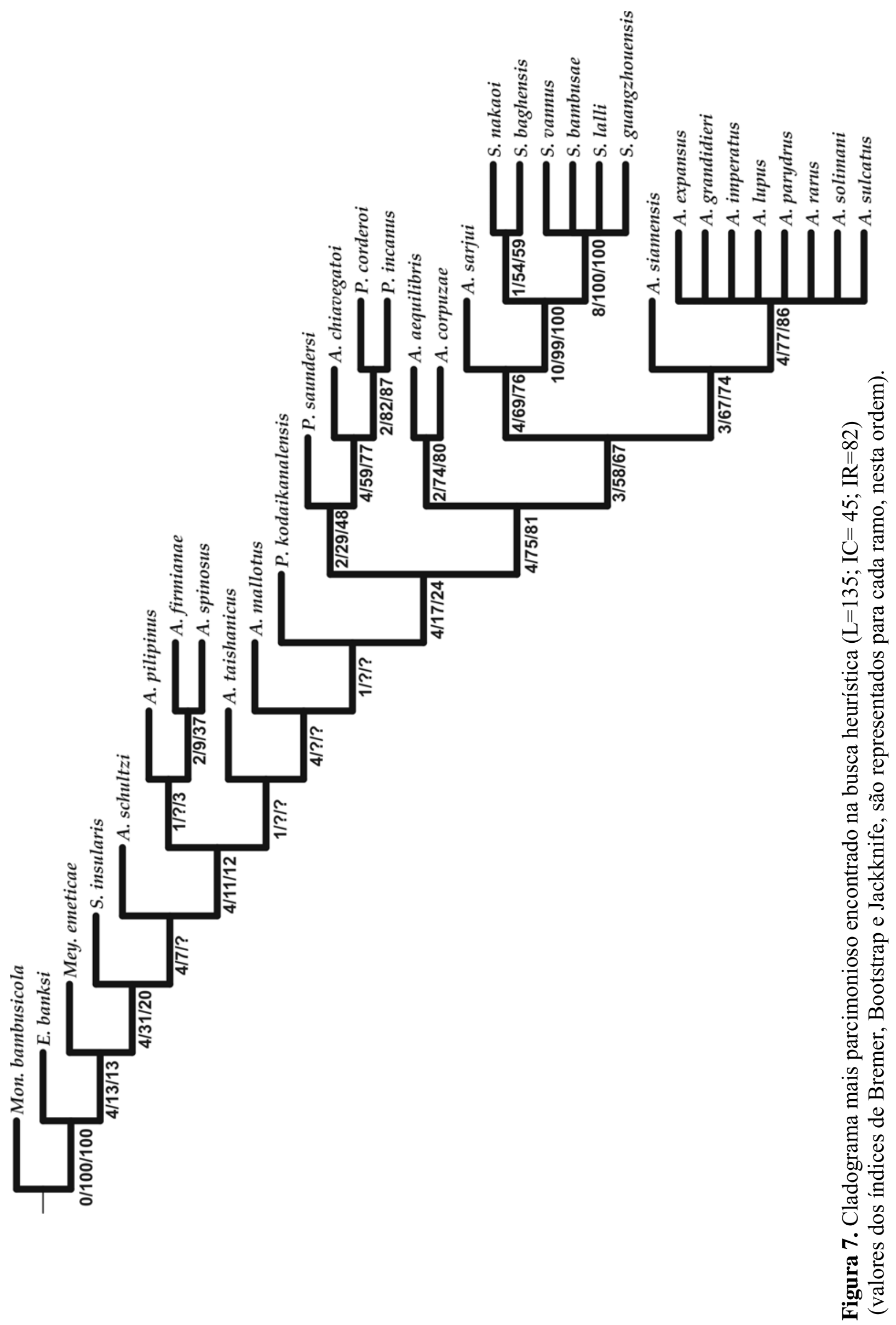




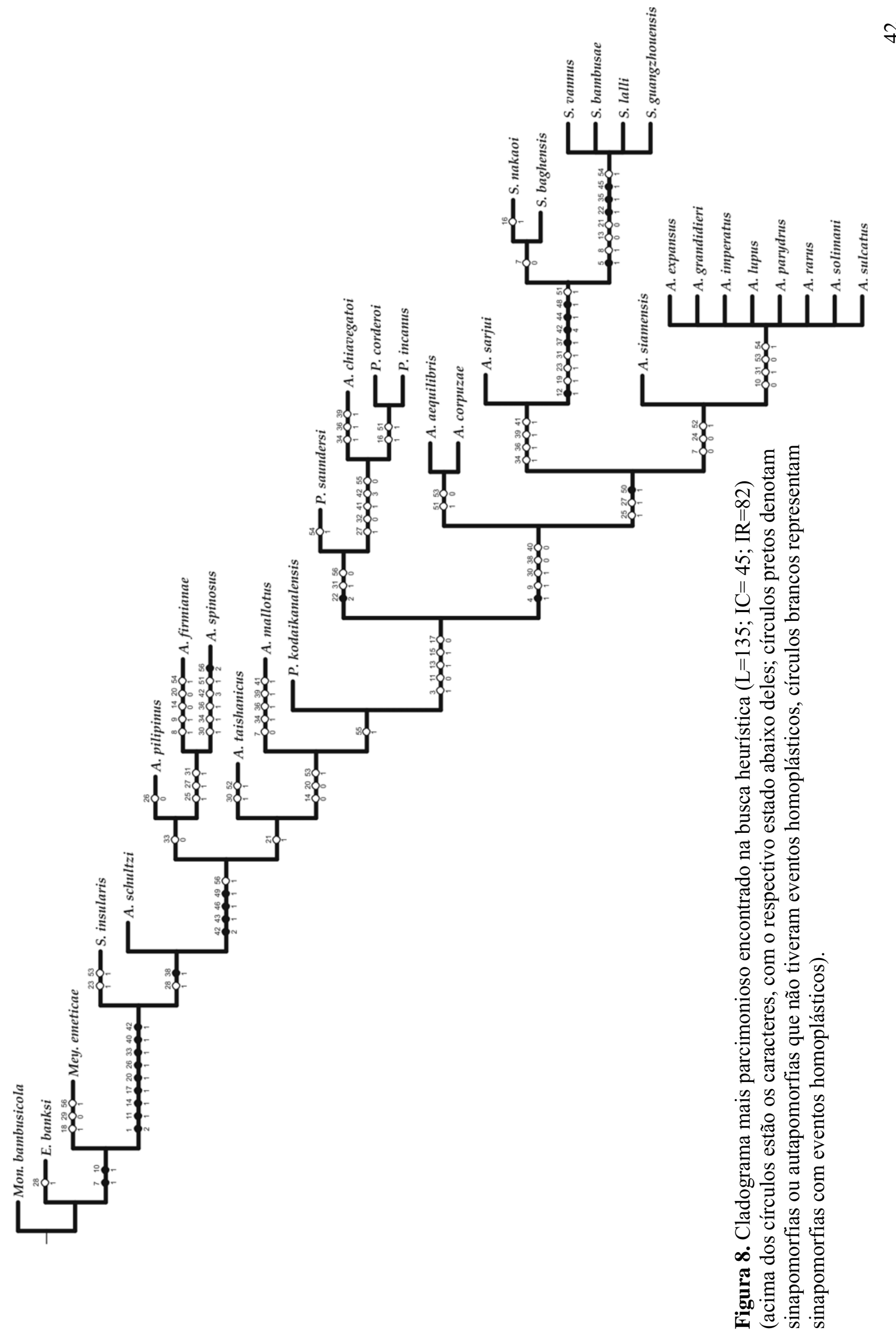




\section{APÊNDICE I}

\section{matriz de caracteres}

e figuras 
Matriz de caracteres utilizados na análise filogenética (táxons 1-3 = grupo externo; 4-33 = grupo interno).

000000000111111111122222222223333333333444444444455555

123456789012345678901234567890123456789012345678901234

1.Mon. bambusicola

2.E. banksi

3. Mey. emeticae

4.A. aequilibris

5.A. chiavegatoi

6.A. corpuzae

7.A. expansus

8.A. firmianae

9.A. grandidieri

10.A. imperatus

11.A. Iupus

12.A. mallotus

13.A. parydrus

14.A. pilipinus

15.A. rarus

16.A. sarjui

17.A. schultzi

18.A. siamensis

19.A. solimani

20.A. spinosus

21.A. sulcatus

22.A. taishanicus

23.P. corderoi

24.P. incanus

25.P. kodaikanalensis

26.P. saundersi

27.S. insularis

28.S. nakaoi

29.S. baghensis

30.S. vannus

31. A. bambusae

32.S. Ialli

33.S. guangzhouensis
001000000000101000001000000010100 ?0000000?????????00? 110001000000000000000000000110000000000000000000000000 $110001100100000001 ? 00000000000000000000000000000000000$ 211101101000101000001001010101011000000002100110101000 211001100100101000101201011110100101011113100110100010 211101101000101000001001010101011000000002100110101000 211101001000101000001000111101110000000002100110110101 210001111110000010000001111110100000010102100100100001 211101001000101000001000111101110000000002100110110101 211101001000101000001000111101110000000002100110110101 211101001000101000001000111101110000000002100110110101 210001000010000010001001010110011101011112100100100010 211101001000101000001000111101110000000002100110110101 210001100110010010010001000110000000010102100100100000 211101001000101000001000111101110000000002100110110101 211101101100101000001001111101010101001012100110110010 210001100110010010010001010110001000010101000000000000 211101001100101000001000111101010000000002100110110110 211101001000101000001000111101110000000002100110110101 210001100110010010010001111111100101 ? 10103100100101000 211101001000101000001000111101110000000002100110110101 210001100010010010011001010111 ??10000????210010010010? $211001100100101101 ? 01201011110100000010113100110101010$ $211001100100101101 ? 01201011110100000010113100110101010$ 211001100 ? 10000011 ?01001?1??0???????????2???????????? $211001100100101001 ? 01201010110110000010102100100100011$ 210001?0011001001001001?010010001000000101000000000010 21110100110110110010101 ? 111101110101101014110111111010 21110100110110100010101 ? 111101110101101014110111111010 21111111110100100010011 ?111101110111101014111111111011 21111111110100100010011 ?111101110111101014111111111011 21111111110100100010011 ? 111101110111101014111111111011 21111111110100100010011 ?111101110111101014111111111011 

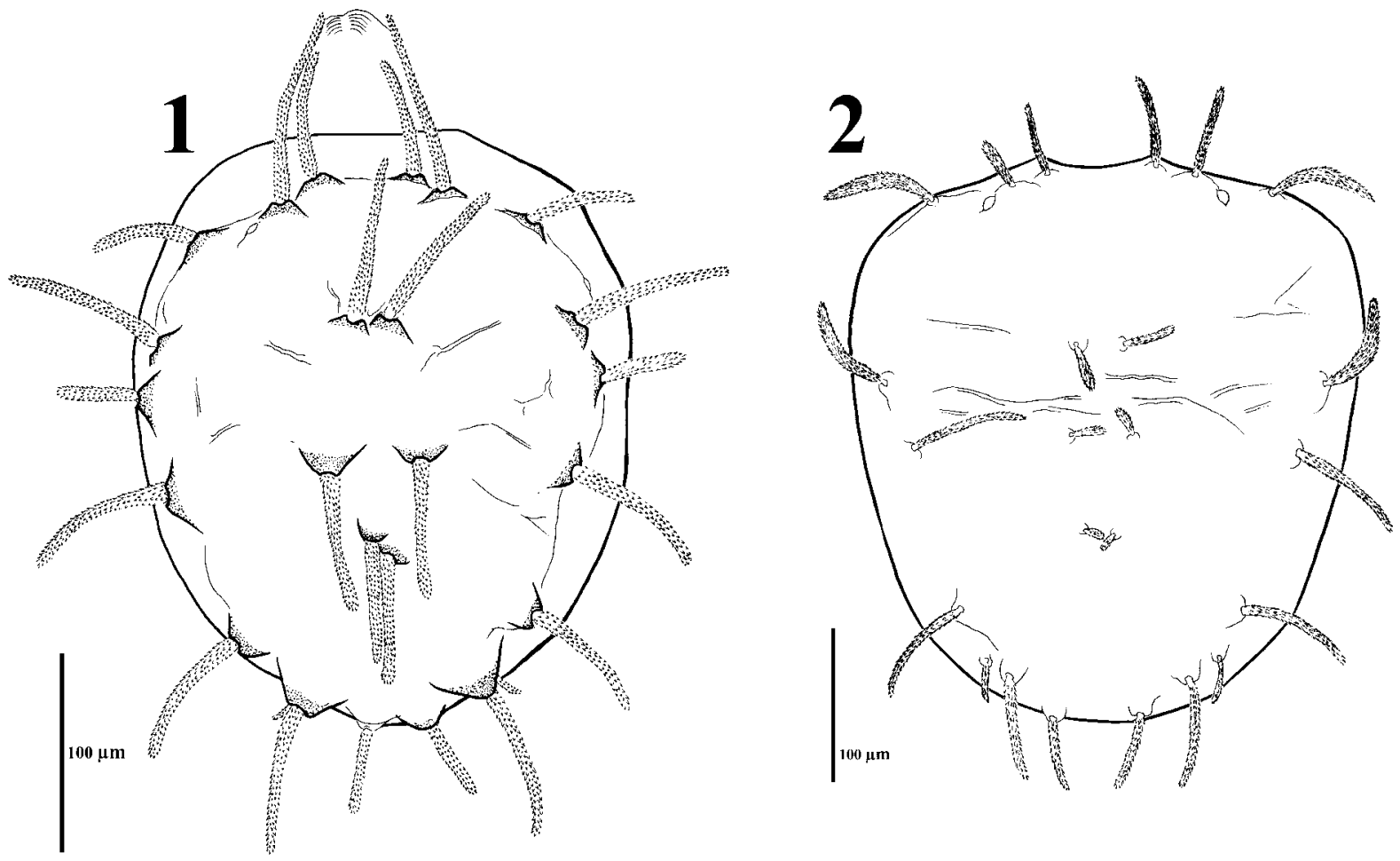

Figura 9. Idiossoma dorsal de Aponychus pilipinus (1) e Paraponychus corderoi (2).
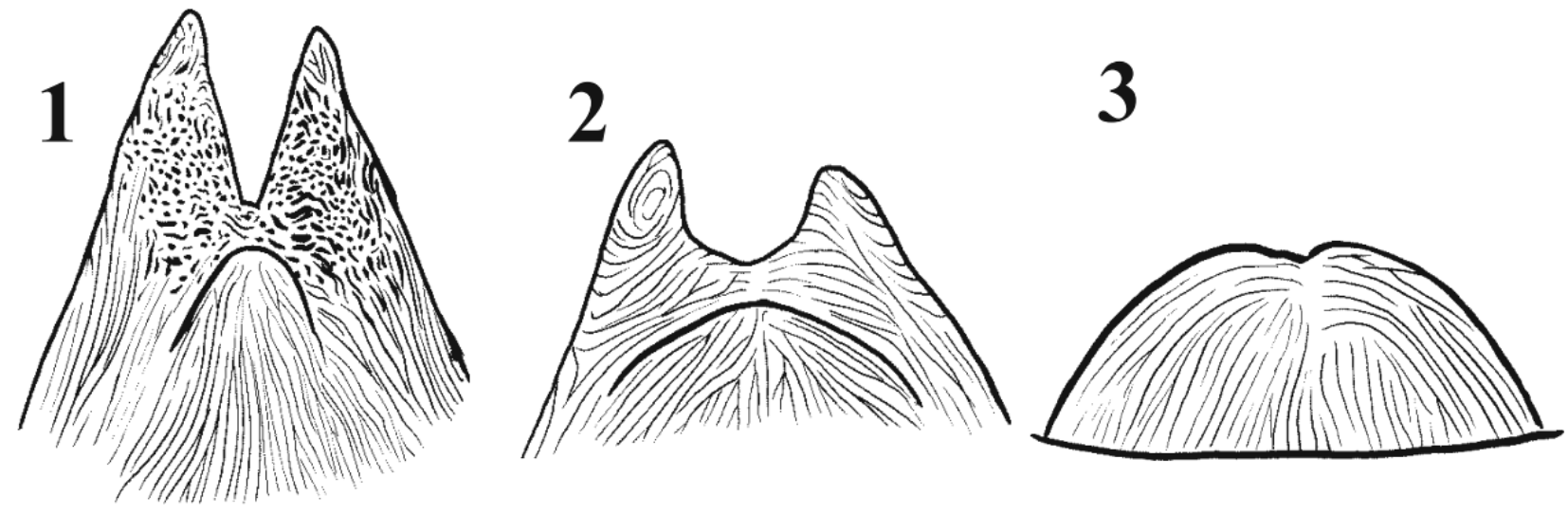

3

Figura 10. Estilóforos de Stylophoronychus vannus (1), Aponychus corpuzae (2) e A. mallotus (3). 


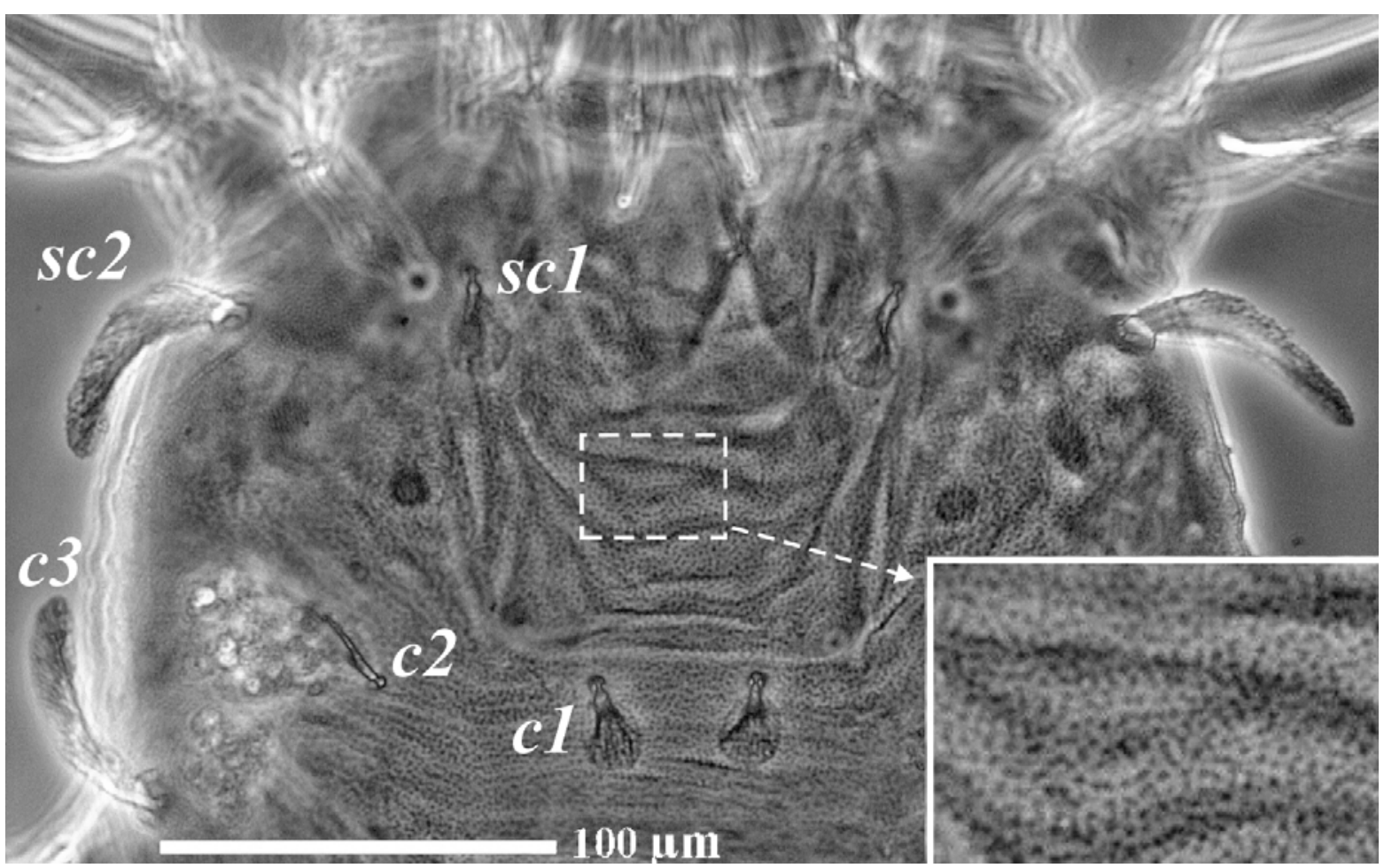

Figura 11. Fotomicrografia em constraste de fases da parte anterior do idiossoma dorsal granulado de Aponychus parydrus, parátipo.

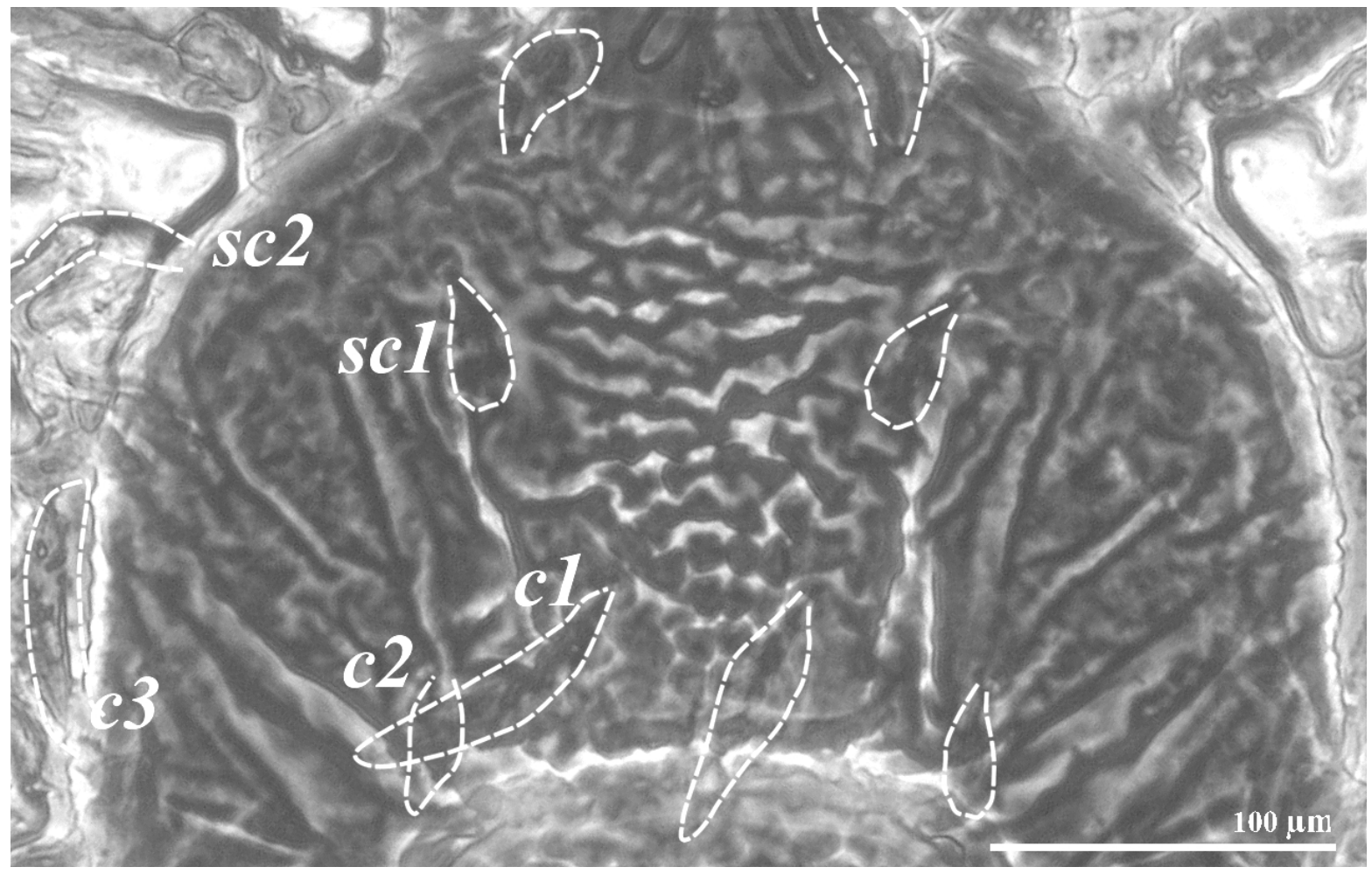

Figura 12. Fotomicrografia em contraste de fases da parte anterior do idiossoma dorsal de parátipo de $S$. vannus, mostrando tegumento com padrão enrugado. 


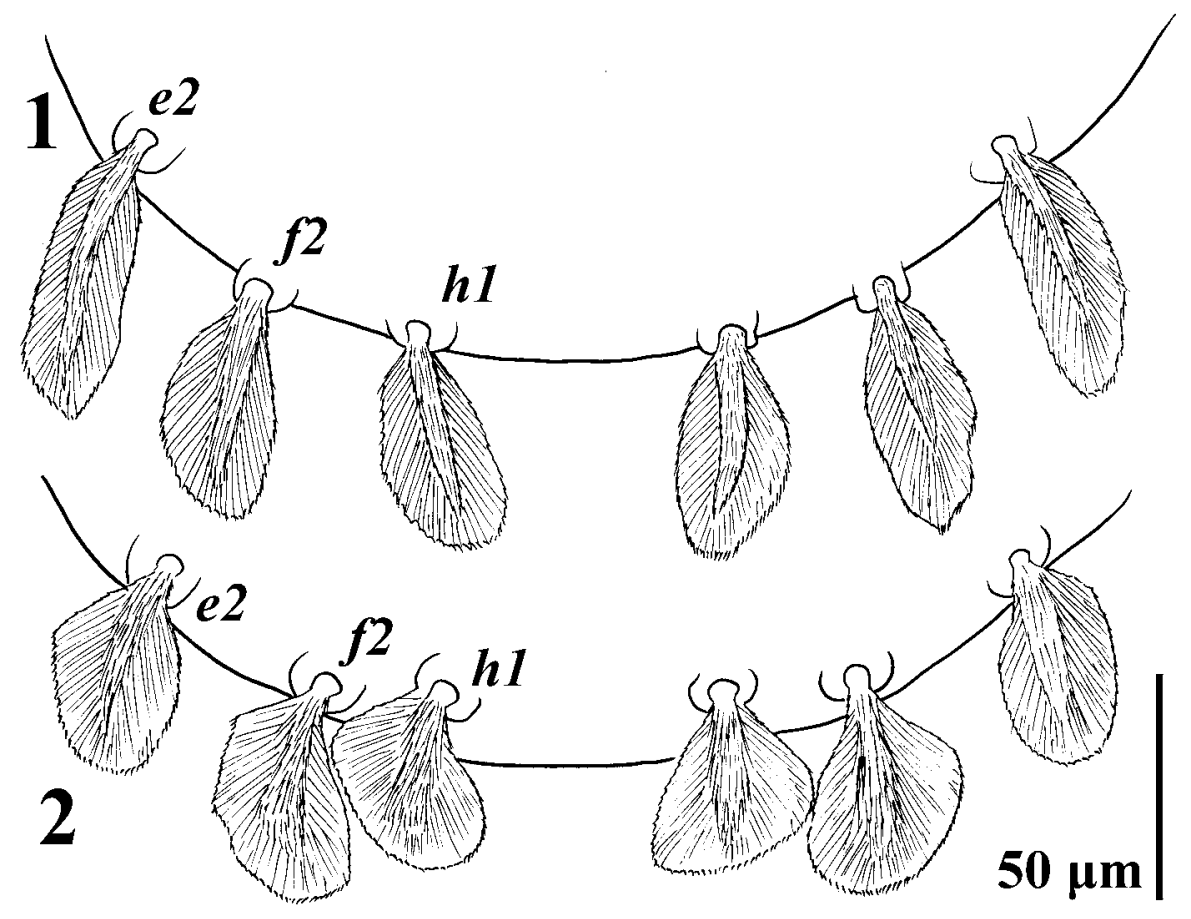

Figura 13. Detalhe de setas da região posterior do opistossoma $(e 2, f 2$ e $h 1)$ de $S$. lalli (1), holótipo, e $S$. vannus (2), parátipo, com cerne visível.
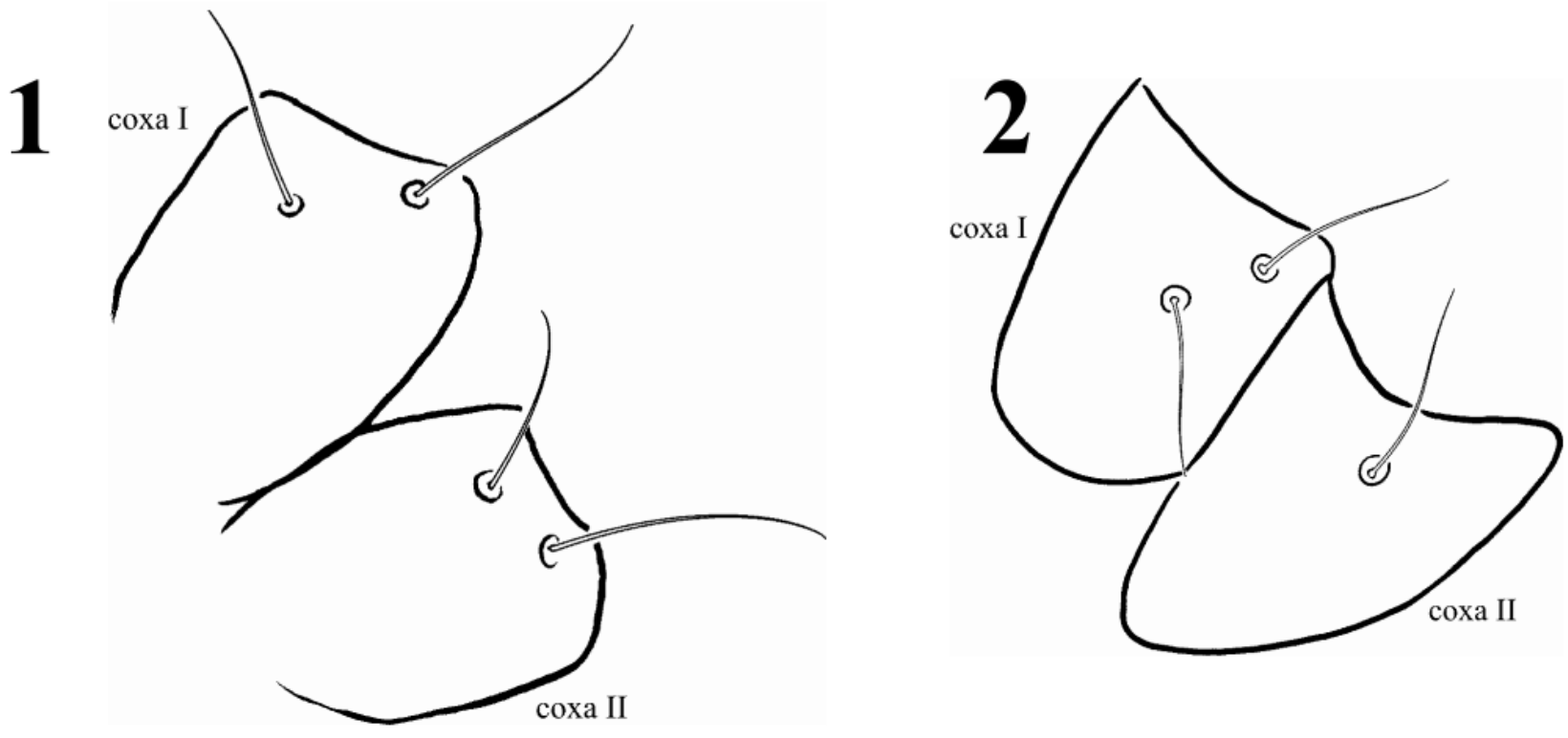

Figura 14. Coxas das pernas I e II de Aponychus corpuzae (1) e Stylophoronychus vannus (2). 


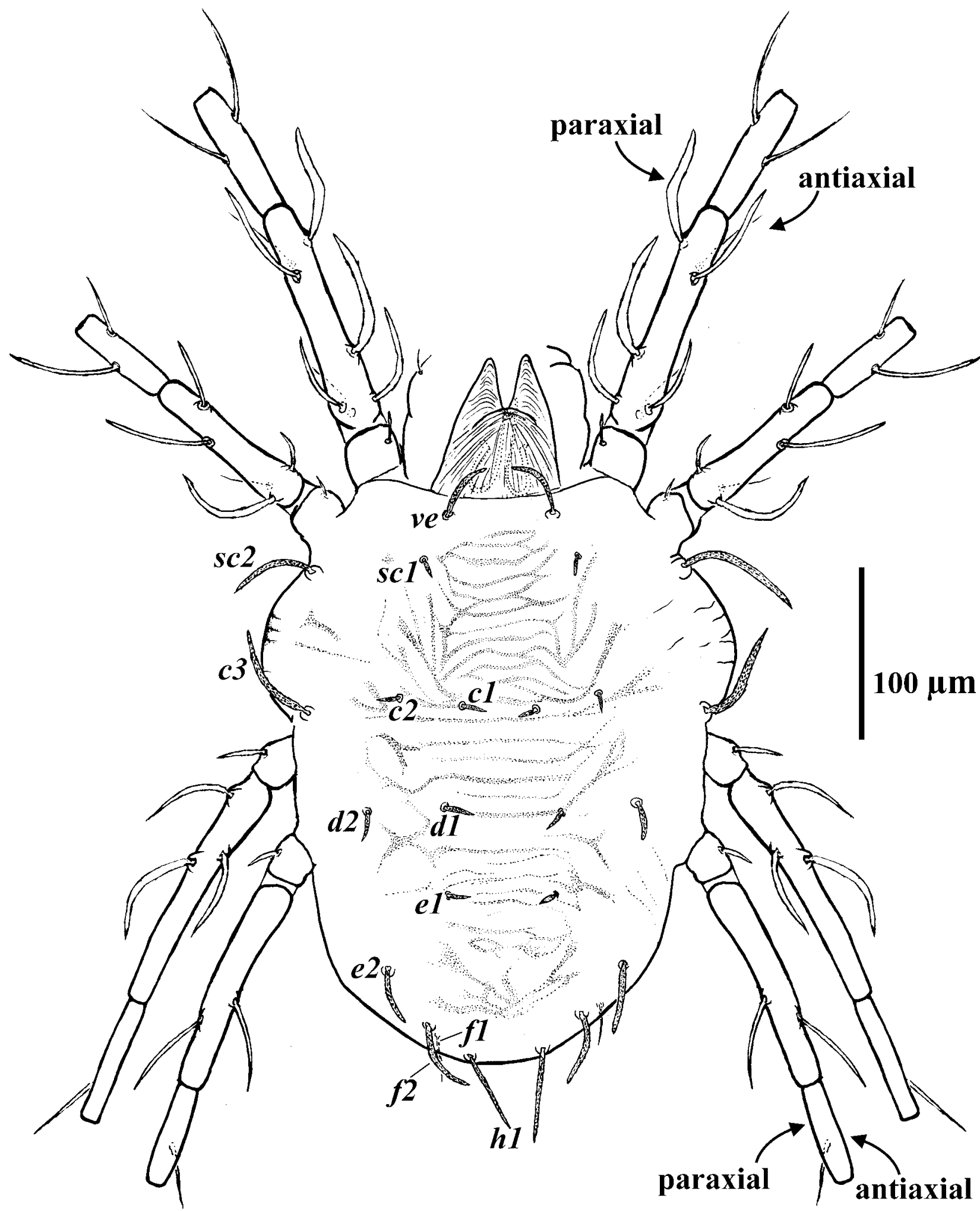

Figura 15. Hábito dorsal de Aponychus corpuzae, mostrando quetotaxia dorsal e posição de inserção das setas nas pernas. 

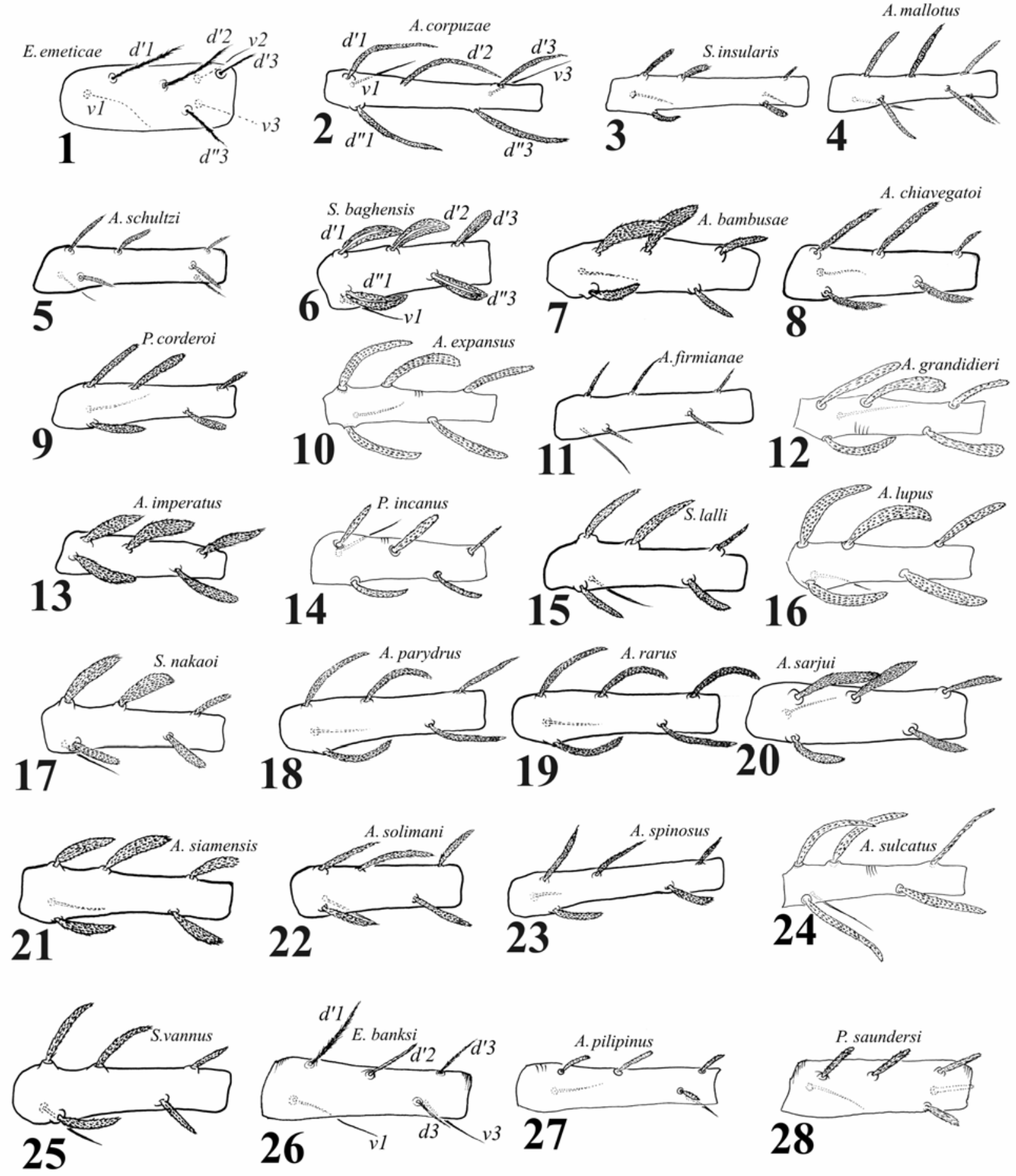

Figura 16. Fêmures da perna I das espécies analisadas no presente estudo. 

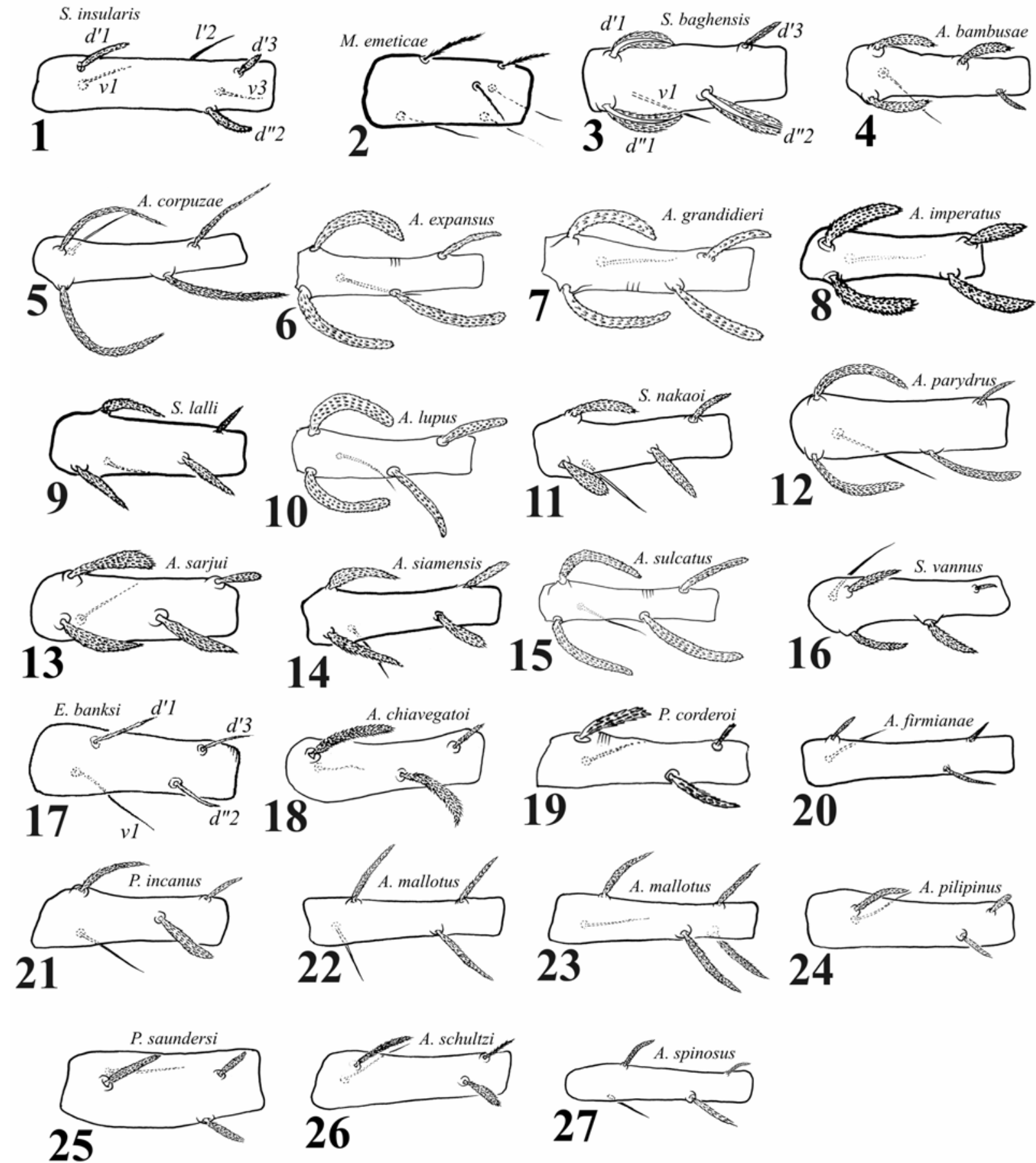

Figura 17. Fêmures da perna II das espécies analisadas no presente estudo. 

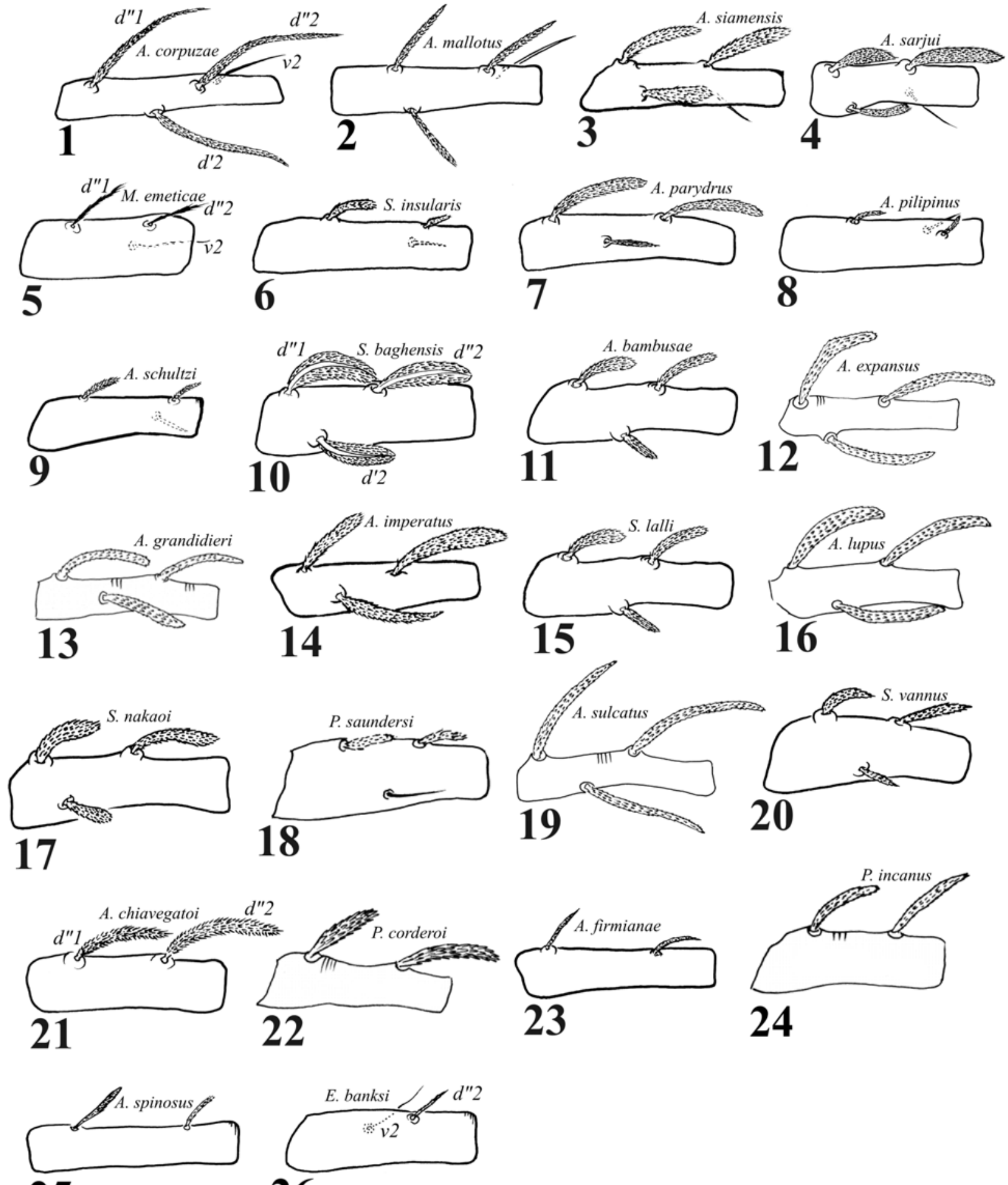

25

26

Figura 18. Fêmures da perna III das espécies analisadas no presente estudo. 

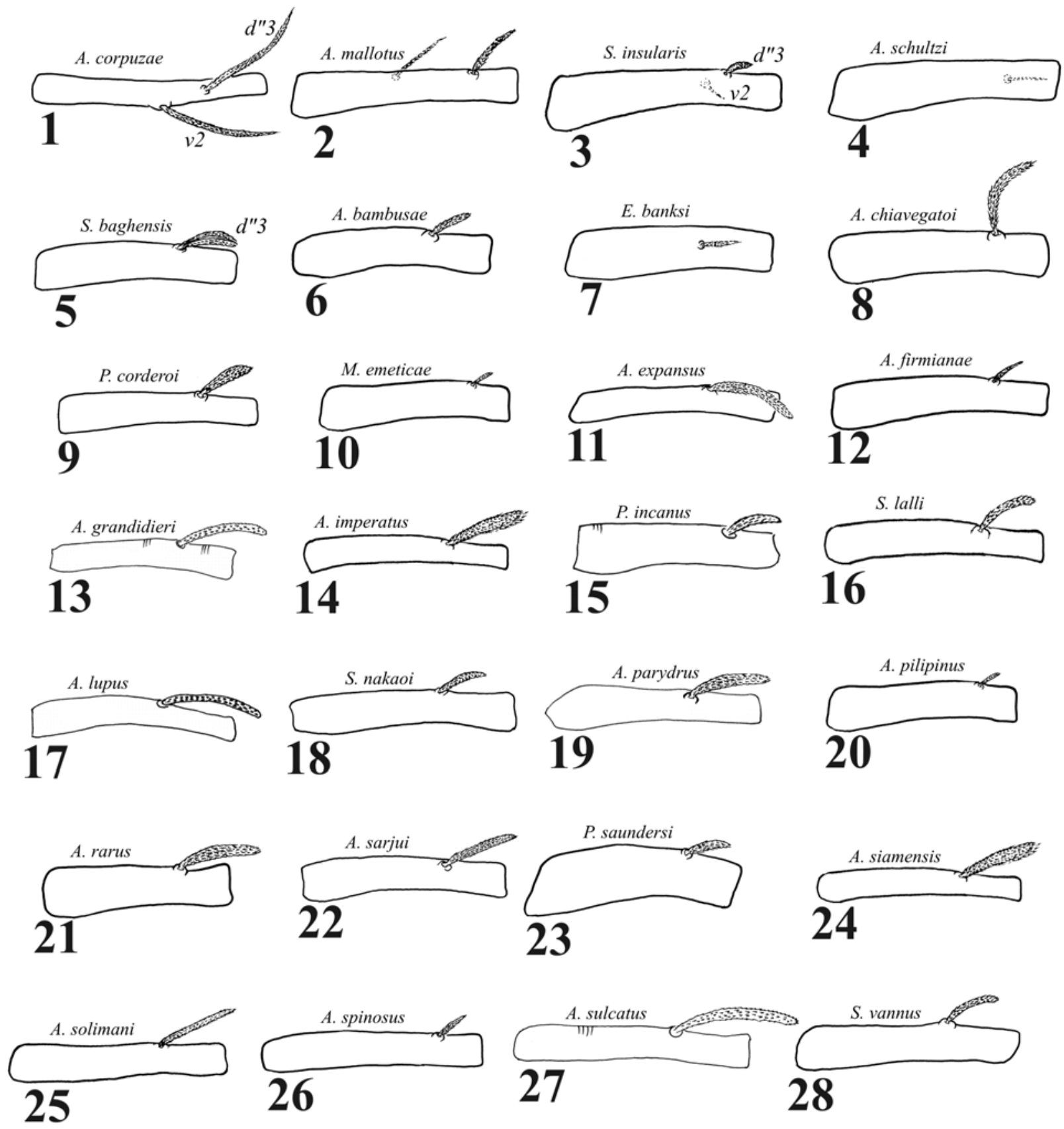

Figura 19. Fêmures da perna IV das espécies analisadas no presente estudo. 

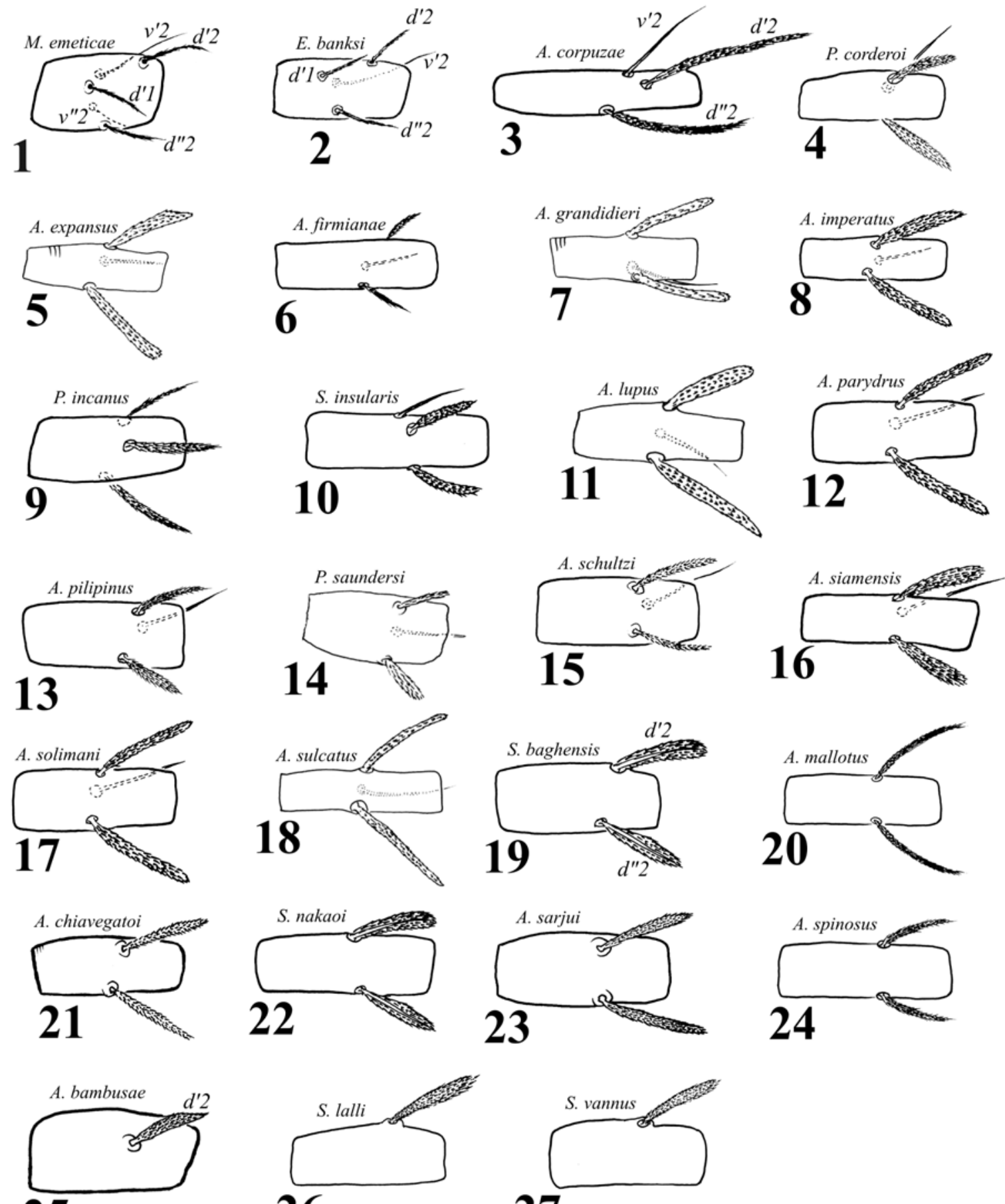

25

26

27

Figura 20. Gênus da perna I das espécies analisadas no presente estudo. 

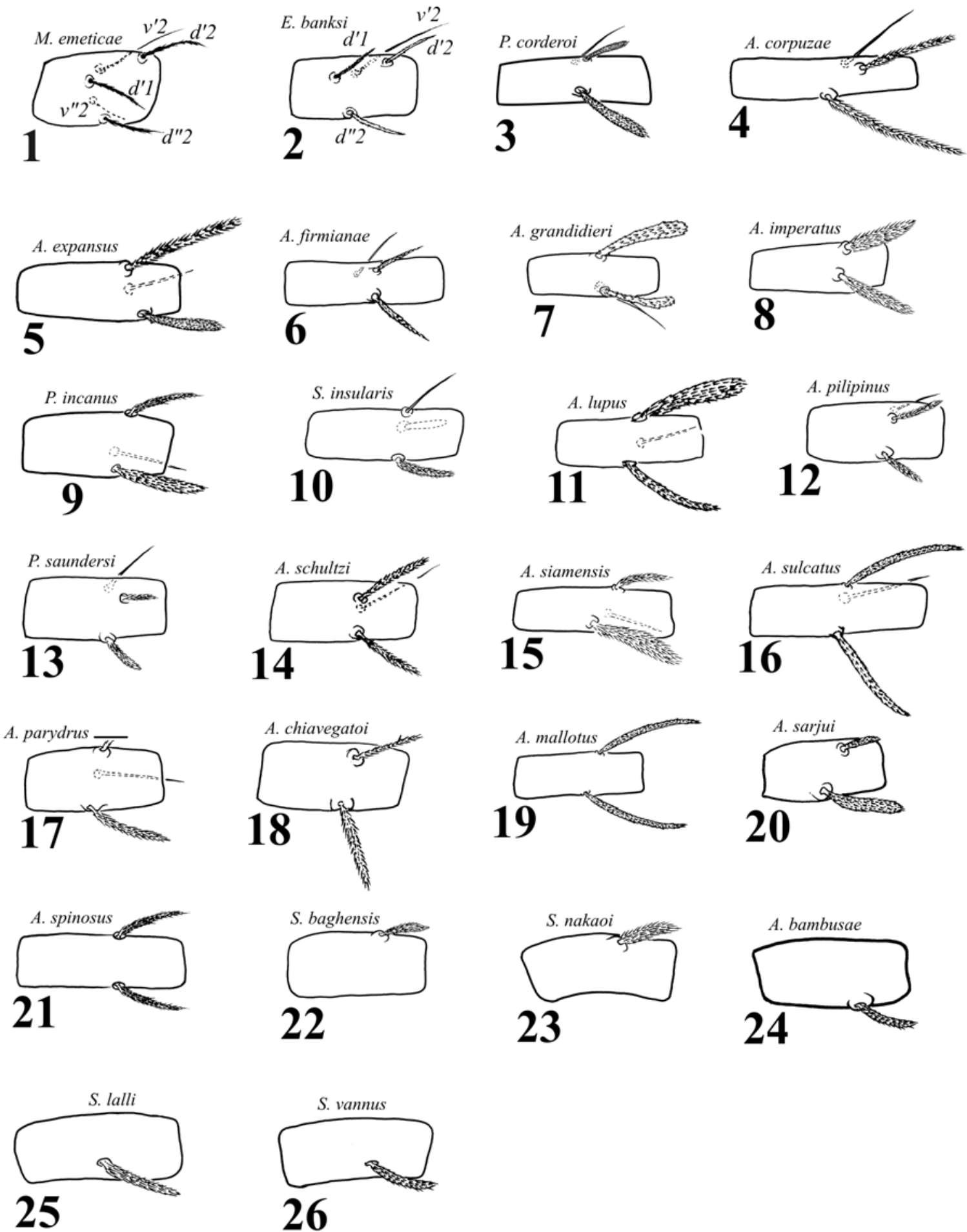

Figura 21. Gênus da perna II das espécies analisadas no presente estudo. 

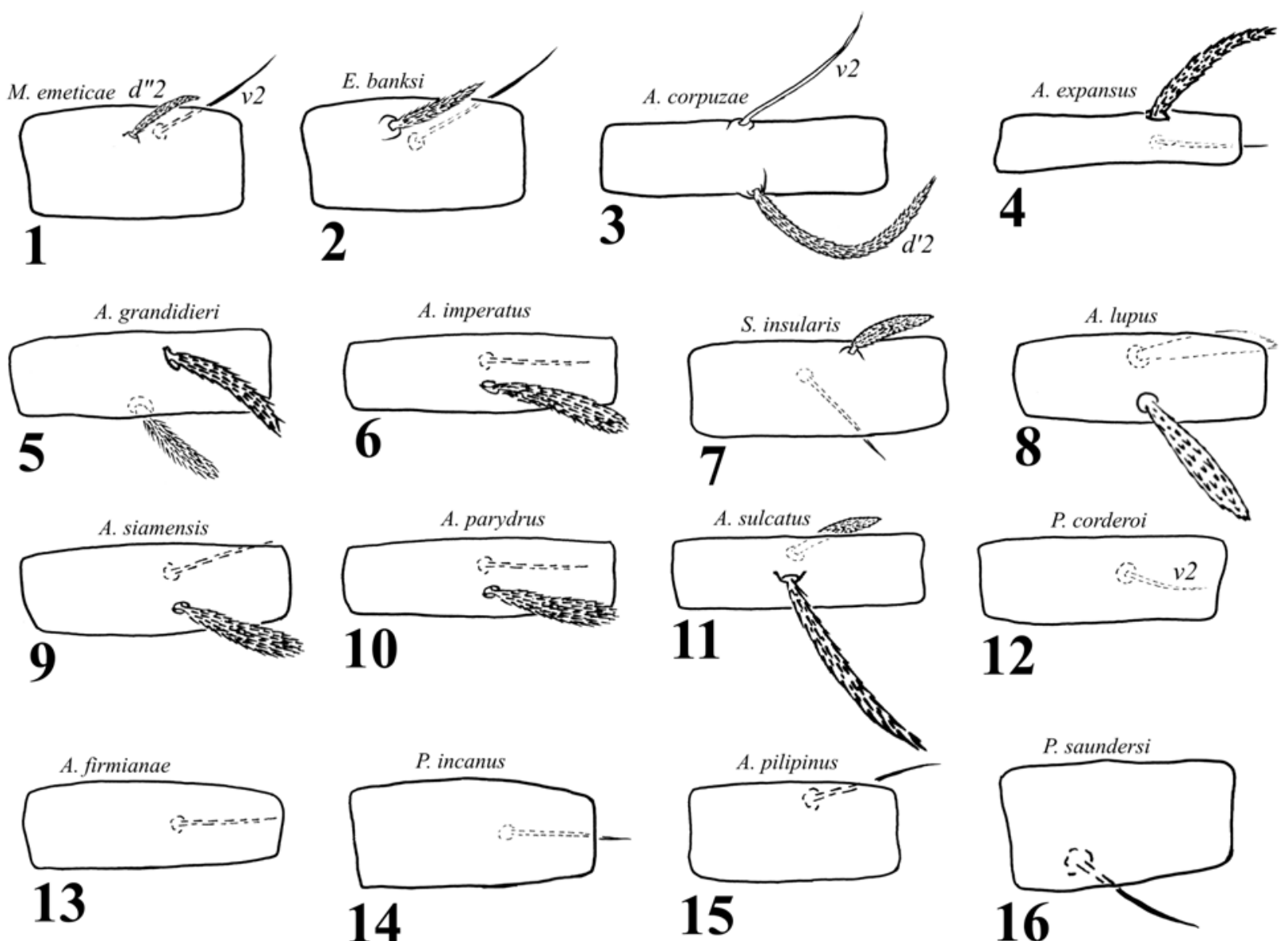

13
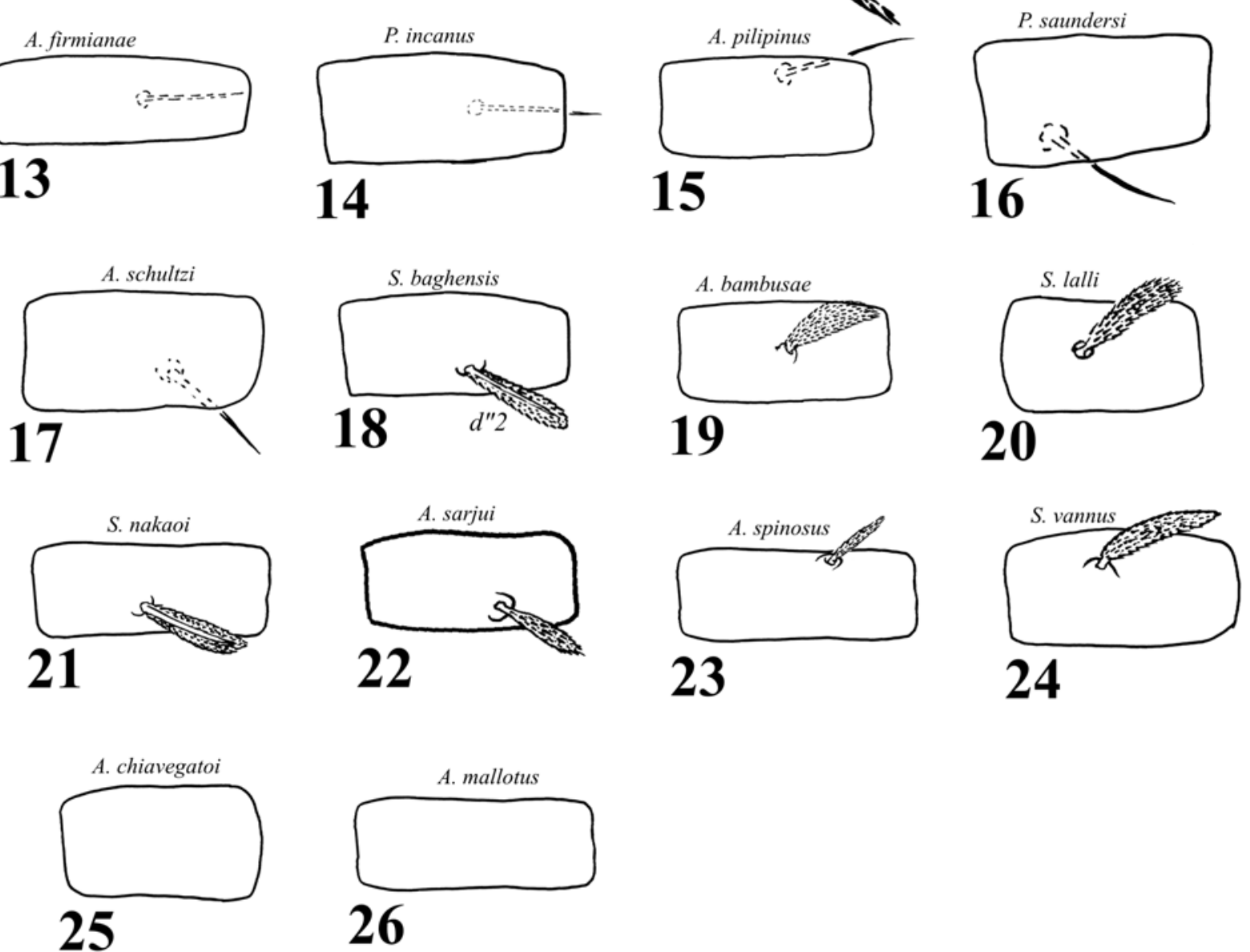

Figura 22. Gênus da perna III das espécies analisadas no presente estudo. 

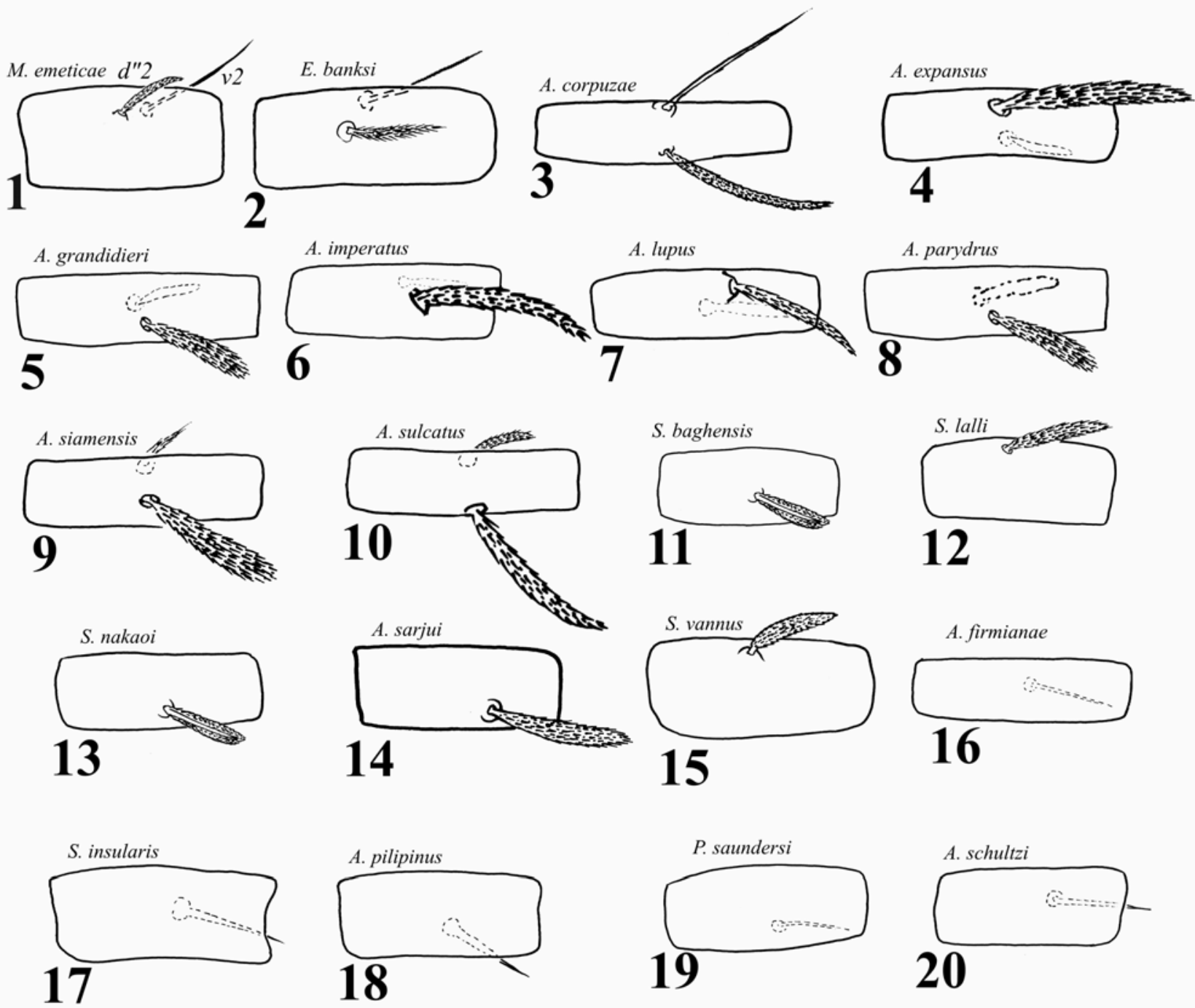

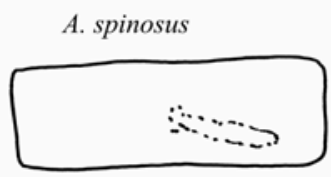

21

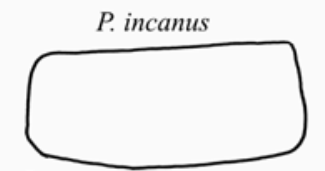

25
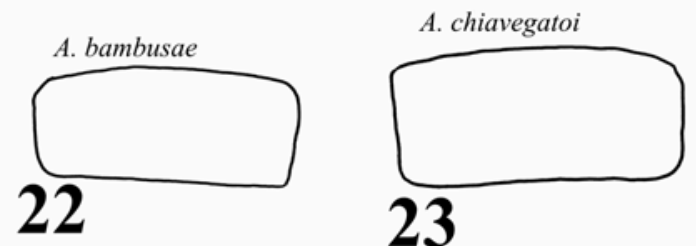

23

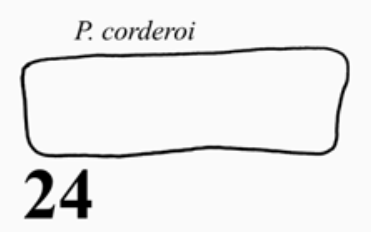

Figura 23. Gênus da perna IV das espécies analisadas no presente estudo. 

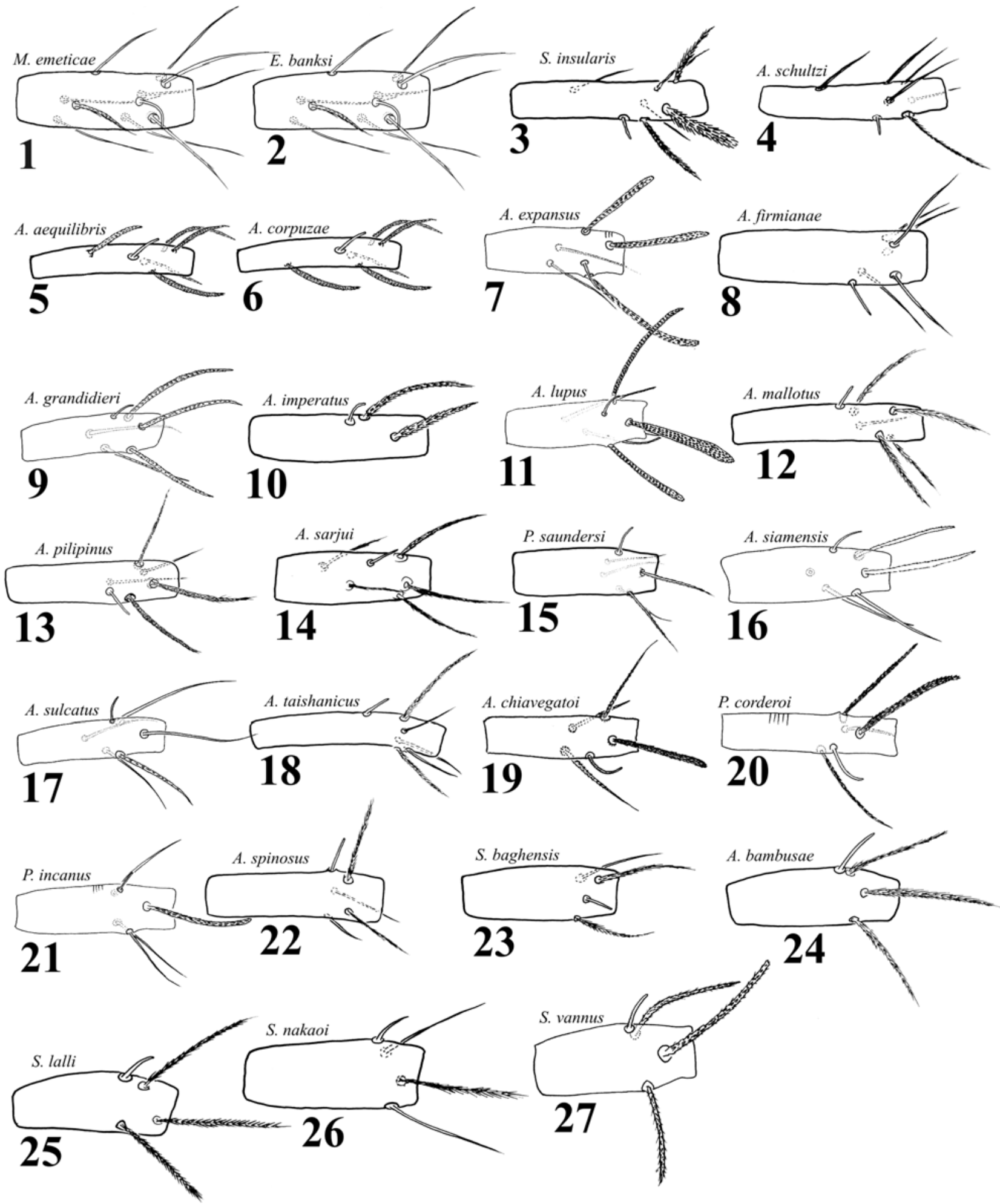

Figura 24. Tíbias da perna I das espécies analisadas no presente estudo. 

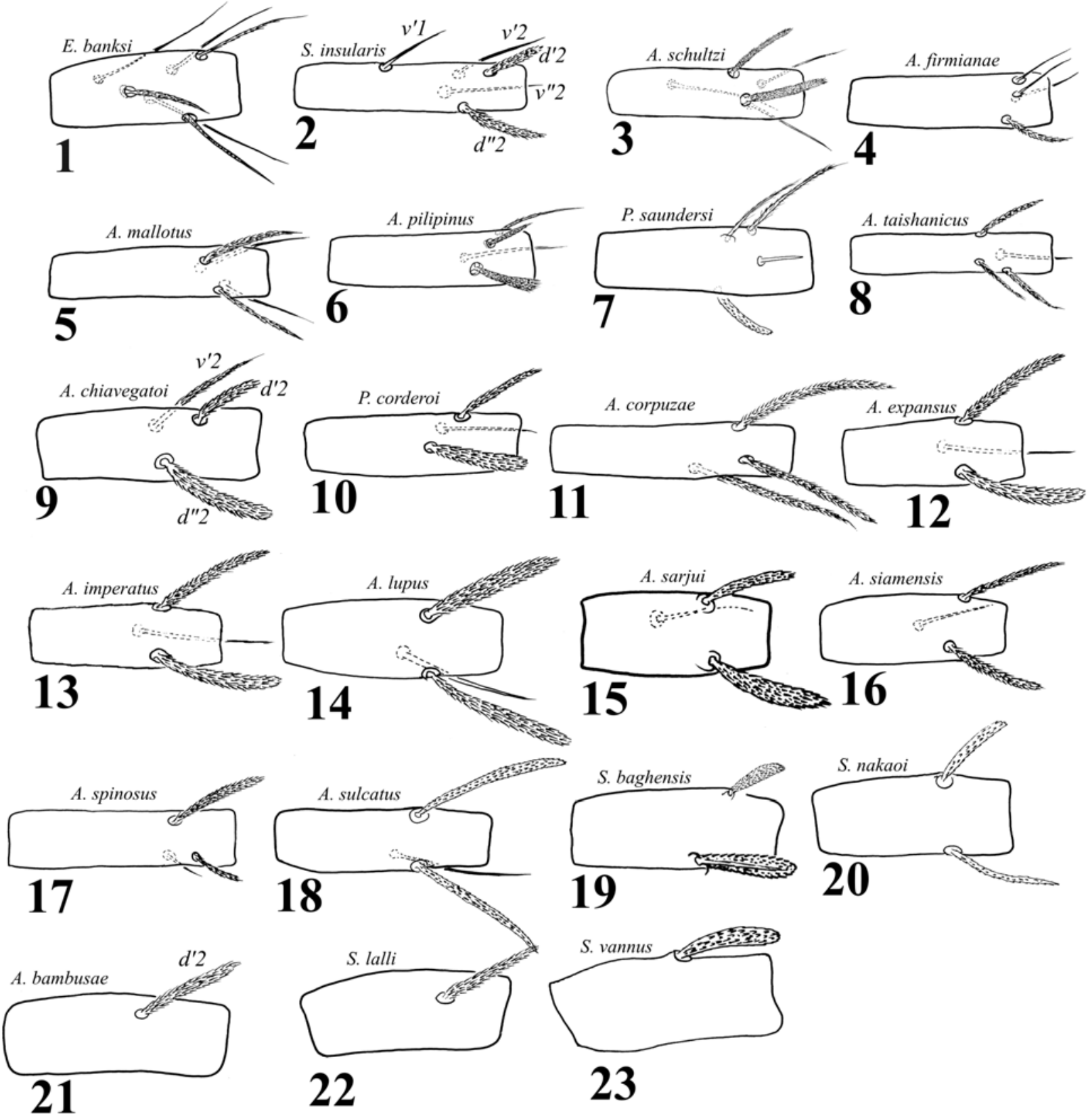

Figura 25. Tíbias da perna II das espécies analisadas no presente estudo. 

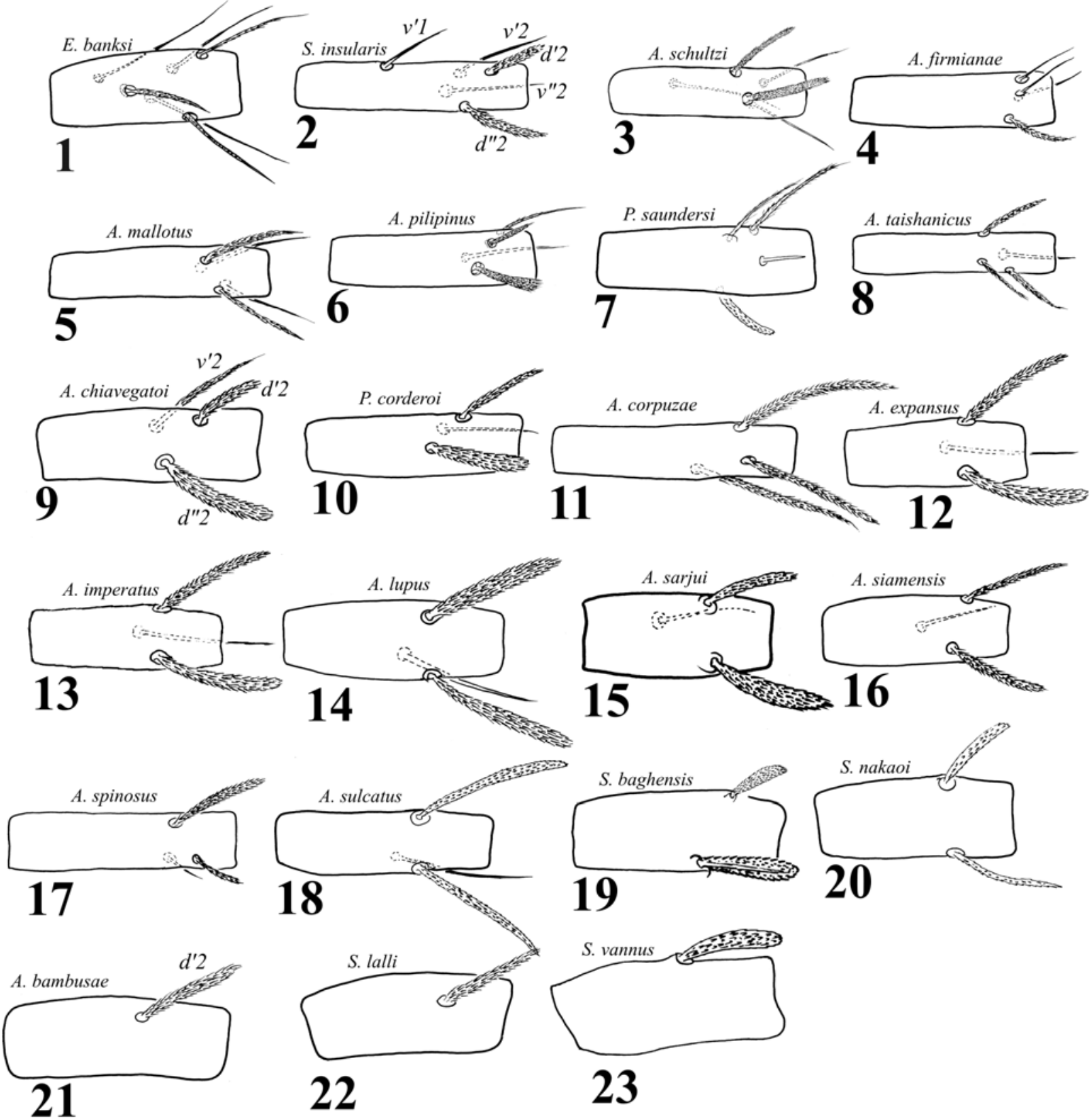

Figura 26. Tíbias da perna III das espécies analisadas no presente estudo. 

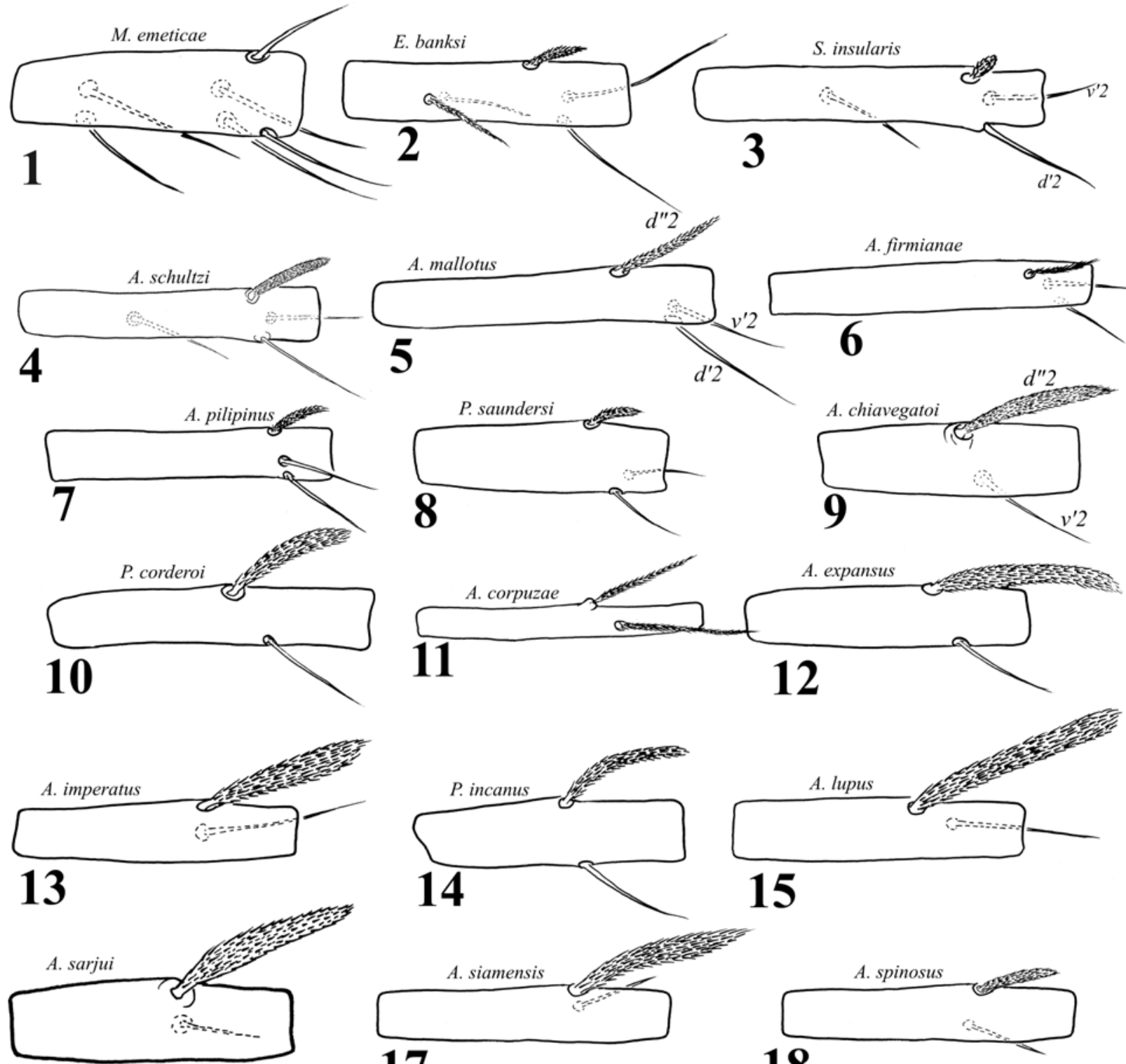

16
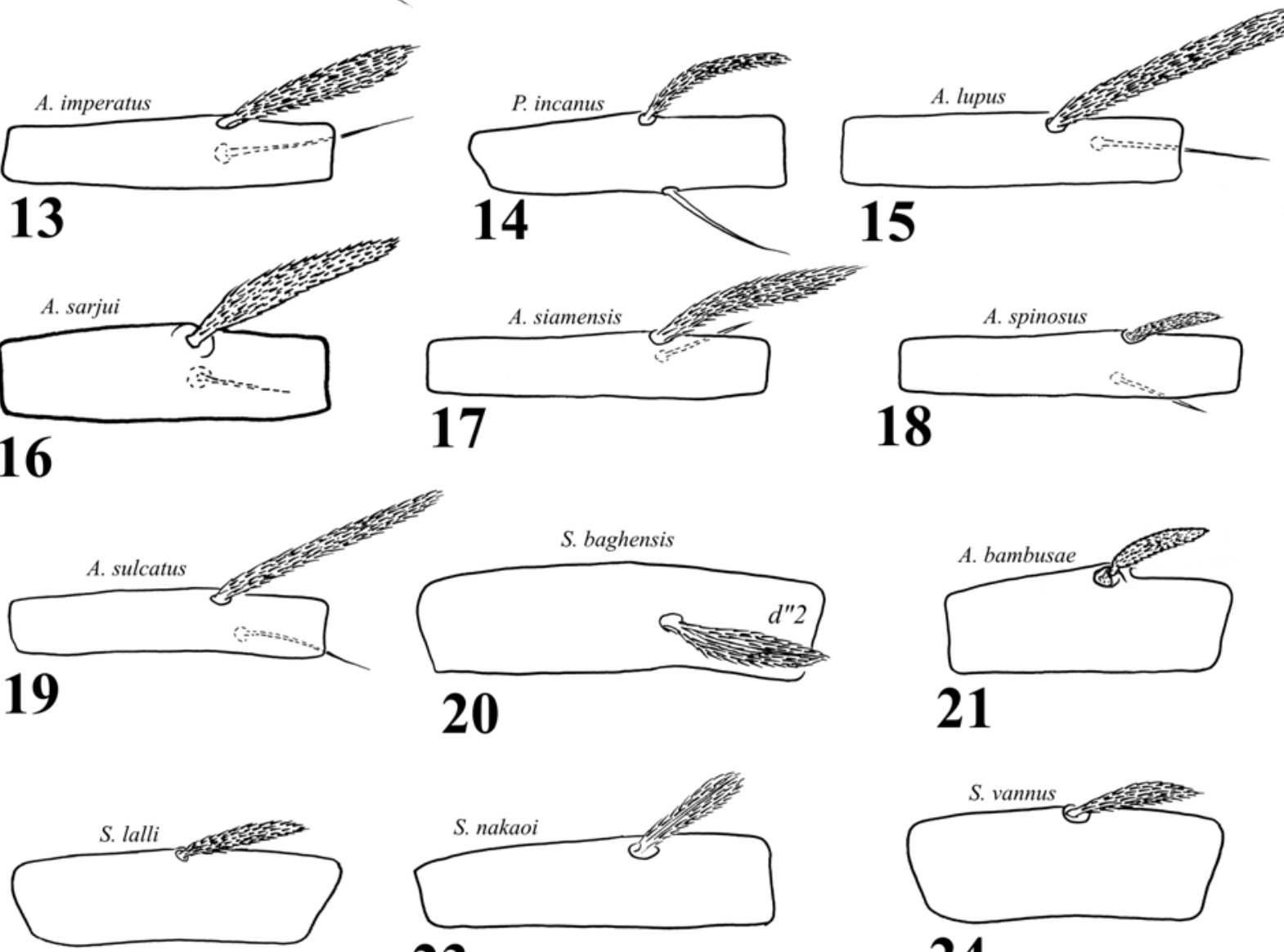

22

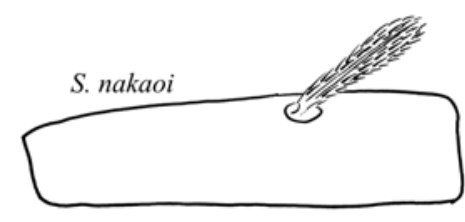

23

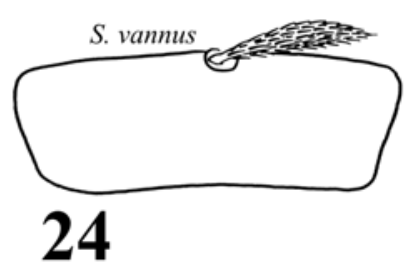

Figura 27. Tíbias da perna IV das espécies analisadas no presente estudo. 

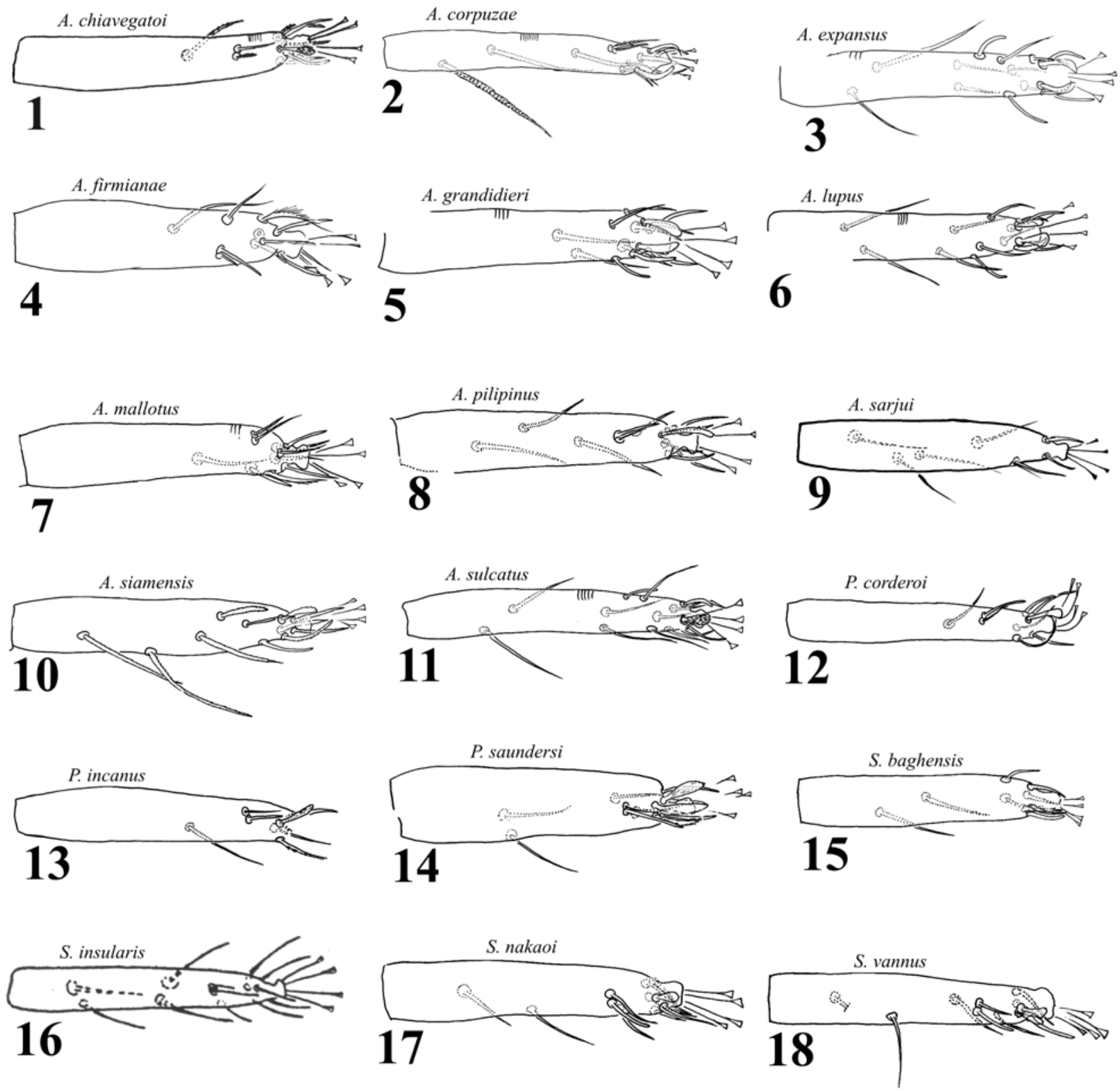

Figura 28. Tarsos da perna I das espécies analisadas no presente estudo. 

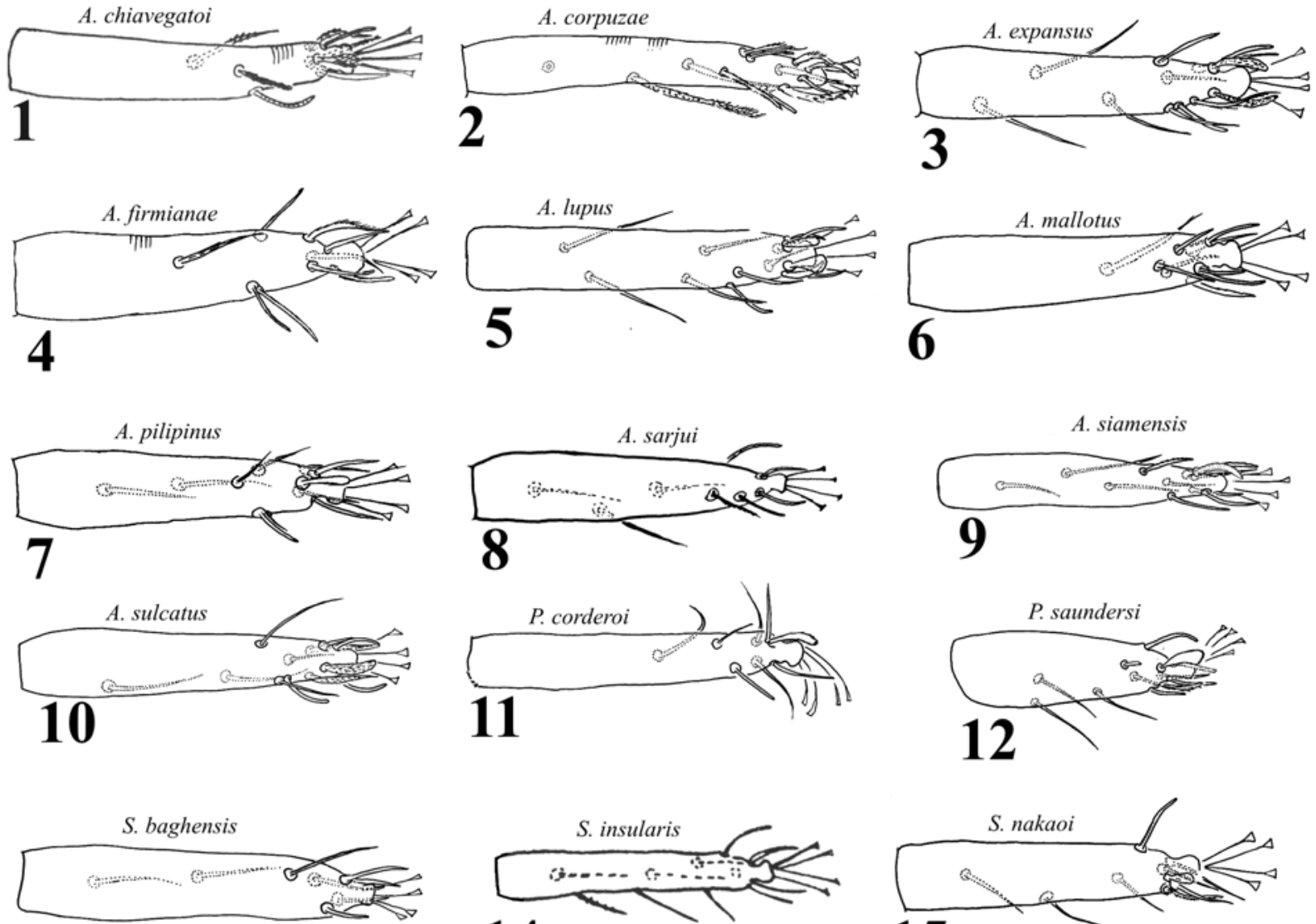

13
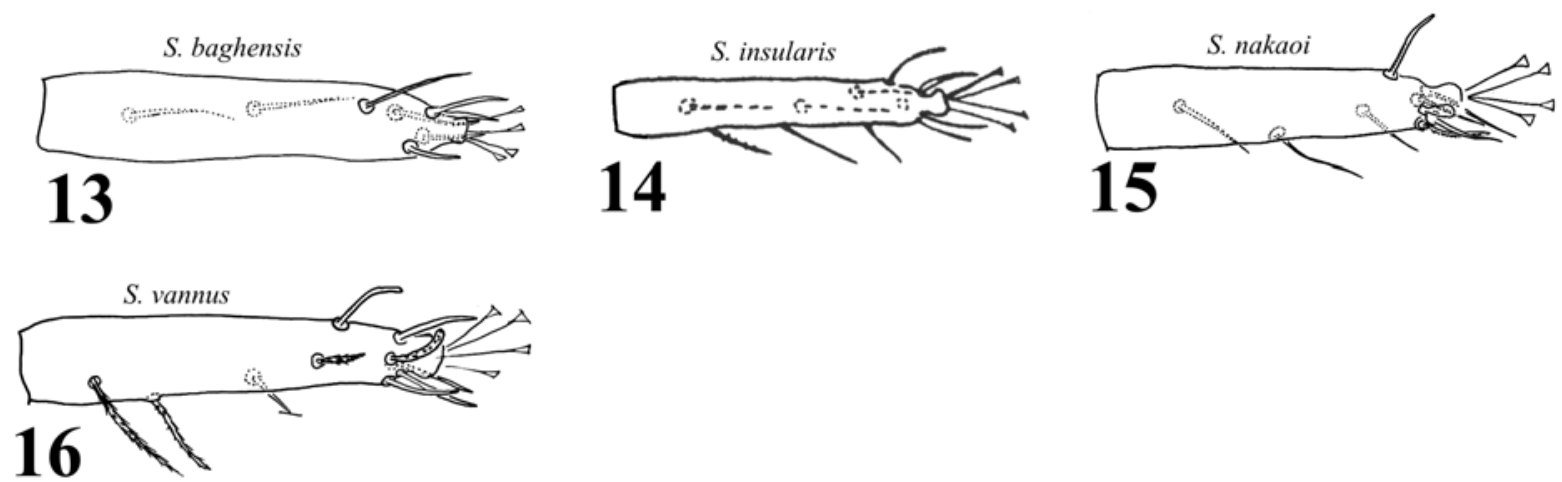

Figura 29. Tarsos da perna II das espécies analisadas no presente estudo. 

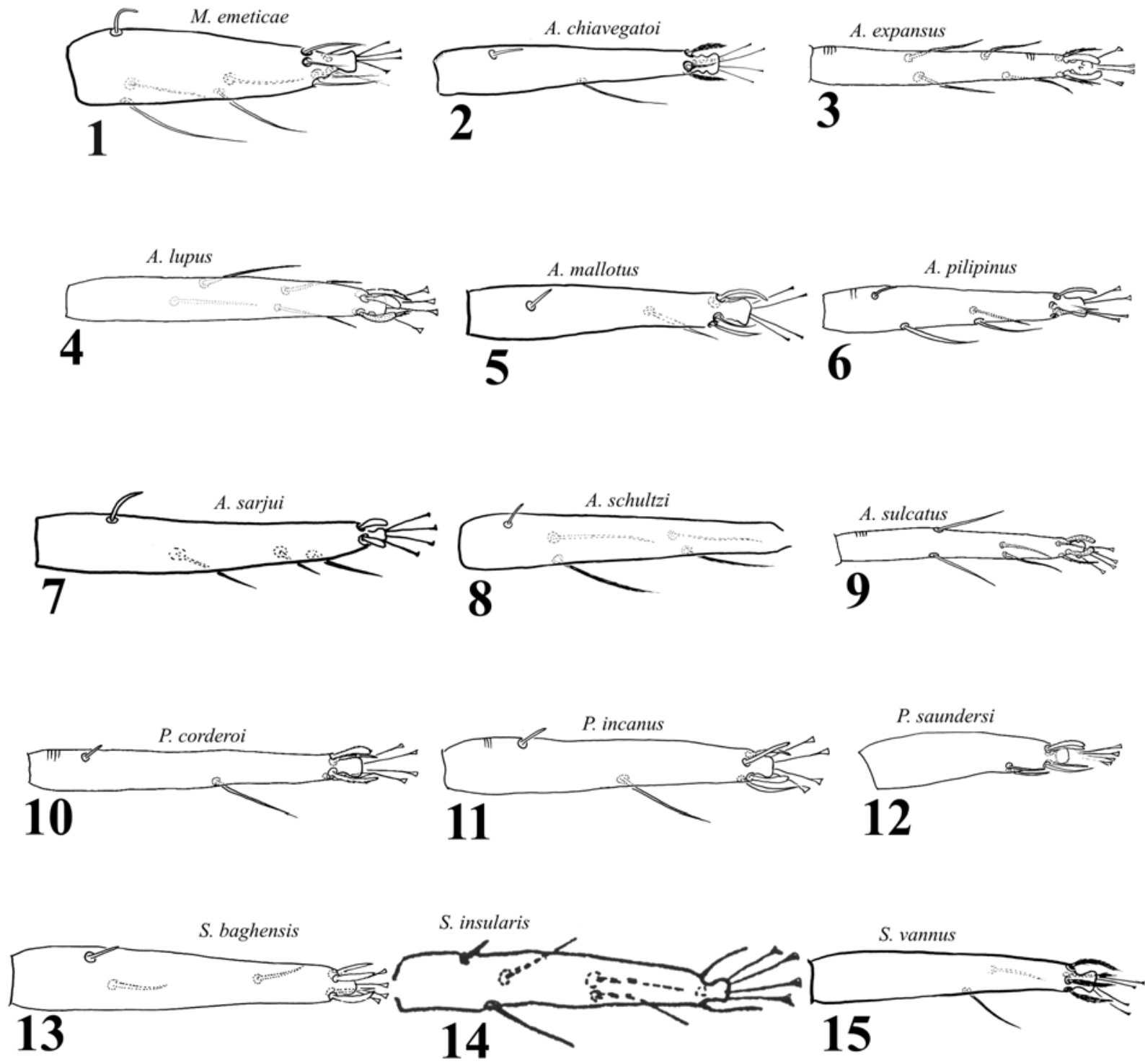

Figura 30. Tarsos da perna III das espécies analisadas no presente estudo. 

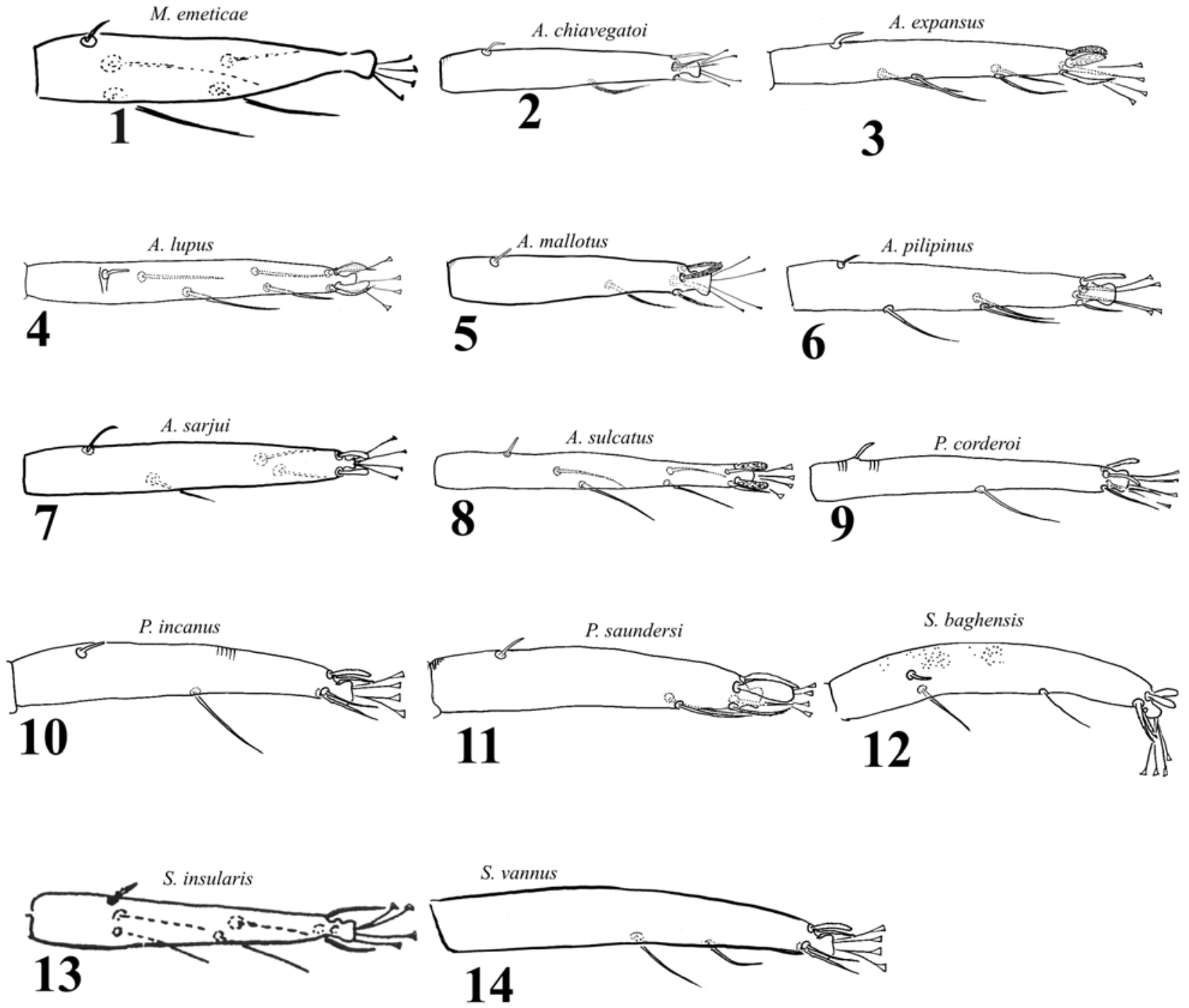

Figura 31. Tarsos da perna IV das espécies analisadas no presente estudo. 


\section{CAPÍtulo II}

Revisão taxonômica das espécies de Aponychus Rimando, Paraponychus González \& Flechtmann e Stylophoronychus Prasad 


\section{INTRODUÇÃO}

Das diversas famílias de ácaros fitófagos, Tetranychidae Donnadieu, 1875 é a que apresenta espécies que causam os mais severos danos à agricultura (Lindquist, 1985a). Em decorrência disso, muita atenção tem sido dada aos aspectos biológicos de seus representantes, com diversos trabalhos sobre ciclo de vida e testes de controle biológico das espécies de principal importância agrícola. Entretanto, poucos trabalhos enfocam a história evolutiva e relações de parentesco entre táxons dessa família (Lindquist, 1985a, b, Gutierrez 1985, Rimando \& CorpuzRaros, 1996).

\section{OBJETIVOS}

- Realizar revisão taxonômica das espécies de Aponychus, Paraponychus e Stylophoronychus, possibilitando melhor diagnóstico das mesmas;

- verificar a validade nomenclatural das espécies;

- propor uma chave dicotômica para auxiliar na separação das espécies desse grupo de Eurytetranychini.

\section{MATERIAL E MÉTODOS}

\section{Espécimes}

Espécimes-tipo obtidos através de empréstimo ou doação, foram estudados, analisados e utilizados para a redescrição das respectivas espécies. Para cada espécie são apresentadas o hospedeiro tipo, hospedeiros já registrados, localidades, etimologia, a lista de sinônimos e a respectiva nomencdlatura tal como originalmente proposto; após o nome do autor e data de publicação, é mencionada a página da publicação original. Os hospedeiros são apresentados no Apêndice 2, p. 179.

Os dados de ocorrência e distribuição geográfica das espécies foram obtidos principalmente da literatura disponível (Bolland et al., 1998, Migeon \& Flechtmann, 2004, Migeon \& Dorkeld, 2006). São apresentados novos registros das espécies Aponychus chiavegatoi e A. schultzi. 
Tabela II. Espécies de Aponychus, Paraponychus e Stylophoronychus utilizadas na revisão taxonômica.

Aponychus Rimando, 1966

1. A. aequilibris Tseng, $1990 \dagger$

2. A. bambusae Gupta \& Gupta, $1990 *(\mathrm{NCZSI})$

3. A. chiavegatoi Feres \& Flechtmann, $1988 *(\mathrm{MZ}-\mathrm{ESALQ})$

4. A. corpuzae Rimando, $1966 *$ (USNM, DZSJRP)

5. A. expansus Chaudhri, $1972 *$ (USNM)

6. A. firmianae (Ma \& Yuan, 1965)*(SH)

7. A. grandidieri (Gutierrez, 1966) * (MZ-ESALQ)

8. A. imperatus Hafez \& El-Badry, $1980 \dagger$

9. A. lupus Chaudhri, $1972 *$ (USNM)

10. A. mallotus Ho, $2003 *$ (TARI)

11. A. parydrus (Meyer, 1987)* (NCA, DZSJRP)

12. A. pilipinus Corpuz-Raros, $1978 *$ (UPLB, DZSJRP)

13. A. rarus Rimando, 1966

14. A. sarjui Gupta, 1980 * (NCZSI)

15. A. schultzi (Blanchard, 1940) (MZ-ESALQ, DZSJRP)

16. A. siamensis Ehara \& Wongsiri, $1975 *(\mathrm{SH})$

17. A. solimani Zaher, Gomaa \& El-Enany, $1982+$

18. A. spinosus (Banks, 1909) * (MCZ)

19. A. sulcatus Chaudhri, $1972 *$ (USNM)

20. A. taishanicus Wang, $1980 *$ (IZSA)

Paraponychus González \& Flechtmann, 1977

21. P. corderoi (Baker \& Pritchard, 1962) * (USNM)

22. P. incanus González \& Flechtmann, $1977 *$ (MZ-ESALQ)

23. P. kodaikanalensis (Gupta, 1984)* (NCZSI)

24. P. saundersi Meyer \& Vargas, $1999 *$ (USNM)

Stylophoronychus Prasad, 1975

25. S. baghensis (Prasad, 1975)*(USNM)

26. S. guangzhouensis (Ma \& Yuan, 1980)

27. S. insularis (Flechtmann, 1981) $\dagger$

28. S. lalli (Prasad, 1975)* (USNM)

29. S. nakaoi (Ehara \& Wongsiri, 1975)*(SH)

30. S. vannus (Rimando, 1968) * (USNM, DZSJRP, OSU)

$*=$ espécies que tiveram exemplares tipo analisados; $\dagger=$ espécimes-tipo perdidos; entre parênteses as coleções depositária de cada espécie. 


\section{RESULTADOS}

Foi possível realizar análise de espécimes tipo de 22 das 30 espécies de Aponychus, Paraponychus e Stylophoronychus. Três espécies, A. aequilibris, A. solimani e S. insularis, não possuem material tipo disponível, com espécimes-tipo perdidos. É possível que essas duas primeiras espécies constituam sinônimos júnior de A. corpuzae e A. rarus, respectivamente, entretanto, essa hipótese não pôde ser confirmada sem a análise dos tipos.

Outra espécie, Aponychus imperatus, também apresenta problemas quanto a sua validade. Apesar dos autores (Hafez \& Elbadry, 1980) fornecerem informações sobre todos os estágios de vida dessa espécie, juntamente com uma razoável descrição morfológica dos mesmos, nada é mencionado acerca da instituição depositária dos tipos, tampouco sobre a designação de holótipo e parátipos. Segundo a recomendação $72 \mathrm{~A}$ do International Code for Zoological Nomenclature (ICZN), a deposição de tipos em algum museu ou instituição semelhante é altamente recomendada para que ocorra a validade de um táxon proposto. Presumivelmente, os espécimes tipo de $A$. imperatus estariam depositados na Faculdade de Agricultura da Universidade de Ain Shams, no Cairo, Egito, instituição onde os autores estavam afiliados quando da publicação da descrição da espécie. Entretanto, não foi obtido sucesso no contato com quaisquer especialistas ou responsáveis daquela instituição com o intuito de fornecer informações acerca da posse desse material. Portanto, sugerimos que essa espécie deva ser considerada como species inquirenda, pelo menos até que análise de material tipo seja realizada, ou no caso destes estarem perdidos ou não disponíveis, que novos exemplares sejam coletados dos hospedeiro e localidades tipo, e neótipos sejam designados. Apesar disto, todas as características morfológicas disponíveis em sua descrição são indicativos de que essa espécie deva ser sinônimo júnior de A. rarus.

Somente 9 das 30 espécies foram coletadas novamente após sua descrição original: $A$. chiavegatoi, A. corpuzae, A. firmianae, A. schultzi, A. spinosus, A. sulcatus, P. corderoi, S. baghensis e $S$. vannus, sendo que algumas delas foram descritas a partir de um único indivíduo (holótipo) (e.g. A. sarjui, S. insularis). Muitas espécies desse grupo foram descritas com base em poucos indivíduos coletados, e mesmo assim, foram diagnosticadas com base em pequenas diferenças no comprimento relativo de algumas setas dorsais. Entretanto, foram encontradas variações no comprimento e formato de várias dessas setas em indivíduos provenientes de diferentes populações, ou mesmo da mesma população. Em alguns casos, foi encontrada grande assimetria nesses caracteres até mesmo em um único indivíduo, nos lados esquerdo e direito do corpo. Deste modo, conclui-se que estas características não mais devam ser utilizadas para separação de espécies desse grupo. Gutierrez (1985: 83) já havia expressado essa mesma opinião com relação a gêneros e até mesmo espécies de Eurytetranychini. Assim sendo, é possível que 
muitas das espécies analisadas constituam sinônimos júnior, e elas serão discutidas na seção de estudos morfológicos de cada espécie. 


\section{Família Tetranychidae Donnadieu, 1875 \\ Subfamília Tetranychinae Berlese, 1913 \\ Tribo Eurytetranychini Reck, 1950}

\section{Gênero Aponychus Rimando, 1966}

Aponychus Rimando, 1966: 107; Aponychus; Rimando, 1968: 6; Tuttle \& Baker, 1968: 82; Ehara, 1969: 87; Meyer, 1974: 156; Zaher, Gomaa \& El-Enany, 1982: 101; Gupta, 1985: 57;

Meyer, 1987: 84; Baker \& Tuttle, 1994: 140; Gupta \& Gupta, 1994: 39; Rimando \& Corpuz-Raros, 1996: 12.

Aponychus (Stylophoronychus) non Prasad, 1975a: 1; sensu Rimando \& Corpuz-Raros, 1996: 12. Chinotetranychus Ma \& Yuan, 1982: 109; Meyer, 1987: 85; espécie-tipo Eutetranychus firmianae Ma \& Yuan, 1965: 247; Rimando \& Corpuz-Raros, 1996: 12.

Espécie-tipo: Aponychus corpuzae Rimando, 1966, designação original.

Etimologia: Aponychus - apo G., destituído, sem, destacado, separado + nychus G. (onych, onycho, onyx), unha, garra, sufixo comumente utilizado em gêneros da família Tetranychidae; refere-se a ausência de empódio.

\section{Diagnose:}

Um par de setas pseudo-anais ( $p s)$ e dois pares de setas paranais nas fêmeas; 3 pares de setas na região genito-anal nos machos; empódio ausente; 10 pares de setas histerossomais ( $c 2$ e $f 1$ presentes); projeções anteriores no estilóforo presentes ou ausentes.

Vinte espécies são atualmente incluídas nesse gênero, associadas principalmente a plantas angiospermas (mono ou dicotiledôneas). Entretanto, algumas espécies devem ser consideradas em sinonímia (ver discussão taxonômica nas páginas 106, 140, 156 e 168). A maioria das espécies é conhecida das regiões equatorial e tropical asiática, com poucas espécies registradas na África, Américas do Norte e do Sul. Não há ocorrência na Antártica, Austrália, Europa e norte Asiático.

É possível reconhecer dois grupos, baseando-se no comprimento das setas dorsais do idiossoma: no primeiro grupo, as setas são longas, ultrapassando as bases do pares subsequentes; em outras espécies, essas setas são curtas, não ultrapassando as bases do pares subsequentes. As projeções bilobadas no estilóforo são encontradas nas espécies asiáticas desse gênero.

Espécies: A. aequilibris, A. bambusae, A. chiavegatoi, A. corpuzae, A. expansus, A. firmianae, A. grandidieri, A. imperatus, A. lupus, A. mallotus, A. parydrus, A. pilipinus, A. rarus, A. sarjui, A. schultzi, A. siamensis, A. solimani, A. spinosus, A. sulcatus, A. taishanicus. 


\section{Stylophoronychus insularis (Flechtmann)}

(Figuras 16.3 p. $49 ; 17.1$ p. $50 ; 18.6$ p. $51 ; 19.3$ p. $52 ; 20.10$ p. $53 ; 21.10$ p. $54 ; 22.7$ p. $55 ; 23.17$ p. $56 ; 24.3$ p. $57 ; 25.2$ p. $58 ; 26.3$ p. $59 ; 27.3$ p. $60 ; 28.16$ p. $61 ; 29.14$ p. $62 ; 30.14$ p. $63 ; 31.13$ p. $64 ; 32$ p. $72 ; 33$ p. $73 ; 81.9$ p. 174$)$

Aponychus insularis Flechtmann, 1981: 87.

Sinotetranychus insularis; Meyer, 1987: 87; Bolland et al., 1998: 173.

Paraponychus insularis; Rimando \& Corpuz-Raros, 1996: 13.

Stylophoronychus insularis; Zhang et al., 2000a: 42.

Série típica: holótipo +, Ilha de Jaguanum, Itacuruçá, Rio de Janeiro, Brasil, 12.I.1979, C.H.W. Flechtmann col., ex liana não identificada.

Coleção depositária: desconhecido (C.H.W. Flechtmann, comunicação pessoal).

Etimologia: provavelmente referente à localidade onde essa espécie foi coletada.

Hospedeiro: erva-trepadeira não identificada.

Distribuição: Brasil (Flecthmann, 1981).

Zhang et al. (2000a) revalidaram o status de gênero de Stylophoronychus, abrigando nele as espécies que não apresentam o par de setas sacrais $f 1$. Os mesmos autores levantaram a hipótese de que $S$. insularis talvez não compartilhe um ancestral comum com as demais espécies de Stylophoronychus, em razão de diversos caracteres incomuns apresentados por esta espécie e não pelos demais representantes desse gênero: setas dorsais longas e ultrapassando as bases dos pares subsequentes, quetotaxia das pernas, registro sobre uma dicotiledônea e ocorrência no Novo Mundo. Com relação a quetotaxia das pernas, S. insularis apresenta as seguintes fómulas: fêmur 76-3-2, gênu 3-3-2-1 e tíbia 7-5-4-4; enquanto que as demais espécies de Stylophoronychus (i.e., baghensis, bambusae, guangzhouensis, lalli, nakaoi e vannus) apresentam: fêmur 6-5-3-1, gênu 21-1-1 ou 1-1-1-1 e tíbia 4-1-1-1 ou 4-2-1-1.

Apesar de uma profunda incisão mediana ter sido relatada no estilóforo dessa espécie (Flechtmann, 1981: 87) (Figura 32.3, p. 72), resultando em duas projeções anteriores, é importante observar que, em outras espécies de Stylophoronychus, as projeções anteriores no estilóforo apresentam distinta conformação, sendo, nestes últimos, consideravelmente maiores e mais pronunciadas. A posição de S. insularis dentro do gênero deverá sofrer alterações em consequencia dos resultados obtidos na análise filogenética. Como, infelizmente, o holótipo dessa espécie (único exemplar) está perdido e não obtivemos sucesso em uma primeira tentativa de coletar exemplares na localidade tipo (excursão realizada em abril de 2007), o aprofundamento dessa análise fica na dependência do sucesso de uma futura excursão de coleta. 


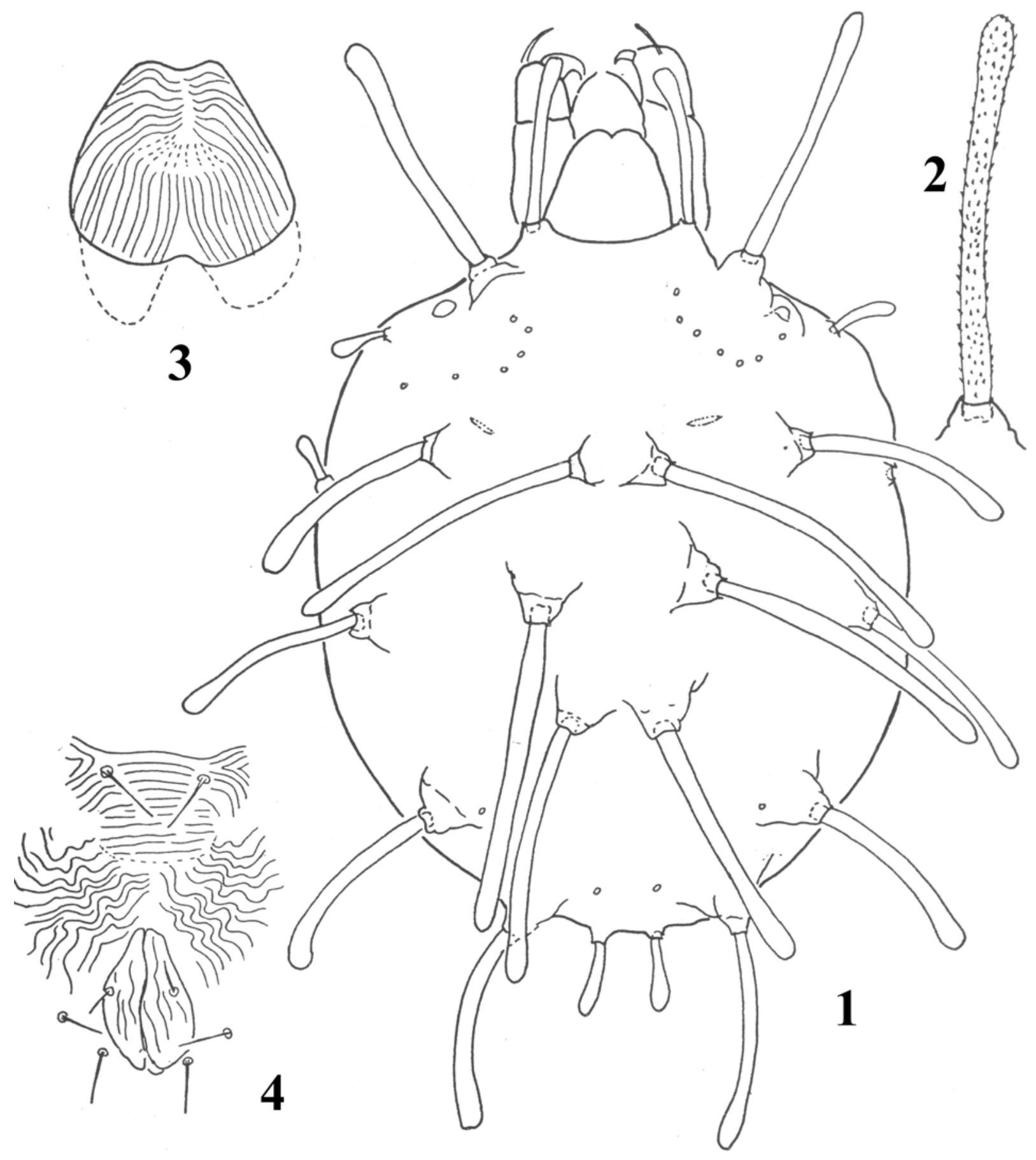

Figura 32. Stylophoronychus insularis, holótipo fêmea: vista dorsal (1), detalhe de seta dorsal (2), estilóforo (3), região genito-anal (4) (ilustrações retiradas de Flechtmann [1981]). 

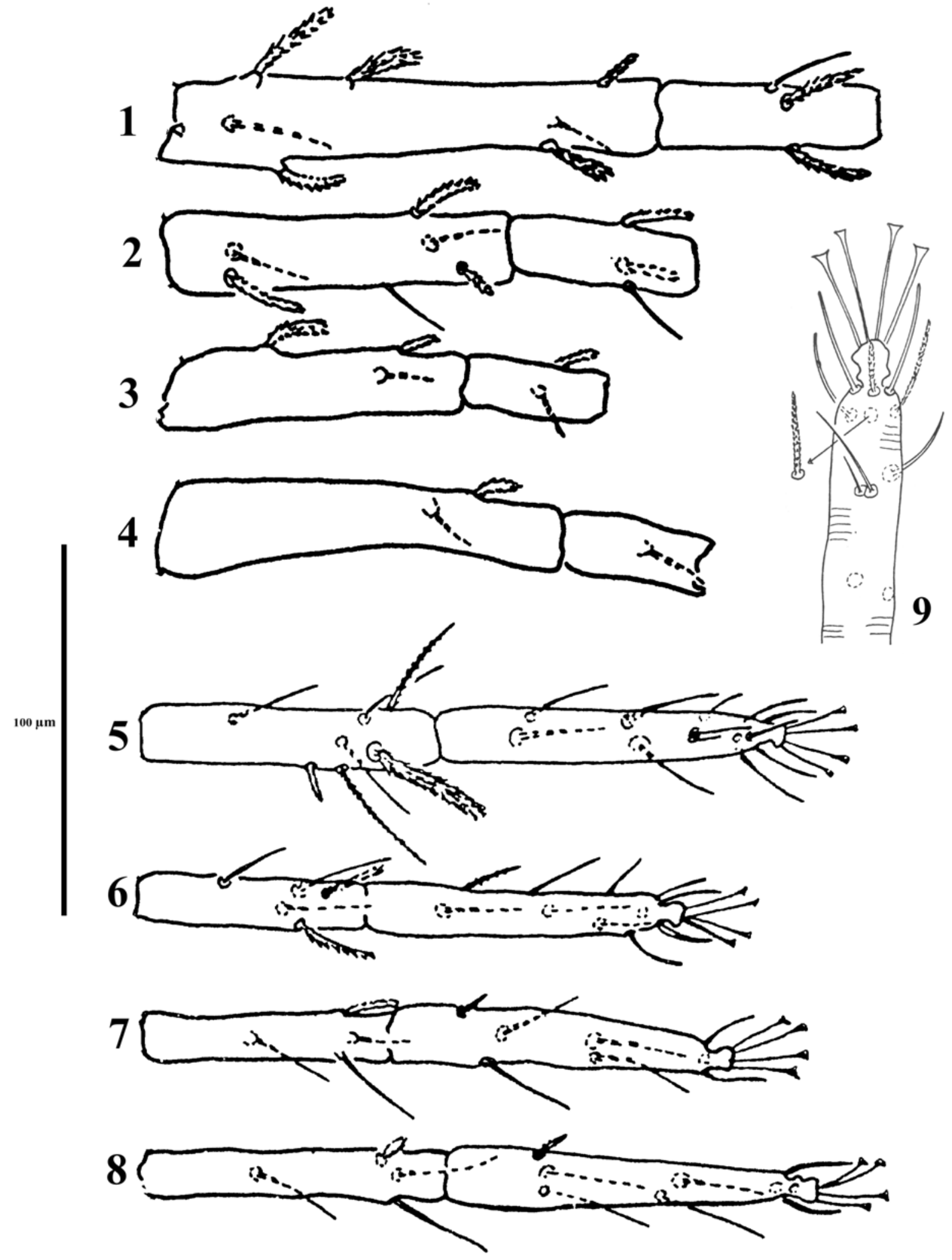

Figura 33. Stylophoronychus insularis, holótipo fêmea: artículos das pernas, fêmur e gênu I a IV (1-4), tíbia e tarso I a IV (5-8), porção distal do tarso I (9) (ilustrações retiradas de Flechtmann [1981]). 


\section{Aponychus schultzi (Blanchard)}

(Figuras 16.5 p. $49 ; 17.26$ p. $50 ; 18.9$ p. $51 ; 19.4$ p. $52 ; 20.15$ p. 53; 21.14 p. $54 ; 22.17$ p. $55 ; 23.20$ p. $56 ; 24.4$ p. 57 ; 25.3 p. $58 ; 26.2$ p. $59 ; 27.4$ p. $60 ; 30.8$ p. $63 ; 34$ p. $77 ; 35$ p. $78 ; 80.5$ p. 173$)$

Anychus schultzi Blanchard, 1940: 24; Meyer, 1974: 156; Bolland et al., 1998: 21.

Eutetranychus schultzi; Pritchard \& Baker, 1955: 115; Ehara, 1966: 140.

Série típica: síntipos + , Tucumán, Argentina, XII.1939, ex Ricinus communis Linnaeus (Euphorbiaceae), E.F. Schultz col..

Coleção depositária: particular do autor.

Etimologia: homenagem ao coletor da espécie, Enrique F. Schultz.

Hospedeiros $(\downarrow=$ novos registros): Carica papaya (Caricaceae), Ipomoea sp. (Convolvulaceae), Sechium edule (Cucurbitaceae), Cycas revoluta (Cycadaceae), Euphorbia sp., Manihot esculenta, Ricinus comunis (Euphorbiaceae), Phaseolus vulgaris (Fabaceae), Hibiscus rosasinensis, Hibiscus sp., Sida rhombifolia (Malvaceae), Azadirachta indica, Melia azedarach (Meliaceae), Morus nigra, Morus sp. (Moraceae), Oriza sativa (Poaceae), Gardenia jasminoides (Rubiaceae), Populus sp. (Salicaceae), Strelitzia augusta (Strelitziaceae), Solanum granulosoleprosum $\downarrow$, S. guaraniticum $\downarrow$, S. variabile $\downarrow$, Vassobia breviflora (Solanaceae).

Distribuição: Argentina (Blanchard, 1940), Brasil (Ehara, 1966; Aranda \& Flechtmann, 1971), Colômbia (Zuluaga, 1971), Paraguai (Aranda \& Flechtmann, 1971).

Obs: Apesar de Corpuz-Raros (1978: 213) afirmar que o macho de A. schultzi era desconhecido, ele já havia sido registrado por Ehara (1966: 140). Antes disso, Pritchard \& Baker (1955: 115) erroneamente afirmaram que o macho da espécie era desconhecido, mas mesmo assim apresentaram ilustrações de tíbias e tarsos I e II, região terminal do opistossoma e edéago.

Essa é, até o momento, a espécie de Aponychus registrada sobre o maior número de plantas hospedeiras, 23. Apresenta também uma grande variação morfológica em diferentes populações, no que diz respeito ao comprimento e formato das setas dorsais.

\section{Material examinado dos seguintes hospedeiros:}

- Carica papaya Linnaeus (Caricaceae): 10̄, 1 q Guaimbê, SP, XI.1966, C.H.W. Flechtmann col.; 8 São Manoel, SP, 15.VII.1981 e 31.V.1982, V. Nagliato col. (MZ-ESALQ); - Ipomoea cairica Linnaeus (Convolvulaceae): 1ð Curitiba, PR, 1.II.1973, C.H.W. Flechtmann col. (MZ-ESALQ). 
- Melia azedarach Linnaeus (Meliaceae): 1ð̃, 1 q São Paulo, SP, V.1968, W.M. Vila col. (MZESALQ).

- Morus sp. (Moraceae): 4§̂, $3 q$ Piracicaba, SP, VIII.1966, C.H.W. Flechtmann col. (MZESALQ).

- Ricinus sp. (Euphorbiaceae): 6§̂, $4 \uparrow$ Ourinhos, SP, XI.1966, C..W. Flechtmann col.; $1 \hat{\jmath}, 3 q$ Buenos Aires, Argentina, 21.XII.1961, A. Ibarra-Grasso col. (MZ-ESALQ).

- Sechium edule (Jacq.) (Cucurbitaceae): 1ð, 1 q Curitiba, PR, 8.II.1973, C.H.W. Flechtmann col.; $7 \widehat{\jmath}, 1 q$ Piracicaba, SP, X.1966, C.H.W. Flechtmann col.; $2 \hat{\jmath}, 2 \uparrow$, 1protoninfa, Poços de Caldas, MG, 21.I.1967, C.H.W. Flechtmann col.; $2 \lesssim$ Guarulhos, SP, 6.I.1967, C.H.W. Flechtmann col. (MZ-ESALQ).

- Solanum granulosoleprosum Dunal (Solanaceae): 29 Carazinho, RS, 23.I.2004, I.P. Furtado

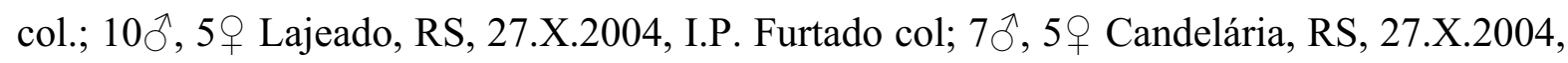
I.P. Furtado col; 4^, $7 q$ Santa Maria, RS, 26.X.2004, I.P. Furtado col; 19 Pinhalzinho, SC, 22.I.2004, I.P. Furtado col.; 19 Anchieta, SC, 22.I.2004, I.P. Furtado col.; 6ึ, 1 q Ijuí, RS, 24.X.2004, 5ภ, 5, 23.I.2004, I.P. Furtado col.; 4ภ, 2 + Horco Molle, Tucumã, Argentina,

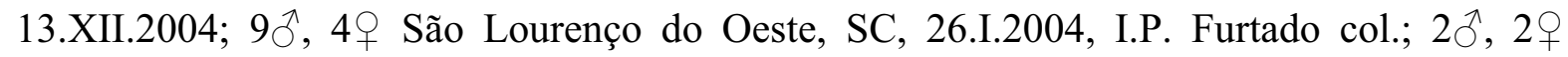
Abelardo Luz, SC, 26.I.2004, I.P. Furtado col.; 4§ิ, 6 ㅇ Xanxerê, SC, 26.I.2004, I.P. Furtado

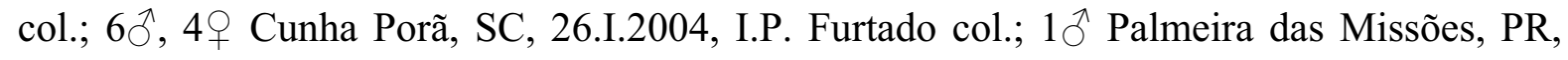

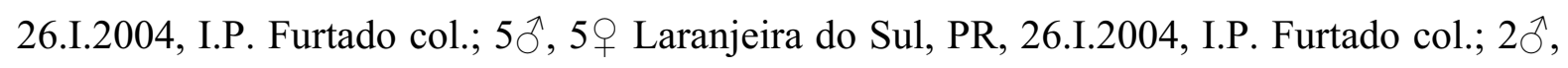
$3 q$ Rio Bonito do Iguaçu, PR, 26.I.2004, I.P. Furtado col.; 8ð, $4 \uparrow$ Chorozinho, PR,

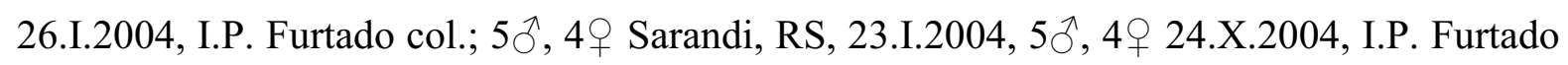

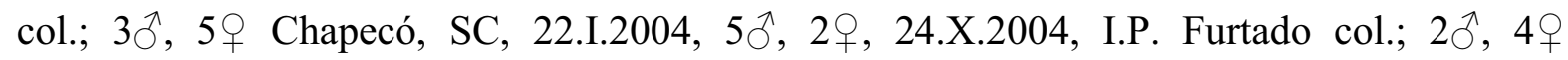
Francisco Beltrão, PR, 22.I.2004, I.P. Furtado col.; $3 \hat{\jmath}, 3 q$ Corbélia, PR, 21.I.2004, I.P. Furtado col.; $2 \hat{\jmath}, 8 \uparrow$ Campo Mourão, PR, 21.I.2004, I.P. Furtado col.; 7ð̂, $4 \uparrow$ Saberi, RS, 26.I.2004, I.P. Furtado col.; 8§, $3 q$ Cruz Alta, RS, 26.I.2004, I.P. Furtado col.; $5 q$ Júlio de

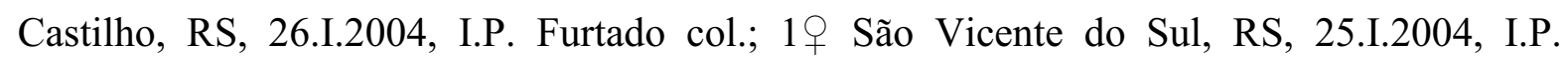
Furtado col.; 2 q Santa Bárbara do Sul, RS, 23.I.2004, 1ðึ 24.X.2004, I.P. Furtado col.; $6 \hat{\jmath}$, 4 + Maravilha, SC, 22.X.2004, I.P. Furtado col.; 8ภ̋, 3 + Marmelândia, PR, 22.X.2004, I.P. Furtado col.; 4ત, $5 q$ Capitão Leônidas, PR, 22.X.2004, I.P. Furtado col.; 7ð̂, $4 \uparrow$ Campos Mourão, PR, 22.X.2004, I.P. Furtado col.; 5ð, $2 q$ Entre Ijuis, RS, 24.X.2004, I.P. Furtado col.; 4 q Parambi, RS, 24.X.2004, I.P. Furtado col. (MZ-ESALQ).

- Solanum guaraniticum Saint Hilaire (Solanaceae): 2q, Ijuí, RS, 24.X.2004, I.P. Furtado col. (MZ-ESALQ).

- Solanum variabile Mart. (Solanaceae): 2 , , Chapecó, SC, 22.I.2004, I.P. Furtado col.; 2 + Nonai, RS, 24.X.2004, I.P. Furtado col. (MZ-ESALQ). 
- Vassobia breviflora (Sendtn.) (Solanaceae): 4, Pato Branco, PR, 26.I.2004, I.P. Furtado col. (MZ-ESALQ).

- hospedeiro não identificado: $3 \widehat{\partial}, 2$, São Lourenço do Oeste, SC, 26.I.2004, I.P. Furtado col.; $3 q$ Campo Erê, SC, 22.I.2004, I.P. Furtado col.; 4 + Marmelândia, 22.I.2004, I.P. Furtado col.; 6 ㅇ Entre Ijuis, RS, 24.X.2004, I.P. Furtado col. (MZ-ESALQ).

- hospedeiro não identificado (Solanaceae): 1ð̂, 1 , Campinas, SP, 22.I.1968, L.G. Chiavegato col. (MZ-ESALQ).

Diagnose: essa espécie assemelha-se a A. spinosus pelas longas setas dorsais, mas difere pela quetotaxia dos artículos das pernas: coxa 2-2-1-1, fêmur 7-4-3-2, gênu 3-3-1-1 e tíbia 6(1)-5-4-4. Em A. spinosus a quetotaxia é: coxa 2-1-1-1, fêmur 6-4-2-1, gênu 2-2-1-1, tíbia 4(1)-3-2-2.

Observação: Pritchard \& Baker (1955: 113) diferenciaram A. schultzi de A. spinosus baseando-se no formato de algumas setas dorsais $(s c 2, c 3$ e $h 1)$, que apresentam extremidades dilatadas na primeira espécie, e afiladas em A. spinosus. Entretanto, como já mencionado por Ehara (1966: 142), e verificado em espécimes provenientes de diversas localidades analisados no presente estudo, as setas dorsais podem variar grandemente quanto ao comprimento e formato. Deste modo, conclui-se que tais caracteres não mais devem ser utilizados para diagnose específica de $A$. schultzi. 


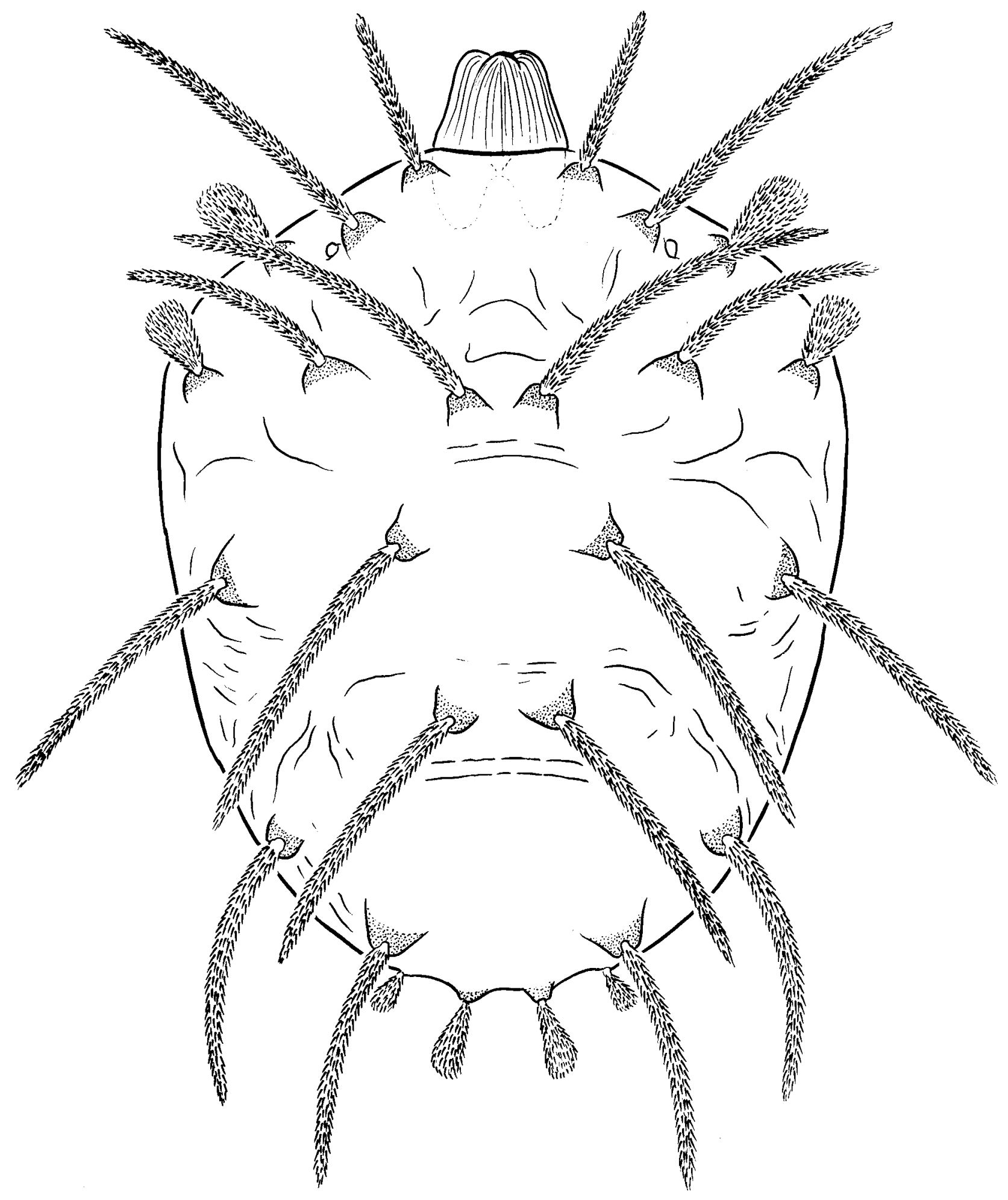

Figura 34. Vista dorsal de Aponychus schultzi, fêmea. 

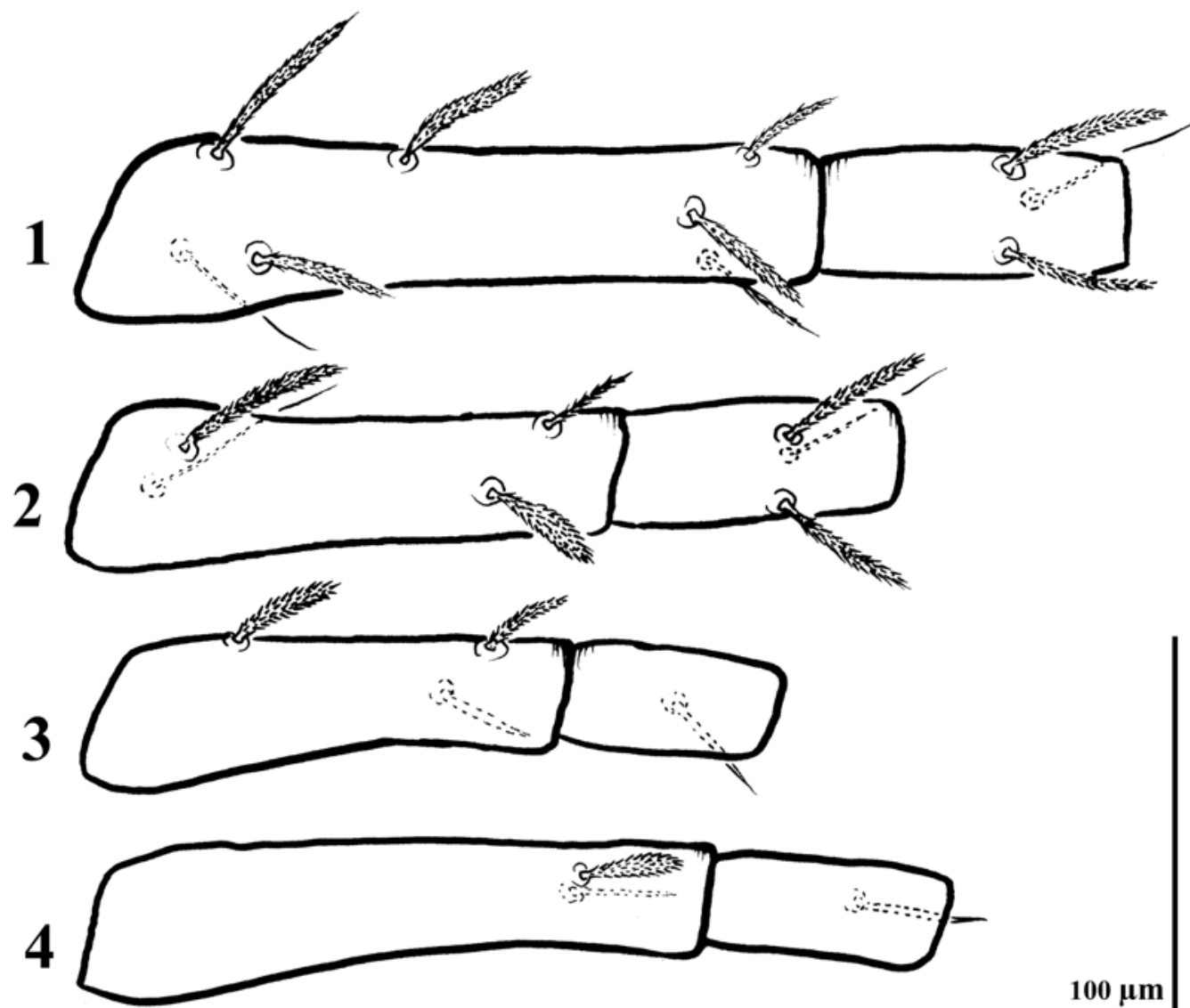

$100 \mu \mathrm{m}$
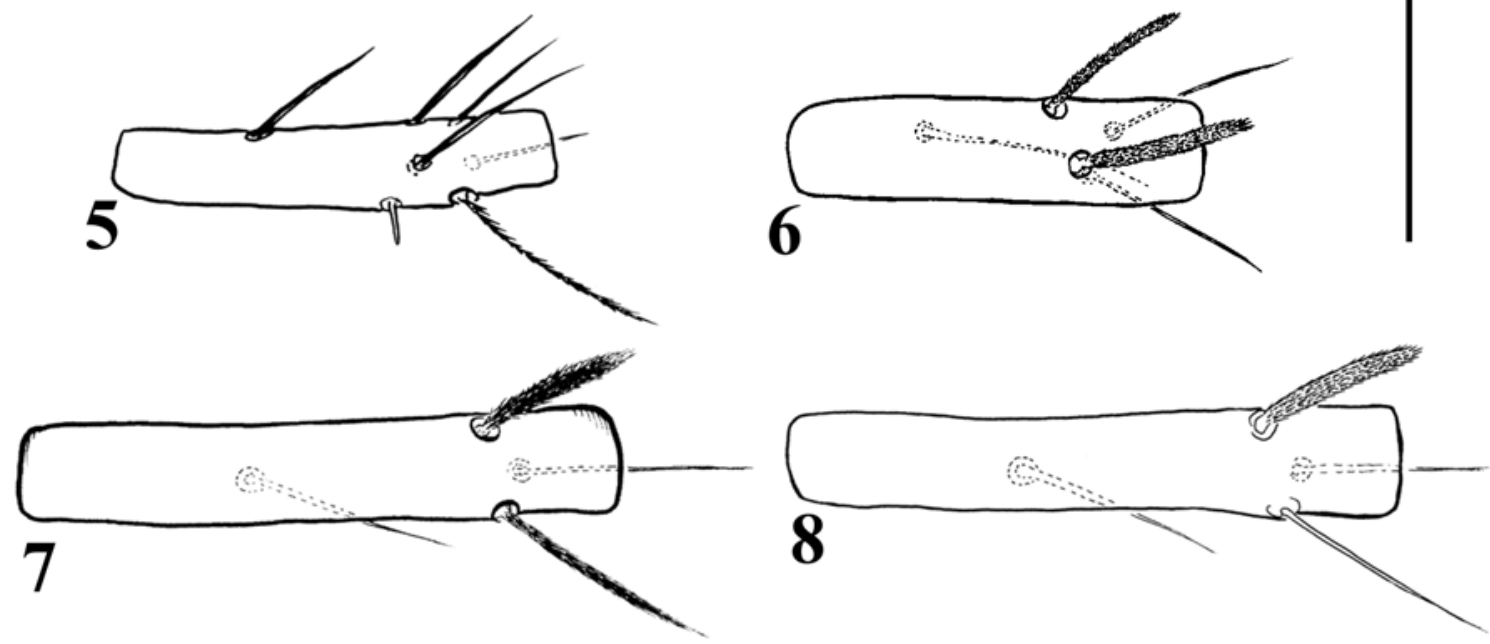

Figura 35. Artículos das pernas de Aponychus schultzi, fêmea: fêmur e gênu das pernas de I a IV (1-4); tíbias I a IV (5-8). 


\section{Aponychus pilipinus Corpuz-Raros}

(Figuras 9.1 p. $45 ; 16.27$ p. $49 ; 17.24$ p. $50 ; 18.8$ p. $51 ; 19.20$ p. $52 ; 20.13$ p. $53 ; 21.12$ p. $54 ; 22.15$ p. $55 ; 23.18$ p. 56 ; 24.13 p. $57 ; 25.6$ p. $58 ; 26.6$ p. $59 ; 27.7$ p. $60 ; 28.8$ p. $61 ; 29.7$ p. $62 ; 30.6$ p. $63 ; 31.6$ p. $64 ; 36$ p. $81 ; 37$ p. $82 ; 80.2$ p.

Aponychus pilipinus Corpuz-Raros, 1978: 212; Bolland et al., 1998: 21.

Paraponychus pilipinus; Rimando \& Corpuz-Raros, 1996: 13.

Série típica: holótipo + , 13 $+4{ }^{\Uparrow}$ parátipos, Mt. Makiling, Puting Lupa, Calamba, Laguna, Filipinas, 03.XI.1976, ex Grewia multiflora Juss. (Tiliaceae), L.A. Corpuz-Raros col.; parátipos $23 \stackrel{+}{9}, 8 \hat{\bigcirc}$, mesmos dados do holótipo, 24.IV.1978, R.C. Garcia col. (USNM).

Coleção depositária: UPLB (holótipo e parátipos), USNM (parátipos $\bigcirc$ đ), DZSJRP (parátipo 9 ). Etimologia: referente ao país onde foi coletada a espécie.

Hospedeiros: Memecylon caeruleum (Melastomataceae), Cephalanthus orientalis L., Psychotria luconiensis (Rubiaceae), Grewia multiflora (Tiliaceae).

Distribuição: Filipinas (Corpuz-Raros, 1978, 1989).

\section{Material examinado:}

- 2 parátipos, DNR 972, Hydroecology, site Mt. Makiling at Puting Lupa, Calambra, Laguna, Philippines, 24.IV.1978, ex Grewia multiflora, R.C. Garcia col. (USNM); parátipo ${ }_{\text {, }}$ UPLBMNH Aça 098 DNR 257, Kaingin - Lagonal Aru H.E. site, Puting Lupa, Calamba, Laguna Philippines, 3.XI.1976, L.A.L. Raros col. (DZSJRP); 4, Nat. Art Center Area, Mt. Makiling, Los Banos, Laguna, Philippines, no 4384, 11.VI.1993, R.C. Garcia col. (DZSJRP).

Diagnose: Aponychus pilipinus assemelha-se a A. spinosus e A. schultzi por apresentar a maioria das setas dorsais longas, ultrapassando a base do par subsequente; pode ser diferenciada pela quetotaxia dos artículos das pernas: fêmur 6-4-3-1, gênu 3-3-1-1 e tíbia 5(1)-4-3-3. Em A. spinosus a quetotaxia apresenta-se como: fêmur 6-4-2-1, gênu 2-2-1-1 e tíbia 4(1)-3-2-2, e em A. schultzi, fêmur 7-4-3-2, gênu 3-3-1-1 e tíbia 6(1)-5-4-4. Aponychus pilipinus dintingue-se das demais espécies do gênero também por ser a única a não apresentar a seta dorso antiaxial $d^{\prime \prime} 1$ no femur I.

\section{Redescrição:}

Fêmea $(\mathrm{n}=2)$ Dorso. Margem anterior do estilóforo arredondada; apenas um ocelo próximo ao tubérculo das setas prodorsais scl; tegumento dorsal não estriado; setas dorsais longas, 
serreadas, ultrapassando a base do pare subsequente, setas escapulares externas e humerais (sc2 e c3) com extremidades não convergentes; setas $c 2$ e $c 1$ de comprimentos equivalentes; setas dorsocentrais com comprimentos equivalentes $(c 1 \approx d 1 \approx e 1)$; idiossoma: comprimento 352-363, largura 253-253; comprimento das setas dorsais: v2 60-65, sc1 71-87, sc2 57-57, c1 79-84, c2 76-84, c3 49-49, d1 79-79, d2 79-79, el 68-71, e2 73-79,f1 22-24,f2 82-84, h1 44-46. Distância entre pares de setas dorsais: v2-v2 52-54, sc1-sc1 90-90, sc2-sc2 174-180, c1-c1 22-27, c2-c2 220-223, c3-c3 242-248, dl-d1 49-54, d2-d2 215-218, el-el 14-19, e2-e2 155-160, fl-f1 95-98, f2-f2 95-98, h1-hl 27-33.

Ventre. Comprimento das setas ventrais: $m$ 24-30, la 22-22, lb 38-41, lc 35-41, $2 b$ 24-27, 2c 27-27, 3 a 24-27, 3b 27-30, 4a 30-33, 4b 24-27, ag 27-27, g1 33-33, g2 35-38, ps3 14-14, h3 2224, h2 24-24. Distância entre pares de setas ventrais: $m-m$ 19-33, la-la 35-38, lb-lb 95-98, lc-lc 122-122, 2b-2b 122-125, 2c-2c 147-150, 3a-3a 68-71, 3b-3b 163-180, 4a-4a 60-76, 4b-4b 150169, ag-ag 27-30, g1-g1 30-30, g2-g2 46-52, ps3-ps3 19-24, h3-h3 52-54, h2-h2 27-27.

Quetotaxia das pernas (artículos nas pernas I a IV): coxa 2-2-1-1, trocânter 1-1-1-1, fêmur 6-4-3-1, gênu 3-3-1-1, tíbia 5(1)-4-3-3, tarso 10(1assoc.)-9(1assoc.)-7(1)-7(1). Solenídio proximal presente nos tarsos III e IV. 


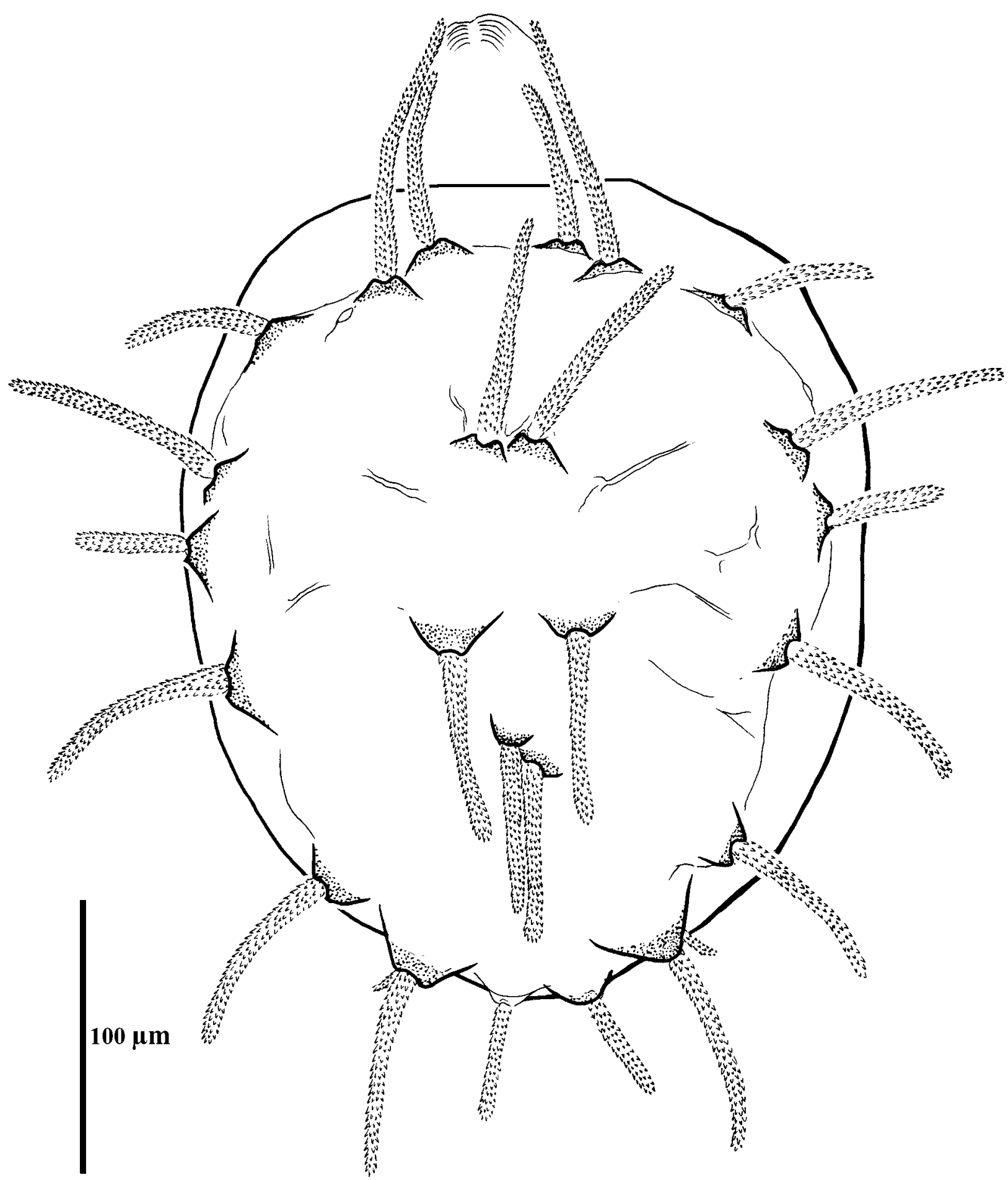

Figura 36. Vista dorsal de Aponychus pilipinus, parátipo fêmea. 

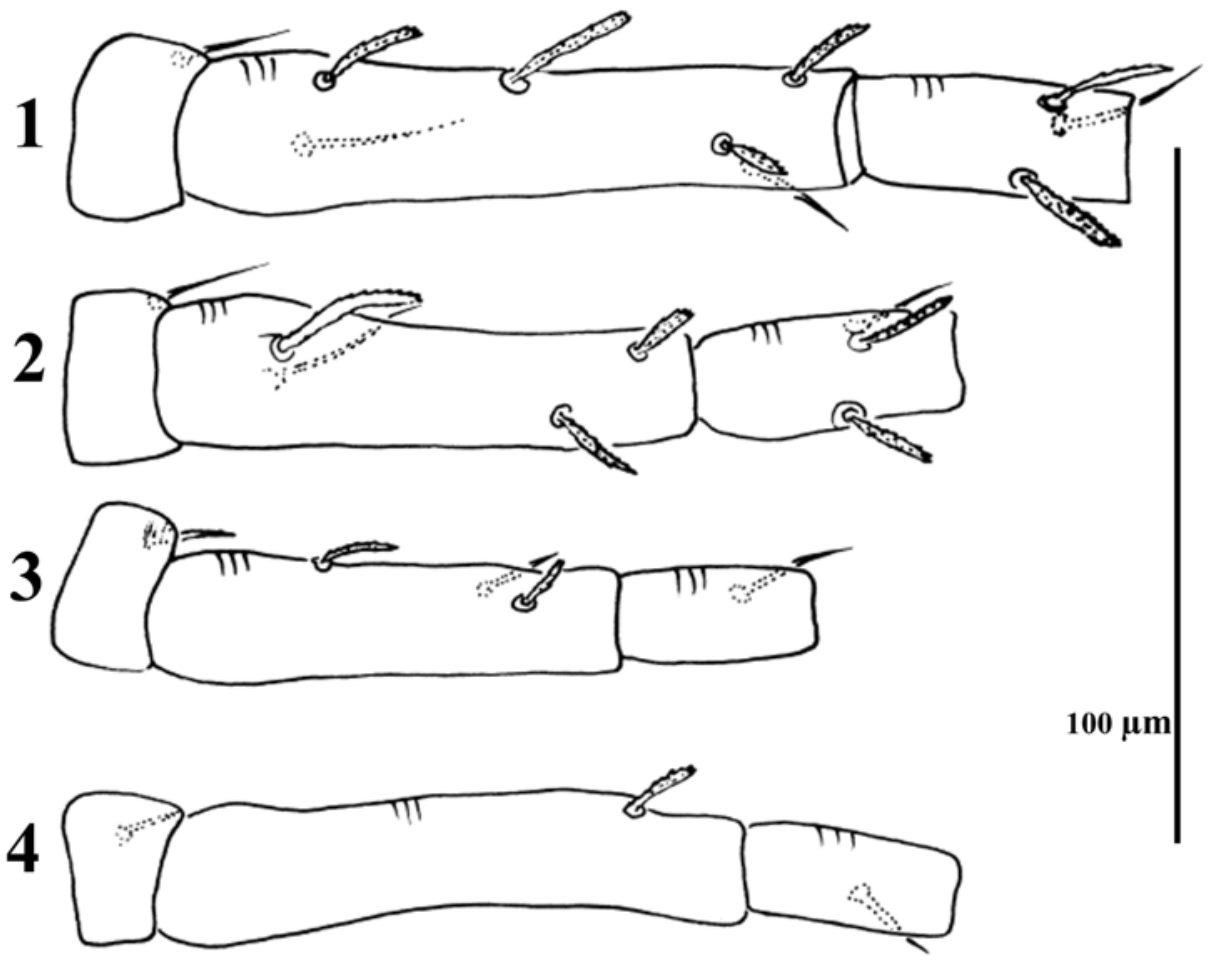

$100 \mu \mathrm{m}$
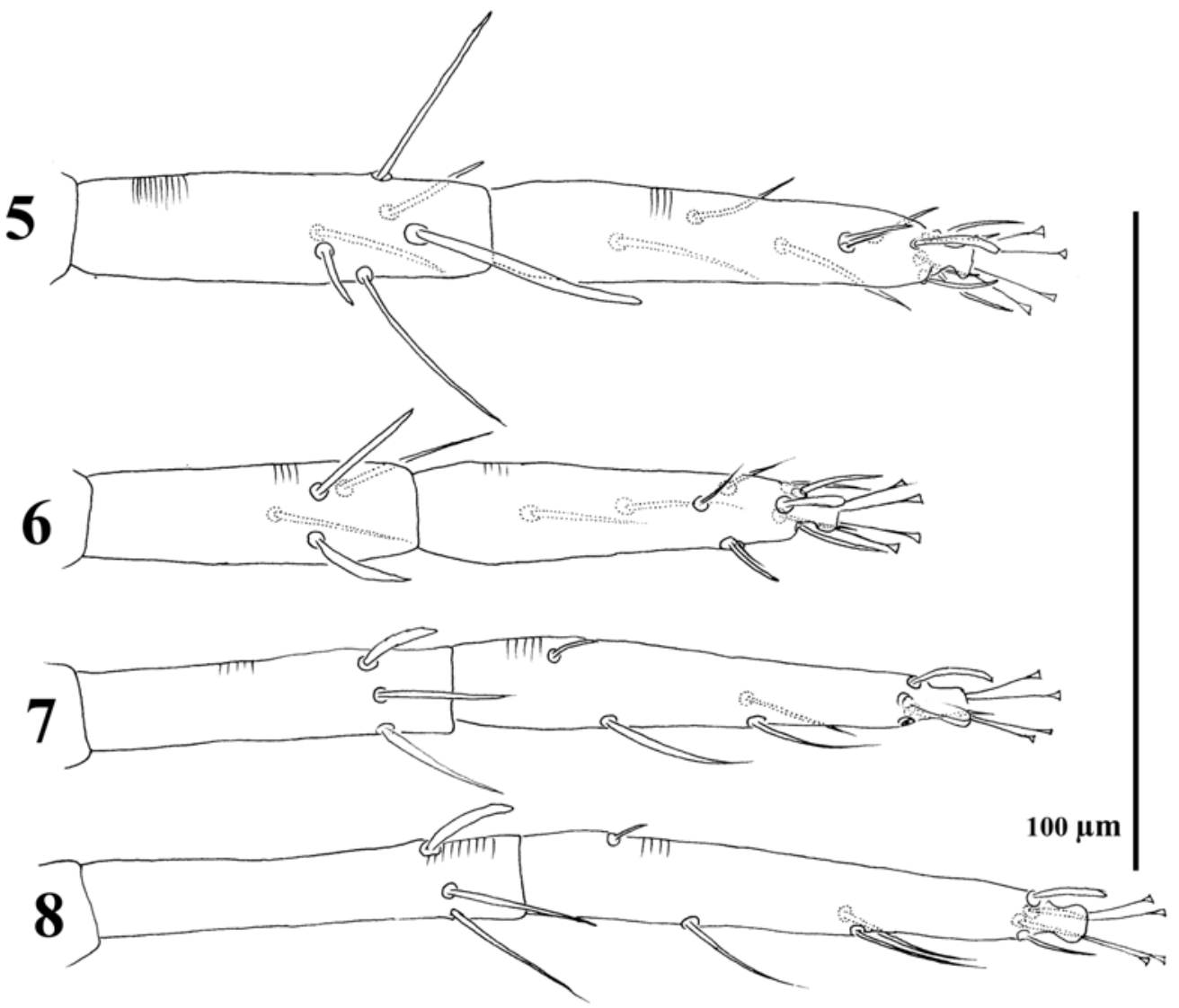

Figura 37. Artículos das pernas de Aponychus pilipinus, parátipo fêmea: trocânter, fêmur e gênu das pernas de I a IV (1-4); tíbias e tarsos I a IV (5-8). 


\section{Aponychus firmianae (Ma \& Yuan)}

(Figuras 16.11 p. $49 ; 17.20$ p. 50; 18.23 p. 51; 19.12 p. 52; 20.6 p. $53 ; 21.6$ p. $54 ; 22.13$ p. $55 ; 23.16$ p. $56 ; 24.8$ p. 57 ; 25.4 p. $58 ; 26.4$ p. $59 ; 27.6$ p. $60 ; 28.4$ p. $61 ; 29.4$ p. $62 ; 38$ p. $85 ; 39$ p. $86 ; 79.5$ p. 172$)$

Eutetranychus firmianae Ma \& Yuan, 1965: 247.

Aponychus firmianae: Ehara, 1980: 206; Rimando \& Corpuz-Raros, 1996: 12; Bolland et al., 1998: 20; Ehara, 1999: 79.

Chinotetranychus firmianae: Ma \& Yuan, 1982: 113.

Série típica: holótipo + , Hsing Yu, província de Kiangsi, China, 15.VII.1964, ex Firmiana simplex (Linnaeus) Wight (Sterculiaceae); parátipos $\widehat{\jmath},+$, Lung Hwa, Shanghai, China, 20.VIII.1964.

Coleção depositária: MHNS (holótipo e parátipos).

Etimologia: refere-se ao gênero do hospedeiro tipo.

Hospedeiros: Firmiana simplex, F. platanifolia (Sterculiaceae) (Bolland et al., 1998).

Distribuição: China (Ma \& Yuan, 1965; 1982), Japão (Ehara, 1980), Coréia do Sul (Lee, 1989).

\section{Material examinado:}

- 4, Fukuchiyama, Japão, 17.VI.1979, ex Firmiana simplex, S. Ehara col. (SH).

Diagnose: Aponychus firmianae assemelha-se a A. mallotus pelas setas dorsais; diferenciase pelo número de setas nos gênus, 3-3-1-1, ao invés de 2-2-0-0 em A. mallotus; também pode ser facilmente reconhecida por ser a única espécie de Aponychus a apresentar tegumento fortemente enrugado, com padrão semelhante ao de um córtex cerebral, como o encontrado em Stylophoronychus vannus.

\section{Redescrição:}

Fêmea $(n=4)$ Dorso. Margem anterior do estilóforo arredondada; conspícuo enrugamento do tegumento dorsal; setas dorsais levemente serreadas, setas escapulares externas e humerais ( $s c 2$ e $c 3$ ) com extremidades não fortemente convergentes; setas $c 2$ e $c 1$ de comprimentos equivalentes; setas dorso-centrais com comprimentos equivalentes $(c l \approx d l \approx e 1)$; idiossoma: comprimento 385462, largura 308-319; comprimento das setas dorsais: v2 52-57, sc1 65-79, sc2 57-60, c1 63-68, c2 72-73, c3 54-60, d1 63-71, d2 71-76, el 60-63, e2 68-68, fl 33-35, f2 65-68, h1 46-52. Distância entre pares de setas dorsais: v2-v2 73-82, sc1-sc1 109-114, sc2-sc2 193-201, c1-c1 19-27, c2-c2 228-237, c3-c3 264-267, d1-d1 38-44, d2-d2 237-239, e1-e1 30-33, e2-e2 163-171, f1-f1 87-103, 
f2-f2 106-114, hl-h1 30-35.

Ventre. Comprimento das setas ventrais: $m$ 19-19, la 41-41, lb 44-44, lc 41-41, 2 b 35-35, 3a 44-44, 3b 33-33, 4a 44-44, 4b 38-38, ag 30-30, g1 41-41, g2 46-46, ps3 19-19, h3 30-30, h2 24-24. Distância entre pares de setas ventrais: $m-m$ 33-33, la-la 24-24, lb-lb 106-106, lc-lc 136136, 2b-2b 188-188, 3a-3a 71-71, 3b-3b 201-201, 4a-4a 95-95, 4b-4b 188-188, ag-ag 33-33, g1g1 27-27, g2-g2 57-57, ps3-ps3 27-27, h3-h3 71-71, h2-h2 24-24.

Quetotaxia das pernas (artículos nas pernas I a IV): coxa 2-1-1-1, trocânter 1-1-1-1, fêmur 6-4-2-1, gênu 3-3-1-1, tíbia 5(1)-4-3-3, tarso 8(1assoc.)-7(1assoc)-5-5(1). Setas do par associado presentes nos tarsos I e II; solenídio proximal ausente no tarso III e presente no IV. 


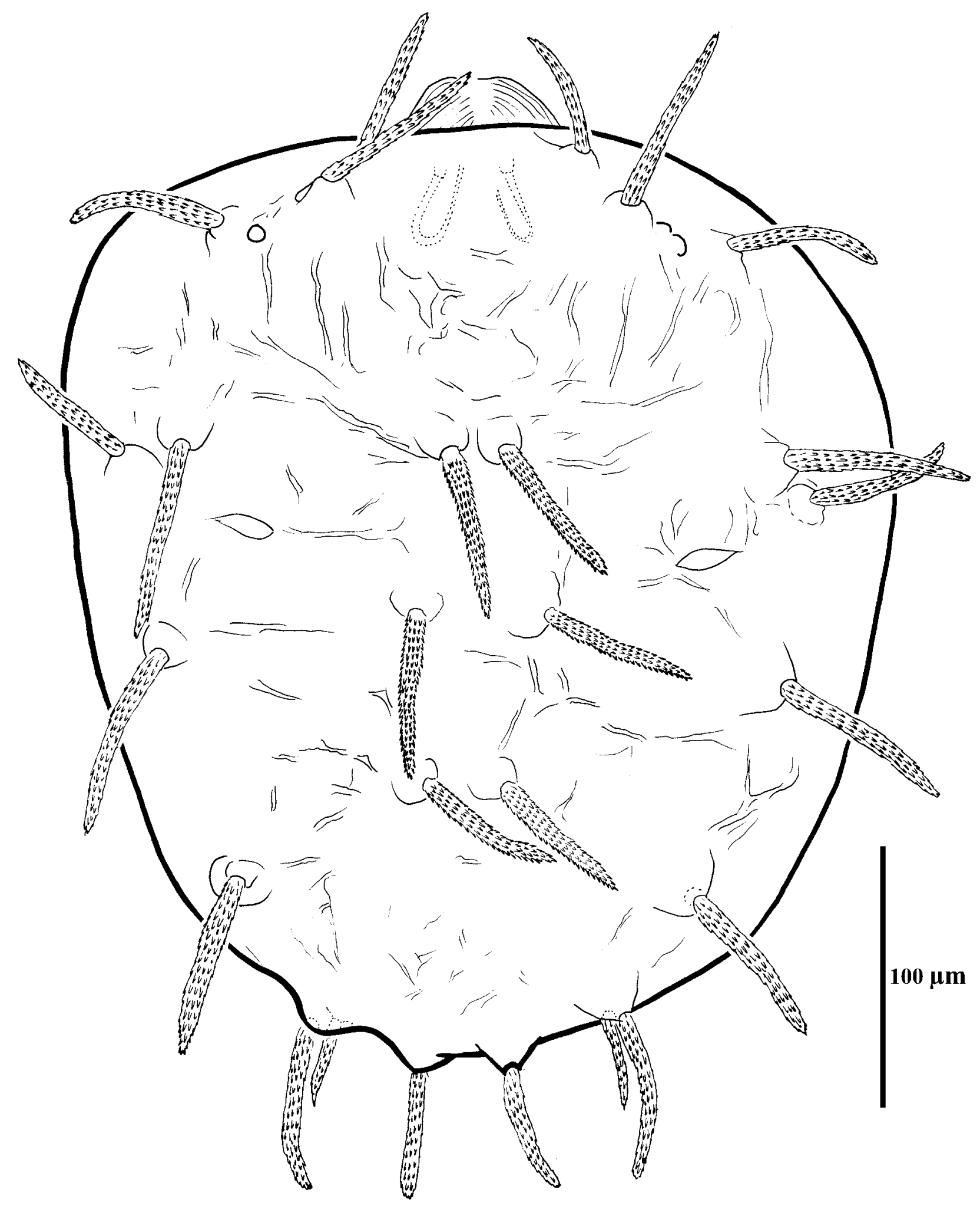

Figura 38. Vista dorsal de Aponychus firmianae, fêmea. 

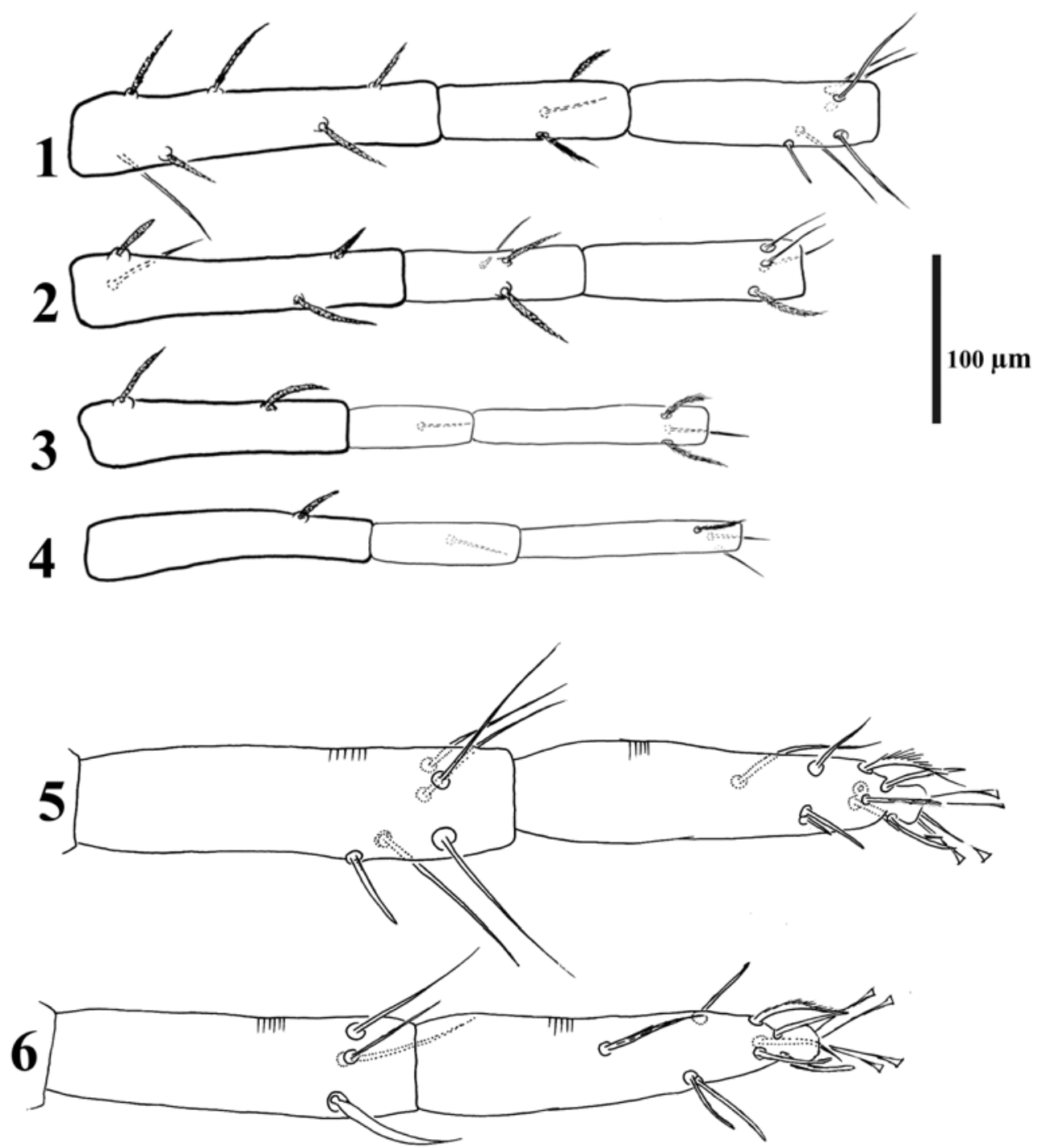

$100 \mu \mathrm{m}$

Figura 39. Artículos das pernas I a IV de Aponychus firmianae, fêmea: fêmur, gênu e tíbia de I a IV (1-4), tibia e tarso I e II (5-6). 


\section{Aponychus spinosus (Banks)}

(Figuras 16.23 p. $49 ; 17.27$ p. 50; 18.25 p. $51 ; 19.26$ p. 52; 20.24 p. 53; 21.21 p. $54 ; 22.23$ p. $55 ; 23.21$ p. $56 ; 24.22$ p. $57 ; 25.17$ p. $58 ; 26.17$ p. $59 ; 27.18$ p. $60 ; 40$ p. $88 ; 41$ p. $89 ; 80.8$ p. 173$)$

Tetranychopsis spinosa Banks, 1909: 134.

Eutetranychus spinosa; McGregor, 1950: 267.

Eutetranychus spinosus; Pritchard \& Baker, 1955: 113.

Aponychus spinosus; Thewke \& Enns, 1969: 26; Meyer, 1974: 156; Baker \& Tuttle, 1994: 140; Bolland et al., 1998: 22.

Série típica: 59 síntipos, Guelph, Ontário, Canadá, $q$ e imaturos, sem informação de data, ex Tilia sp. (Tiliaceae).

Coleção depositária: MCZ.

Etimologia: possivelmente referente ao formato das longas setas dorsais, assemelhando-se a espinhos.

Hospedeiros: Lactuca serriola (Asteraceae), Lonicera tatarica (Caprifoliaceae), Cucurbita pepo (Cucurbitaceae), Ricinus comunis (Euphorbiaceae), Phaseolus vulgaris (Fabaceae), Hibiscus rosasinensis (Malvaceae), Morus alba (Moraceae), Poaceae, Rubus occidentalis, R. orientalis, Rubus sp. (Rosaceae), Citrus sp. (Rutaceae), Tilia americana, Tilia sp. (Tiliaceae), Celtis occidentalis, Ulmus americana, U. rubra (Ulmaceae).

Distribuição: Canadá, Estados Unidos, Brasil, Paraguai, Filipinas.

Obs: Pritchard \& Baker (1955: 113) erroneamente citam o trabalho de Banks (1917: 197) registrando a espécie como Neotetranychus (Eutetranychus) spinosa, quando em tal trabalho não há tal menção.

\section{Material examinado:}

- 5 q síntipos (75522), Ontário, Canadá, ex Tilia sp. (MCZ). 1 fêmea, ex Ulmus americana, Cont. Educ. Bldq. Athens, Geórgia, 16.IX.1961, col. R. Davis, on lower leaf surface-green color det PEH (MZ-ESALQ).

Diagnose: Essa espécie assemelha-se a outras do gênero Aponychus que apresentam setas dorsais longas, principalmente A. schultzi. Difere desta por apresentar distinta quetotaxia nos artículos das pernas: coxa 2-1-1-1, fêmur 6-4-2-1, gênu 2-2-1-1 e tíbia 4(1)-3-2-2. Em A. schultzi a quetotaxia desses mesmos artículos apresenta-se 2-2-1-1, 7-4-3-2, 3-3-1-1 e 6(1)-5-4-4. 


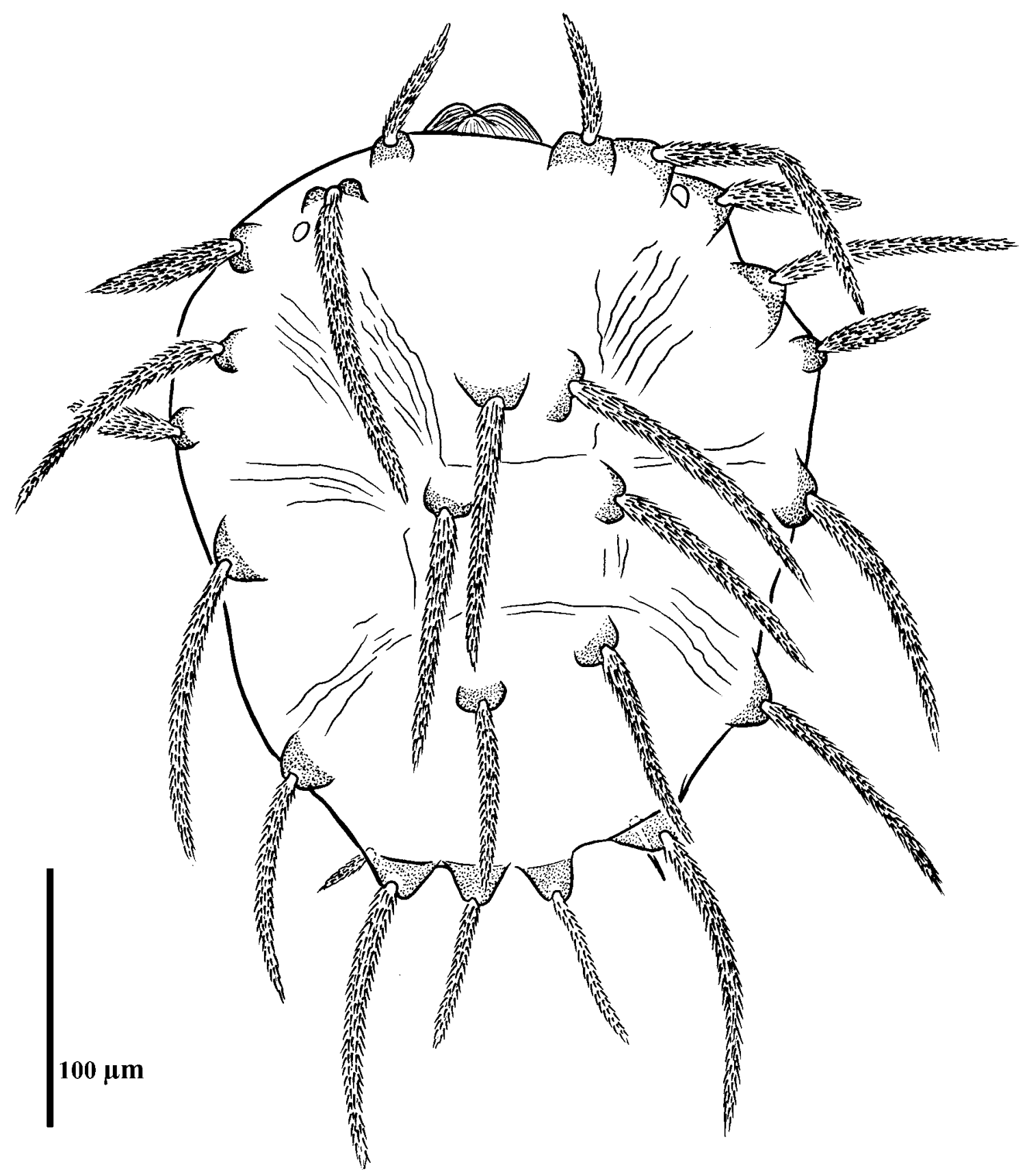

Figura 40. Vista dorsal de Aponychus spinosus, lectótipo fêmea. 

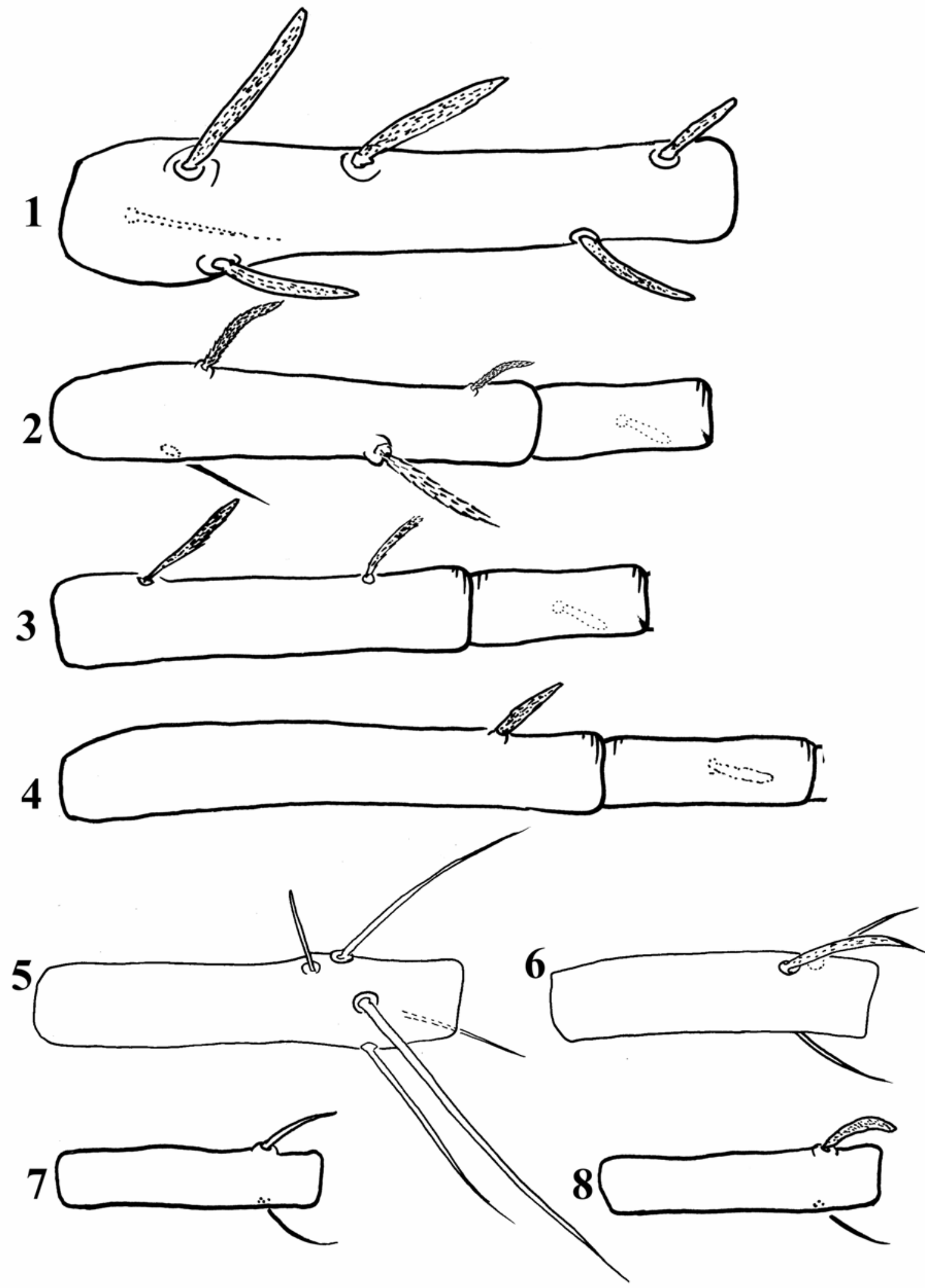

Figura 41. Artículos das pernas de Aponychus spinosus, lectótipo fêmea: fêmur e gênu das pernas de I a IV (1-4); tíbias I a IV (5-8). 


\section{Aponychus taishanicus Wang}

(Figuras 24.18 p. $57 ; 25.8$ p. $58 ; 42$ p. $91 ; 81.1$ p. 174 )

Aponychus taishanichus Wang, 1981: 221; Bolland et al., 1998: 22.

Série típica: holótipo $9,7 \uparrow, 4 \bigcirc$ parátipos, Tai Shan, Shantung Province, China, 16.IX.1974, ex Grewia biloba G. Don. (Tiliaceae).

Coleção depositária: IZSA (holótipo e parátipos).

Etimologia: referente a localidade tipo, cidade de Taishan, província de Guangdong, China.

Hospedeiro: Grewia biloba (Tiliaceae).

Distribuição: China (Wang, 1981).

Diagnose: essa espécie assemelha-se a A. schultzi pelas longas setas dorsais, mas distingue-se pela quetotaxia das tíbias, seguindo a fórmula 5(1)-4-3-3, sendo 6(1)-5-4-4 em A. schultzi.

Essa espécie não foi analisada a partir de espécimes-tipo, mas apenas a partir de imagens de indivíduos da série típica, enviadas pelo curador de Acari da Academia Sinica, Beijing, China, Dr. Jun Chen. Entretanto, foi possível constatar pelas fotos que o material parátipo está em más condições de montagem e preservação, com os artículos das pernas altamente torcidos, o que dificulta a visualização das inserções das setas em seus artículos, caráter esse de grande importância na taxonomia e diagnose das espécies deste grupo de Tetranychidae. 


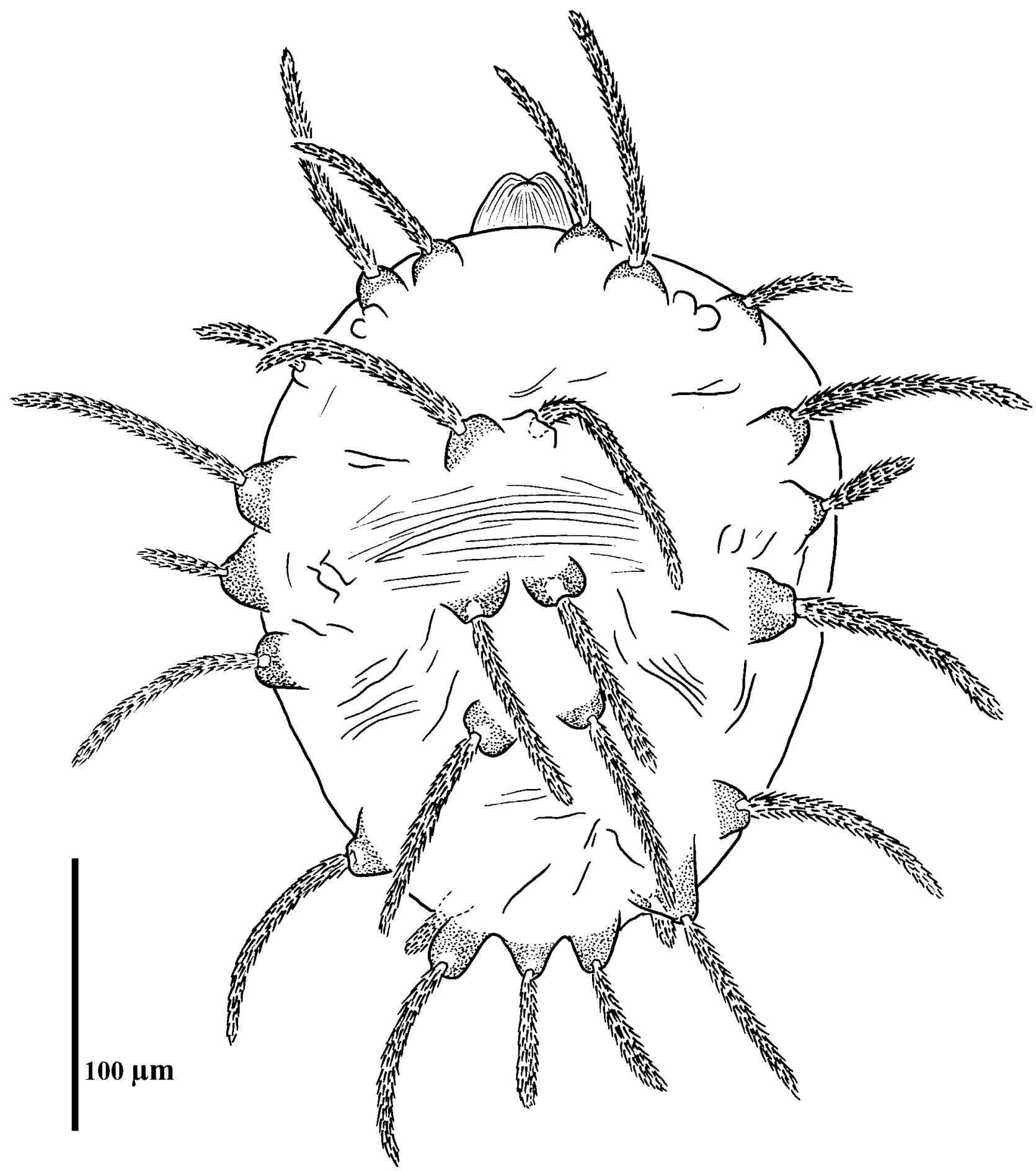

Figura 42. Vista dorsal de Aponychus taishanicus, fêmea (redesenhado a partir de ilustração no trabalho de descrição da espécie). 


\section{Aponychus mallotus Ho}

(Figuras 10.3 p. $45 ; 16.4$ p. $49 ; 17.22-23$ p. $50 ; 18.2$ p. $51 ; 19.2$ p. $52 ; 20.20$ p. $53 ; 21.19$ p. $54 ; 22.26$ p. $55 ; 23.26$ p. $56 ; 24.12$ p. $57 ; 25.5$ p. $58 ; 26.5$ p. $59 ; 27.5$ p. $60 ; 28.7$ p. $61 ; 29.6$ p. $62 ; 30.5$ p. $63 ; 31.5$ p. $64 ; 44$ p. $94 ; 45$ p. $95 ; 79.9$ p. 172)

Aponychus mallotus Ho, 2003: 344.

Série típica: holótipo + , 4§, 69 parátipos, Taichung, Dakon, Taiwan, 23.II.2003, ex Mallotus paniculatus (Lam.) Müell. Arg. (Euphorbiaceae), C.C. Ho col.; $2 \uparrow$ parátipos, Nantou, Yuchih, Maolanshan, Taiwan, 28.III.2003.

Coleção depositária: TARI (holótipo e parátipos).

Etimologia: referente ao gênero do hospedeiro tipo.

Hospedeiro: Mallotus paniculatus (Euphorbiaceae) (Ho, 2003).

Distribuição: Taiwan (Ho, 2003).

\section{Material examinado:}

$-1+$, 1ठ, 1 protoninfa, 1 deutoninfa parátipos, Taichung, Dakon, Taiwan, 23.II.2003, ex Mallotus paniculatus, C.C. Ho col. (TARI).

Diagnose: assemelha-se a A. firmianae pelas setas dorsais longas e barbuladas; diferenciase pela quetotaxia presente nos gênus I-IV, seguindo a fórmula 2-2-0-0, ao invés de 3-3-1-1 como em A. firmianae. Diferencia-se também pelo tegumento dorsal liso, enquanto que em $A$. firmianae este apresenta-se com padrão enrugado.

\section{Redescrição:}

Fêmea ( $n=6$, dados da literatura) Dorso. Estilóforo com duas leves projeções arredondadas anteriormente; dois ocelos próximos ao tubérculo das setas prodorsais $s c 1$, lente posterior resquicial; setas dorsais fortemente serreadas, inseridas em proeminentes tubérculos, setas escapulares externas e humerais ( $s c 2$ e $c 3$ ) com extremidades não convergentes; setas $c 2$ e $c 1$ de comprimentos equivalentes; setas dorso-centrais com comprimentos equivalentes $(c 1 \approx d l \approx e 1)$; idiossoma: comprimento 334-404, largura 320-390; comprimento das setas dorsais: v2 42-64, sc1 57-71, sc2 65-81, c1 52-72, c2 58-77, c3 66-84, d1 48-66, d2 52-78, e1 48-60, e2 54-75.

Quetotaxia das pernas (artículos nas pernas I a IV): coxa 2-2-1-1, trocânter 1-1-1-1, fêmur 7-5-4-2, gênu 2-2-0-0, tíbia 5(1)-4-3-4, tarso 8(1assoc.)-5(4)-5(1)-5(1). Setas do par associado presentes no tarso I, mas dissociadas no tarso II; solenídio proximal presente nos tarsos III e IV. 


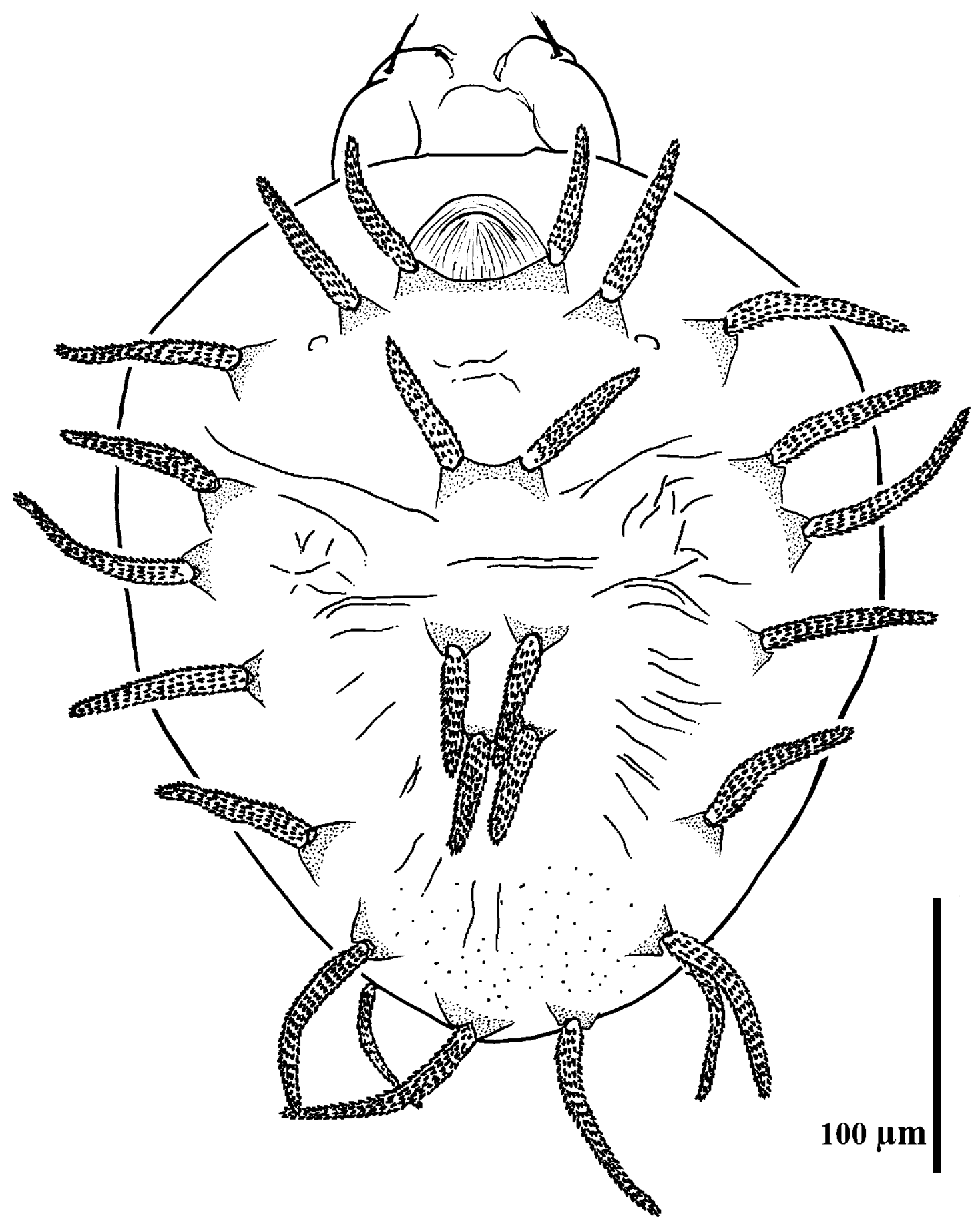

Figura 43. Vista dorsal de Aponychus mallotus, parátipo fêmea. 

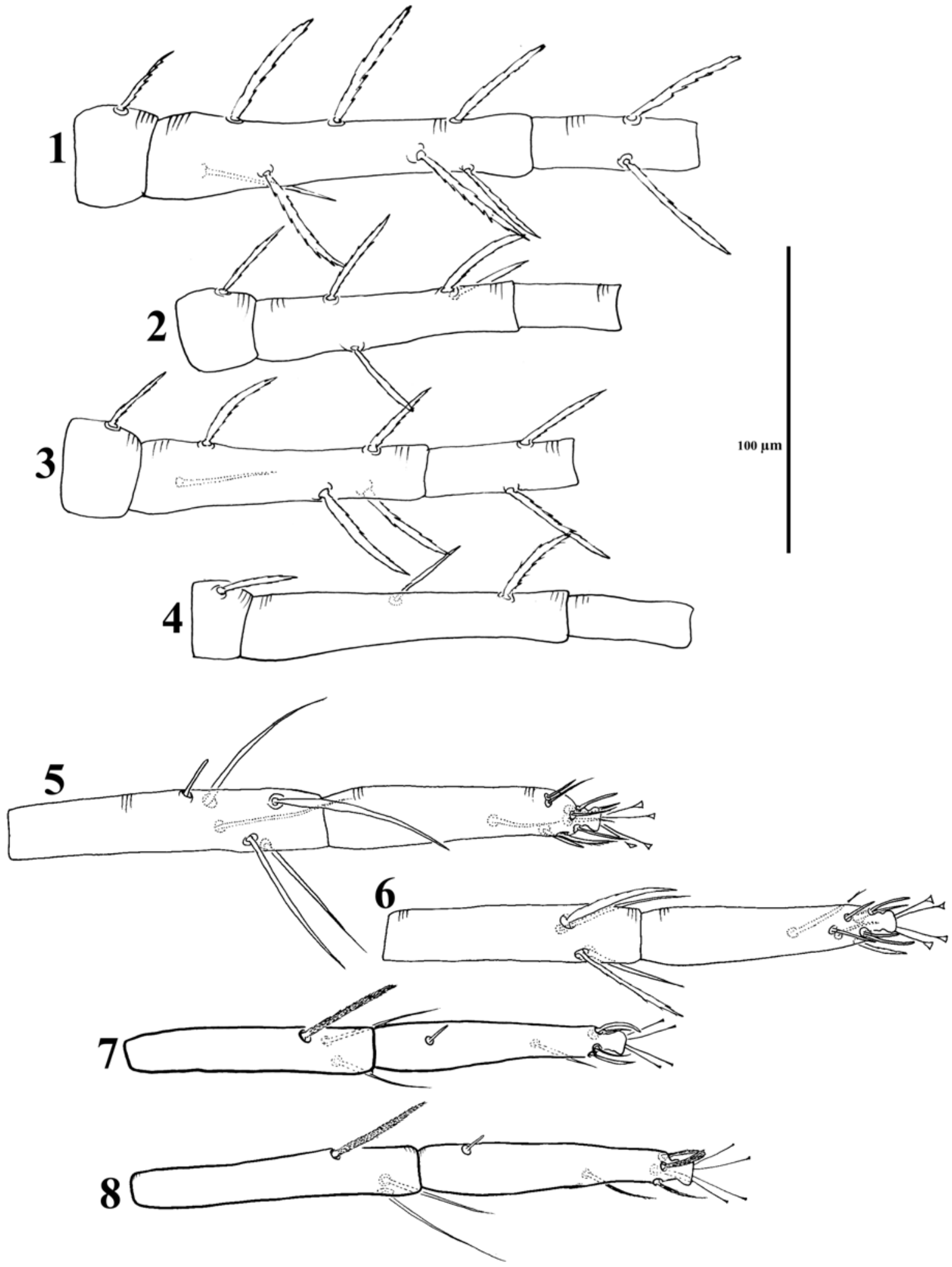

Figura 44. Artículos das pernas de Aponychus mallotus, parátipo fêmea: trocânter, fêmur e genu de I a IV (1-4); tíbia e tarso de I a IV (5-8). 


\section{Paraponychus kodaikanalensis (Gupta)}

(Figuras 45 p. 96; 81.8 p. 174)

Aponychus kodaikanalensis Gupta, 1984: 238; Gupta \& Gupta, 1994: 44.

Paraponychus kodaikanalensis; Bolland et al., 1998: 148.

Série típica: holótipo,$+ 1 q$ parátipo, Kodaikanal, Tamil Nadu, Índia (em direção ao Golf Club), 24.II.1982, ex Bambusa arundinacea (Retz.) Willd. (Poaceae).

Coleção depositária: NCZSI.

Etimologia: referente a localidade tipo, a cidade de Kodaikanal, no sul da Índia, estado de Tamil Nadu.

Hospedeiro: Bambusa arundinacea (Poaceae).

Distribuição: Índia (Gupta, 1984; Gupta \& Gupta, 1994).

Obs: macho desconhecido.

\section{Material examinado:}

- holótipo ${ }_{+}$, parátipo ${ }_{+}$, Kodaikanal, Tamil Nadu, Índia, 24.II.1982, ex folha de bambu (NCZSI).

Essa espécie apresenta registro único, e os dois únicos exemplares da espécie, depositados no NCZSI, atualmente encontram-se em mal estado de conservação. Em decorrência disso, diversos caracteres não puderam ser obtidos a partir daqueles exemplares. 


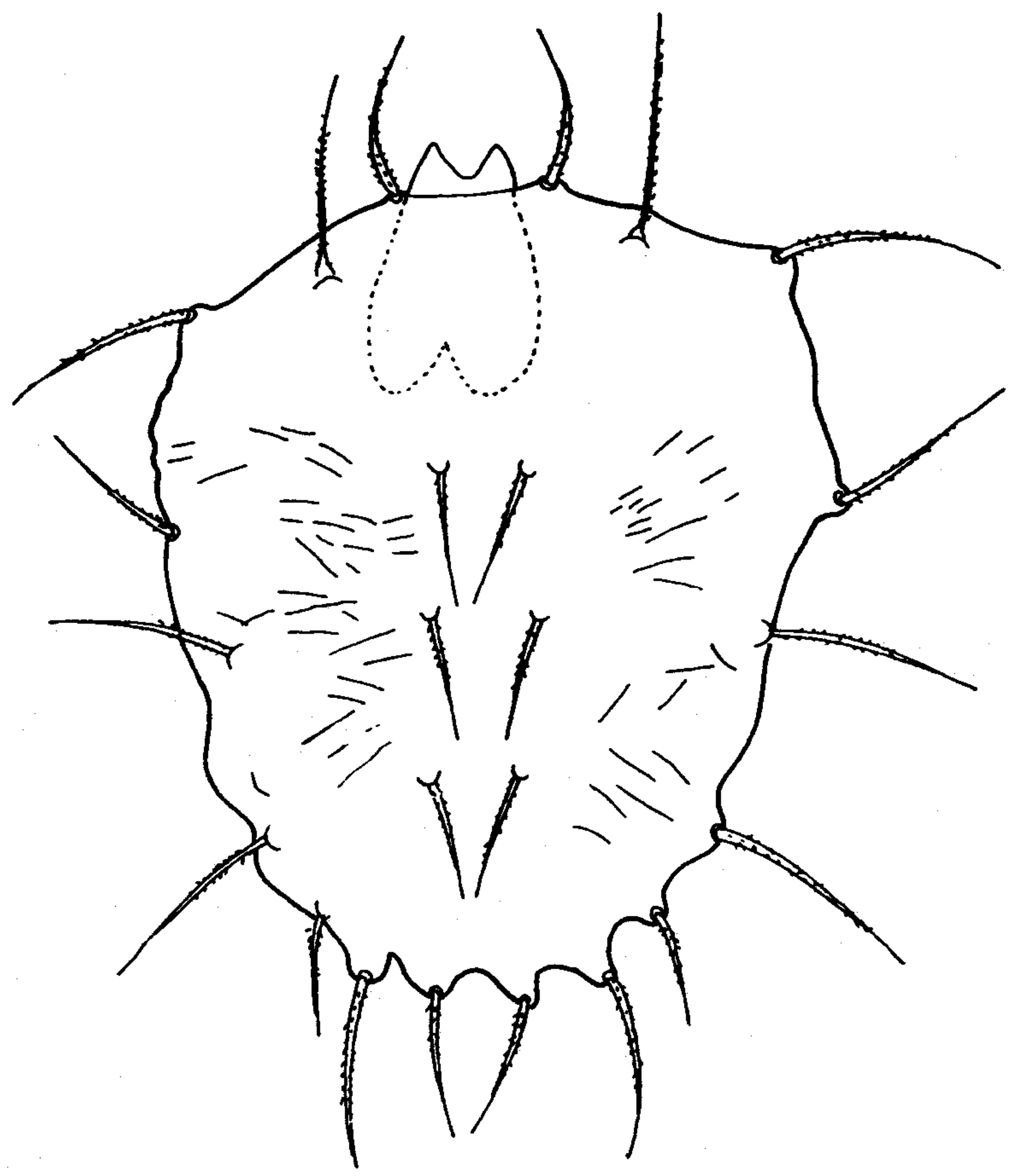

Figura 45. Vista dorsal de Paraponychus kodaikanalensis, holótipo fêmea (ilustração original). 


\section{Paraponychus saundersi Meyer \& Vargas}

(Figuras 16.28 p. $49 ; 17.25$ p. 50; 18.18 p. 51; 19.23 p. 52; 20.14 p. 53; 21.13 p. 54; 22.16 p. 55; 23.19 p. 56; 24.15 p. $57 ; 25.7$ p. $58 ; 26.7$ p. $59 ; 27.8$ p. $60 ; 28.14$ p. $61 ; 29.12$ p. $62 ; 30.12$ p. $63 ; 31.11$ p. $64 ; 46$ p. $99 ; 47$ p. $100 ; 81.7$ p.

Paraponychus saundersi Meyer \& Vargas, 1999: 111; Migeon \& Flechtmann, 2004: 147.

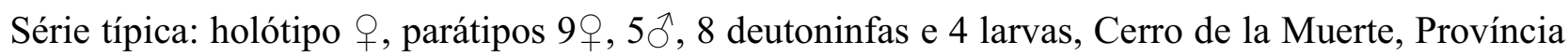
de San José, Costa Rica, C. Vargas col., 22.II.1994, ex Chusquea tonduzii Hack. (Poaceae); $29,2 \Uparrow, 1$ deutoninfa, 1 protoninfa, 08.XI.1992, demais dados iguais aos do holótipo.

Coleção depositária: NCA (holótipo e parátipos); USNM e CATIE (parátipos).

Etimologia: homenagem a Joseph L. Saunders, entomólogo norte americano, que introduziu os princípios do Manejo Integrado de Pragas na América Central.

Hospedeiro: Chusquea tonduzii Hack. (Poaceae).

Distribuição: Costa Rica (Meyer \& Vargas, 1999).

\section{Material examinado:}

- parátipos 1ㅇ, 1§, 1 deutoninfa, Costa Rica, 22.II.1994, ex Chusquea tonduzii, C. Vargas col. (USNM).

\section{Diagnose:}

Essa espécie pode ser facilmente separada das demais do gênero Paraponychus por apresentar o idiossoma com comprimento aproximadamente 2 vezes maior que a largura. Apresenta também quetotaxia diferente nas tíbias: 5(1)-4-3-3 ao invés de 4(1)-3-2-2 como em $P$. corderoi.

\section{Redescrição:}

Fêmea $(n=1)$. Dorso: opistossoma alongado, de comprimento aproximadamente 2 vezes maior do que a largura; margem anterior do estilóforo arredondada, sem projeções; apenas um ocelo próximo ao tubérculo das setas prodorsais $s c 1$; setas dorsais levemente serreadas, setas escapulares externas e humerais ( $s c 2$ e $c 3$ ) com extremidades convergentes; seta $c 2$ ausentes; setas dorso-centrais com comprimentos equivalentes $(c 1 \approx d l \approx e 1)$; idiossoma: comprimento 495, largura 286; comprimento das setas dorsais: v2 38, sc1 22, sc2 30, c1 16, c3 27, d1 16, d2 33, e1 14, e2 57,fl 11,f2 41, h1 35. Distância entre pares de setas: v2-v2 57, sc1-sc1 128, sc2-sc2 207, c1-c1 26, c3-c3 226, d1-d1 22, d2-d2 182, el-el 16, e2-e2 109, f1-fl 76, f2-f2 90, hl-hl 49.

Ventre. Comprimento das setas ventrais: $m$ 19, la 41, $l b 41, l c 33,2 b 27,2 c-, 3 a 38,3 b 24$, 
$4 a$ 27, $4 b$ 24, ag 22, g1 -, g2 -, ps3 14, h3 24, h2 24. Distância entre pares de setas ventrais: $m-m$ 38, la-la 60, lb-lb 112, lc-lc 136, $2 b-2 b$ 171, $2 c-2 c-, 3 a-3 a$ 76, 3b-3b 188, 4a-4a 106, 4b-4b 185, ag-ag 44, g1-g1 -, g2-g2 -, ps3-ps3 27, h3-h3 68, h2-h2 30.

Quetotaxia das pernas (artículos nas pernas I a IV): coxa 2-1-1-1, trocânter 1-1-1-1, fêmur 6/7-4-3-1, gênu 3-3-1-1, tíbia 5(1)-4-3-3, tarso 9(1assoc)-9(1)-6-6(1). 


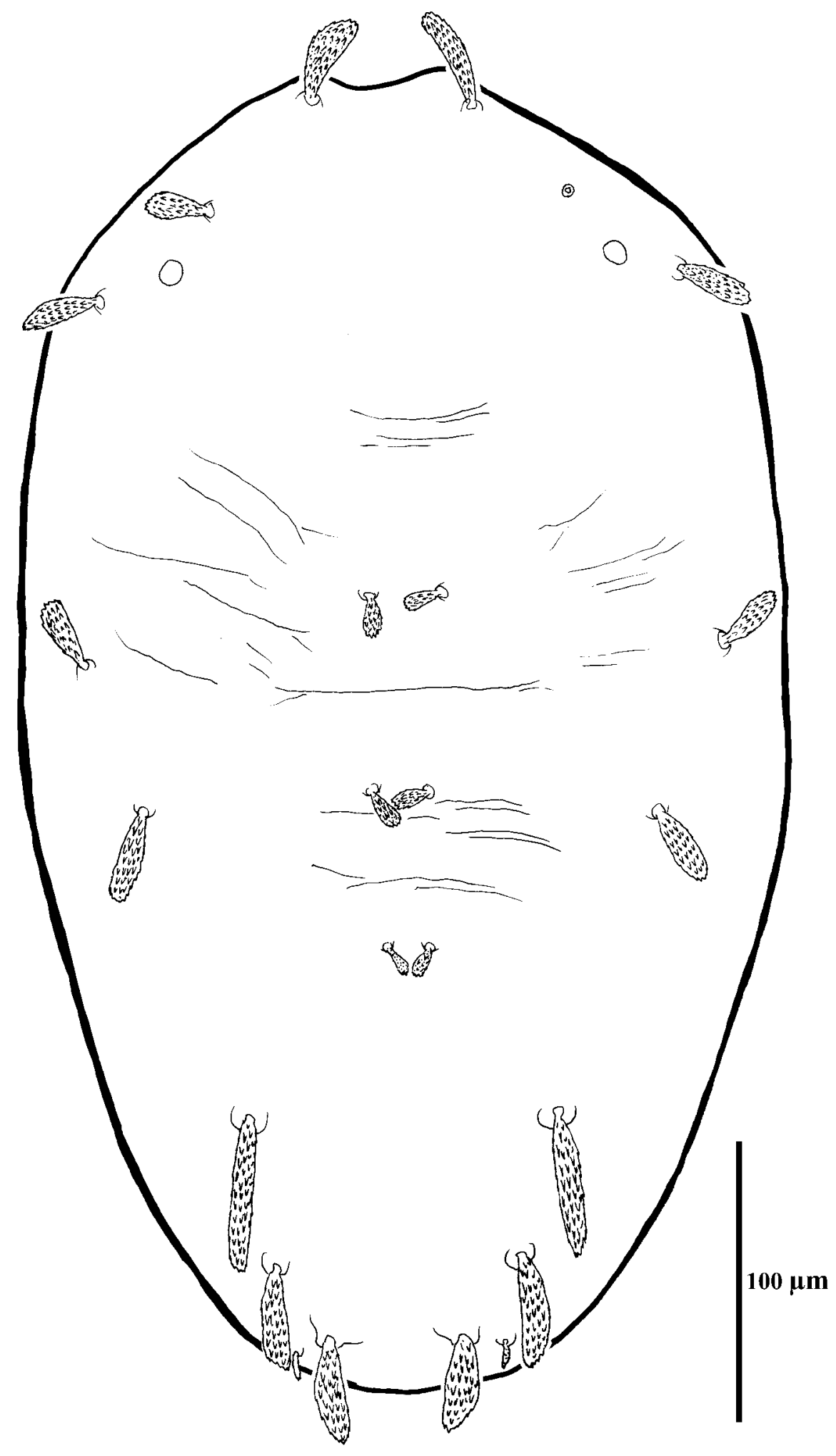

Figura 46. Vista dorsal do idiossoma de Paraponychus saundersi, parátipo fêmea. 


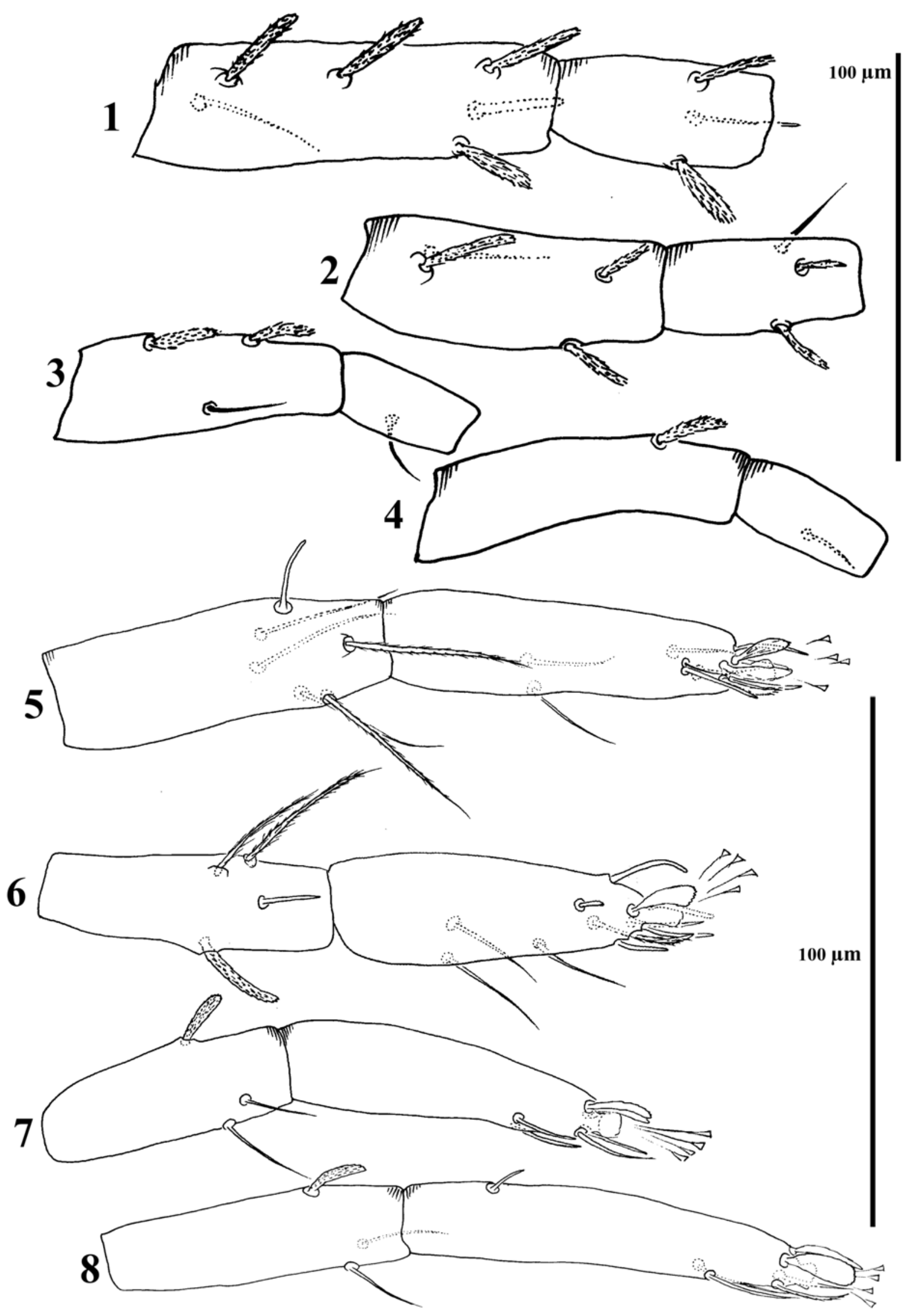

Figura 47. Artículos das pernas de Paraponychus saundersi, holótipo fêmea: fêmur e gênu das pernas de I a IV (1-4); tíbia e tarso de I a IV (5-8). 


\section{Aponychus chiavegatoi Feres \& Flechtmann}

(Figuras 16.8 p. $49 ; 17.18$ p. $50 ; 18.21$ p. $51 ; 19.8$ p. $52 ; 20.21$ p. $53 ; 21.18$ p. $54 ; 22.25$ p. $55 ; 23.23$ p. $56 ; 24.19$ p. 57 ; 25.9 p. $58 ; 26.8$ p. $59 ; 27.9$ p. $60 ; 28.1$ p. $61 ; 29.1$ p. $62 ; 30.2$ p. $63 ; 31.2$ p. $64 ; 48$ p. $103 ; 49$ p. $104 ; 79.3$ p. 172$)$

Aponychus chiavegatoi Feres \& Flechtmann, 1988: 960; Bolland et al., 1998: 19.

Série típica: holótipo ${ }_{+}$, Sítio Jaguari, Jaguariúna, São Paulo, Brasil, 27.IV.1981, ex Citrus sp. (Rutaceae), .L.G. Chiavegato col.; $8+, 10 \hat{\jmath}, 3$ protoninfas, 8 larvas $+7 \hat{\jmath}$ sob via úmida, coletados em 1980 e 1981.

Coleção depositária: MZ-ESALQ.

Etimologia: homenagem a Luiz G. Chiavegato, coletor da espécie.

Hospedeiros ( $\bullet$ novos registros): Citrus sp. (Rutaceae), Hevea brasiliensis $\downarrow$, Manihot $\mathrm{sp}$.

(Euphorbiaceae), Bombacopsis glabra (Bombacaceae), Theobroma cacao (Malvaceae). Distribuição: Brasil (Feres \& Flechtmann, 1988), Colômbia •

\section{Material examinado:}

- holótipo †, Sitio Jaguarí, Jaguariúna, SP, 27.IV.1981, ex Citrus sp. (Rutaceae) L.G. Chiavegato col. (MZLQ A-163); topótipo q Jaguariúna, SP, 21.VIII.1980, L.G. Chiavegato col. (DZSJRP).

- 3q, Departamento de Córdoba, Colômbia, 777B- Cenaga de Oro Burastegui, 25.II.1987, 779B- Monteria Garzon, 25.I.1987, 875 San Carlos, 13.I.1987, J.M. Guerrero col. (DZSJRP) ex Manihot esculenta Crantz (Euphorbiaceae).

- 3, CEIB, Campinas, SP, 12.VI.2008, ex Bombacopsis glabra (Pasq.) Robyns (Bombacaceae) J.L.C. Mineiro col. (DZSJRP).

- 2, Fazenda Frupical, Ituberá, BA, 21.IV.2007, ex Theobroma cacao Linnaeus (Malvaceae) A.R. Oliveira col. (DZSJRP).

\section{Diagnose:}

Essa espécie pode ser facilmente identificada por ser a única do gênero a apresentar a seta histerossomal $c 2$ consideravelmente reduzida $(4-8 \mu \mathrm{m})$, resquicial, e deslocada para a região do prossoma.

\section{Redescrição:}

Fêmea (medidas do holótipo seguidas da variação de 9 fêmeas entre parênteses). Dorso: estilóforo com duas leves projeções arredondadas anteriormente; apenas um ocelo próximo ao tubérculo das setas prodorsais $s c 1$; setas dorsais levemente serreadas, inseridas em proeminentes 
tubérculos, setas escapulares externas e humerais ( $s c 2$ e $c 3)$ com extremidades convergentes; seta $c 2$ fortemente reduzidas, inseridas em nível ligeiramente anterior às setas $c 1$ e $c 3$; setas dorsocentrais com comprimentos equivalentes $(c 1 \approx d 1 \approx e 1)$; idiossoma: comprimento 440 (374-473), largura 352 (264-385); comprimento das setas dorsais: v2 63 (49-68), sc1 33 (27-49), sc2 82 (5782), c1 44 (30-54), c2 5 (4-8), c3 84 (60-87), d1 41 (18-52), d2 68 (54-71), e1 38 (14-46), e2 71 (54-73), fl 54 (24-54), f2 82 (63-82), h1 71 (49-73). Distância entre pares de setas: v2-v2 82 (6090), sc1-sc1 125 (79-144), sc2-sc2 218 (199-234), c1-c1 41 (24-52), c2-c2 163 (133-185), c3-c3 277 (237-326), d1-d1 63 (38-68), d2-d2 245 (207-272), e1-e1 33 (24-41), e2-e2 177 (163-204), f1fl 152 (122-185), f2-f2 125 (95-136), hl-hl 63 (49-76).

Ventre. Comprimento das setas ventrais: $m$ 16, la 16, $l b 30, l c 44,2 b 22,2 c 30,3 a 19,3 b$ 22, $4 a$ 22, $4 b$ 24, ag 19, g1 27, g2 33, ps3 14, h3 24, h2 30. Distância entre pares de setas ventrais: $m-m$ 30, la-la 30, lb-lb 101, lc-lc 122, 2b-2b -, 2c-2c 171, 3a-3a 84, 3b-3b 239, 4a-4a 95, 4b-4b 231, ag-ag 44, g1-g1 22, g2-g2 57, ps3-ps3 22, h3-h3 63, h2-h2 41.

Quetotaxia das pernas (artículos nas pernas I a IV): coxa 2-2-1-1, trocânter 1-1-1-1, fêmur 6-4-2-1, gênu 2-2-0-0, tíbia 4(1)-3-2-2, tarso 7(1assoc.)-8(1)-5(1)-5(1). Setas do par associado presentes no tarso I, mas dissociadas no tarso II; solenídio proximal presente nos tarsos III e IV.

Tabela III. Medidas $(\mu \mathrm{m})$ do corpo e de setas dorsais de espécimes de Aponychus chiavegatoi fêmeas provenientes de diferentes localidades e hospedeiros: Citrus sp., Manihot esculenta, Bombacopsis glabra e Theobroma cacao.

\begin{tabular}{cccccc}
\hline Hospedeiro & $\begin{array}{c}\text { Citrus sp. } \\
\text { Localidade } \\
\text { Jaguariúna, SP. } \\
(\mathrm{n}=2)\end{array}$ & $\begin{array}{c}\text { M. esculenta } \\
\text { Colômbia } \\
(\mathrm{n}=3)\end{array}$ & $\begin{array}{c}\text { B. glabra } \\
\text { Campinas, SP } \\
(\mathrm{n}=3)\end{array}$ & $\begin{array}{c}\text { T. cacao } \\
\text { Ituberá, BA } \\
(\mathrm{n}=2)\end{array}$ & $\begin{array}{c}\text { amplitude geral } \\
(\mathrm{n}=10)\end{array}$ \\
\hline comp.id. & $440-462$ & $374-418$ & $440-473$ & $429-473$ & $374-473$ \\
larg.id. & $352-385$ & $264-286$ & $330-385$ & $319-352$ & $264-385$ \\
$v 2(P 1)$ & $63-68$ & $49-57$ & $63-68$ & $57-57$ & $49-68$ \\
$s c 1(P 2)$ & $33-33$ & $46-49$ & $35-38$ & $27-35$ & $27-49$ \\
$s c 2(\mathrm{P} 3)$ & $79-82$ & $57-65$ & $65-71$ & $71-71$ & $57-82$ \\
$c 3(H)$ & $84-87$ & $60-65$ & $68-76$ & $71-76$ & $60-87$ \\
$c 2(L 1)$ & $5-5$ & $4-7$ & $7-8$ & $5-5$ & $4-8$ \\
$d 2(L 2)$ & $68-68$ & $54-60$ & $60-71$ & $63-71$ & $54-71$ \\
$e 2(L 3)$ & $71-71$ & $54-60$ & $65-68$ & $71-73$ & $54-73$ \\
$f 2(L 4)$ & $82-82$ & $63-68$ & $65-71$ & $79-82$ & $63-82$ \\
$c 1(D 1)$ & $44-52$ & $30-38$ & $52-54$ & $35-49$ & $30-54$ \\
$d 1(D 2)$ & $41-52$ & $18-30$ & $44-52$ & $38-41$ & $18-52$ \\
$e 1(D 3)$ & $38-46$ & $13-19$ & $33-38$ & $24-30$ & $14-46$ \\
$f 1(D 4)$ & $44-54$ & $24-35$ & $38-44$ & $35-44$ & $24-54$ \\
$h 1(D 5)$ & $71-73$ & $49-68$ & $60-73$ & $68-71$ & $49-73$ \\
\hline
\end{tabular}

* = hospedeiro e localidade tipos. 


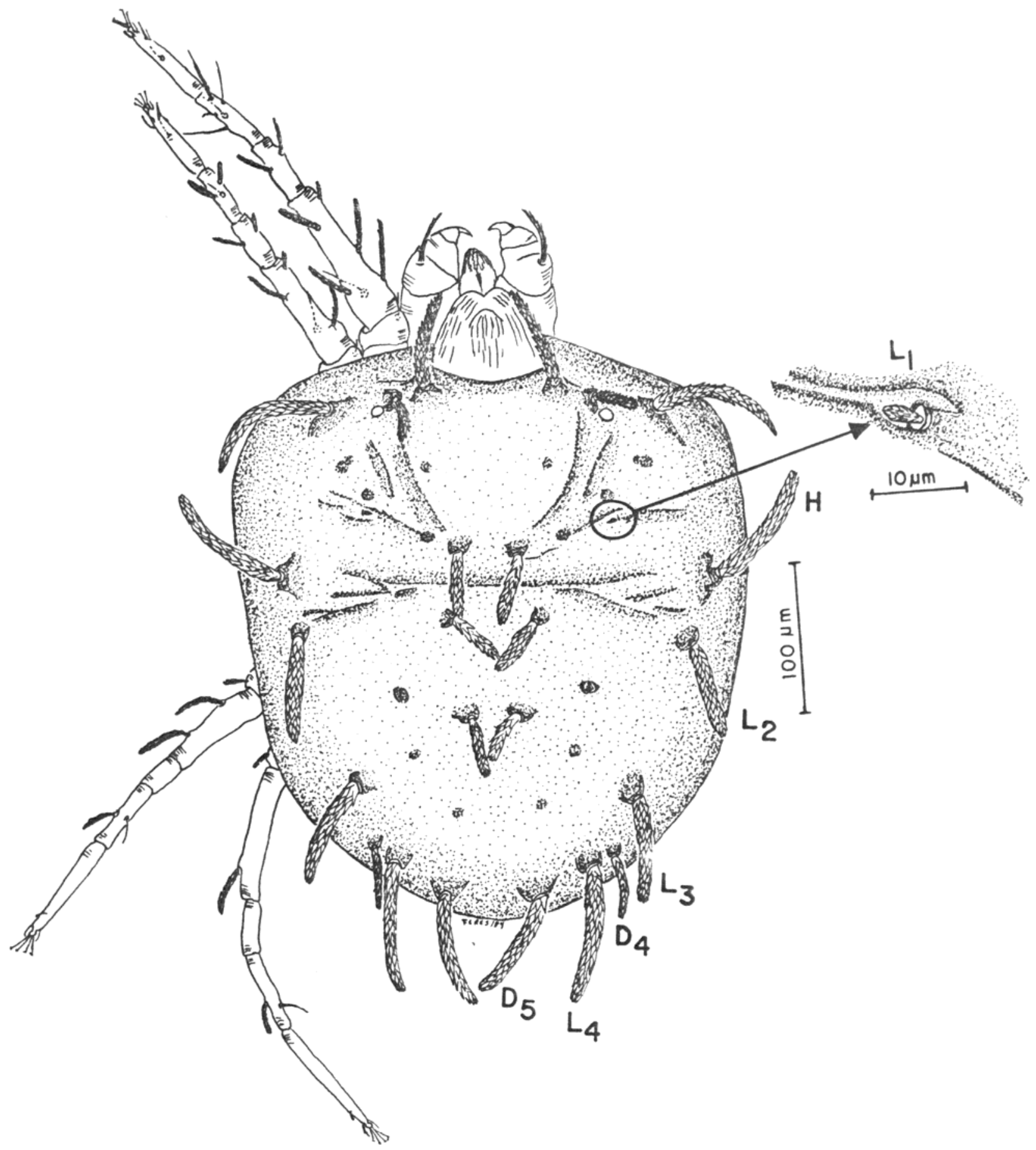

Figura 48. Vista dorsal de Aponychus chiavegatoi, holótipo fêmea (ilustração original). 


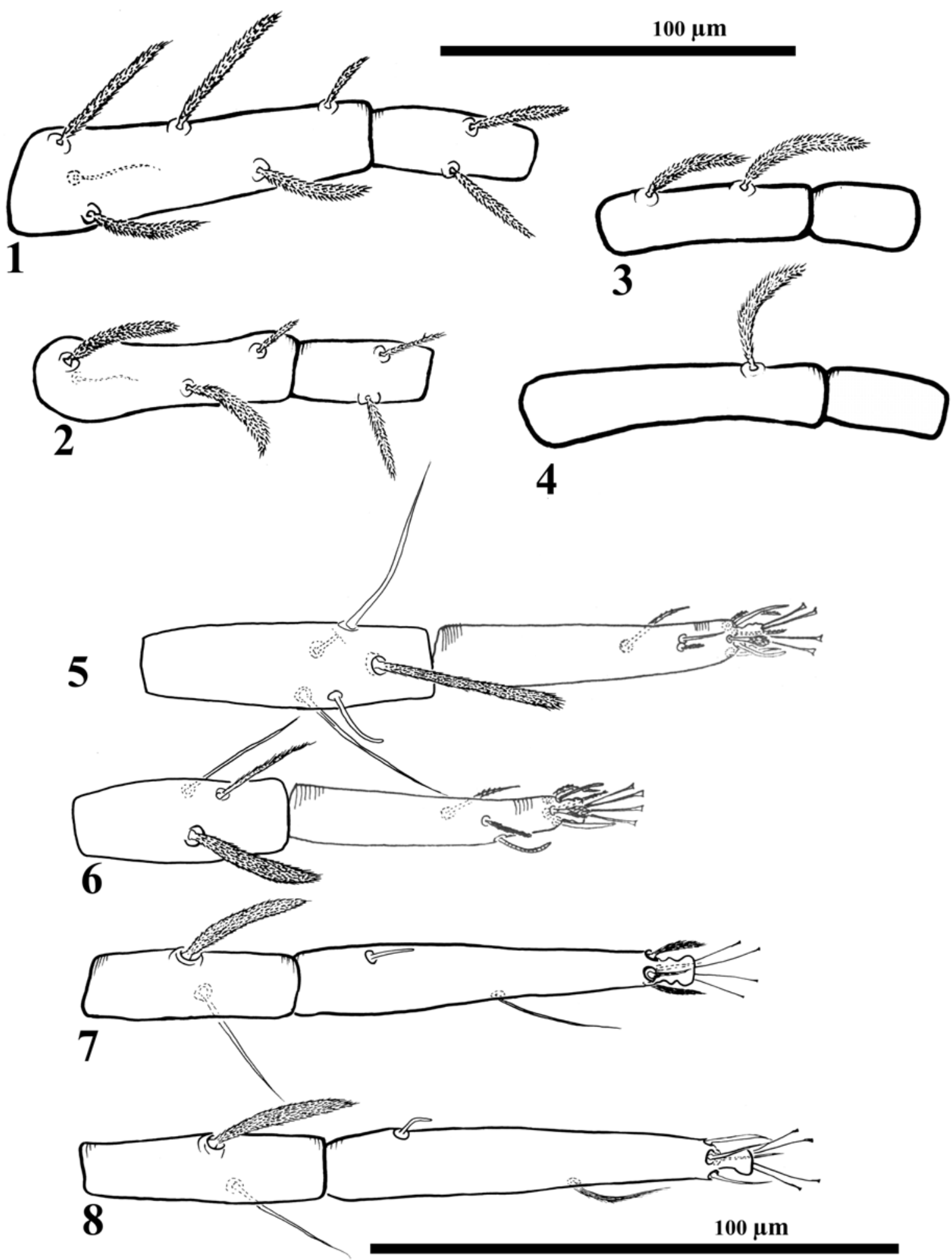

Figura 49. Artículos das pernas I a IV de Aponychus chiavegatoi, holótipo fêmea: fêmur e gênu de I a IV (1-4), tibia e tarso de I a IV (5-8). 


\section{Paraponychus corderoi (Baker \& Pritchard, 1962)}

(Figuras 9.2 p. $45 ; 16.9$ p. $49 ; 17.19$ p. $50 ; 18.22$ p. $51 ; 19.9$ p. $52 ; 20.4$ p. $53 ; 21.3$ p. $54 ; 22.12$ p. $55 ; 23.24$ p. 56 ; 24.20 p. $57 ; 25.10$ p. $58 ; 26.10$ p. $59 ; 27.10$ p. $60 ; 28.12$ p. $61 ; 29.11$ p. $62 ; 30.10$ p. $63 ; 31.9$ p. $64 ; 50$ p. $108 ; 51.1-2$ p. $109 ; 52$ p. $110 ; 81.2-3$ p. 174)

Eutetranychus corderoi Baker \& Pritchard, 1962: 311.

Paraponychus corderoi; Meyer, 1987: 87; Bolland et al., 1998: 148.

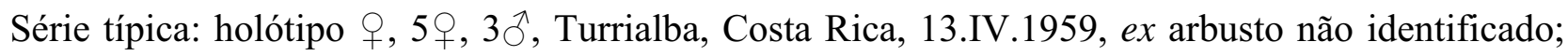
exemplares Nicarágua, 16.IV.1959, ex Hevea sp. (seringueira); San Pedro, Honduras, 30.XI.1958, ex Byttneria aculeata; La Lima, Honduras, 20.VII.1959, ex B. aculeata; Lima, Peru, 30.III.1954, ex Ipomoea batatas.

Coleção depositária: USNM (holótipo e parátipos).

Etimologia: homenagem a Alvaro Cordero (na época, engenheiro do Ministério da Agricultura da Costa Rica).

Hospedeiros: Ipomoea batatas (Convolvulaceae), Sechium edule (Cucurbitaceae), Hevea sp., Ricinus comunis (Euphorbiaceae), Byttneria aculeata (Sterculiaceae) (Baker \& Pritchard, 1962).

Distribuição: Costa Rica, Honduras, Nicarágua, Peru (Baker \& Pritchard, 1962).

\section{Material examinado:}

- holótipo $q$, parátipos 5, , 3ð, Turrialba lab., Costa Rica, 3.IV.1959, ex “large leaf shrub”, E.W. Baker col., C.R.\# 34 (USNM).

Diagnose: essa espécie distingue-se de P. kodaikanalensis por apresentar as setas dorsais de espessura equivalente ao longo do seu comprimento, ao invés de afiladas distalmente como em $P$. kodaikanalensis, e pelo estilóforo arredondado anteriomente (pronunciadas projeções bilobadas presentes em $P$. kodaikanalensis); diferencia-se de $P$. saundersi por apresentar o idiossoma com comprimento e largura equivalentes, enquanto que em $P$. saudersi o idiossoma apresenta-se com quase duas vezes a largura. Adicionalmente, apresenta quetotaxia diferente das pernas: coxa 2-2-11, fêmur 6-4-2-1, gênu 3-3-1-0, tíbia 4(1)-3-2-2, e solenídio proximal presente no tarso III; em $P$. saundersi a quetotaxia apresenta-se: coxa 2-1-1-1, fêmur 6/7-4-3-1, gênu 3-3-1-1, tíbia 5(1)-4-3-3, e solenídio proximal ausente no tarso III.

\section{Redescrição}

Fêmea: dorso (medidas do holótipo seguidas de 5 parátipos entre parênteses): estilóforo 
sem as projeções anteriores; um par de ocelos próximo ao tubérculo das setas prodorsais $s c 1$; setas dorsais levemente serreadas, setas escapulares externas e humerais ( $s c 2$ e $c 3$ ) com extremidades convergentes; seta $c 2$ ausentes; setas dorso-centrais com decréscimo no comprimento relativo ( $c 1$ $>d l>e l)$; idiossoma: comprimento 382 (363-390), largura 350 (327-345); comprimento das setas dorsais (variação nos pares de setas do holótipo seguida da amplitude dos valores para os parátipos entre parênteses): v2 58-67 (60-69), sc1 38-58 (70-80), sc2 72-78 (70-81), c1 36-38 (30-62), c3 6870 (65-79), d1 23-29 (23-40), d2 85-90 (85-105), e1 16-17 (15-24), e2 79-83 (76-90), f1 30-33 (26-39), f2 75-80 (73-97), h1 55-57 (51-68). Distância entre pares de setas: v2-v2 65 (54-63), sc1sc1 112 (109-114), sc2-sc2 204 (190-204), cl-c1 30 (27-30), c3-c3 264 (253-258), dl-d1 38 (3541), d2-d2 231 (209-226), el-e1 19 (19-22), e2-e2 174 (158-169), f1-f1 141 (131-139, f2-f2 109 (98-109), hl-hl 54 (46-54).

Distância entre pares de setas ventrais: $m$ - $m 30$ (24-30), la-la 41 (38-46), lb-lb 84 (79-106), $l c-l c 109$ (101-125), 2b-2b 133 (122-136), 2c-2c 160 (147-170), 3a-3a 71 (76-82), 3b-3b 226 (212220), 4a-4a 82 (79-84), 4b-4b 215 (201-207), ag-ag 38 (30-38), g1-g1 27 (27-33), g2-g2 76 (6065), ps3-ps3 35 (22-24), h3-h3 60 (52-57), h2-h2 27 (24-30).

Quetotaxia das pernas (artículos nas pernas I a IV): coxa 2-2-1-1, trocânter 1-1-1-1, fêmur 6-4-2-1, gênu 3-3-1-0, tíbia 4(1)-3-2-2, tarso 7(1assoc.)-7(1)-5(1)-5(1).

\section{Discussão taxonômica}

Essa espécie foi descrita da Costa Rica sobre uma planta dicotiledônea não identificada (“...sobre un arbusto, Turrialba, Costa Rica...”, Baker \& Pritchard, 1962: 337), sendo que os autores mencionam que foram estudados exemplares coletados sobre três outros hospedeiros nas Américas Central e do Sul: Hevea sp. na Nicarágua, Byttneria aculeata em Honduras e Ipomoea batatas no Peru, todas elas dicotiledôneas. Foram analisados os espécimes-tipo (holótipo e cinco parátipos fêmeas presentes na mesma lâmina) coletados na Costa Rica. Foram encontradas variações no comprimento das setas dorsais entre indivíduos diferentes analisados, inclusive grande variação em um mesmo indivíduo, em setas nos lados esquerdo e direito do corpo (Tabela IV, p. 107). Em algumas setas, verificou-se que elas tinham duas vezes o comprimento do respectivo membro do par no mesmo indivíduo, ou em algumas vezes, em comparação aos demais indivíduos presentes na mesma lâmina.

Como já mencionado e ilustrado por Baker \& Pritchard (1962), exemplares de P. corderoi provenientes de Honduras apresentam diferenças no comprimento de algumas setas dorsais em comparação com os espécimes da Costa Rica (Figura 51, p. 109). Por exemplo, nos primeiros, as setas $h 1$ e as $c 3$ são relativamente mais longas, enquanto que outros pares $(s c 2, c 1, d 1, d 2$ e $e 1)$ são 
mais curtos.

Paraponychus incanus González \& Flechtmann, 1977 foi descrito sobre Ipomoea batatas coletado no Peru. No presente trabalho foram analisados três parátipos fêmea dessa espécie, e as únicas diferenças observadas em relação aos espécimes tipo de $P$. corderoi provenientes da Costa Rica foram que em $P$. incanus as setas dorsais eram relativamente mais curtas e espessas, sendo essas variações já observadas nos espécimes-tipo de $P$. corderoi. Em todos os demais caracteres analisados (e.g. quetotaxia de todos os artículos das pernas, disposição das setas dorso-centrais, formato do estilóforo) as duas espécies mostraram-se idênticas.

Meyer (1987) apresentou uma chave para separação das duas espécies conhecidas do gênero até então ( $P$. incanus e $P$. corderoi), baseando-se no aspecto do tegumento dorsal ilustrado para os espécimes-tipo dessas duas espécies, sendo granulado em $P$. incanus e com fortes estrias transversais em $P$. corderoi. Entretanto, em alguns dos parátipos presentes na mesma lâmina que o holótipo de $P$. corderoi, foi verificada variação no grau de estriação dorsal, sendo mais pronunciado em alguns indivíduos do que em outros. Tendo em vista as variações encontradas em exemplares de $P$. corderoi provenientes de regiões geográficas distintas, e mesmo provenientes da mesma região, adicionado ao fato de $P$. corderoi já ter sido relatado anteriormente sobre Ipomoea batatas no Peru, $P$. incanus deve ser considerada como um sinônimo júnior de $P$. corderoi. Um caráter que contribui para confirmar essa sinonímia é a presença, nas duas espécies, de dois grandes poros na região do histerossoma próximo às setas $c 3$. Além disso, a filogenia (cap. 1) desses grupos indica $P$. corderoi como grupo irmão de $P$. incanus sem nenhuma autapomorfia que sustente cada clado separadamente. O clado $P$. incanus $+P$. corderoi apresenta apenas homoplasias como base de sustentação, o que indica a necessidade de maiores estudos.

Tabela IV. Dimensões corpóreas e das setas dorsais, em micrômetros $(\mu \mathrm{m})$ de espécimes-tipo de Paraponychus.

\begin{tabular}{|c|c|c|c|c|}
\hline & \multicolumn{2}{|c|}{ P. corderoi $(\mathrm{n}=6)$} & \multicolumn{2}{|c|}{ P. incanus $(\mathrm{n}=3)$} \\
\hline & amplitude & média & amplitude & média \\
\hline Comprimento do idiossoma & $363-390$ & 375 & $418-440$ & 433 \\
\hline Largura do idiossoma & $327-350$ & 340 & $352-352$ & 352 \\
\hline$v 2(P 1)$ & $58-69$ & 64 & $63-84$ & 69 \\
\hline$s c 1(P 2)$ & $38-80$ & 69 & $35-54$ & 45 \\
\hline $\operatorname{sc2}(P 3)$ & $70-81$ & 76 & $60-65$ & 63 \\
\hline$c 1(D 1)$ & $30-62$ & 45 & $35-41$ & 37 \\
\hline$c 3(H)$ & $65-79$ & 73 & $63-73$ & 68 \\
\hline$d 1(D 2)$ & $23-40$ & 30 & $19-24$ & 21 \\
\hline$d 2(L 2)$ & $85-105$ & 94 & $57-68$ & 64 \\
\hline e1 (D3) & $15-24$ & 18 & $8-12$ & 10 \\
\hline$e 2(L 3)$ & $76-90$ & 84 & $63-73$ & 66 \\
\hline$f 1(D 4)$ & $26-39$ & 33 & $35-44$ & 40 \\
\hline$f 2(L 4)$ & $73-97$ & 84 & $65-76$ & 70 \\
\hline h1 (D5) & $51-68$ & 60 & $57-63$ & 58 \\
\hline
\end{tabular}




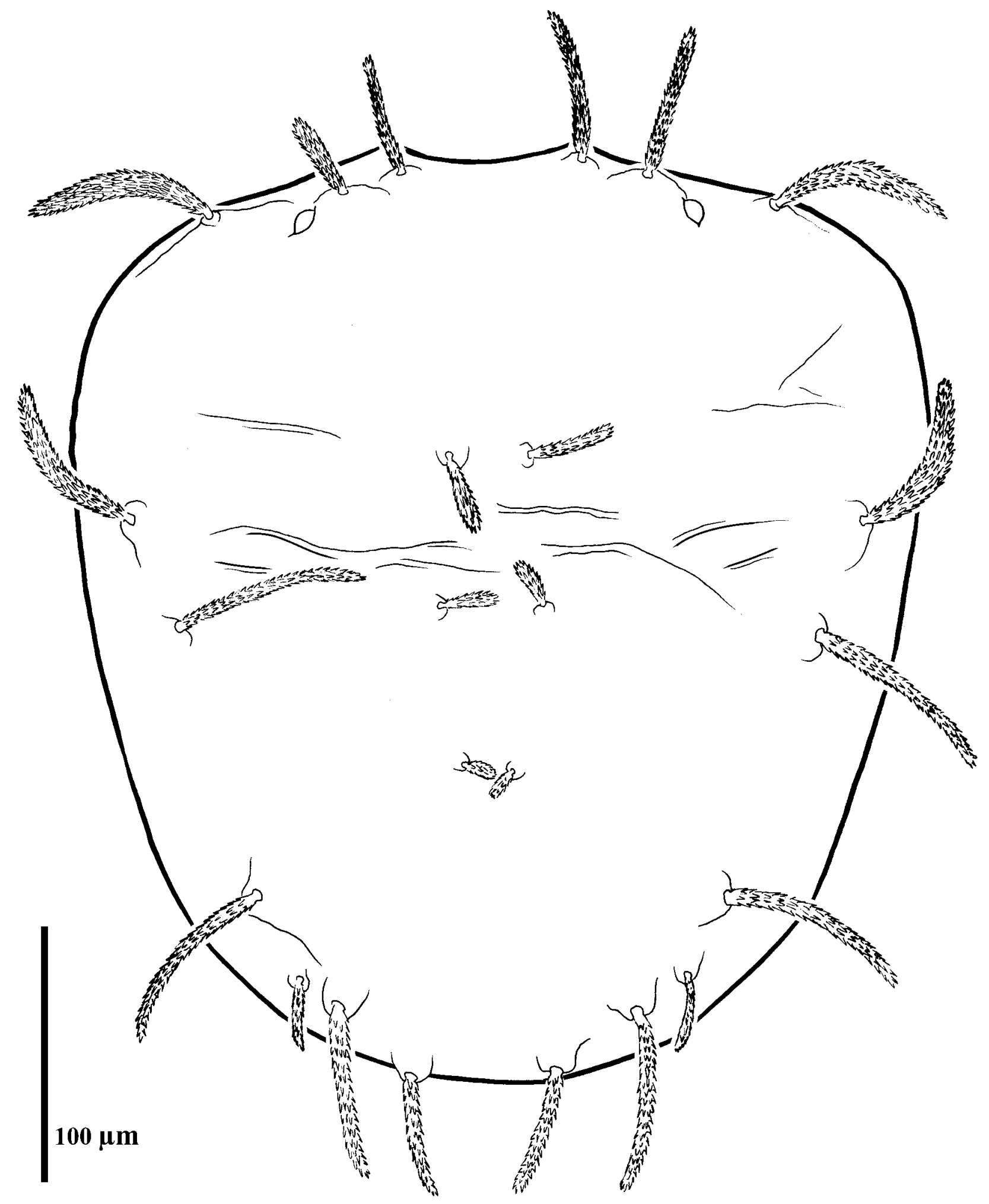

Figura 50. Vista dorsal do idiossoma de Paraponychus corderoi, holótipo fêmea. 

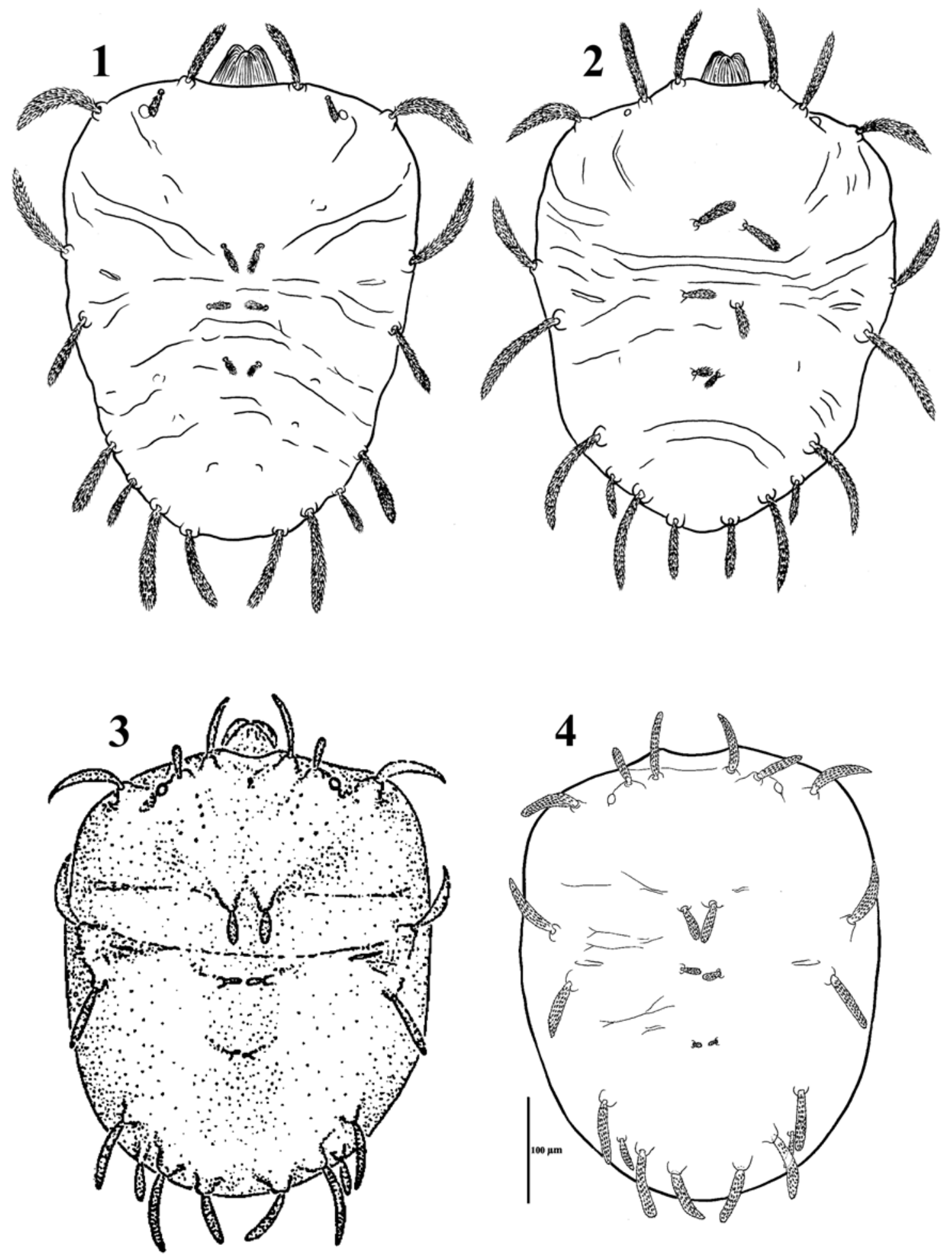

Figura 51. Vista dorsal de espécimes de Paraponychus, fêmeas: P. corderoi, coletado em Honduras (1), Costa Rica (2) (1-2, redesenhados a partir de Baker \& Pritchard [1962]); P. incanus, holótipo (3 - ilustração original), e parátipo (4). 


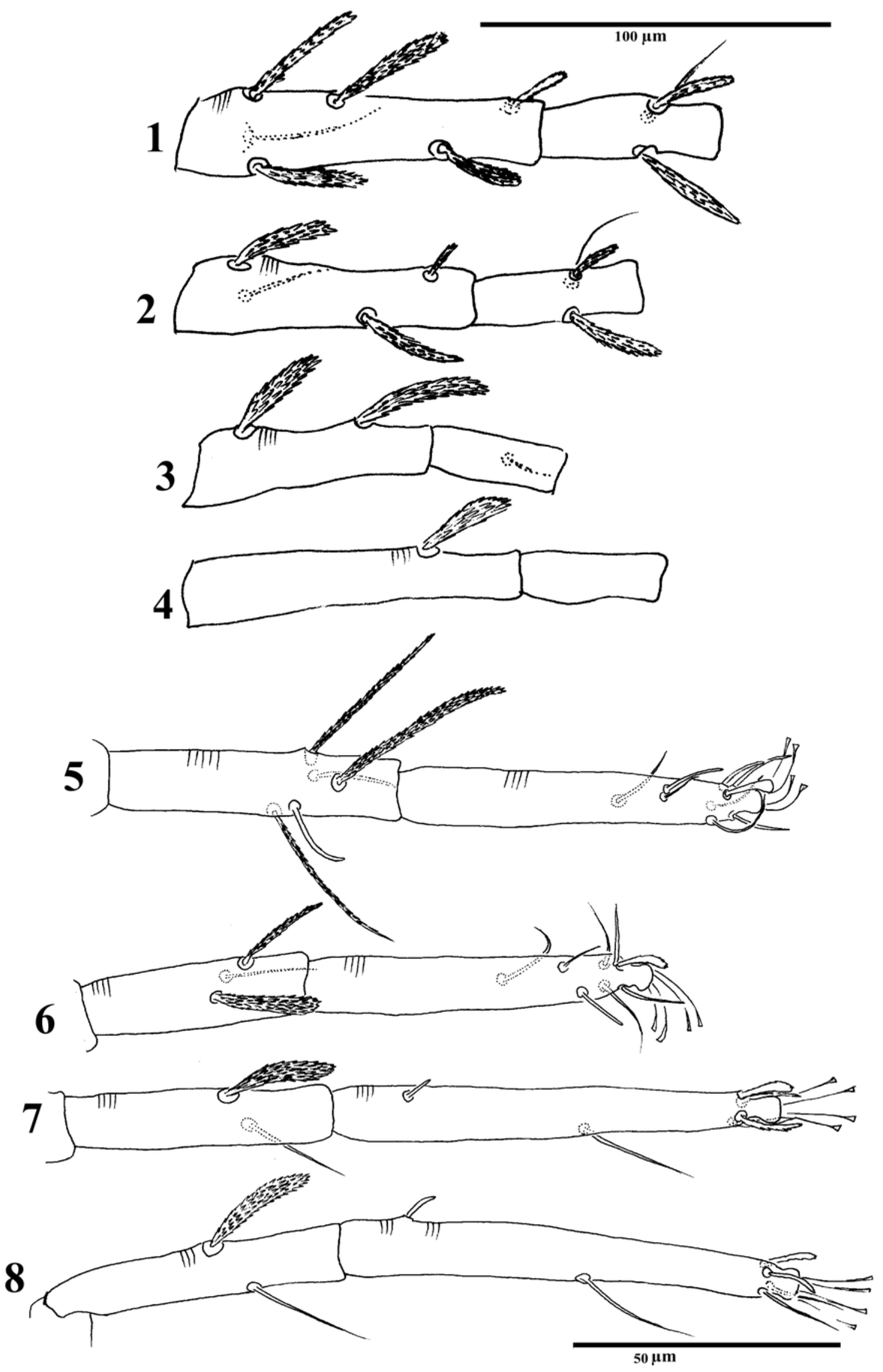

Figura 52. Artículos das pernas de Paraponychus corderoi, holótipo fêmea: fêmur e gênu das pernas de I a IV (1-4); tíbia e tarso de I a IV (5-8). 


\section{Paraponychus incanus González \& Flechtmann}

(Figuras 16.14 p. $49 ; 17.21$ p. $50 ; 18.24$ p. $51 ; 19.15$ p. 52; 20.9 p. $53 ; 21.9$ p. $54 ; 22.14$ p. $55 ; 23.25$ p. $56 ; 24.21$ p. 57 ; 26.13 p. $59 ; 27.14$ p. $60 ; 28.13$ p. $61 ; 30.11$ p. $63 ; 51.3-4$ p. $109 ; 81.4$ p. 174$)$

Paraponychus incanus González \& Flechtmann, 1977: 67; Bolland et al., 1998: 148.

Série típica: holótipo , parátipos 5, 2へ, Lima, Peru, 1974, ex Ipomoea batatas (Linnaeus) Lam. (Convolvulaceae), L. Castilho col.

Coleção depositária: MZ-ESALQ (holótipo e parátipos).

Etimologia: referência à extinta civilização Inca, onde hoje é o Peru.

Hospedeiro: Ipomoea batatas (Convolvulaceae).

Distribuição: Peru (González \& Flechtmann, 1977).

\section{Material examinado:}

- parátipos 3 9, Lima, Peru, 1974, ex Ipomoea batatas Lam., L. Castilho col. (MZ-ESALQ n.853).

Apesar de Paraponychus incanus ser a espécie tipo do gênero, por designação original, concluímos se tratar de um sinônimo júnior de $P$. corderoi. Ver discussão taxonômica na página 106 e ilustrações (Figura 50 e 51, p. 108-109). 


\section{Aponychus aequilibris Tseng}

(Figuras 24.5 p. 57 ; $53.1-5$ p. 114)

Aponychus aequilibris Tseng, 1990: 33; Bolland et al., 1998: 19.

Série típica: holótipo + , parátipos 2, Kuantsuling, Tainan Hsien, Taiwan, 31.X.1984, ex Phyllostachys makinoi Hayata (Poaceae).

Coleção depositária: Particular do autor.

Etimologia: desconhecida.

Hospedeiro: Phyllostachys makinoi (Poaceae) (Tseng, 1990).

Distribuição: Taiwan (Tseng, 1990).

Obs.: macho desconhecido.

Essa espécie provavelmente constitui um sinônimo júnior de A. corpuzae. Entretanto, não foi possível concluir definitivamente essa hipótese, pois não foi obtido sucesso no contato com o autor a fim de solicitar empréstimo de material tipo dessa espécie.

Tseng (1990: 33) diferencia A. aequilibris de A. corpuzae com base em sutis diferenças que, a exemplo do que foi observado em outras espécies, podem estar presentes em indivíduos provenientes de diferentes localidades ou até mesmo da mesma população:

"Fitting very closely to corpuzae Rimando by the shape of dorsal setae on idiosoma and shape of body. Differing by having L4 [f1] as long as dorsocentral setae; tarsus 1 with far distant duplex setae, of which proximal tactile setae is longer than distal sensory seta".

Entretanto, essa primeira característica, seta $f 1$ com o mesmo comprimento das dorso centrais, foi verificada em exemplar parátipo analisado de $A$. corpuzae. Com relação à segunda característica, que é um caráter importante utilizado para a classificação de gêneros da tribo Tetranychini, mas não dos Eurytetranychini, é importante mencionar que essas setas apresentam conformação distinta nos representantes dessa última tribo (Figura 5.2, p. 9), com a seta quimiossensorial distal bastante reduzida. Além disso, Ho (2003) sintetizou informações encontradas na literatura que mencionam diferenças no número de setas nos tarsos I e II em indivíduos de A. corpuzae provenientes de diferentes localidades. Em alguns espécimes coletados na China (Ho, 2003) foi reportada ainda que as setas associadas podem estar ausentes.

Outro aspecto que merece ser destacado é que A. corpuzae já foi registrada sobre uma 
grande variedade de hospedeiros e localidades na Ásia (Rimando, 1966, Ehara, 1969; Gupta, 1976), incluindo plantas do mesmo gênero e localidade na qual A. aequilibris foi descrita (Phyllostachis em Taiwan). Essa última espécie apresenta um número extremamente pequeno de exemplares conhecidos e analisados (apenas 3 fêmeas, nenhum macho ou outro estágio), sendo que essa espécie não foi mais coletada após sua descrição. Em outras espécies de Aponychus e gêneros afins, como em A. grandidieri, A. schultzi, Paraponychus corderoi e Stylophoronychus vannus, entre outros, foram observadas variações morfológicas em indivíduos provenientes de diferentes localidades, ou mesmo entre indivíduos da mesma população, quanto ao comprimento e formato de algumas setas dorsais, e também quanto ao número de setas presentes nos artículos das pernas.

Não foi possível a análise de espécimes-tipo de A. aequilibris, presumivelmente em posse do autor da espécie (Tseng, 1990: 4). O Dr. Yi-Hsiung Tseng, que já produziu importantes monografias sobre diversos grupos de ácaros de Taiwan, como Bdellidae, Stigmaeidae e Tetranychidae, entre outros (Tseng, 1978, 1982, 1990), não mais se encontra atuante no campo da taxonomia acarológica (S. Kreiter, comunicação pessoal), o que dificulta o seu contato e, consequentemente, o acesso aos espécimes tipo descritos por aquele autor.

Portanto, tendo em vista a grande variação morfotípica já encontrada em $A$. corpuzae, juntamente com o pequeno número de exemplares conhecidos de A. aequilibris, julgamos que essa última espécie deva ser considerada como um sinônimo júnior de A. corpuzae, ou como species inquirenda, até que novos exemplares sejam coletados e analisados, e encontradas diferenças que justifiquem sua validade. 

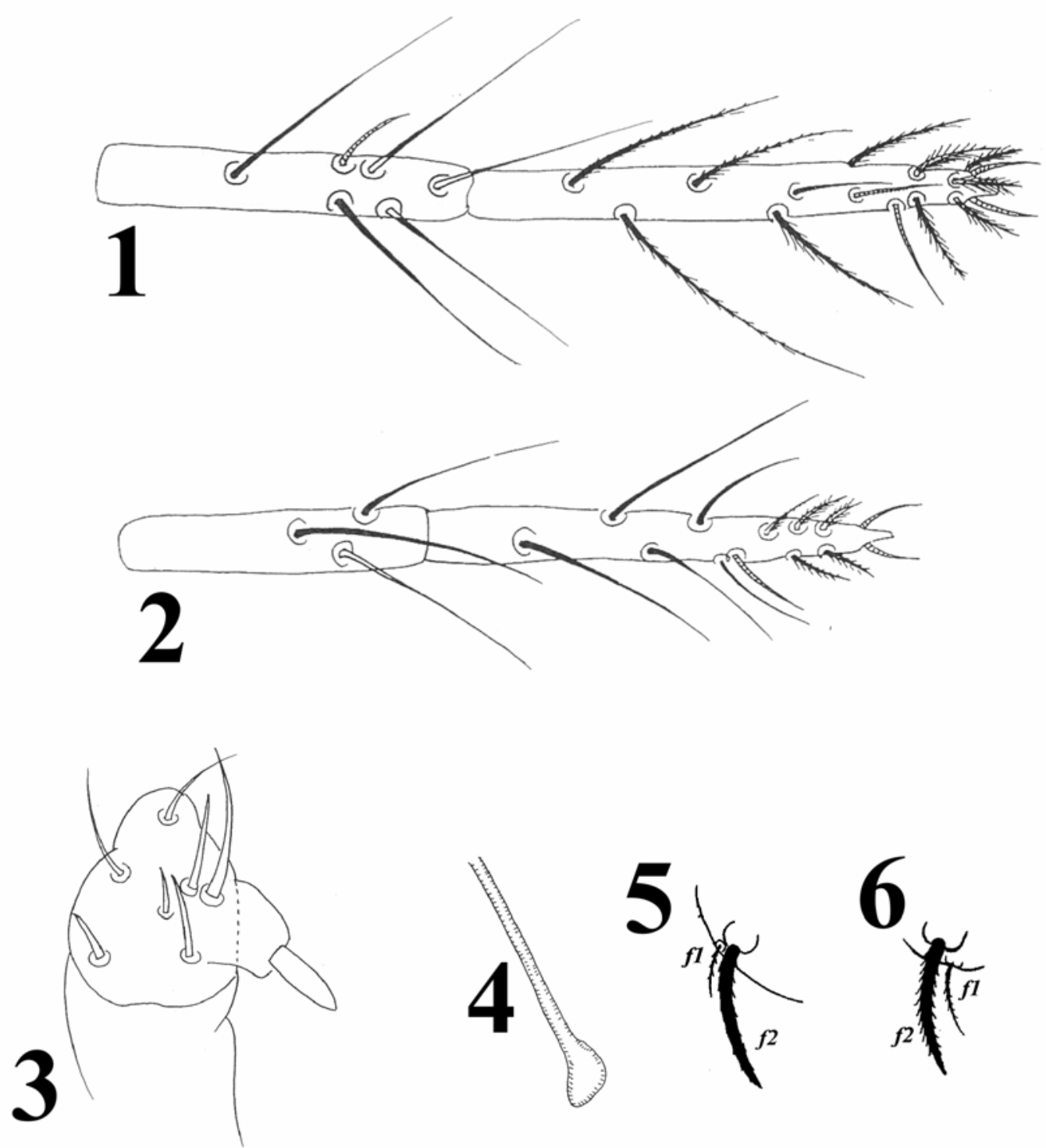

Figura 53. Aponychus aequilibris Tseng: tíbia e tarso I de fêmea (1) e macho (2); palpo (3) e peritrema (4) de fêmea; setas $f 1$ e $f 2$ de fêmeas de A. aequilibris (5) e A. corpuzae (6) [retirado de Tseng (1990)]. 


\section{Aponychus corpuzae Rimando}

(Figuras 10.2 p. $45 ; 14.1$ p. $47 ; 15$ p. $48 ; 16.2$ p. $49 ; 17.5$ p. $50 ; 18.1$ p. $51 ; 19.1$ p. $52 ; 20.3$ p. $53 ; 21.4$ p. 54 ; 22.3 p. $55 ; 23.3$ p. $56 ; 24.6$ p. $57 ; 25.11$ p. $58 ; 26.9$ p. $59 ; 27.11$ p. $60 ; 28.2$ p. $61 ; 29.2$ p. $62 ; 53.6$ p. $114 ; 54$ p. $117 ; 55$ p. $118 ; 79.1-2$ p.172)

Aponychus corpuzae Rimando, 1966: 107; Rimando, 1968: 7; Ehara, 1969: 87; Meyer, 1974: 156; Ehara \& Wongsiri, 1975: 152; Gupta, 1976: 332; Gupta, 1984: 238; Ma et al., 1984: 112; Gupta, 1985: 59; Tseng, 1990: 34; Gupta, 1992: 79; Gupta \& Gupta, 1994: 41; Rimando \& Corpuz-Raros, 1996: 12; Bolland et al., 1998: 19; Ehara, 1999: 78; Ho, 2003: 347. Aponychus (Stylophoronychus) corpuzae; Prasad, 1975a: 1; Johnston \& Flechtmann, 1990: 247.

Série típica: holótipo + , parátipos $7 \widehat{\jmath}$ e $7+$, Mt. Maquiling, Laguna, Filipinas, 23.III.1963, ex Shizostachyum lima (Blanco) Merr. (Poaceae).

Coleção depositária: UPLB (holótipo e parátipos) e USNM (parátipos).

Etimologia: homenagem a Leonilla Corpuz-Raros, acaróloga filipina.

Hospedeiros: Arundinaria ciliata, Bambusa sp., B. arundinacea, B. beecheyana, B. spinosa, B. stenostachya, B. vulgaris, B. tulda, B. vulgaris, Bambuseae sp., Oryza sativa, Saccharum spontaneum, Schizostachyum lima, Sasa purpurescens, Sasa senanensis, Thyrsostachys siamensis (Poaceae), Pyrus communis, Fragraria sp. (Rosaceae), Syzygium aqueum (Myrtaceae), Feronia limonia (Rutaceae).

Distribuição: China, Coréia do Sul, Filipinas, Hainan, Índia, Indonésia, Japão, Malásia, Taiwan, Tailândia.

Aponychus corpuzae é a espécie-tipo do gênero Aponychus, e dentre as demais espécies desse gênero, é uma das que já foram relatadas sobre o maior número de espécies de hospedeiros (20), sendo a maioria delas (16) monocotiledôneas da família Poaceae. É também a espécie registrada no maior número de localidades, todas elas na Ásia (9 países), já sendo, inclusive, reportada como praga de bambu (Zhang et al., 2000b).

\section{Material examinado:}

- 2 parátipos ․ Mt. Makiling, Laguna, Filipinas, 23.IV.1963, ex Schizostachyum lima (Blanco) Merr. (Poaceae) (USNM).

- 29, Gambung, Java, Indonesia, 13.III.1988, ex bambu amarelo ornamental, D.E. Johnston col. (DZSJRP).

-39, Sarapee, Tailândia, 5.XI.1970, ex folha de bambu, S. Ehara col. (SH). 
Diagnose: $A$. corpuzae assemelha-se a A. siamensis por apresentar as setas dorsais da região central do idiossoma ( $s c 1, c 1, c 2, d 1, d 2$ e $e 1)$ bastante reduzidas, não dilatadas, de comprimento pelo menos $1 / 3$ o das setas da região marginal do idiossoma. Pode ser separada por apresentar a seta caudal $f 1$ reduzida em relação às demais setas caudais $(e 2, f 2$ e $h l)$.

\section{Redescrição:}

Fêmea ( $\mathrm{n}=11$, inclui medidas de 5 fêmeas obtidas em Ho [2003]). Dorso. Estilóforo com duas fortes projeções anteriormente; dois ocelos próximos ao tubérculo das setas prodorsais $s c 1$, lente posterior resquicial em alguns espécimes; pronunciadas estrias preponderantemente transversais na região central do dorso; setas dorsais levemente serreadas, setas escapulares externas e humerais ( $s c 2$ e $c 3$ ) com extremidades convergentes; setas $c 2$ e $c 1$ de comprimentos equivalentes; setas dorso-centrais com comprimentos equivalentes $(c l \approx d l \approx e l)$; idiossoma: comprimento 330-452, largura 220-413; comprimento das setas dorsais: $v 2$ 30-53, sc1 14-22, sc2 49-76, c1 11-26, c2 14-25, c3 49-90, d1 14-23, d2 16-32, e1 14-28, e2 34-61, f1 18-28, f2 38-65, h1 49-90. Distância entre pares de setas dorsais: v2-v2 54-63, sc1-sc1 84-95, sc2-sc2 204-226, c1c1 35-49, c2-c2 106-128, c3-c3 199-248, d1-d1 63-79, d2-d2 131-163, el-el 60-65, e2-e2 131150,fl-fl 82-112, f2-f2 98-120, h1-h1 46-52.

Ventre. Comprimento das setas ventrais: $m$ 22-24, la 14-19, lb 38-46, lc 49-52, $2 b$ 35-41, 2c 52-54, $3 a$ 14-16, 3b 54-57, 4a 11-14, 4b 41-49, ag 14-14, g1 27-30, g2 27-30, ps3 11-14, h3 2227, h2 19-22. Distância entre pares de setas ventrais: $m-m$ 30-35, la-la 24-27, $l b-l b$ 95-109, $l c-l c$ 122-136, $2 b-2 b$ 155-173, $2 c-2 c$ 177-190, 3a-3a 33-46, 3b-3b 199-231, 4a-4a 46-54, 4b-4b 185215, ag-ag 27-31, g1-g1 24-31, g2-g2 35-52, ps3-ps3 19-26, h3-h3 38-54, h2-h2 16-30.

Quetotaxia das pernas (artículos nas pernas I a IV): coxa 2-2-1-1, trocânter 1-1-1-1, fêmur 7-5-4-2, gênu 3-3-2-2, tíbia 5(1)-3-2-2, tarso 7(1assoc.)-7(1assoc.)-8(1)-8(1). Setas do par associado presentes nos tarsos I e II; solenídio proximal presente nos tarsos III e IV. 


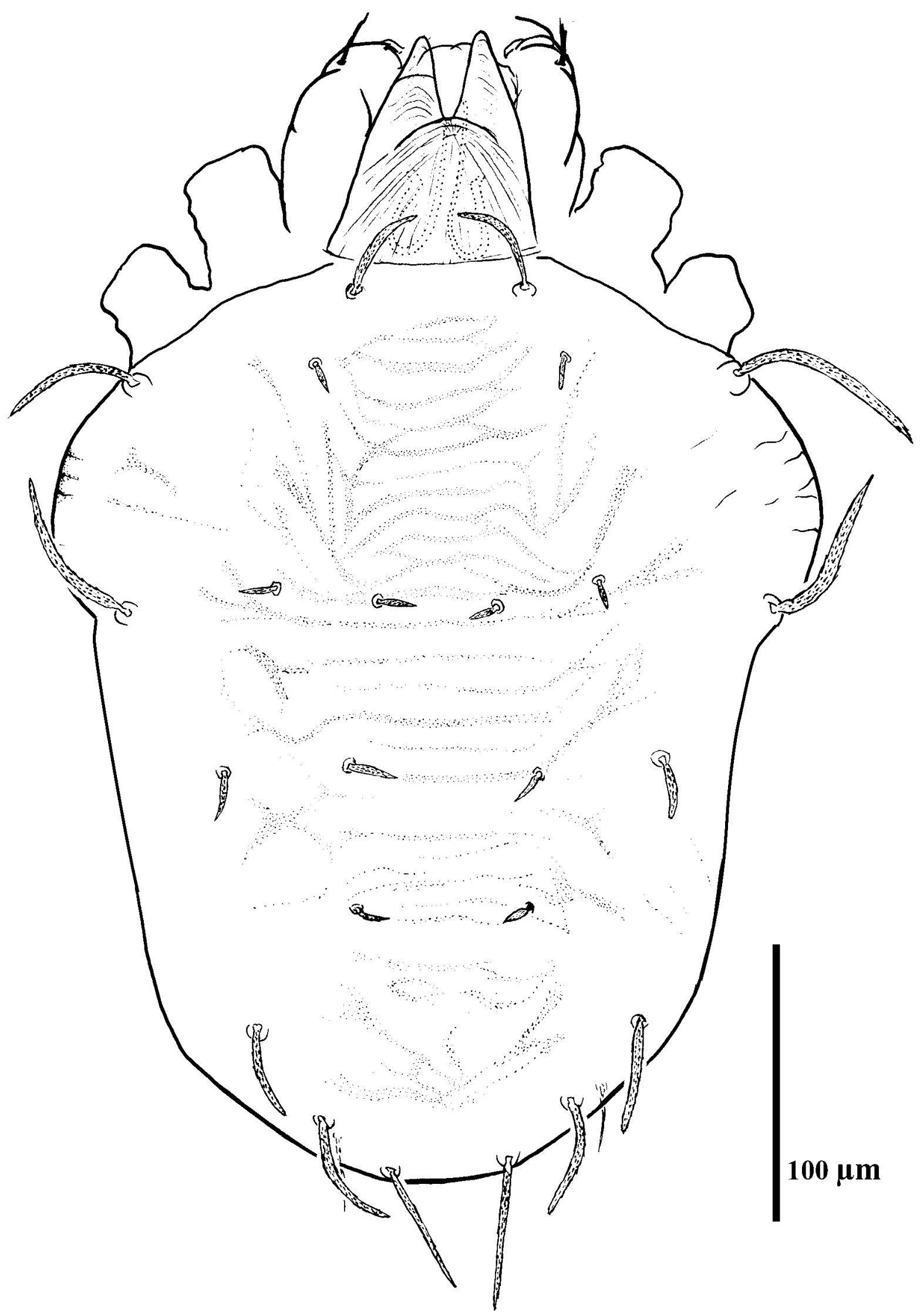

Figura 54. Vista dorsal de Aponychus corpuzae, parátipo fêmea. 

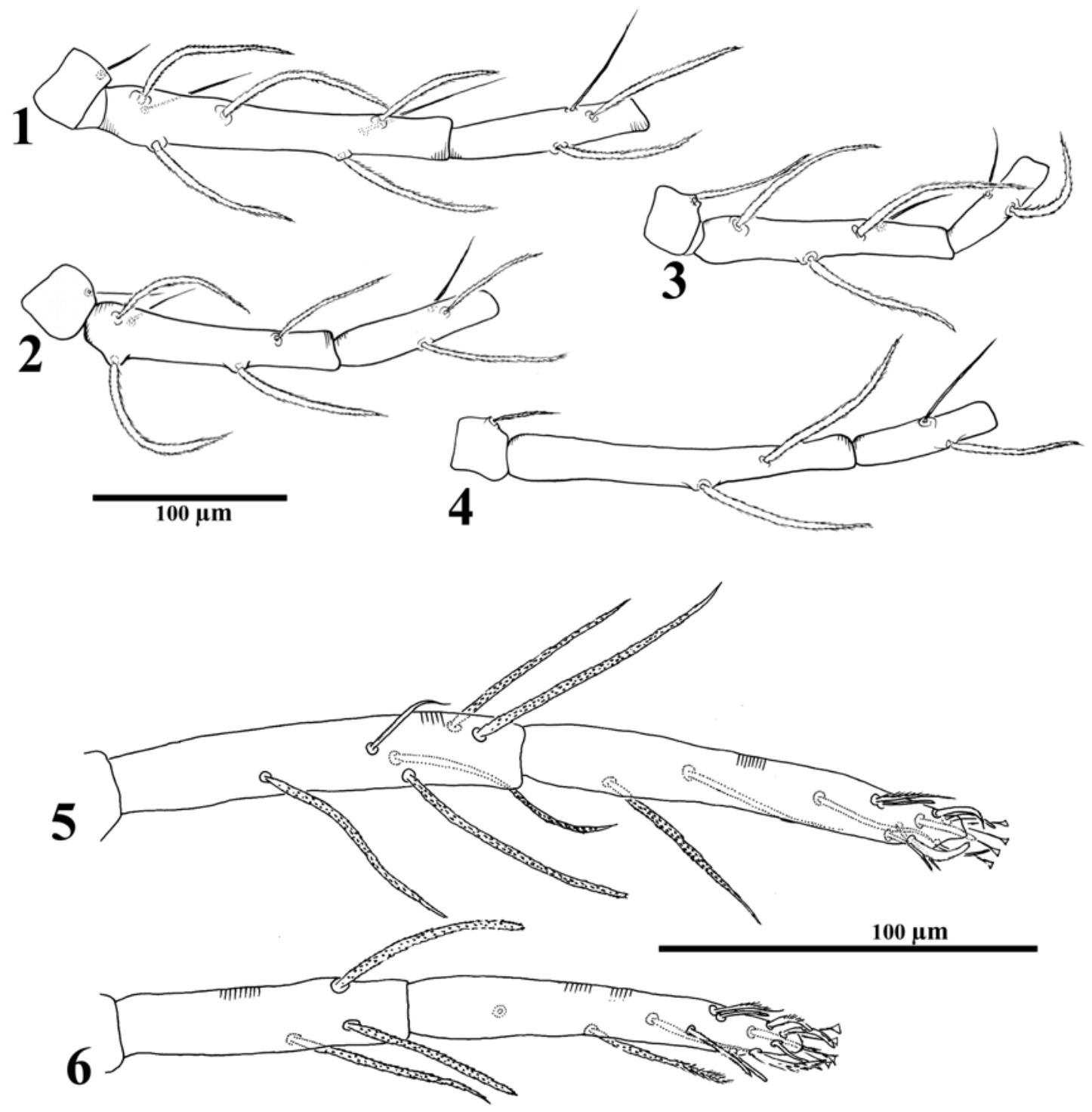

Figura 55. Artículos das pernas I a IV de Aponychus corpuzae, fêmea: trocânter, fêmur e gênu de I a IV (1-4), tibia e tarso I e II (5-6). 


\section{Aponychus siamensis Ehara \& Wongsiri}

(Figuras 16.21 p. $49 ; 17.14$ p. $50 ; 18.3$ p. 51; 19.24 p. 52; 20.16 p. $53 ; 21.15$ p. 54; 22.9 p. $55 ; 23.9$ p. 56; 24.16 p. 57 ; 25.16 p. $58 ; 26.16$ p. $59 ; 27.17$ p. $60 ; 28.10$ p. $61 ; 29.9$ p. $62 ; 56$ p. $121 ; 57$ p. $122 ; 80.6$ p. 173$)$

Aponychus siamensis Ehara \& Wongsiri, 1975: 151; Bolland et al., 1998: 21.

Série típica: holótipo q, parátipos 5q, Mt. Doi Chiang, Tailândia, 02.XI.1970, ex Bambuseae, S. Ehara col.

Coleção depositária: NSMJ.

Etimologia: provavelmente referente a Siam, antigo nome dado à república da Tailândia até 1939, onde foi coletada essa espécie.

Hospedeiro: bambú (Poaceae).

Distribuição: Tailândia (Ehara \& Wongsiri, 1975).

Obs: macho desconhecido.

\section{Material examinado:}

- holótipo 9 e 3 parátipos $q$, Doi Cheng Dao, 2.XI.1970, ex bambu, S. Ehara col.

Diagnose: esta espécie assemelha-se a $A$. corpuzae por apresentar as setas dorsais da região central do idiossoma ( $s c 1, c 1, c 2, d 1, d 2$ e $e 1)$ bastante reduzidas, de comprimento pelo menos $1 / 3$ o das setas da região marginal do idiossoma. Pode ser separada por apresentar a seta caudal $f 1$ de comprimento e espessura equivalente às demais setas caudais (e2, $f 2$ e $h 1)$; em A. corpuzae, essa seta é bastante afilada e reduzida.

\section{Redescrição:}

Fêmea holótipo $(n=1)$ Dorso. Estilóforo com duas fortes projeções anteriormente; setas dorsais levemente serreadas, apenas setas da região marginal do idiossoma ( $v 2, s c 2, c 3, e 2, f 1, f 2$, h1) inseridas em fortes tubérculos, setas escapulares externas e humerais ( $s c 2$ e $c 3$ ) com extremidades convergentes; setas $c 2$ e $c 1$ de comprimentos equivalentes; setas dorso-centrais com comprimentos equivalentes $(c 1 \approx d 1 \approx e 1)$; idiossoma: comprimento 473, largura 297; comprimento das setas dorsais: $v 2$ 24, sc1 8, sc2 63, c1 11, c2 8, c3 60,d1 11, d2 16, e1 14, e2 44, $f 1$ 44, f2 52, h1 54. Distância entre pares de setas dorsais: v2-v2 71, sc1-sc1 109, sc2-sc2 231, c1c1 38, c2-c2 131, c3-c3 245, d1-d1 41, d2-d2 163, e1-e1 22, e2-e2 131,fl-f1 106,f2-f2 63, h1-hl 33.

Ventre. Comprimento das setas ventrais: $m$-, la 16, $l b 27, l c 44,2 b 22,3 a 14,3 b 27,4 a 16$, 4b 27, ag 14, g1 27, g2 33, ps3 14, h3 27, h2 19. Distância entre pares de setas ventrais: $m$-m -, la- 
la 35, lb-lb 95, lc-lc 117, 2b-2b 163, 3a-3a 68, 3b-3b 201, 4a-4a 57, 4b-4b 193, ag-ag 27, g1-gl 30, g2-g2 65, ps3-ps3 27, h3-h3 65, h2-h2 38.

Quetotaxia das pernas (artículos nas pernas I a IV): coxa 2-1-1-1, trocânter 1-1-1-1, fêmur 6-4-3-1, gênu 3-3-1-1, tíbia 5(1)-4-3-3, tarso 11(1assoc.)-10-7(1)-7(1). Solenídio proximal presente nos tarsos III e IV. 


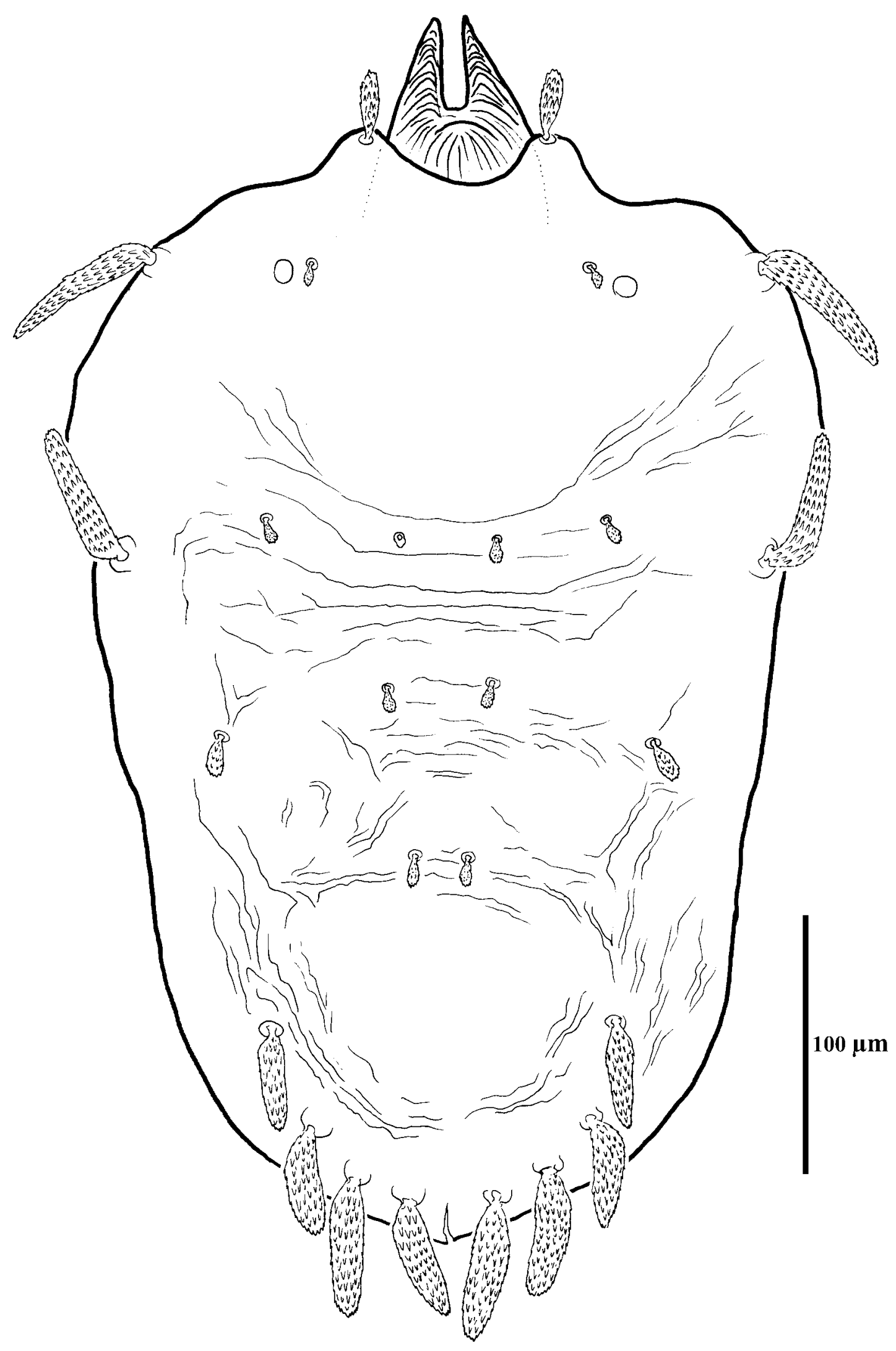

Figura 56. Vista dorsal de Aponychus siamensis, holótipo fêmea. 

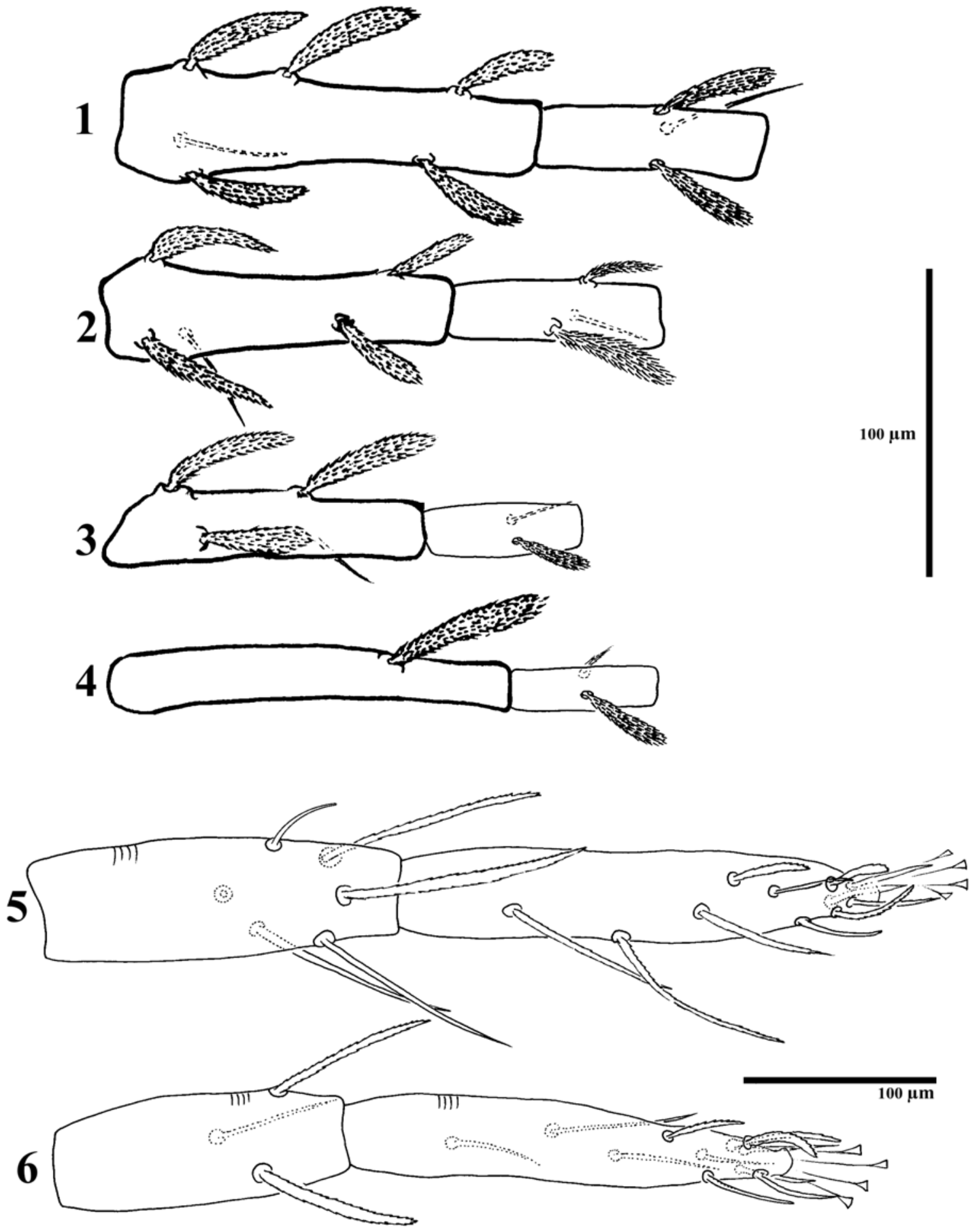

Figura 57. Artículos das pernas de Aponychus siamensis, holótipo fêmea: fêmur e gênu das pernas de I a IV (1-4); tíbias I e II (5-6). 


\section{Aponychus expansus Chaudhri}

(Figuras 16.10 p. $49 ; 17.6$ p. 50; 18.12 p. $51 ; 19.11$ p. 52; 20.5 p. $53 ; 21.5$ p. $54 ; 22.4$ p. $55 ; 23.4$ p. $56 ; 24.7$ p. 57 ; 25.12 p. $58 ; 26.11$ p. $59 ; 27.12$ p. $60 ; 28.3$ p. $61 ; 29.3$ p. $62 ; 30.3$ p. $63 ; 31.3$ p. $64 ; 58$ p. $124 ; 67.5-6$ p. $144 ; 79.4$ p.

Aponychus expansus Chaudhri, 1972: 166; Bolland et al., 1998: 20.

Aponychus (Stylophoronychus) expansus; Prasad, 1975a: 1.

Série típica: holótipo,+ 2 milhas a oeste de Choa Saiden Shah, Paquistão, 7.IX.1971, ex Acacia arabica; parátipos 3 , Hasanabdal, Paquistão, 08.VIII.1971, ex Arundo donax.

Coleção depositária: UAL (holótipo e parátipos), USNM (parátipo ㅇ).

Etimologia: possivelmente devido a sutis expansões laterais no prodorso, entre as setas $s c 2$ e $c 3$.

Hospedeiros: Arundo donax Linnaeus (Poaceae), Acacia arabica (Lam.) Willd. (Fabaceae).

Distribuição: Paquistão (Chaudhri, 1972).

Obs.: macho desconhecido.

\section{Material examinado:}

- parátipo q, Hassan Abdal, Paquistão, 8.VIII.1971, ex Arundo donax, W.M. Chaudhri col. (USNM).

Essa espécie provavelmente constitui um sinônimo júnior de A. rarus (ver discussão taxonômica na página 140). 


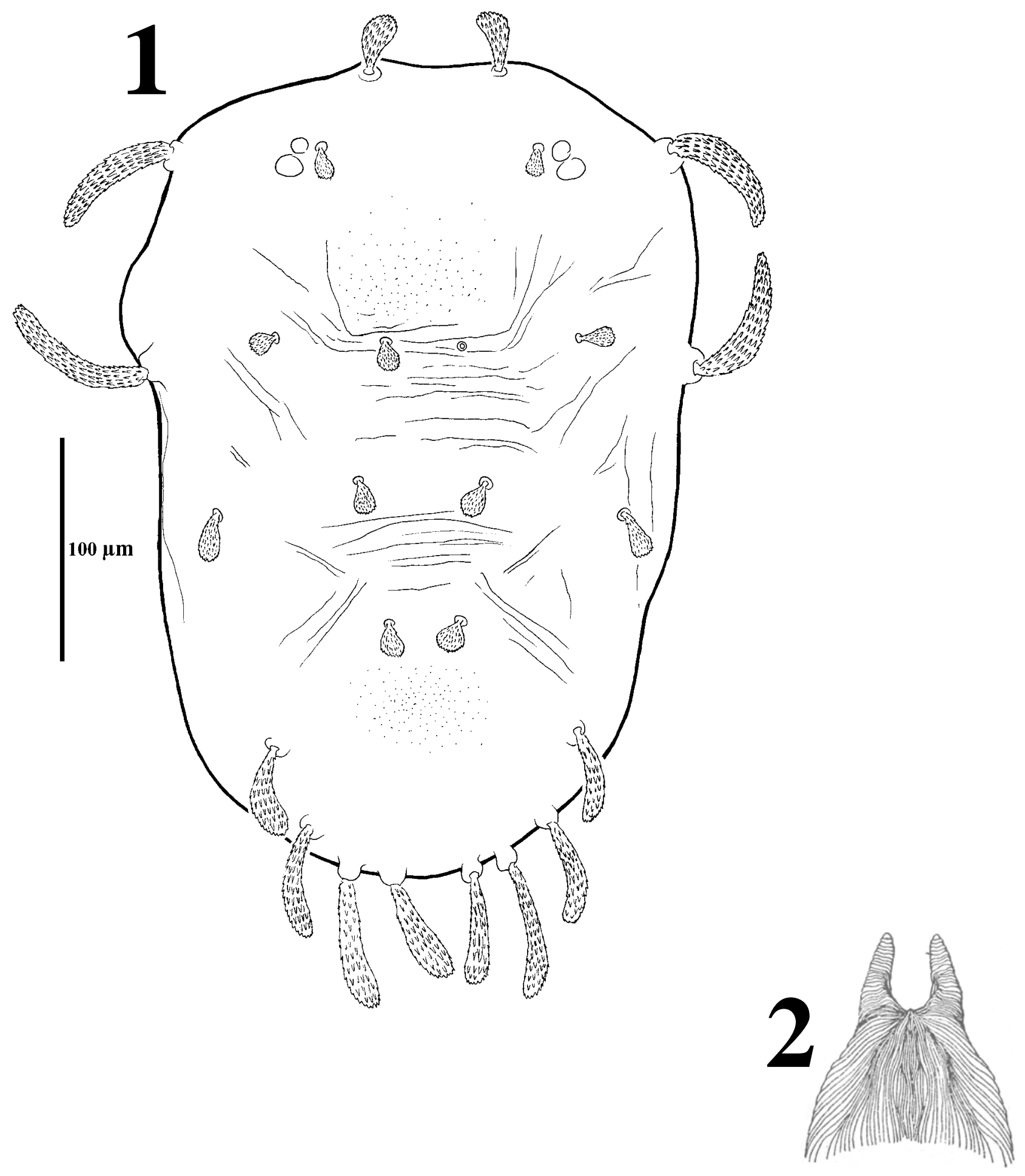

Figura 58. Aponychus expansus, parátipo fêmea: vista dorsal do idiossoma (1) e estilófor (2). 


\section{Aponychus grandidieri (Gutierrez)}

(Figuras 16.12 p. $49 ; 17.7$ p. $50 ; 18.13$ p. $51 ; 19.13$ p. 52; 20.7 p. $53 ; 21.7$ p. $54 ; 22.5$ p. $55 ; 23.5$ p. $56 ; 24.9$ p. $57 ; 28.5$ p. $61 ; 59$ p $126 ; 60$ p. $127 ; 67.1-2$ p. $144 ; 79.6$ p. 172)

Eutetranychus grandidieri Gutierrez, 1966: 597.

Aponychus grandidieri; Meyer, 1974: 156; Rimando \& Corpuz-Raros, 1996: 12; Bolland et al., 1998: 20.

Chinotetranychus grandidieri; Meyer, 1987: 87.

Série típica: holótipo $\widehat{\jmath}, 17 \widehat{\jmath}, 15 q$ parátipos, Faratsiho, Província de Antananarivo, 1.700m, Madagascar, 3.III.1965, ex Phragmites communis var. mauritiana Kunth (Poaceae).

Coleção depositária: MNHN (holótipo e parátipos), MZ-ESALQ (parátipo + ).

Etimologia: homenagem a Alfred Grandidier (1836-1921), naturalista e explorador francês, dedicado à exploração de Madagascar.

Hospedeiro: Phragmites communis var. mauritiana (Poaceae).

Distribuição: Madagascar (Gutierrez, 1966).

\section{Material examinado:}

- parátipo , Faratsiho, Madagascar, 3.III.1965, ex Phragmites communis, (MZ-ESALQ). 


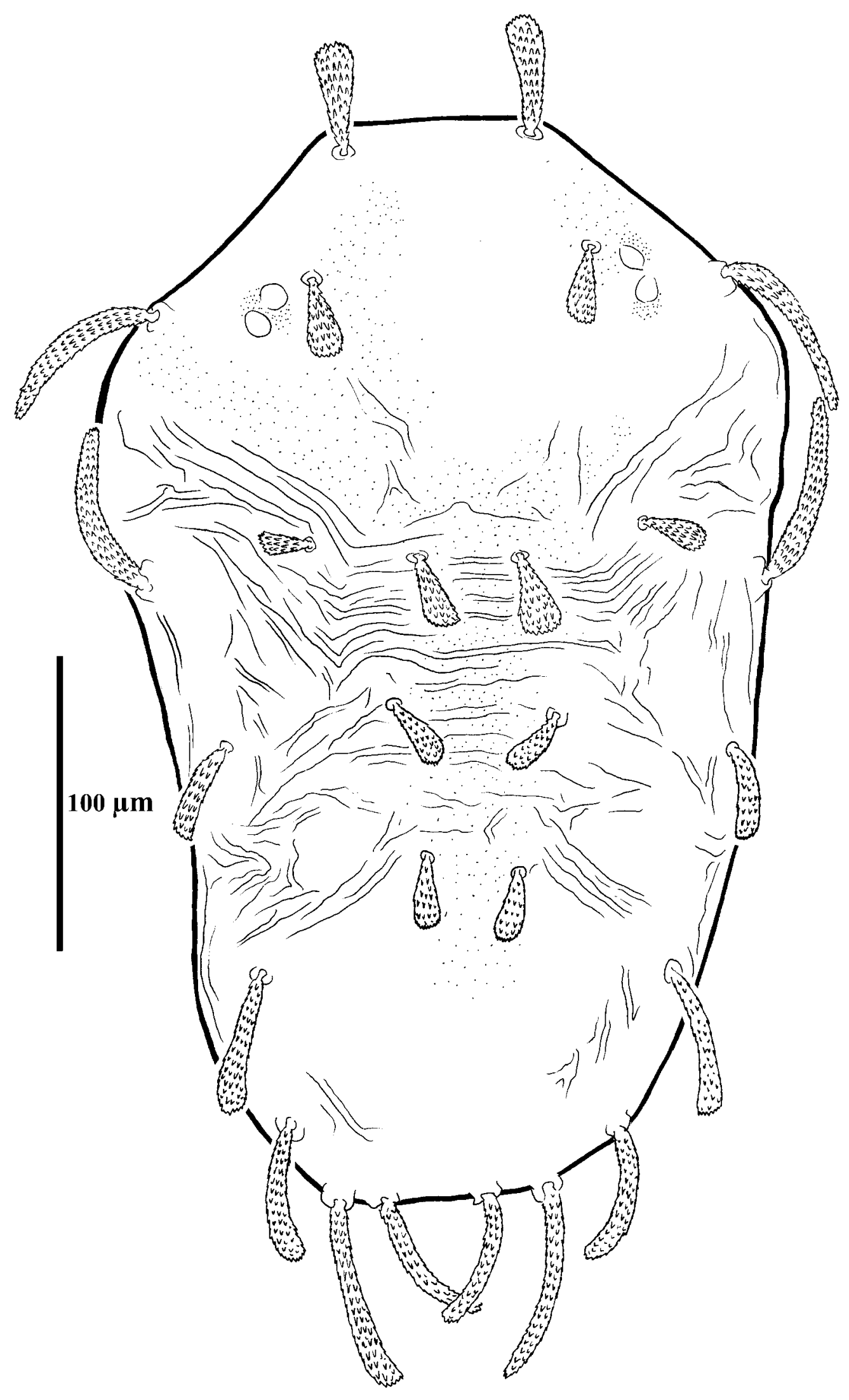

Figura 59. Vista dorsal de Aponychus grandidieri, parátipo fêmea. 


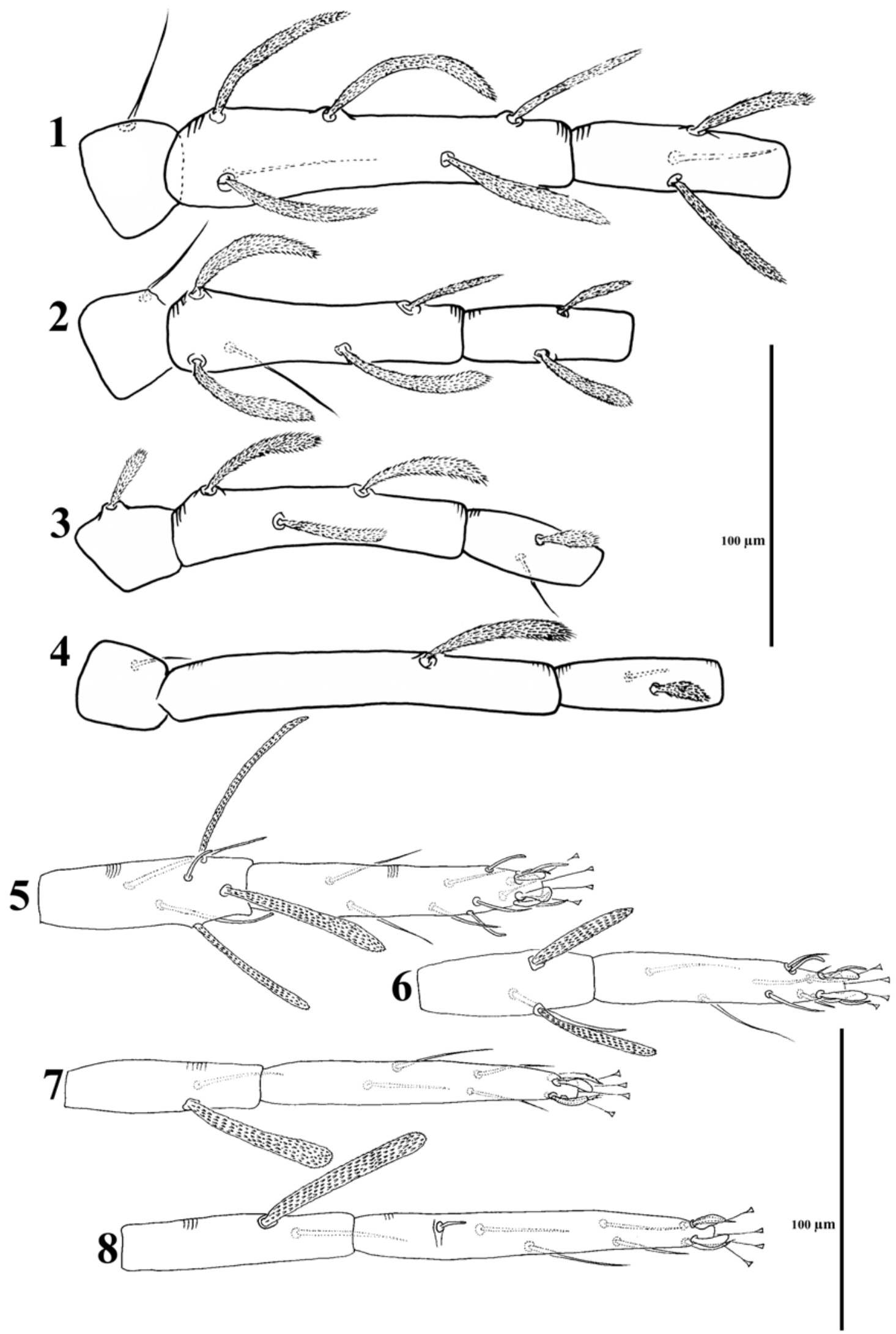

Figura 60. Artículos das pernas I a IV de Aponychus grandidieri, parátipo fêmea: trocânter, fêmur e gênu de I a IV (1-4), tibia e tarso de I a IV (5-8). 


\section{Aponychus imperatus Hafez \& El-Badry}

(Figuras 16.13 p. $49 ; 17.8$ p. 50; 18.14 p. $51 ; 19.14$ p. $52 ; 20.8$ p. $53 ; 21.8$ p. $54 ; 22.6$ p. $55 ; 23.6$ p. $56 ; 24.10$ p. 57 ; 25.13 p. $58 ; 26.12$ p. $59 ; 27.13$ p. $60 ; 61$ p. $129 ; 79.7$ p. 172$)$

Aponychus imperatus Hafez \& El-Badry, 1980: 1; Zaher, Gomaa \& El-Enany, 1982: 101; Rimando \& Corpuz-Raros, 1996: 12; Bolland et al., 1998: 20.

Chinotetranychus imperatus; Meyer, 1987: 85.

Série típica: não informada, sem data, Faculty of Agriculture Ain Shams University, Shoubra Elkeima, Cairo, Egito, ex Imperata cylindrica (L.) Beauv. (Poaceae).

Coleção depositária: desconhecida.

Etimologia: provavelmente referente ao gênero do hospedeiro tipo.

Hospedeiro: Imperata cylindrica (Poaceae) (Hafez \& El-Badry, 1980).

Distribuição: Egito (Hafez \& El-Badry, 1980).

Pelos caracteres fornecidos na descrição da espécie, ela se assemelha muito à Aponychus rarus, sendo possível que ela constitua um sinônimo júnior daquela espécie (ver discussão taxonômica na página 140). Entretanto, tal suposição não pôde ser confirmada sem a análise de espécimes-tipo. 


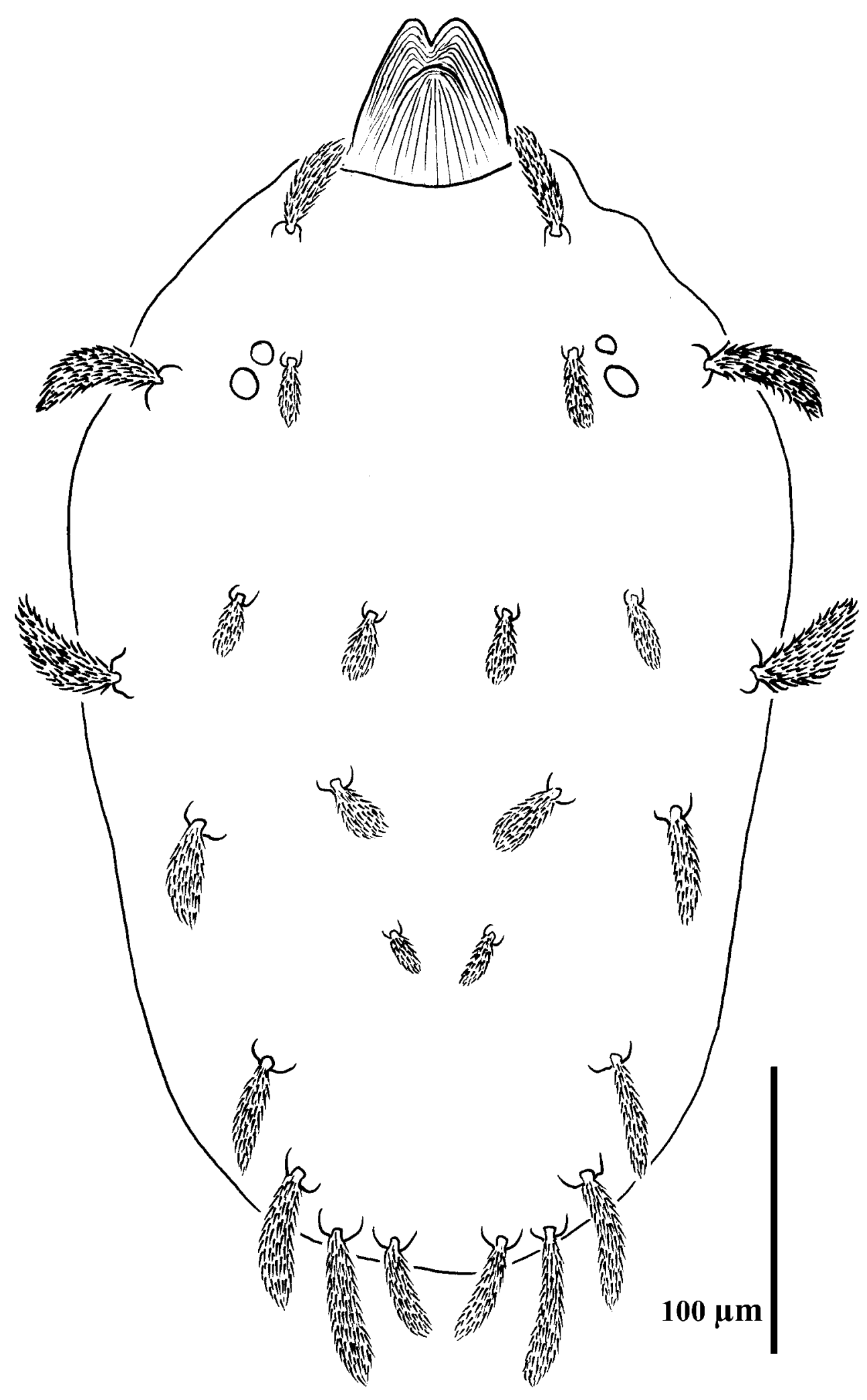

Figura 61. Vista dorsal de Aponychus imperatus, fêmea (redesenhado a partir de ilustração presente no trabalho de descrição da espécie [Hafez \& El-Badry, 1980]). 


\section{Aponychus lupus Chaudhri}

(Figuras 16.16 p. $49 ; 17.10$ p. 50; 18.16 p. $51 ; 19.17$ p. 52; 20.11 p. 53; 21.11 p. 54; 22.8 p. $55 ; 23.7$ p. $56 ; 24.11$ p. 57; 25.14 p. $58 ; 26.14$ p. $59 ; 27.15$ p. $60 ; 28.6$. p. $61 ; 29.5$ p. $62 ; 30.4$ p. $63 ; 31.4$ p. $64 ; 62$ p. $131 ; 67.3-4$ p. $144 ; 79.8$ p.

Aponychus lupus Chaudhri, 1972: 161; Bolland et al., 1998: 21; Chaudhri et al., 1974.

Aponychus (Stylophoronychus) lupus Rimando; Prasad, 1975a: 1; Bolland et al., 1998: 21.

Série típica: holótipo + , parátipos 4옹 Narwala, Lyallpur, Paquistão, 26.VIII.1969, ex Bambusa sp. (Poaceae), W.M. Chaudhri col.

Coleção depositária: UAL (holótipo e parátipos), USNM (parátipo †).

Etimologia: desconhecida.

Hospedeiros: Bambusa sp., Arundo donax Linnaeus, Thysanolaena maxima (Roxb.) Kuntze (Poaceae), Acacia modesta Wall. (Fabaceae), Cannabis sativa Linnaeus (Cannabaceae), Withania somnifera (Linnaeus) Dunal (Solanaceae), Morus alba Linnaeus (Moraceae), Malvastrum sp. (Malvaceae).

Distribuição: Paquistão (Chaudhri, 1972, Chaudhri et al., 1974).

\section{Material examinado:}

- parátipo +, Canal Bank Narwala, Paquistão, 26.VIII.1969, ex Bambusa sp., W.M. Chaudhri col. (USNM).

Essa espécie provavelmente constitui um sinônimo júnior de A. rarus (ver discussão taxonômica na página 140$)$. 


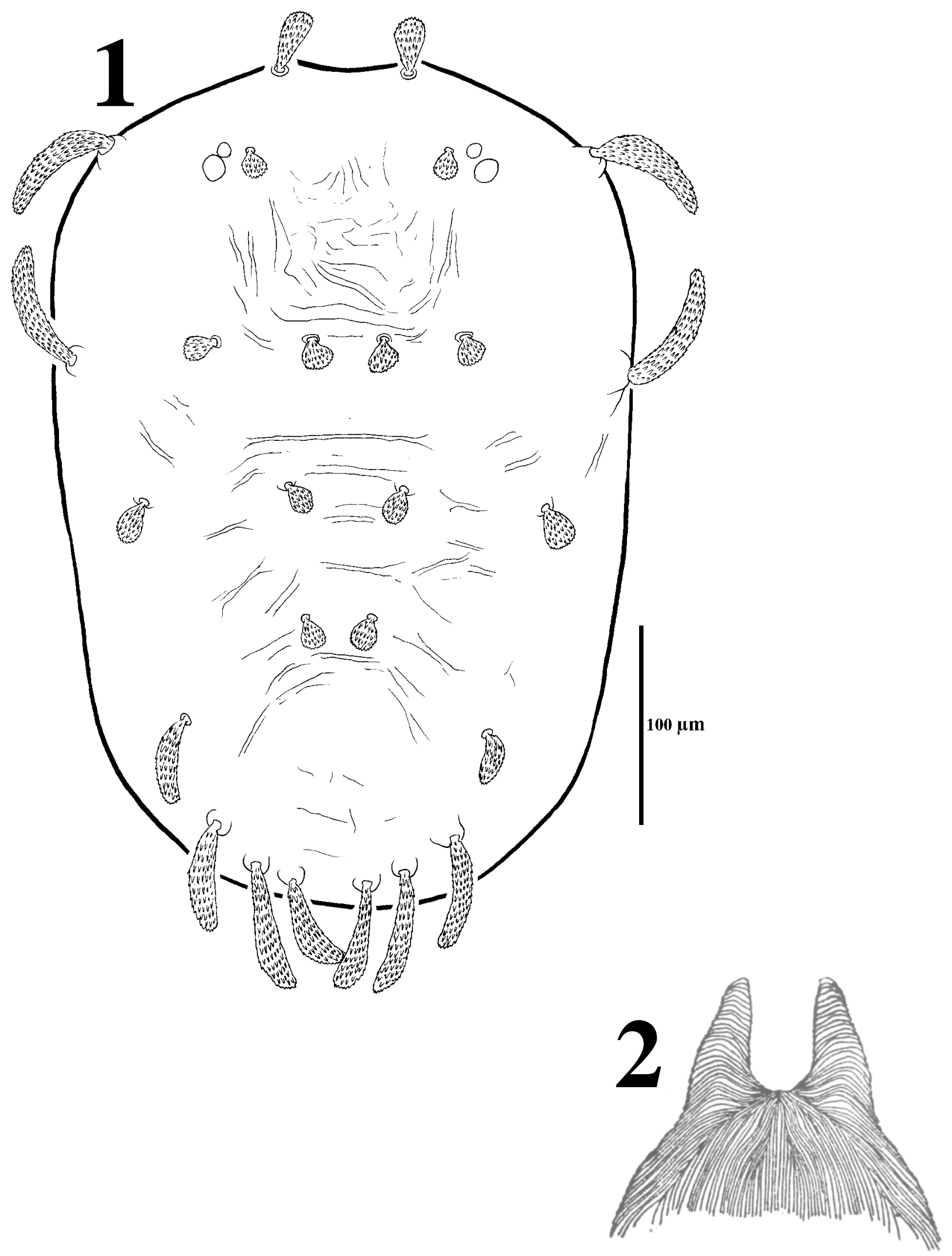

Figura 62. Aponychus lupus, parátipo fêmea: vista dorsal do idiossoma (1) e estilóforo (2). 


\section{Aponychus parydrus (Meyer)}

(Figuras 11 p. $46 ; 16.18$ p. $49 ; 17.12$ p. $50 ; 18.7$ p. 51; 19.19 p. 52; 20.12 p. 53; 21.17 p. $54 ; 22.10$ p. $55 ; 23.8$ p. $56 ; 63$ p. $133 ; 67.9-10$ p. $144 ; 80.1$ p. 173$)$

Chinotetranychus parydrus Meyer, 1987: 85.

Aponychus parydrus; Rimando \& Corpuz-Raros, 1996: 12; Bolland et al., 1998: 21.

Série típica: holótipo + , parátipos 13, 3§ , Roodeplat Dam, próximo a Pretória, 15.I.1980, ex Phragmites mauritianus Kunth (Poaceae), M.P.K. Meyer col.; parátipos 4, Rietspruit, próximo a Pongola, Natal, 19.VIII.1980, ex Phragmites sp., M.P.K. Meyer col.; parátipos 15 9 , 1 đ, Pongola River, próximo a Golela, Natal, 19.VIII.1980, M.P.K. Meyer col.

Coleção depositária: NCA (holótipo e parátipos), DZSJRP (parátipo + ).

Etimologia: desconhecida; possivelmente de L. para, ao lado de, + G. hydrus, água, próximo a água. Essa espécie foi originalmente coletada sobre hospedeiros próximos a corpos d'água (E.A. Ueckermann, comunicação pessoal).

Hospedeiros: Phragmites mauritianus, Phragmites sp. (Poaceae).

Distribuição: África do Sul (Meyer, 1987).

\section{Material examinado:}

- parátipo q, Roodeplaat Dam, África do Sul, M.K.P. Acy 82/546, 19.VIII.1980, ex Phragmites mauritianus Kunth (Poaceae) Meyer col. (DZSJRP).

Essa espécie possivelmente é um sinônimo júnior de A. rarus (ver discussão taxonômica na página 140). 


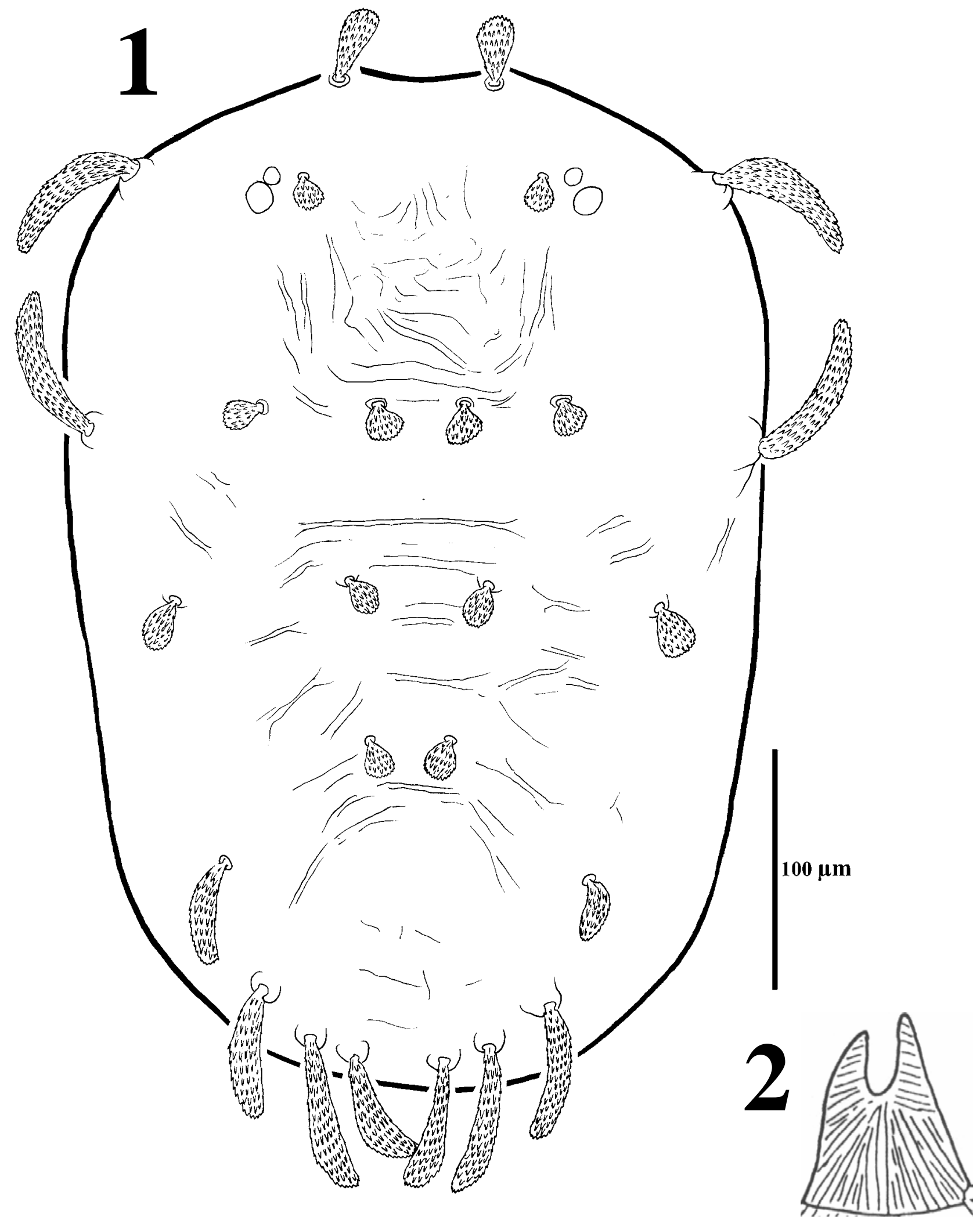

Figura 63. Aponychus parydrus, parátipo fêmea: vista dorsal do idiossoma (1) e estilóforo (2). 


\section{Aponychus rarus Rimando}

(Figuras 16.19 p. $49 ; 19.21$ p. 52; 64 p. $135 ; 67.11$ p. 144; 80.3 p. 173)

Aponychus rarus Rimando, 1966: 110; Rimando, 1968: 8; Bolland et al., 1998: 21.

Aponychus (Stylophoronychus) rarus Rimando; Prasad, 1975a: 1.

Série típica: holótipo + , parátipos 10, 5ð^, Echague, Isabela, Filipinas, 18.VI.1963, ex Phragmites vulgaris (Lam.) (Poaceae).

Coleção depositária: UPLB (holótipo e parátipos).

Etimologia: desconhecida.

Hospedeiros: Phragmites vulgaris (Poaceae) (Rimando, 1966).

Distribuição: Filipinas (Rimando, 1966).

Em todos os caracteres analisados e disponíveis no trabalho de descrição original dessa espécie, A. rarus assemelha-se morfológica e filogeneticamente à A. expansus, A. grandidieri, A. lupus, A. parydrus e A. sulcatus, sendo possível que todas essas espécies constituam, na realidade, sinônimos júnior de A. rarus (ver discussão taxonômica na página 140). Entretanto, não foi possível analisar exemplares-tipo dessa espécie, não sendo possível concluir definitivamente essa hipótese de sinonímia.

Assim como A. grandidieri, A. rarus foi também descrita em 1966, sendo que o trabalho que descreve A. rarus foi publicado em julho, enquanto A. grandidieri foi publicado em dezembro de 1966. Portanto, caso se confirme a sinonímia dessas espécies, o sinônimo sênior será A. rarus . 


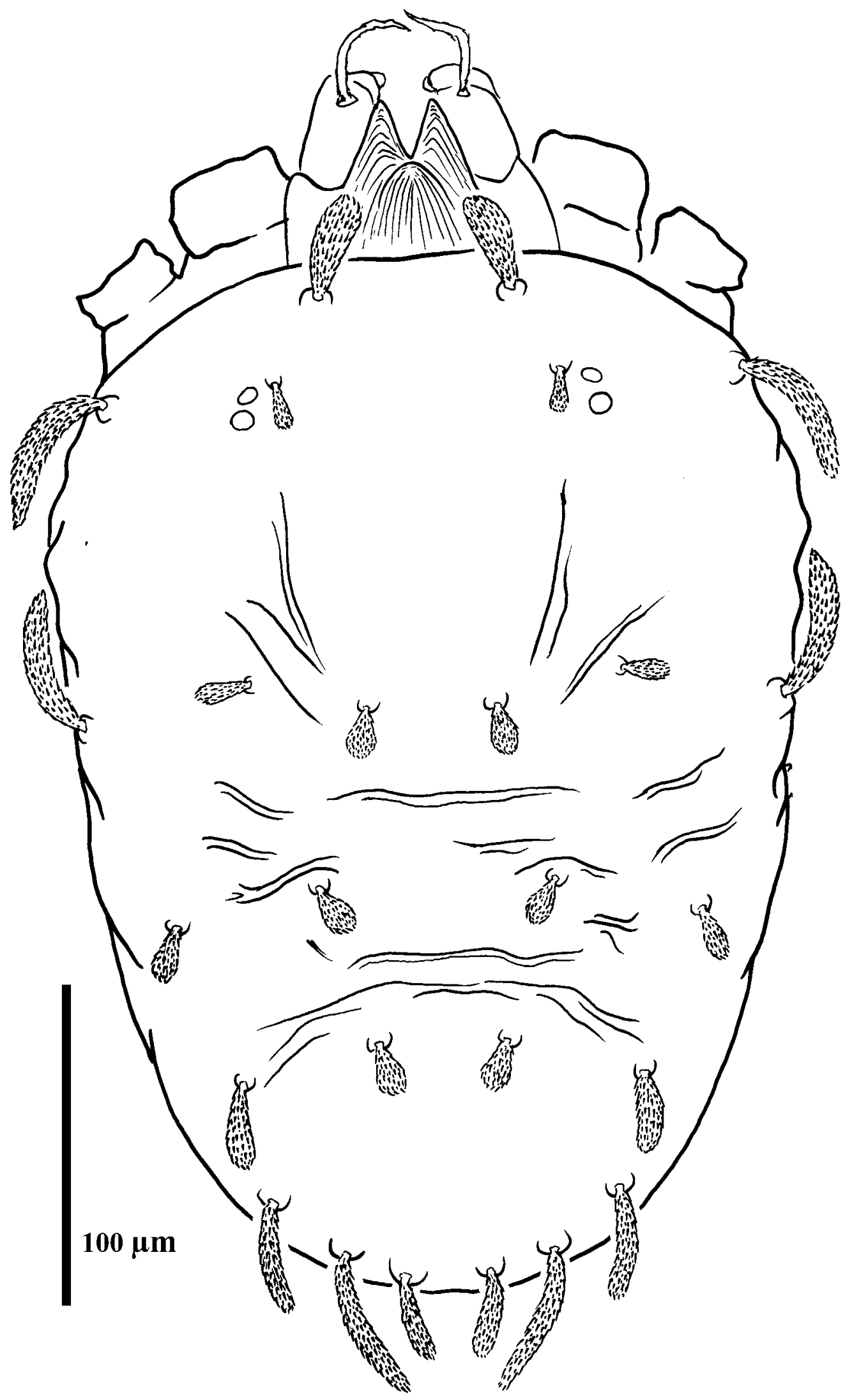

Figura 64. Vista dorsal de Aponychus rarus, fêmea (redesenhado a partir de ilustração presente no trabalho de descrição da espécie). 


\section{Aponychus solimani Zaher, Goma \& El-Enany}

(Figuras 16.22 p. $49 ; 19.25$ p. 52; 20.17 p. $53 ; 65$ p. $137 ; 80.7$ p.173)

Aponychus solimani Zaher, Gomaa \& El-Enany, 1982: 101; Rimando \& Corpuz-Raros, 1996: 12; Bolland et al., 1998: 21.

Chinotetranychus solimani; Meyer, 1987: 85.

Série típica: holótipo +, El-Hawamdia, Badrashain, Giza, Egito, 30.XII.1976, ex Arundo donax Linnaeus (Poaceae); 3 parátipos, ex Phragmites communis Trin. (Poaceae).

Etimologia: provavelmente em homenagem a Z.R. Soliman, acarólogo egípcio.

Hospedeiros: Arundo donax, Phragmites communis (Zaher et al., 1982).

Distribuição: Egito (Zaher et al., 1982).

Obs: macho desconhecido; originalmente são citadas 2 fêmeas "holotype" sobre Arundo donax.

Não foi possível analisar espécimes tipo dessa espécie. Segundo o curador da coleção de ácaros da Faculdade de Agricultura, Universidade do Cairo, onde supostamente estariam depositados os espécimes-tipo de A. solimani, os mesmos estão perdidos (A.M. Afifi, comunicação pessoal). Pelas informações obtidas na descrição original dessa espécie, é provável que A. solimani seja um sinônimo júnior de A. rarus, assim como A. expansus, A. grandidieri, A. lupus, A. parydrus e A. sulcatus, mas por causa da indisponibilidade dos espécimes-tipo dessa espécie, essa hipótese não pôde ser confirmada.

Portanto, sugerimos que Aponychus solimani deva ser considerada como uma species inquirenda, até que os espécimes tipo sejam encontrados, ou mais exemplares da mesma localidade sejam coletados e analisados. 


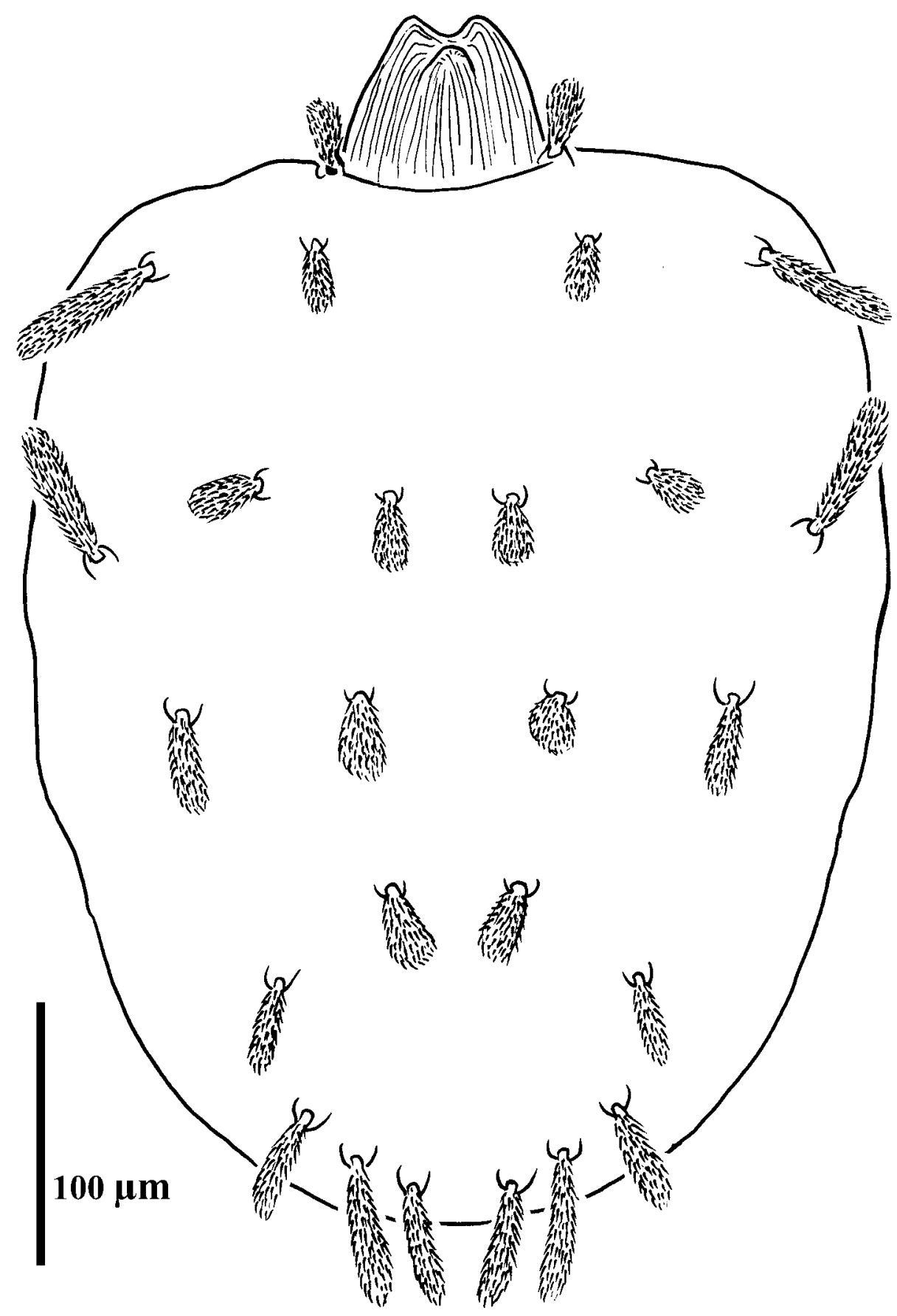

Figura 65. Vista dorsal de Aponychus solimani, fêmea (redesenhado a partir de ilustração presente no trabalho de descrição da espécie). 


\section{Aponychus sulcatus Chaudhri}

(Figuras 16.24 p. $49 ; 17.15$ p. $50 ; 18.19$ p. $51 ; 19.27$ p. 52; 20.18 p. 53; 21.16 p. $54 ; 22.11$ p. $55 ; 23.10$ p. $56 ; 24.17$ p. $57 ; 25.18$ p. $58 ; 26.18$ p. $59 ; 27.19$ p. $60 ; 28.11$ p. $61 ; 29.10$ p. $62 ; 30.9$ p. $63 ; 31.8$ p. $64 ; 66$ p. $139 ; 67.7-8$ p. $144 ;$ 80.9 p. 173)

Aponychus sulcatus Chaudhri, 1972: 164; Sadana et al., 1981: 325; Sadana et al., 1982: 398; Gupta, 1985: 61; Gupta \& Gupta, 1994: 45; Bolland et al., 1998: 22.

Aponychus (Stylophoronychus) sulcatus; Prasad, 1975a: 1.

Série típica: holótipo + , parátipo + , 1 milha a leste de Sheikhupura, Paquistão, 25.XI.1970, ex Arundo donax Linnaeus (Poaceae), W.M. Chaudhri col.; parátipo,+ 2 milhas a leste de Campbellpur, Paquistão, 9.VIII.1971, W.M. Chaudhri col..

Coleção depositária: UAL (holótipo e parátipo), USNM (parátipo + ).

Etimologia: presumivelmente devido à presença de sulcos dorsais evidentes na ilustração original do holótipo; entretanto, foi verificado que tais sulcos não são característicos da espécie, mas sim uma variação individual ou artefato de montagem do holótipo, uma vez que em parátipo analisado isso não foi verificado. Em parátipo de A. grandidieri esses sulcos foram também observados, não sendo ilustrados para holótipo dessa espécie.

Hospedeiros: Arundo donax, Saccharum spontaneum (Poaceae), Boerhavia diffusa (Nyctaginaceae), Carica papaya (Caricaceae).

Distribuição: Paquistão (Chaudhri, 1972), Índia (Gupta, 1985; Gupta \& Gupta, 1994).

Obs.: macho desconhecido.

Essa espécie possivelmente é um sinônimo júnior de A. rarus (ver discussão taxonômica na página 140).

\section{Material examinado:}

- parátipo †, 2 milhas a leste de Sheikhupura, Paquistão, 25.XI.1970, ex Arundo donax Linnaeus (Poaceae), W.M. Chaudhri col. (USNM). 


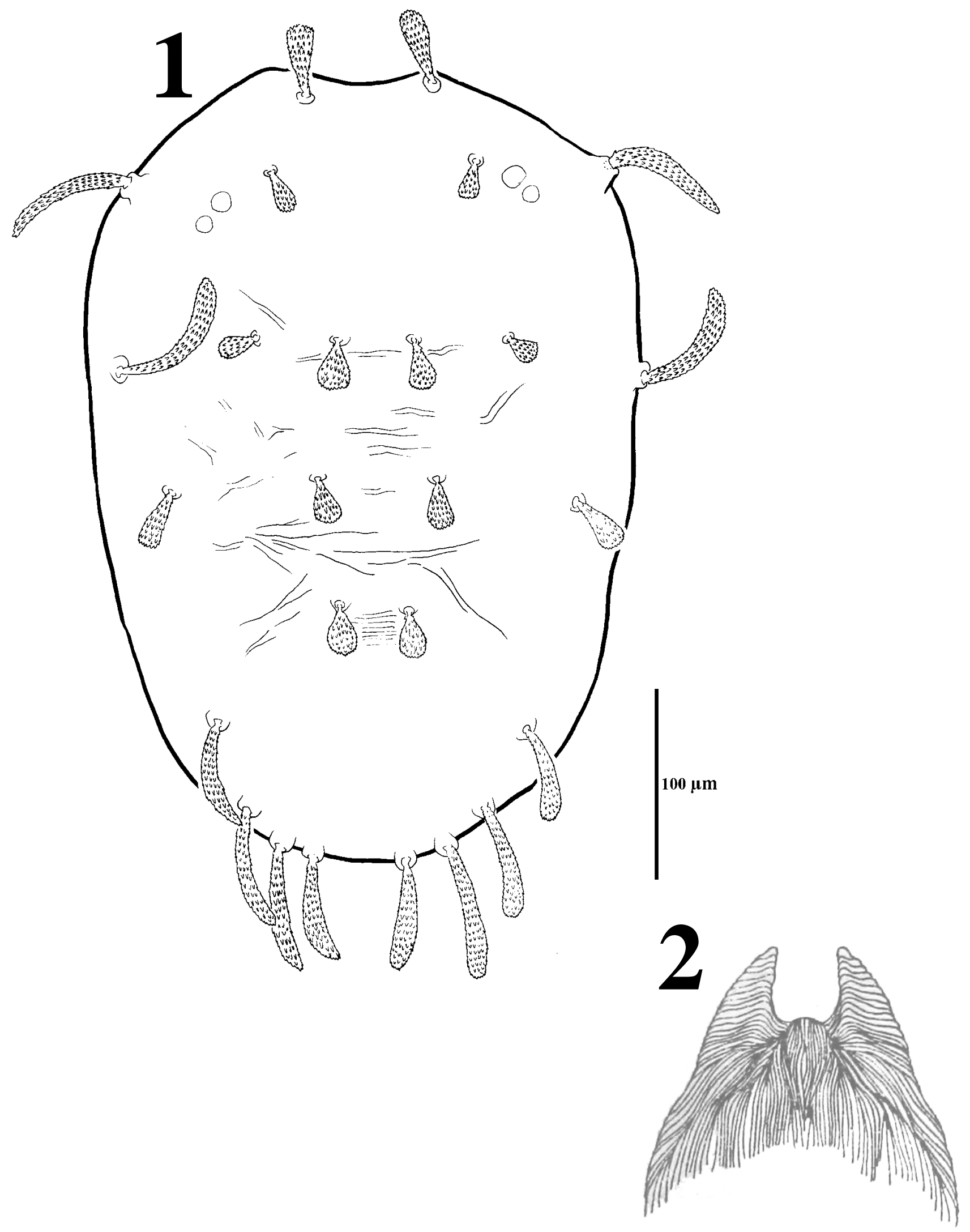

Figura 66. Aponychus sulcatus, parátipo fêmea: vista dorsal do idiossoma (1) e estilóforo). 


\section{Discussão taxonômica}

Foi possível observar grandes semelhanças entre oito espécies de Aponychus, com a possibilidade que constituam, na realidade, sinônimos: Aponychus expansus Chaudhri, 1972, A. grandidieri (Gutierrez, 1966), A. imperatus Hafez \& El-Badry, 1980, A. lupus Chaudhri, 1972, A. parydrus (Meyer, 1987), A. rarus Rimando, 1966, A. solimani Zaher, Gomaa \& El-Enany 1982 e A. sulcatus Chaudhri, 1972.

Foi possível realizar análise de espécimes tipo de cinco delas (Aponychus expansus, A. grandidieri, A. lupus, A. parydrus e A. sulcatus), nas quais foram encontradas pequenas diferenças morfológicas, discutidas abaixo. Entretanto, é provável que essas diferenças reflitam variações populacionais, ou mesmo intra-populacionais, sendo que o número de espécimes conhecidos dificulta uma decisão definitiva acerca da validade taxonômica dessas espécies. Dessas oito espécies, machos são conhecidos apenas para quatro delas: A. grandidieri, A. imperatus, A. rarus e A. parydrus, sendo que nessa última os machos são consideravelmente menos numerosos (4 machos conhecidos, e 47 fêmeas). Em A. solimani, A. expansus e A. sulcatus, apenas poucos indivíduos fêmea são conhecidos (5, 4 e 3 indivíduos, respectivamente).

Após análise comparativa dos parátipos examinados com as ilustrações originais dos holótipos, foi possível perceber que algumas diferenças que até então eram utilizadas para a separação das espécies estão presentes em indivíduos (holótipo e parátipos) da mesma espécie. Por esta razão, conclui-se que elas devem ser consideradas em sinonímia. A espécie mais antiga entre elas é Aponychus rarus, entretanto, não foi possível análise de material tipo dessa espécie. Caso essa hipótese de sinonímia se confirme, a espécie válida será $A$. rarus.

Na diagnose específica de A. lupus, Chaudhri (1972: 163) o diferencia de A. rarus baseando-se no comprimento de algumas setas dorsais e também no número de setas presentes nos fêmures I e II. Assim, menciona que as setas:

1) $v 2$ possuem mais do que duas vezes o comprimento das $s c 1$ em A. rarus, e menos do que duas vezes em A. lupus;

2) $f l$ mais longas que $h l$ em A. rarus, mas de comprimentos iguais em A. lupus;

3) fêmures I e II com 5 e 3 setas em A. rarus, enquanto que com 6 e 5 setas, respectivamente, em A. lupus.

Comparando-se apenas os holótipos dessas duas espécies, verifica-se que as aferidas diferenças no comprimento dessas setas (ítens 1 e 2) de fato ocorrem. Entretanto, essas pequenas 
variações também foram encontradas no parátipo analisado de A. lupus, que apresenta as setas dorsais comparativamente mais curtas que no holótipo (Figuras 67.3-4, p. 144).

Chaudhri (1972) menciona que o holótipo e os quatro parátipos de A. lupus foram coletados na mesma localidade, data e hospedeiro, o que indica que essas sutis diferenças em comprimento de seta constituem variações intra-populacionais e não específicas, de modo que estas não mais devem ser utilizadas para separação dessas espécies (Tabela V, p. 143, Figura 67, p. 144). O autor salienta também que, além da localidade e hospedeiros tipo, A. lupus foi registrado em mais 8 localidades e 6 hospedeiros, entre mono e dicotiledôneas.

Com relação ao ítem 3, Chaudhri (1972) possivelmente equivocou-se ao fundamentar a diagnose de A. lupus com base nas ilustrações apresentadas por Rimando (1966: 112). Apesar deste último autor ter ilustrado apenas 5 e 3 setas nos fêmures I e II, respectivamente, de A. rarus, provavelmente essa espécie apresenta na verdade 6 e 5 setas, respectivamente, sendo que as setas representadas nesses artículos foram somente as dorsais. Considerando-se que em todas as demais espécies de Aponychus estudadas essas setas ventrais são sempre presentes nesses artículos, é altamente provável que elas também estejam presentes em A. rarus. Apesar de não ter sido possível análise de espécimes-tipo dessa última espécie, isto pôde ser confirmado pelas ilustrações originais de A. corpuzae, no qual Rimando (1966: 109) ilustrou apenas as setas dorsais das pernas, sendo que as setas ventrais estão presentes nos parátipos analisados.

Chaudhri (1972: 167) diferencia A. expansus de A. lupus com base nas quatro características que se seguem:

1) $v 2$ mais do que o dobro do comprimento de $s c 1$ em A. lupus, mas menos do que essa distância em A. expansus;

2) $h 152 \mu \mathrm{m}$ em $A$. lupus, enquanto que $39 \mu \mathrm{m}$ em A. expansus;

3) $e 247 \mu \mathrm{m}$ em $A$. lupus, enquanto que $36 \mu \mathrm{m}$ em A. expansus;

4) $f 1$ menores em A. expansus do que em A. lupus.

Entretanto, verificou-se que essas variações estão presentes em indivíduos da mesma espécie (Tabela V, p. 143). Algumas setas (e.g. setas e2 e hl em A. lupus) variam ligeiramente no comprimento e no formato no mesmo indivíduo, lados esquerdo e direito. Essas características, portanto, não devem ser utilizadas como diagnósticas para a separação dessas espécies.

Meyer (1987: 85) diferenciou A. parydrus de A. expansus com base no comprimento relativo das setas caudais $h l$ em relação às $f l$, sendo essa razão de aproximadamente $2 / 3$ em $A$. parydrus e $1 / 2$ em A. expansus. Tais diferenças de fato são observadas nos holótipos, mas 
verificou-se que essas variações estão presentes em diferentes indivíduos (parátipos) da mesma espécie. Em todos os demais caracteres morfológicos analisados, essas espécies são idênticas. Isso justificaria, portanto, a sinonimização dessas espécies.

A partir das ilustrações originais feitas por Chaudhri (1972: 164) do exemplar holótipo de Aponychus sulcatus, pode-se concluir que aquele autor considerou como distintivo para aquela espécie um distinto enrugamento do tegumento dorsal, resultando em um padrão característico de sulcos dorsais. Apesar de não apresentar qualquer etimologia na sua publicação, é provável que o autor tenha utilizado esse marcante caráter para nomear a espécie nova. Entretanto, o exemplar parátipo analisado dessa espécie apresenta o tegumento dorsal sem essa característica, o que leva à hipótese de que o maior grau de enrugamento dorsal apresentado pelo holótipo seja uma diferença não específica, podendo meramente ser resultado de artefato ocasionado durante a preparação das lâminas semi-permanentes ou refletir um estado nutricional ou fisiológico mais deficiente.

Adicionalmente, o mesmo grau de enrugamento dorsal foi observado em exemplar parátipo de A. grandidieri (Gutierrez, 1966), muito semelhante ao observado no holótipo de A. sulcatus. Tal aspecto não foi ilustrado originalmente para o exemplar alótipo de A. grandidieri. Chaudhri (1972) ainda menciona que $A$. sulcatus é uma espécie próxima de $A$. corpuzae, no entanto, não apresenta nenhum argumento para tal comparação. Essas duas espécies são suficientemente distintas para se evitar qualquer sugestão de proximidade entre elas, baseando-se em caracteres tais como quetotaxia das pernas, formato e comprimento das setas dorsais e padrão de reticulação no tegumento dorsal.

Todas as aferidas espécies foram descritas da região oriental, sendo a maioria sobre plantas monocotiledôneas da família Poaceae. Uma tentativa de se analisar mais profundamente a questão da sinonímia entre essas espécies seria analisar caracteres presentes nos machos, como os edeagos, sendo esse caráter de grande importância taxonômica para a diagnose específica de diversos grupos de tetraniquídeos. Entretanto, em A. lupus, A. sulcatus e A. expansus somente as fêmeas são conhecidas. Em A. rarus, A. grandidieri e A. parydrus, o edeago apresenta o mesmo formato, o que reforça a hipótese de sinonímia entre elas. 
Tabela V. Dimensões corpóreas e das setas dorsais, em micrômetros $(\mu \mathrm{m})$ de espécimes-tipo de algumas espécies de Aponychus.

\begin{tabular}{|c|c|c|c|c|c|c|c|c|c|c|}
\hline & \multicolumn{2}{|c|}{$\begin{array}{l}\text { Aponychus } \\
\text { grandidieri }\end{array}$} & \multicolumn{2}{|c|}{$\begin{array}{l}\text { Aponychus } \\
\text { expansus }\end{array}$} & \multicolumn{2}{|c|}{$\begin{array}{l}\text { Aponychus } \\
\text { lupus }\end{array}$} & \multicolumn{2}{|c|}{$\begin{array}{c}\text { Aponychus } \\
\text { sulcatus }\end{array}$} & \multicolumn{2}{|c|}{$\begin{array}{c}\text { Aponychus } \\
\text { parydrus }\end{array}$} \\
\hline & alótipo* & parátipo & holótipo* & parátipo & holótipo* & parátipo & holótipo* & parátipo & holótipo* & parátipo \\
\hline comprimento total & - & 515 & - & 465 & - & 555 & - & 490 & 567 & $533-567$ \\
\hline comprimento do idiossoma & 375 & 407 & 408 & 429 & 428 & 495 & 377 & 473 & 467 & $433-467$ \\
\hline largura do idiossoma & 225 & 242 & 275 & 275 & 286 & 297 & 255 & 297 & 307 & - \\
\hline$v 2(P 1)$ & 23 & 44 & 36 & 27 & 31 & 33 & 47 & 41 & - & $40-43$ \\
\hline $\operatorname{sc1}(\mathrm{P} 2)$ & 16 & 27 & 21 & 16 & 16 & 16 & 31 & 22 & - & $25-28$ \\
\hline$s c 2(P 3)$ & 50 & 63 & 60 & 63 & 65 & 68 & 65 & 71 & - & $60-63$ \\
\hline$c 3(H)$ & 54 & 65 & 62 & 71 & 70 & 68 & 62 & 68 & - & $60-60$ \\
\hline$c 2(L 1)$ & 15 & 24 & 18 & 16 & 16 & 16 & 26 & 22 & - & $16-21$ \\
\hline$d 2(L 2)$ & 35 & 38 & 26 & 24 & 23 & 24 & 52 & 33 & - & $34-38$ \\
\hline$e 2(L 3)$ & 40 & 54 & 36 & 44 & 47 & 46 & 65 & 52 & - & $30-53$ \\
\hline$f 2(L 4)$ & 53 & 68 & 34 & 68 & 65 & 65 & 73 & 73 & - & $70-73$ \\
\hline$c 1(D 1)$ & 12 & 27 & 26 & 16 & 18 & 16 & 29 & 30 & - & $21-27$ \\
\hline$d 1(\mathrm{D} 2)$ & 15 & 24 & 21 & 16 & 21 & 16 & 34 & 27 & - & $18-22$ \\
\hline$e 1(D 3)$ & 22 & 24 & 23 & 16 & 23 & 16 & 39 & 27 & - & $18-22$ \\
\hline$f 1(D 4)$ & 38 & 49 & 42 & 54 & 52 & 57 & 60 & 60 & - & $49-57$ \\
\hline$h 1(D 5)$ & 33 & 52 & 39 & 54 & 52 & 57 & 65 & 60 & - & $44-54$ \\
\hline
\end{tabular}

* = medidas obtidas da publicações originais. 

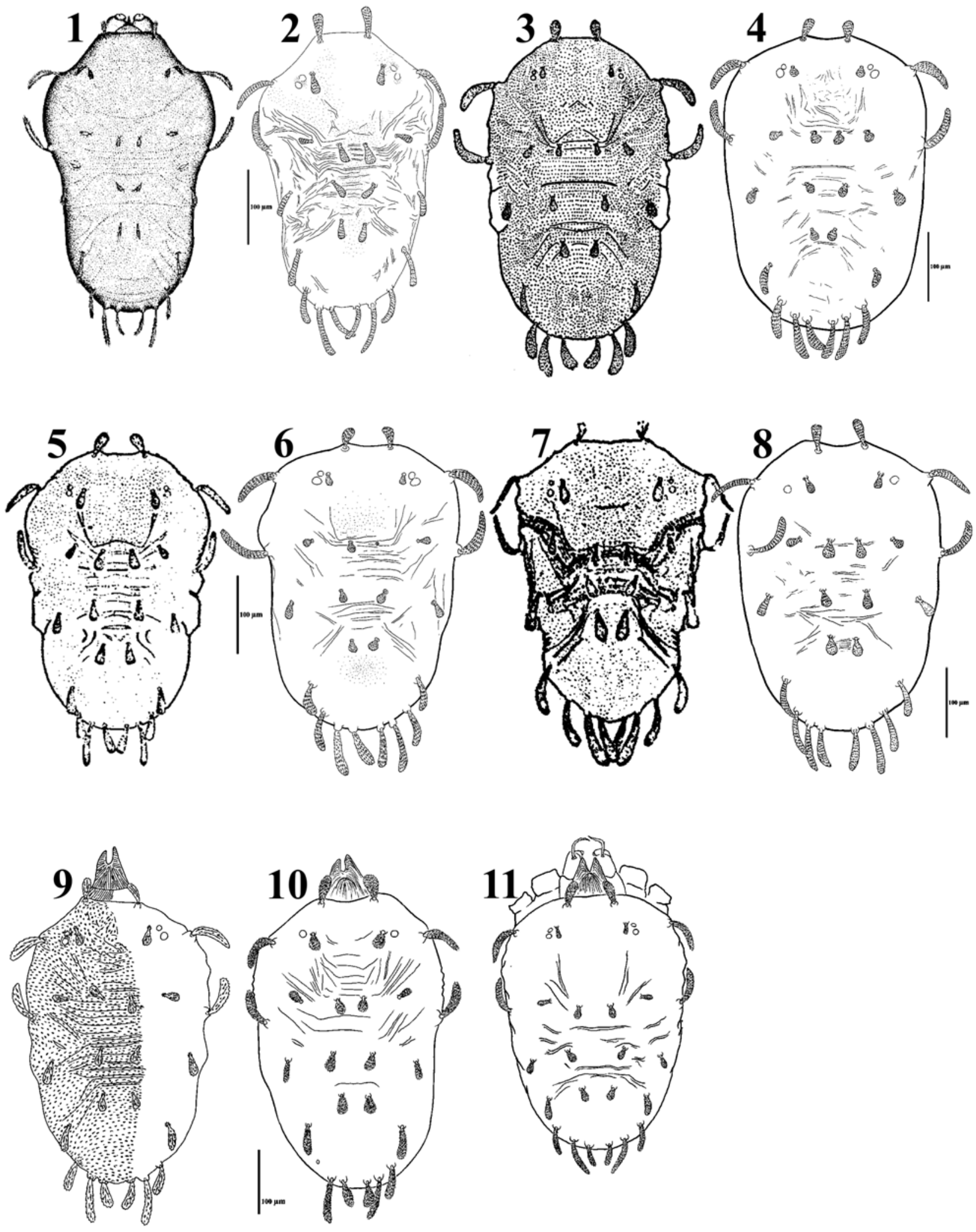

Figura 67. Vista dorsal dos holótipos $(1,3,5,7,9,11$, ilustrações originais) e parátipos $(2,4,6,8$, 10), desenhados a partir de exemplares analisados) de espécies de Aponychus: 1-2, A. grandidieri; 3-4, A. lupus; 5-6, A. expansus; 7-8, A. sulcatus; 9-10, A. parydrus; 11, A. rarus. 


\section{Aponychus sarjui Gupta}

(Figuras 16.20 p. $49 ; 17.13$ p. $50 ; 18.4$ p. 51; 19.22 p. 52; 20.23 p. 53; 21.20 p. 54; 22.22 p. 55; 23.14 p. 56; 24.14 p. $57 ; 25.15$ p. $58 ; 26.15$ p. $59 ; 27.16$ p. $60 ; 28.9$ p. $61 ; 29.8$ p. $62 ; 30.7$ p. $63 ; 31.7$ p. $64 ; 68$ p. $147 ; 69$ p. $148 ; 80.4$ p.

Aponychus sarjui Gupta, 1980: 111; Gupta, 1985: 60; Gupta \& Gupta, 1994: 43; Bolland et al., 1998: 21.

Série típica: holótipo + , South Andaman Island, Chiriatapu, Índia, 20.XII.1972, ex Bambusa arundinacea, S.K. Gupta col. (NCZSI).

Coleção depositária: NCZSI.

Obs: macho desconhecido.

Etimologia: homenagem feita pelo autor da espécie a seu pai, Sri Sarju Prasad.

Hospedeiro: Bambusa arundinacea (Retz.) Willd (Poaceae) (Gupta, 1980).

Distribuição: Índia (Gupta, 1980).

Essa espécie é conhecida apenas por um indivíduo fêmea (holótipo), coletado no arquipélago de Andaman, no Oceano Índico. Originalmente, a seta escapular interna não foi ilustrada, apesar de presente.

\section{Material examinado:}

Aponychus sarjui: holótipo +, 20.XII.1972, Chiriatapu, Andaman Islands, Índia, ex bambu em (NCZSI).

\section{Diagnose:}

A. sarjui assemelha-se a A. siamensis pelo formato reduzido das setas da região central do dorso. Pode ser diferenciada dessa última por apresentar as setas sacrais externas $(f 1)$ bastante reduzidas, praticamente vestigiais em relação à $h 1, f 2$ e $e 2$, sendo todas essas setas de comprimentos equivalentes em $A$. siamensis.

\section{Redescrição:}

Fêmea $(n=1)$ Dorso. Estilóforo com duas fortes projeções anteriores; um ocelo visível próximo à base das setas prodorsais $s c 1$, lente posterior resquicial não discernível; pronunciadas estrias preponderantemente transversais na região central do dorso; setas dorsais levemente serreadas, setas da região central do opistossoma dorsal diminutas $(s c 1, c 1, c 2, d 1, d 2, e 1)$, setas escapulares externas e humerais $(s c 2$ e $c 3)$ com extremidades convergentes; setas $c 2$ e $c 1$ de 
comprimentos equivalentes; setas dorso-centrais com comprimentos equivalentes $(c 1 \approx d 1 \approx e 1)$, apenas setas da região marginal do idiossoma $(v 2, s c 2, c 3, e 2, f 1, f 2, h l)$ inseridas em fortes tubérculos. Idiossoma: comprimento 370 (base da seta $v 2$ até base das setas h1), largura 233; comprimento das setas dorsais: $v 2$ 24-26, sc1 6-7, sc2 57, c1 7-9, c2 8-10, c3 55-60, d1 7-7, d2 78, el 6-9, e2 42-46, f1 7-8, f2 63-66, h1 65-66. Distância entre pares de setas dorsais: v2-v2 65, sc1-sc1 97, sc2-sc2 224, c1-c1 37, c2-c2 115, c3-c3 218, d1-d1 34, d2-d2 140, e1-e1 34, e2-e2 118,fl-f1 95, f2-f2 78, h1-h1 39.

Quetotaxia das pernas (artículos nas pernas I a IV): coxa 2-2-1-1, trocânter 1-1-1-1, fêmur 6-5-3-1, gênu 2-2-1-1, tíbia 5(1)-3-2-2, tarso 9(1assoc.)-10(1)-8(1)-8(1). Setas do par associado presentes no tarso I, mas dissociadas no tarso II; solenídio proximal presente nos tarsos III e IV. 


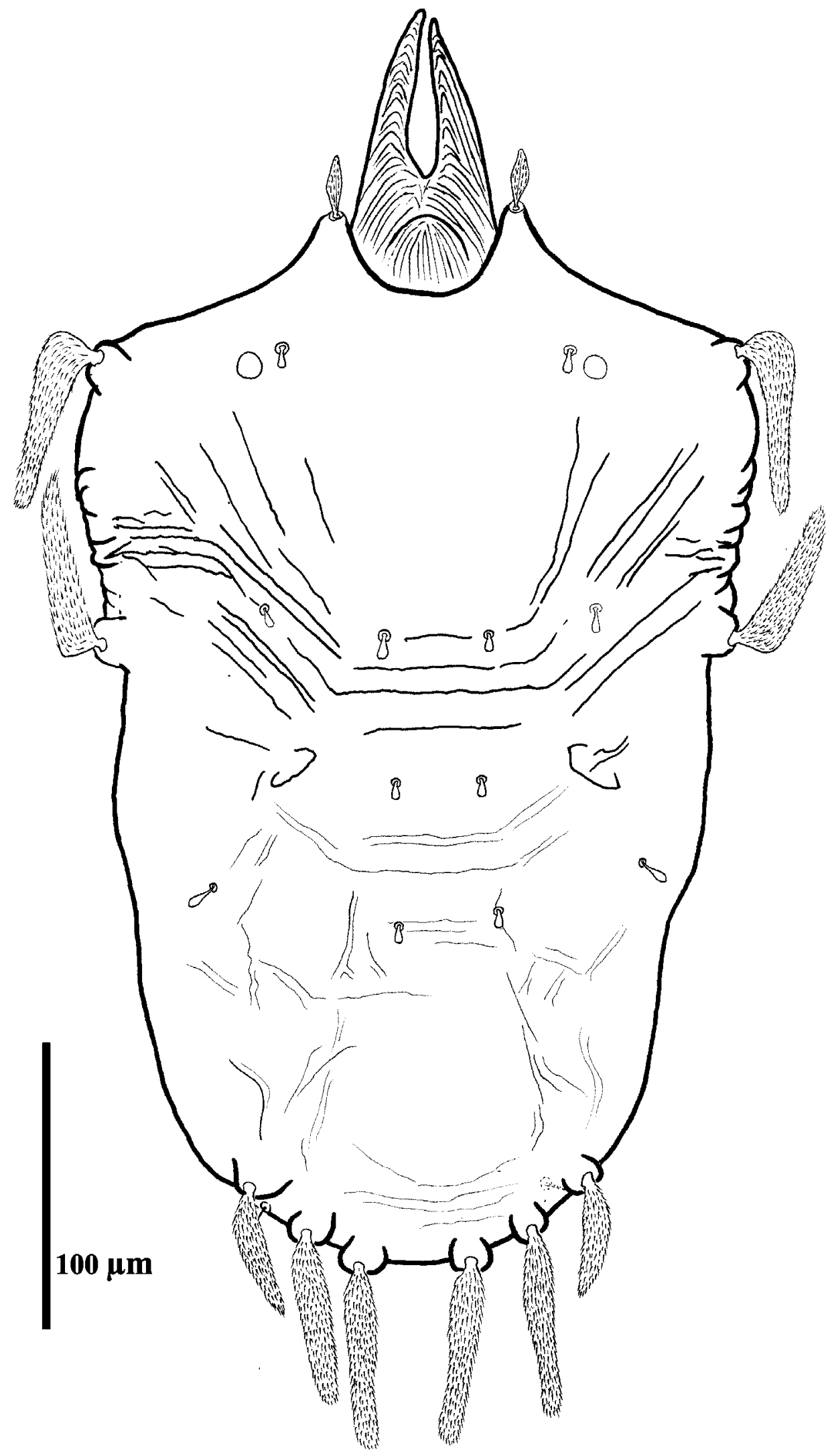

Figura 68. Vista dorsal de Aponychus sarjui, holótipo fêmea. 

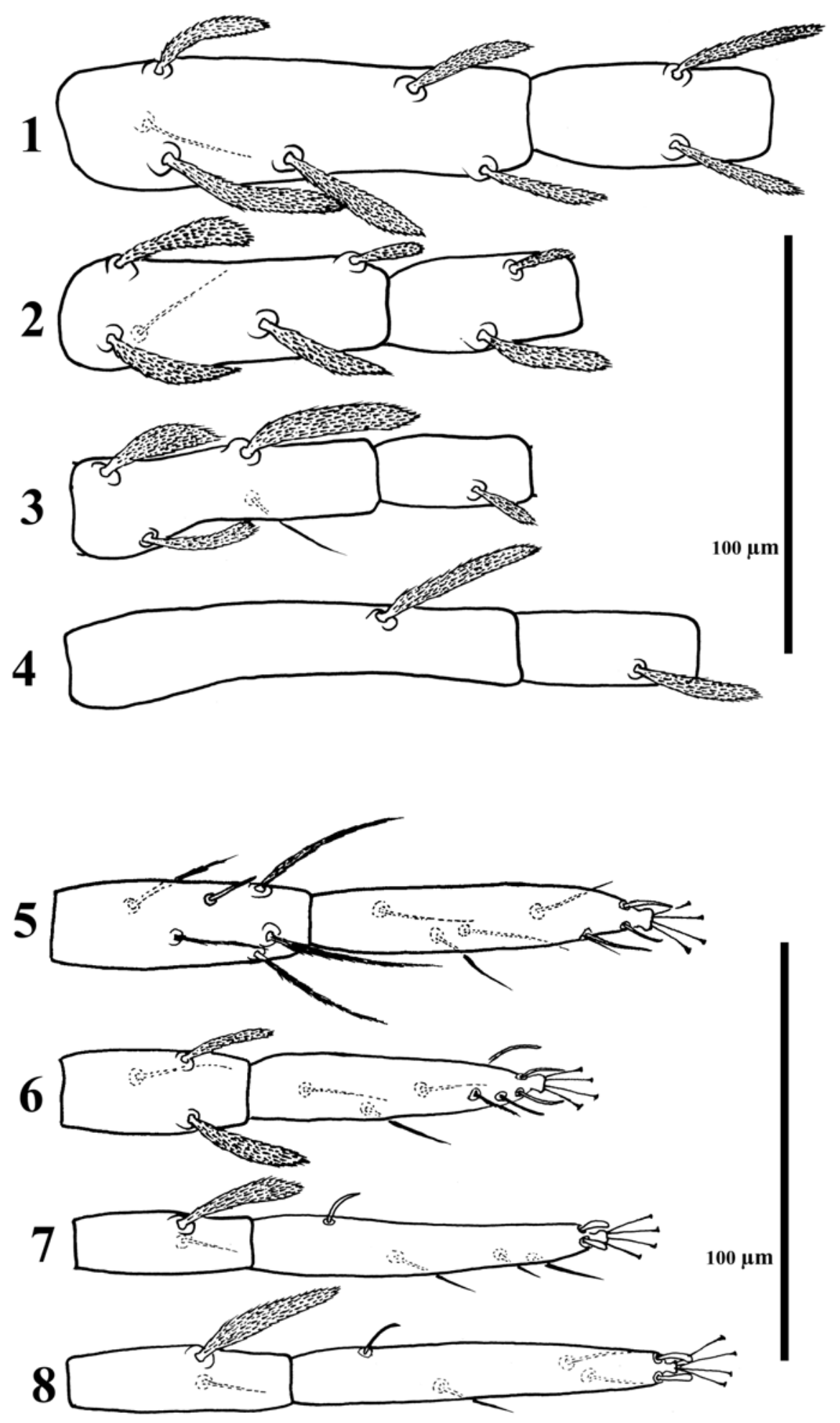

Figura 69. Artículos das pernas de Aponychus sarjui, holótipo fêmea: fêmur e gênu das pernas de I a IV (1-4); tíbias e tarsos I a IV (5-8). 


\section{Gênero Stylophoronychus Prasad, 1975}

Aponychus (Stylophoronychus) Prasad, 1975a: 1

Sinotetranychus Ma \& Yuan, 1980: 441; Meyer, 1987: 87; Bolland et al., 1998: 173.

Stylophoronychus: Meyer, 1987: 88; Gupta \& Gupta, 1994: 46.

Espécie-tipo: Aponychus (Stylophoronychus) baghensis Prasad.

Etimologia: L. styl, estrutura pontiaguda + G. phoros, de portador, estrutura portadora dos estiletes, formada pela fusão dos artículos basais da quelícera nos Tetranychoidea; refere-se ao estilóforo singular encontrado nessas espécies, apresentando dois lobos alongados anteriormente (V. Prasad, informação pessoal).

Diagnose: um par de setas pseudo-anais ( $p s$ ) nas fêmeas, empódio ausente; 9 pares de setas histerossomais ( $f 1$ ausentes).

Seis espécies são incluídas atualmente nesse gênero, associadas principalmente a plantas monocotiledôneas da família Poaceae. Seis das sete espécies são conhecidas das regiões equatorial e tropical asiática, com exceção de $S$. insularis, registrada sobre uma dicotiledônea no Brasil. Não há registro de ocorrência na América do Norte, Antárctica, Austrália, Europa e norte Asiático.

Excetuando-se S. insularis, as demais espécies apresentam a seta dorsal $c 2$ reduzida em relação à $c 1$. Rimando (1966) considerou a ausência das setas $f 1$ como uma "acceptedly oddity" (anomalia). Zhang et al. (2000a) revisaram a taxonomia desse gênero, sugerindo que $S$. insularis (Flechtmann) não compartilha um ancestral comum com as demais espécies de Stylophoronychus. Com exceção dela, as demais espécies apresentam setas dorsais curtas ou ultrapassando pouco a base dos pares subsequentes, e as projeções bilobadas marcadas anteriores no estilóforo.

$\mathrm{Na}$ análise filogenética realizada, essa espécie foi posicionada próxima à raiz do cladograma, em posição basal próxima às espécies do grupo externo (Figura 7, p. 41). Portanto, sugerimos que essa espécie deva sofrer alterações quanto à sua classificação, deixando Stylophoronychus monofilético. 


\section{Stylophoronychus nakaoi (Ehara \& Wongsiri)}

(Figuras 16.17 p. $49 ; 17.11$ p. 50; 18.17 p. 51; 19.18 p. 52; 20.22 p. 53; 21.23 p. $54 ; 22.21$ p. $55 ; 23.13$ p. 56; 24.26 p. $57 ; 25.20$ p. $58 ; 26.22$ p. $59 ; 27.23$ p. $60 ; 28.17$ p. $61 ; 29.15$ p. $62 ; 70$ p. 152$)$

Aponychus nakaoi Ehara \& Wongsiri, 1975: 153; Rimando \& Corpuz-Raros, 1996: 12.

Stylophoronychus nakaoi; Meyer, 1987: 88; Zhang et al., 2000a: 44.

Sinotetranychus nakaoi; Bolland et al., 1998: 174.

Série típica: holótipo $q$, parátipos 5q, Ban Kad próximo a Chiang Mai, Tailândia, 30.X.1970, ex bambu (Poaceae); $1 \uparrow$ 17.XII.1970.

Coleção depositária: NSMJ.

Etimologia: homenagem a Shun-ichi Nakao.

Obs: macho desconhecido.

Hospedeiros: bambu (Poaceae).

Distribuição: Tailândia (Ehara \& Wongsiri, 1975).

\section{Material examinado:}

- holótipo +, parátipos 29, Tailândia, 30.X.1070, ex bambú, S. Ehara col. (SH, NSMJ).

Diagnose: Esta espécie assemelha-se a $S$. vannus pela ausência da seta caudal $f 1$, mas distingue-se por apresentar o tegumento dorsal liso e sem fortes enrugamentos como naquela espécie. A quetotaxia dos gênus e tíbias também é distinta, apresentando-se como 2-1-1-1 e 3(1)-1-1-1 em $S$. nakaoi, respectivamente, enquanto que em $S$. vannus ela apresenta-se como1-1-1-1 e 3(1)-2-1-1, respectivamente.

\section{Redescrição:}

Fêmea $(n=3)$. Dorso: Estilóforo com duas fortes projeções anteriormente; apenas um ocelo próximo ao tubérculo das setas prodorsais sci; setas dorsais levemente serreadas, setas escapulares externas e humerais ( $s c 2$ e $c 3$ ) com extremidades convergentes; seta $c 2$ presentes, de comprimento reduzido em relação a $c l$; seta $f 1$ ausente; setas dorso-centrais com comprimentos equivalentes ( $c 1$ $\approx d 1 \approx e 1$ ); idiossoma: comprimento 385-396, largura 264-264; comprimento das setas dorsais: v2 19-19, sc1 11-11, sc2 49-52 (c1, dl e el quebradas em espécimes analisados), c2 11-11, c3 49-52, d2 16-19, e2 35-35, f2 44-46, h1 44-46.

Distância entre pares de setas dorsais: v2-v2 57-60, sc1-sc1 98-103, sc2-sc2 223-228, c1-c1 33-35, c2-c2 128-136, c3-c3 248-256, d1-d1 22-27, d2-d2 185-199, e1-el 14-16, e2-e2 150-152, 
f2-f2 109-117, hl-hl 54-60.

Ventre. Comprimento das setas ventrais: $m$ 19, la 19-22, lb 24-27, lc 27-30, 2b 27-30 (2c ausente nos espécimes analisados), $3 a$ 16, $3 b$ 24-27, $4 a$ 14-16, 4b 24-27, ag 14, g1 22-24, g2 3335, ps3 19, h3 27-30, h2 24-30. Distância entre pares de setas ventrais: m-m 30, la-la 60-65, lb-lb 87-90, lc-lc 109-114, 2b-2b 166-169, 3a-3a 60-73, 3b-3b 193-201, 4a-4a 65-73, 4b-4b 204, ag-ag 22, gl-g1 30-33, g2-g2 49-52, ps3-ps3 22, h3-h3 57-60, h2-h2 33-35.

Quetotaxia das pernas (artículos nas pernas I a IV): coxa 2-1-1-1, trocânter 1-1-1-1, fêmur 6-5-3-1, gênu 2-1-1-1, tíbia 3(1)-2-1-1, tarso 8(1assoc.)-9-6(1)-6(1). Setas do parassociado presentes no tarso I, mas dissociadas no tarso II; solenídio proximal presente nos tarsos III e IV. 


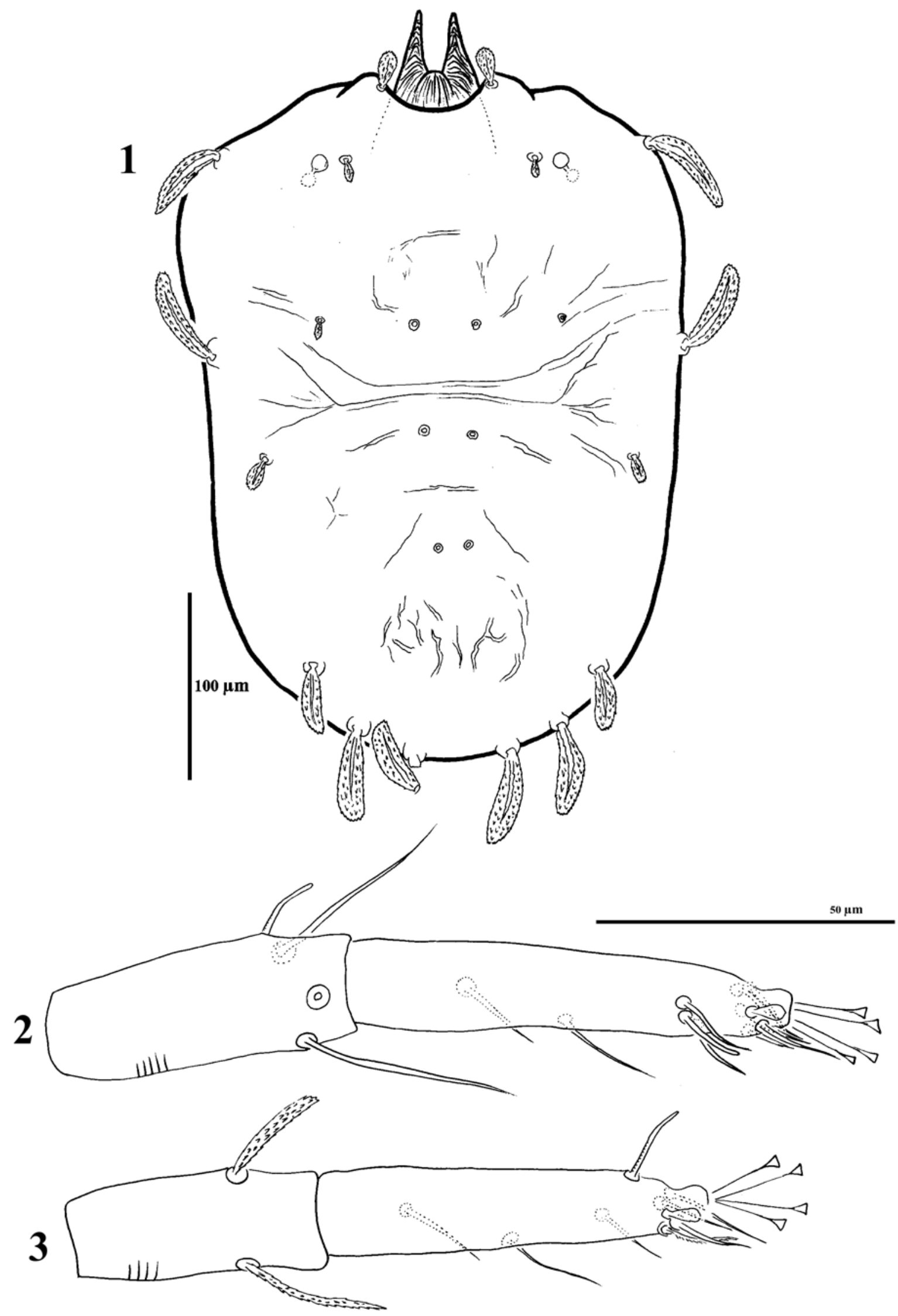

Figura 70. Stylophoronychus nakaoi, holótipo fêmea: vista dorsal (1), tíbia e tarso I e II (2-3). 


\section{Stylophoronychus baghensis (Prasad)}

(Figuras 16.6 p. $49 ; 17.3$ p. $50 ; 18.10$ p. $51 ; 19.5$ p. $52 ; 20.19$ p. $53 ; 21.22$ p. $54 ; 22.18$ p. $55 ; 23.11$ p. $56 ; 24.23$ p. 57 ; 25.19 p. $58 ; 26.19$ p. $59 ; 27.20$ p. $60 ; 28.15$ p. $61 ; 29.13$ p. $62 ; 30.13$ p. $63 ; 31.12$ p. $64 ; 71$ p. $154 ; 72$ p. $155 ; 81.5-6$ p.

Aponychus (Stylophoronychus) baghensis Prasad, 1975a: 1; Prasad, 1975b: 8; Gupta, 1985: 59.

Stylophoronychus baghensis; Meyer, 1987: 88; Gupta \& Gupta, 1994: 46; Zhang et al., 2000a: 40. Aponychus baghensis; Rimando \& Corpuz-Raros, 1996: 12.

Sinotetranychus baghensis; Bolland et al., 1998: 173.

Série típica: holótipo , , Lal Bagh, Bangalore, estado de Karnataka, Índia, 19.III.1973, ex folhas de bambu (Poaceae), V. Prasad col.; parátipos 2q, 22.X.1972, mesma localidade e hospedeiro que o holótipo.

Coleção depositária: USNM (holótipo e parátipos).

Etimologia: refere-se à localidade tipo, o jardim botânico Lal Bagh, na cidade de Bangalore, estado de Karnakata, Índia; do termo Hindi bag, jardim (V.Prasad, comunicação pessoal).

Hospedeiros: Bambusa arundinacea, Bambusa sp., Bambuseae sp., Phyllostachys pubescens (Poaceae), Musa sp. (Musaceae).

Distribuição: Índia (Prasad, 1975a; Gupta \& Gupta, 1994; Gupta, 1995), China (Zhang et al., 2000a).

Obs: macho desconhecido.

Gupta \& Gupta (1994: 46) erroneamente citaram o hospedeiro tipo de S. baghensis como "Bauhinia aurandinaceae ? (bamboo)" [sic.], referindo-se a Bambusa arundinacea (Retz.) Willd. (Poaceae).

\section{Material examinado:}

- holótipo + , Lal Bagh, Bangalore, Karnataka State, Índia, 19.III.1973, ex folha de bambu, V. Prasad col., VP 73-184 (USNM); parátipos 2ᄋ, 22.X.1972, V. Prasad col., VP 72-196 (USNM).

Esta é a espécie tipo do gênero, por designação subsequente, quando Meyer (1987) elevou o subgênero Aponychus (Stylophoronychus) para status genérico. Entretanto, foi possível concluir a partir da análise de espécimes tipo que esta espécie deve ser considerada um sinônimo júnior de Stylophoronychus nakaoi (ver discussão taxonômica na página 156). 


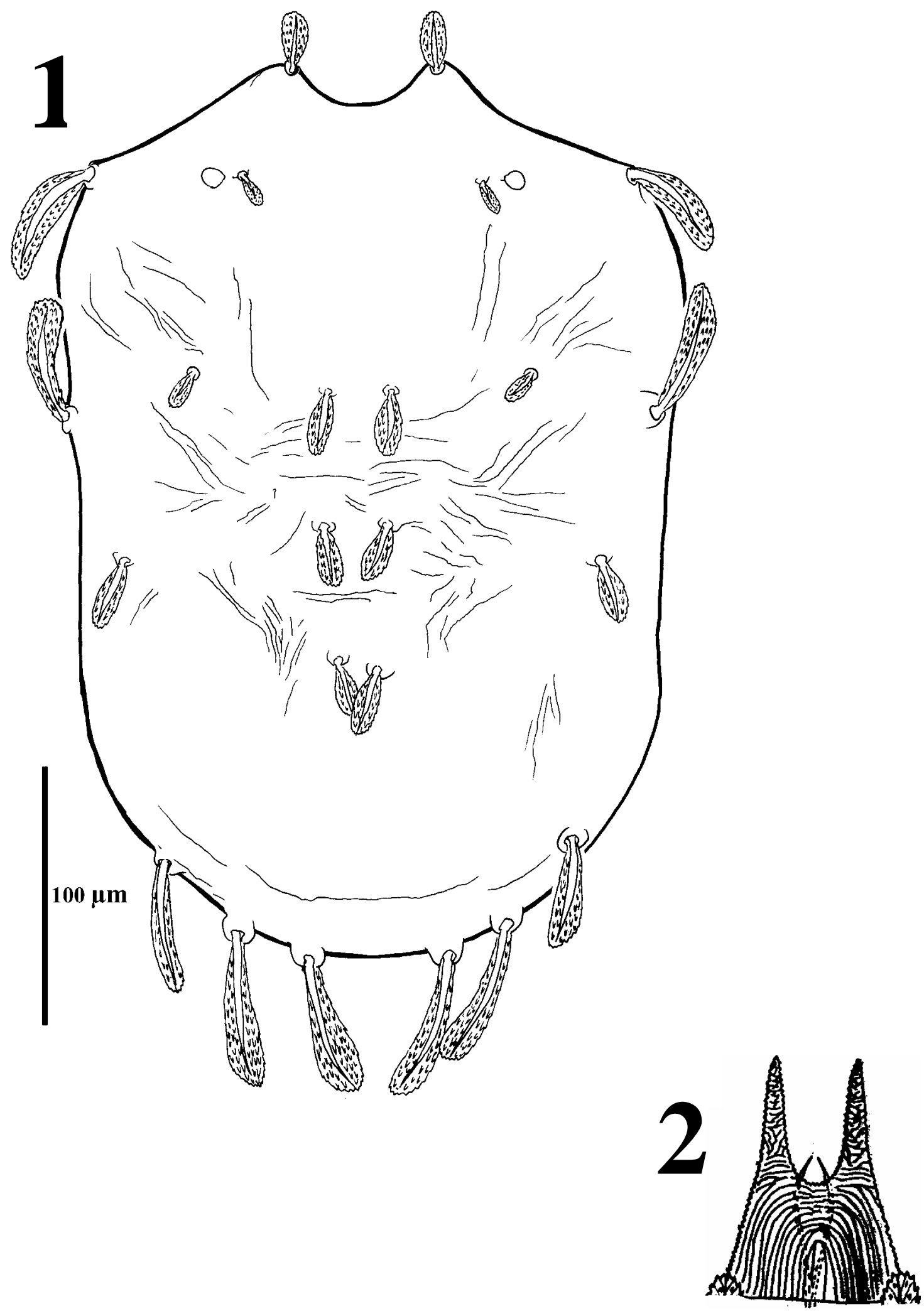

Figura 71. Stylophoronychus baghensis, holótipo fêmea: vista dorsal do idiossoma (1) e estilóforo (2). 

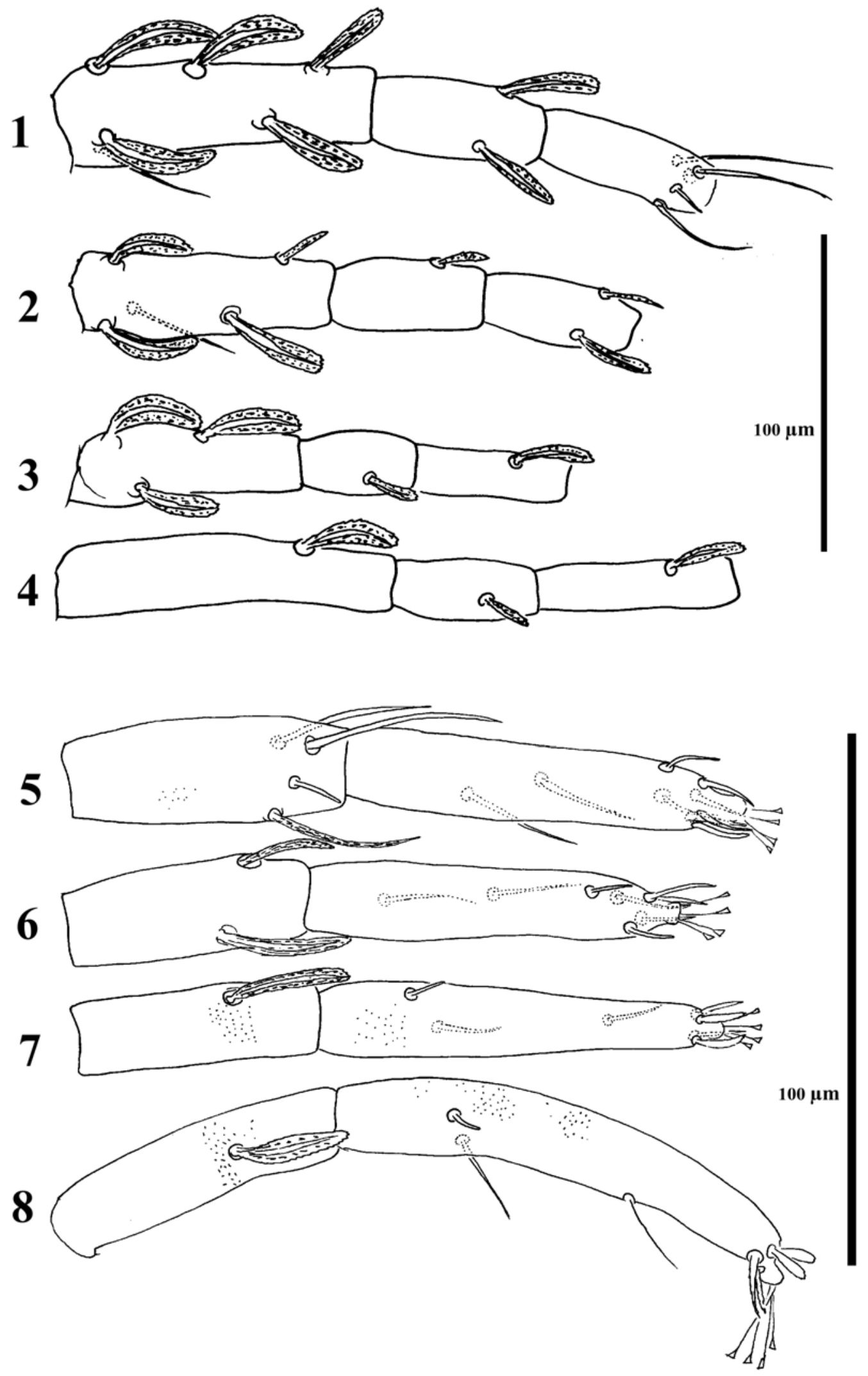

Figura 72. Stylophoronychus baghensis, holótipo fêmea: artículos das pernas, fêmur, gênu e tíbia de I a IV (1-4), tíbia e tarso I a IV (5-8). 


\section{Discussão taxonômica:}

Após análise de espécimes tipo de $S$. nakaoi e $S$. baghensis, foi possível concluir que a segunda deve ser considerada um sinônimo júnior da primeira. Ambas foram descritas em 1975, mas o volume que apresenta a descrição de $S$. nakaoi foi publicado em abril, enquanto que o trabalho que apresenta S. baghensis, o primeiro volume do periódioco International Journal of Acarology, agendado para o mês de junho de 1975, foi publicado em outubro daquele ano (Prasad, 1987).

Zhang et al. (2000a) diferenciaram as duas espécies baseando-se no comprimento relativo das setas dorso-centrais, que sofrem um decréscimo progressivo $(c l>d l>e l)$ em $S$. nakaoi e são do mesmo comprimento em S. baghensis (Figura 71, p. 154). Entretanto, o número de espécimes conhecidos é muito pequeno para se concluir asseguradamente que se tratam de duas espécies distintas: apenas 6 fêmeas de S. nakaoi e 3 fêmeas de S. baghensis foram descritas originalmente; posteriormente, mais 4 fêmeas de S. baghensis foram coletadas na China (Zhang et al., 2000a). O macho de ambas permanece desconhecido. Em outras espécies analisadas, como A. grandidieri, A. schultzi, $P$. corderoi e $S$. vannus, encontramos grande variação com relação ao comprimento e espessura das setas dorsais.

Em todos os outros caracteres analisados, as duas espécies revelaram-se idênticas, inlcuindo a quetotaxia dos artículos das pernas, caráter específico bastante constante em todas espécies analisadas. Um outro caráter encontrado somente nas espécies de Stylophoronychus é a presença de um eixo central visível nas setas dorsais, originalmente não ilustrado para S. nakaoi, mas que verificamos estar presente nos espécimes tipo obtidos por empréstimo. Um outro fator que corrobora a hipótese de sinonímia dessas duas espécies é que algumas variações nos comprimentos do idiossoma, pernas e setas dorsais já foram encontradas em indivíduos de $S$. baghensis provenientes de diferentes localidaes (China e Índia) (Zhang et al., 2000a) (Tabela VI, p. 157). 
Tabela VI. Medidas de corpo e setas dorsais de Stylophoronychus baghensis e S. nakaoi.

\begin{tabular}{ccccc}
\hline $\begin{array}{c}\text { Espécie } \\
\text { Localidade }\end{array}$ & Índia $(\mathrm{n}=3)$ & $\begin{array}{c}\text { S. baghensis } \\
\text { Sanmin }(\mathrm{n}=4)^{*}\end{array}$ & $\begin{array}{c}\text { S. nakaoi } \\
\text { Yailândia }(\mathrm{n}=3) \mathbf{s}\end{array}$ \\
\hline Comprimento do idiossoma & 342 & $350-459$ & 260 & $385-396$ \\
Largura do idiossoma & 240 & $260-390$ & 285 & $264-264$ \\
$v 2(P I)$ & $21-25$ & $23-28$ & 23 & $19-19$ \\
$s c 1(P 2)$ & $10-15$ & $9-12$ & 9 & $11-11$ \\
$s c 2(P 3)$ & $48-55$ & $50-56$ & 45 & $49-52$ \\
$c 1(D 1)$ & $20-28$ & $23-28$ & 21 & - \\
$c 2(L 1)$ & $11-18$ & $9-10$ & 8 & $11-11$ \\
$c 3(H)$ & $55-58$ & $47-60$ & 47 & $49-52$ \\
$d 1(D 2)$ & $20-27$ & $25-30$ & 24 & - \\
$d 2(L 2)$ & $20-28$ & $25-30$ & 24 & $16-19$ \\
$e 1(D 3)$ & $19-30$ & $24-28$ & 28 & - \\
$e 2(L 3)$ & $45-53$ & $49-56$ & 46 & $35-35$ \\
$h 1(D 5)$ & $52-58$ & $50-56$ & 49 & $46-49$ \\
$f 2(L 4)$ & $53-63$ & $49-56$ & 46 & $44-46$ \\
\hline$=$ espécimes tipo; ${ }^{*}=$ medidas de espécimes coletados na China, obtidas de Zhang et & &
\end{tabular}




\section{Stylophoronychus vannus (Rimando)}

(Figuras 10.1 p. $45 ; 12$ p. $46 ; 13.2$ p. $47 ; 14.2$ p. $47 ; 16.25$ p. $49 ; 17.16$ p. $50 ; 18.20$ p. $51 ; 19.28$ p. $52 ; 20.27$ p. 53 ; 21.26 p. $54 ; 22.24$ p. $55 ; 23.15$ p. $56 ; 24.27$ p. $57 ; 25.23$ p. $58 ; 26.23$ p. $59 ; 27.24$ p. $60 ; 28.18$ p. $61 ; 29.16$ p. $62 ; 30.15$ p. $63 ; 31.14$ p. $64 ; 73$ p. $160 ; 74$ p. $161 ; 78$ p. $171 ; 82.1-3$ p. 175$)$

Aponychus vannus Rimando, 1968: 8; Ehara \& Wongsiri, 1975: 153; Rimando \& Corpuz-Raros, 1996: 12.

Aponychus (Stylophoronychus) vannus; Johnston \& Flechtmann, 1990: 247.

Stylophoronychus vannus; Meyer, 1987: 88; Zhang et al., 2000a: 44; Migeon \& Flechtmann, 2004: 148.

Sinotetranychus vannus; Bolland et al., 1998: 174.

Série típica: holótipo + , 25.I.1967; 18 \& $5 ð$ parátipos, 26.I.1967, College campus, Los Baños, Filipinas, ex Bambusa sp. (Poaceae); parátipo + , mesmo dados que o holótipo, 23.IV.1963. Coleção depositária: UPLB (holótipo e parátipos), USNM (parátipo).

Etimologia: do inglês fan (leque), referindo-se ao formato das setas caudais (fan-shaped).

Hospedeiros: Elephantopus sp. (Asteraceae), Bambusa sp., B. ventricosa, B. vulgaris, Bambuseae sp., Gigantochloa laevis, G. Ligulata, Thyrsostachys siamensis (Poaceae), Melanolepis multiglandulosa (Euphorbiacae).

Distribuição: Indonésia (Johnston \& Flechtmann, 1990), Malásia (Ehara \& Tho, 1988), Filipinas (Rimando, 1966), Tailândia (Baker, 1975; Ehara \& Wongsiri, 1975), India (Gupta \& Gupta, 1990; Gupta \& Gupta, 1994).

Observação: Segundo Zhang et al. (2000a) a quetotaxia dessa espécie não foi estudada, portanto ela é aqui apresentada pela primeira vez.

\section{Material examinado:}

- parátipo + , College Campus, Laguna, Filipinas, 23.IV.1963, ex Bambusa sp. (Poaceae) (USNM); 6ㅇ, 3ㅅ, Bang Khen, Pesticide Research Center, Tailândia, ex Gigantochloa ligulata Gamble (Poaceae) (USNM); 3 + Ban Kad, 30.X.1970, ex folha de bambu, S. Ehara col. (SH); 2 q Gambung, Java, Indonésia, 13.III.1988, ex bambu ornamental, D.E. Johnston col. (DZSJRP); 2 , mesmos dados (OSU).

Diagnose: essa espécie se distingue das demais do gênero por apresentar conspícuo enrugamento do tegumento dorsal semelhante ao aspecto de um córtex cerebral, e setas caudais ( $h 1, f 2$ e $e 2)$ dilatadas e palmadas; a quetotaxia do gênus e tíbias também são distintivas: 1-1-1-1 e 3(1)-1-1-1, respectivamente, enquanto que em $S$. nakaoi as setas nesses artículos apresentam-se 
segundo a fórmula 2-1-1-1 e 3(1)-2-1-1. 


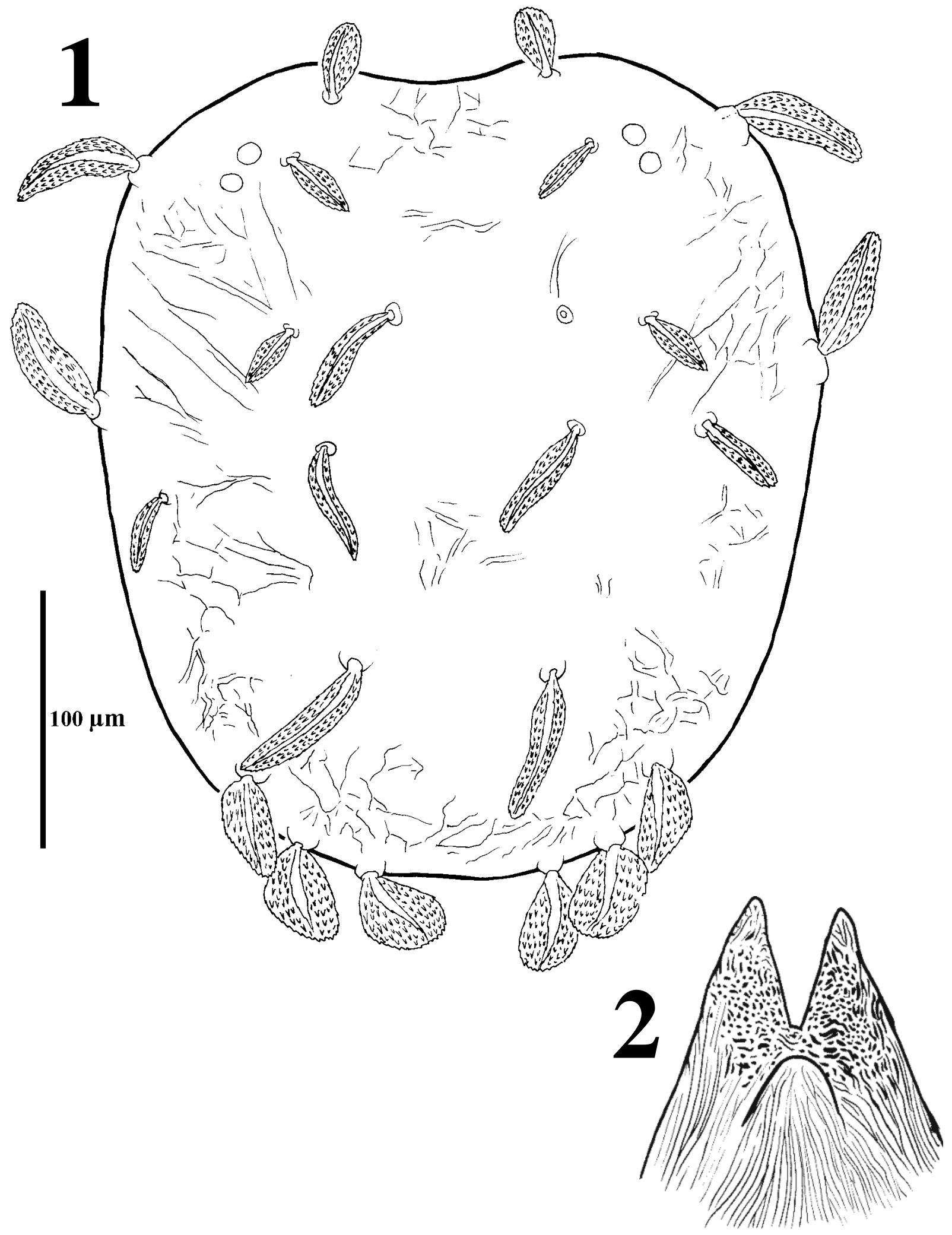

Figura 73. Stylophoronychus vannus, parátipo fêmea: vista dorsal do idiossoma (1) e estilóforo (2). 


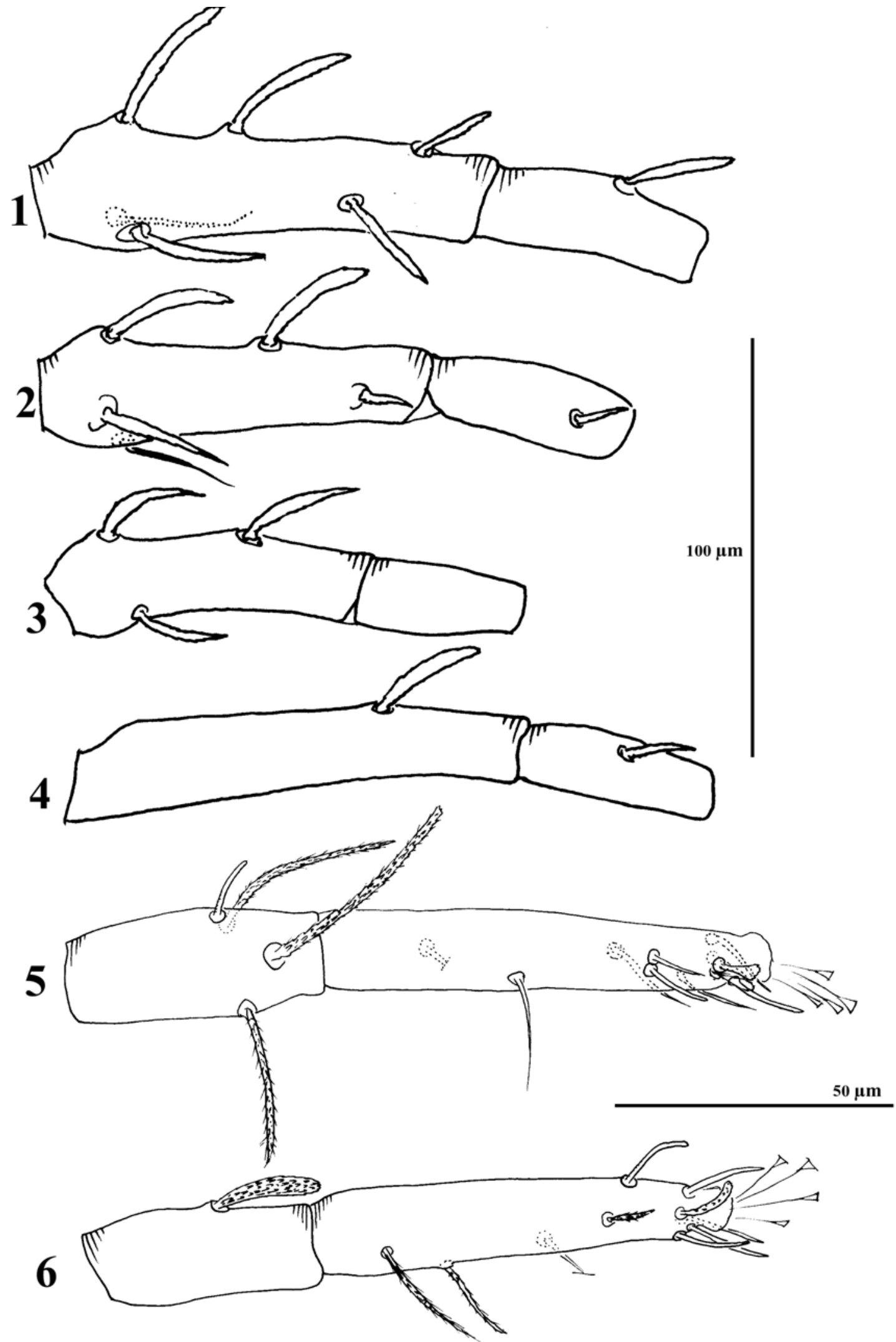

Figura 74. artículos das pernas I a IV de Stylophoronychus vannus, fêmea: fêmur e gênu de I a IV (1-4), tíbia e tarso I e II (5-6). 


\section{Stylophoronychus lalli (Prasad)}

(Figuras 13.1 p. $47 ; 16.15$ p. $49 ; 17.9$ p. $50 ; 18.15$ p. $51 ; 19.16$ p. $52 ; 20.26$ p. $53 ; 21.25$ p. $54 ; 22.20$ p. $55 ; 23.12$ p. 56 ; 24.25 p. $57 ; 25.22$ p. $58 ; 26.21$ p. $59 ; 27.22$ p. $60 ; 75$ p. $163 ; 82.5-6$ p. 175$)$

Aponychus (Stylophoronychus) lalli Prasad, 1975b: 8.

Aponychus lalii [sic]; Gupta, 1985: 60; Rimando \& Corpuz-Raros, 1996: 12.

Aponychus lalli; Bolland et al., 1998: 20.

Stylophoronychus lalli; Gupta \& Gupta, 1994: 48; Zhang et al., 2000a: 43.

Série típica: holótipo + , parátipo +, Bihar Agriculture College, Sabour, Bhagalpur District, 24.I.1973, ex folhas de bambu (Poaceae), V. Prasad col. (USNM).

Coleção depositária: USNM (holótipo e parátipos).

Etimologia: homenagem a B.S. Lall, que apresentou ao autor o "fascinante mundo da acarologia".

Obs: o autor da espécie, V. Prasad, fundou em 1975 um dos mais importantes periódicos científicos de acarologia, o International Journal of Acarology.

Hospedeiros: Bambusa arundinacea (Retz.) Willd. (Poaceae).

Distribuição: India (Prasad, 1975b).

\section{Material examinado:}

- holótipo q, parátipo q, Bihar Agriculture College, Sabour, Bhagalpur District, estado de Bihar, Índia, 24.I.1973, ex folhas de bambu, V. Prasad col. (USNM).

Essa espécie provavelmente constitui um sinônimo júnior de $S$. vannus. Apenas 2 indivíduos fêmeas são conhecidos, coletados no nordeste da Índia. Nessa região já foi registrada a espécie Aponychus bambusae, que também deve ser considerada um sinônimo júnior de $S$. vannus (ver discussão sobre sinonímias dessas espécies na página 163). 


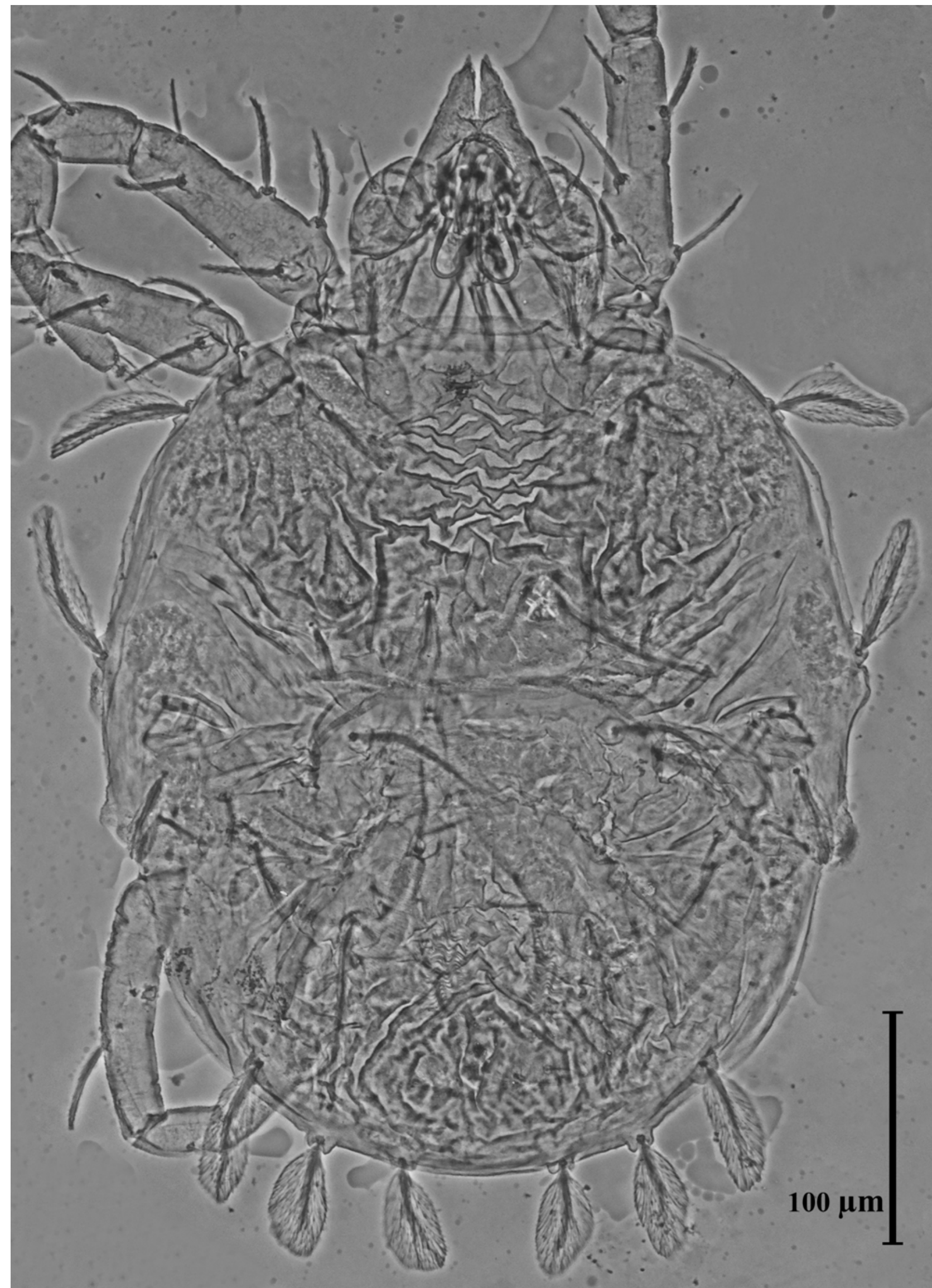

Figura 75. Stylophoronychus lalli, holótipo fêmea: vista dorsal (fotomicrografia em contraste de fase). 


\section{Stylophoronychus guangzhouensis (Ma \& Yuan)}

(Figuras 76 p. 165; 82.7 p. 175)

Sinotetranychus guangzhouensis Ma \& Yuan, 1980: 441; Ma et al., 1984: 111; Meyer, 1987: 87; Bolland et al., 1998: 173.

Paraponychus guangzhouensis; Rimando \& Corpuz-Raros, 1996: 13.

Stylophoronychus guangzhouensis; Zhang et al., 2000a: 42; Migeon \& Flechtmann, 2004: 148.

Série típica: holótipo + , parátipo $\uparrow$, 18.XII.1977, Kwangchow, China, ex Poaceae sp..

Coleção depositária: MNHS (holótipo e parátipo).

Etimologia: provavelmente referente à localidade tipo, Guangzhou, capital da província de Guangdong, China.

Hospedeiros: folha de bambú (Poaceae).

Distribuição: China (Ma \& Yuan, 1980).

Obs: macho desconhecido.

É provável que essa espécie constitua um sinônimo júnior de S. vannus (Rimando, 1966), devido às semelhanças encontradas em todos os caracteres analisados (ver discussão taxonômica na página 168). Entretanto, não foi obtido sucesso no contato com o curador do Museu de História Natural de Shangai, onde estão depositados os espécimes-tipo de S. guangzhouensis, com o intuito de confirmar essa hipótese. 


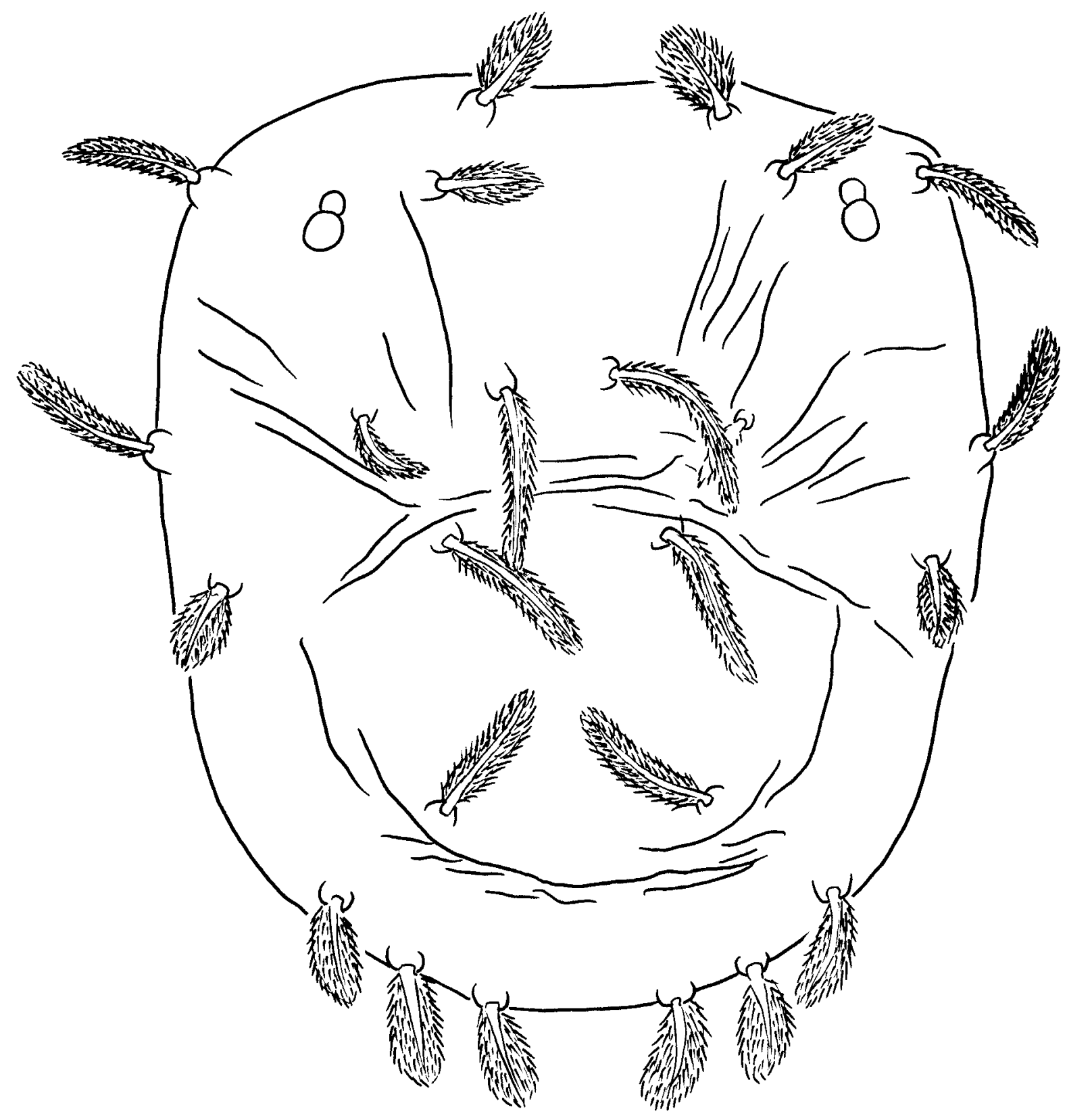

Figura 76. Vista dorsal do idiossoma de Stylophoronychus guangzhouensis, holótipo fêmea [redesenhado a partir de ilustração presente em Ma et al. (1984: 112)]. 


\section{Aponychus bambusae Gupta \& Gupta}

(Figuras 16.7 p. $49 ; 17.4$ p. 50; 18.11 p. $51 ; 19.6$ p. $52 ; 20.25$ p. 53; 21.24 p. $54 ; 22.19$ p. $55 ; 23.22$ p. 56 ; 24.24 p. $57 ; 25.21$ p. $58 ; 26.20$ p. $59 ; 27.21$ p. $60 ; 77$ p. $167 ; 82.4$ p. 175$)$

Aponychus bambusae Gupta \& Gupta, 1990: 16; Gupta \& Gupta, 1994: 39.

Série típica: holótipo $\widehat{\jmath}$, parátipo $q$ (ver material examinado abaixo).

Coleção depositária: NCZSI (holótipo e parátipo).

Etimologia: refere-se ao hospedeiro tipo, Bambusa sp..

Hospedeiros: Bambusa arundinacea, Saccharum officinarum (Poaceae).

Distribuição: India (Gupta \& Gupta, 1990; Gupta \& Gupta, 1994).

\section{Material examinado:}

- holótipo $\widehat{\partial}$, parátipo $q$ (NCZSI). Foram verificadas inconsistências quanto ao hospedeiro tipo e data de coleta nas informações apresentadas na descrição original dessa espécie e nas etiquetas das lâminas-tipo. Na etiqueta dos tipos consta a localidade como a cidade de Baruipur, distrito de South 24 Paraganas, estado de West Bengal (Índia), hospedeiro bambu, 10.V.1978, Y.N. Gupta col.; entretanto, na publicação original é mencionada a localidade como Arun Bihar, Tezu, estado de Arunachal Pradesh (Índia), hospedeiro cana-de-açúcar, 21.I.1983. Os números de registros são os mesmos nas duas fontes para holótipo (3185/17) e parátipo (3186/17). É mencionada ainda a presença de cinco parátipos fêmea (3186/17), mas apenas uma lâmina contendo apenas uma fêmea foi encontrada com esse número de registro.

Essa espécie, apesar de originalmente incluída no gênero Aponychus, não apresenta a seta histerossomal caudal $f 1$, o que a diagnostica como pertencente ao gênero Stylophoronychus. Essa espécie não foi incluída no catálogo da família Tetranychidae (Bolland et al., 1998), e no trabalho que adiciona espécies ao catálogo juntamente com correções (Migeon \& Flechtmann, 2004). Zhang et al. (2000a) também não mencionaram essa espécie quando estudaram a taxonomia do gênero Stylophoronychus. A partir da análise dos tipos dessa espécie, juntamente com os resultados obtidos na análise filogenética, foi constatado que a mesma representa um sinônimo júnior de Stylophoronychus vannus (Rimando, 1966) (ver discussão taxonômica na página 168). 


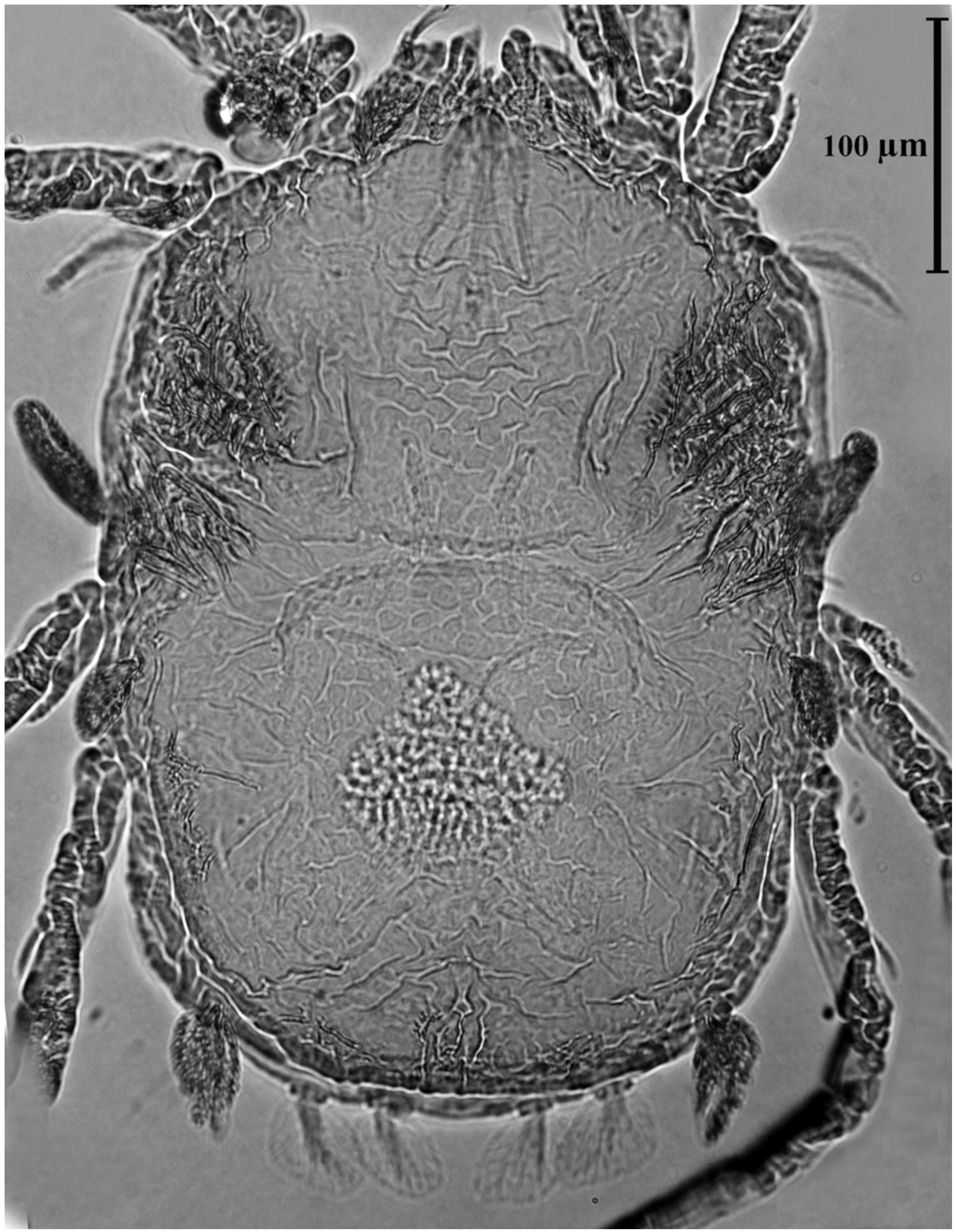

Figura 77. Aponychus bambusae, alótipo fêmea: fotomicrografia em vista dorsal. 


\section{Discussão taxonômica:}

\section{Stylophoronychus vannus: S. lalli, S. guangzhouensis e Aponychus bambusae.}

Essas quatro espécies são muito semelhantes entre si e possivelmente constituem sinônimos da espécie sênior, S. vannus (Rimando, 1968). Apresentam em comum as seguintes características: (1) estilóforo com um par de projeções anteriores bem desenvolvidas; (2) pelo menos em $S$. vannus, $S$. lalli e A. bambusae podem ser observadas granulações nas extremidades distais dessas projeções; (3) apresentam várias setas dorsais dilatadas na porção mediana, principalmente as setas caudais e sacrais $(h 1, f 2$ e $e 2)$; (4) apresentam a mesma quetotaxia nos artículos das pernas: coxa, trocânter, fêmur, gênu e tíbia; em relação aos tarsos, é provável que a quetotaxia seja a mesma também em S. guangzhouensis, descrita como sendo 11-9-7-7 para essa espécie, e verificada como 10(a)-8(1)-6(1)-6(1) em S. vannus; (5) pelo menos em S. vannus, $S$. lalli e A. bambusae existem ornamentações conspícuas de aspecto altamente enrugado em praticamente todo o tegumento dorsal, resultando em um padrão semelhante ao de um córtex cerebral. Não foi possível determinar se esse padrão é ausente em S. guangzhouensis, ou se não foi representado em sua descrição. Entretanto, observamos que em alguns espécimes de $S$. vannus (e.g. provenientes de Java e da Tailândia), esse caráter pode estar menos evidente, ainda que presente (Figura 78, p. 171). Diferentes metodologias aplicadas durante a preparação das lâminas também podem resultar em alteração do aspecto dorsal.

Zhang et al. (2000a) concluíram que S. guangzhouensis e S. lalli são muito semelhantes em relação às setas dorsais e das pernas, e propuseram uma chave dicotômica para a separação dessas duas espécies baseando-se em tênues diferenças no comprimento e formato das setas dorsais. Assim, mencionaram que ocorre um alargamento na porção mediana da seta $c l \mathrm{em} S$. lalli, mas não em S. guangzhouensis. Entretanto, essas setas não sofrem tal alargamento mediano em parátipo de $S$. lalli, o que evidencia tratar-se de um caráter variável dentro da espécie. Esses autores também diferenciaram essas duas espécies de $S$. vannus pelo comprimento relativo da seta $e 1$, que nessa última espécie corresponde a distância entre as bases dessas setas, não atingindo as bases do respectivo par em $S$. guangzhouensis e S. lalli. Apesar dessa última característica ser facilmente notada na ilustração original de S. vannus (Rimando, 1968: 9, fig.3), observamos que o mesmo não ocorre no parátipo analisado dessa espécie, tampouco em demais exemplares coletados na Tailândia e em Java. Portanto, conclui-se que esse caráter é bastante variável, e não suficientemente constante para ser utilizado na diagnose específica dessas espécies.

Outra diferença atribuída a S. lalli e S. guangzhouensis em relação à S. vannus é que nesta última as setas $h 1$ são espatuladas, com comprimento e largura praticamente semelhantes; nas duas primeiras espécies, o comprimento dessa seta é aproximadamente duas vezes a largura. Entretanto, 
essa característica pode ocorrer devido ao posicionamento fora de plano das setas nos espécimes montados em lâminas, como pôde ser verificado em espécime coletado em Java, no qual várias das setas dorsais apresentam-se "inclinadas" e fora de plano, resultando em uma redução relativa da largura visível dessas setas. Adicionalmente, como já visto para outras espécies analisadas, pequenas variações no comprimento e formato de setas dorsais são relativamente comuns em algumas espécies, até mesmo em indivíduos de uma mesma população (e.g. Paraponychus incanus, Aponychus grandidieri, A. schultzi).

Em outras espécies de Aponychus, com registro em diversos hospedeiros e localidades, foi reportada variação intra e interpopulacional em relação a alguns desses caracteres. Ehara (1966: 142) apontou que existe uma grande variação tanto no formato quanto no comprimento das setas dorsais de $A$. schultzi, espécie registrada sobre 23 plantas hospedeiras na América do Sul. Em A. corpuzae, foi registrada variação no número de setas presentes nos tarsos I e II. Ho (2003) sintetizou informações de diversos autores que estudaram essa espécie, que já foi registrada sobre 20 plantas hospedeiras em 9 países da Ásia. Deste modo, visto que diferenças muito sutis foram usadas para diagnosticar essas espécies, sugerimos que esses caracteres não mais devam ser utilizados nesses casos, a menos que um grande número de indivíduos seja estudado, e que esses caracteres se mostrem confiáveis e sem valores de sobreposição.

Um outro fator que deve ser destacado é o número extremamente pequeno de exemplares estudados de três dessas espécies: A. bambusae (1 fêmea e 1 macho), S. lalli (2 fềmeas) e $S$. guangzhouensis (2 fêmeas). Desse modo, quando compara-se essas espécies, está se comparando, na realidade, diferentes indivíduos, que podem meramente apresentar pequenas variações populacionais, ou até mesmo representar diferentes metodologias aplicadas durante a preparação das lâminas permanentes. A validade dessas espécies representadas por poucos indivíduos permanece, portanto, bastante questionável.

Em outros grupos de tetraniquídeos, como na tribo Tetranychini, muitas espécies são indistinguíveis a partir das fêmeas, sendo necessária análise comparativa da morfologia dos edéagos dos machos. O mesmo não ocorre nas espécies aqui estudadas, que apresentam as fêmeas suficientemente distintas para permitir diagnose específica a partir de sua análise. Mesmo assim, comparando-se os edéagos de $S$. vannus e A. bambusae, percebe-se que estes apresentam-se de acordo com a mesma morfologia básica, o que reforça a sugestão de sinonímia entre elas. Os machos de S. lalli e S. guangzhouensis não são conhecidos.

Portanto, sugerimos que essas espécies sejam consideradas como sinônimos júnior de $S$. vannus. 
Tabela VII. Medidas de corpo e setas dorsais de espécimes-tipo de Stylophoronychus; ${ }^{*}=$ parátipo).

\begin{tabular}{|c|c|c|c|c|c|c|}
\hline $\begin{array}{c}\text { Espécie } \\
\text { Localidade }\end{array}$ & $\begin{array}{l}\text { S. vannus } \\
\text { Filipinas } \\
(\mathrm{n}=1)\end{array}$ & $\begin{array}{l}\text { S. vannus } \\
\text { Java } \\
(\mathrm{n}=2)\end{array}$ & $\begin{array}{l}\text { S. vannus } \\
\text { Tailândia } \\
(\mathrm{n}=8)\end{array}$ & $\begin{array}{c}\text { S. lallia } \\
\text { India } \\
(\mathrm{n}=1)\end{array}$ & $\begin{array}{c}\text { A. bambusaes } \\
\text { Índia }(\mathrm{n}=1)\end{array}$ & $\begin{array}{c}\text { total } \\
(\mathrm{n}=13)\end{array}$ \\
\hline comprimento idiossoma & 325 & $325-335$ & $315-391$ & 320 & 285 & $285-291$ \\
\hline largura idiossoma & 274 & $269-274$ & $259-320$ & 264 & 207 & $207-320$ \\
\hline$v i$ & $33-33$ & $34-40$ & $27-33$ & $37-38$ & $29-33$ & $27-40$ \\
\hline Sci & $33-33$ & $38-42$ & $28-37$ & $39-39$ & $23-25$ & $23-42$ \\
\hline sce & $51-51$ & $57-59$ & $45-54$ & $51-52$ & $45-48$ & $45-59$ \\
\hline$c 1$ & $63-63$ & $71-77$ & $51-69$ & $63-68$ & $63-64$ & $51-77$ \\
\hline$c l-c l$ & 49 & $44-45$ & $40-47$ & 40 & 40 & $40-47$ \\
\hline$c 2$ & $27-27$ & $25-29$ & $20-29$ & $25-25$ & $19-22$ & $19-29$ \\
\hline$c 3$ & $44-51$ & $58-59$ & $45-58$ & $52-53$ & $42-48$ & $42-59$ \\
\hline$d l$ & $72-72$ & $66-72$ & $52-66$ & $69-69$ & $62-70$ & $52-72$ \\
\hline$d l-d l$ & 97 & $97-99$ & $90-104$ & 97 & 80 & $80-104$ \\
\hline$d 2$ & $34-34$ & $44-47$ & $28-38$ & $35-38$ & $28-32$ & $28-47$ \\
\hline$e 1$ & $54-58$ & $63-71$ & $54-67$ & $66-67$ & $45-50$ & $45-71$ \\
\hline$e 1-e 1$ & 80 & $72-82$ & $71-76$ & 83 & 88 & $71-82$ \\
\hline$e 2$ & $43-44$ & $54-59$ & $37-48$ & $51-53$ & $42-45$ & $37-59$ \\
\hline$h 1$ & $37-38$ & $42-48$ & $35-40$ & $45-47$ & $32-33$ & $32-48$ \\
\hline$f 2$ & $44-45$ & $45-52$ & $34-44$ & $48-49$ & $34-35$ & $34-52$ \\
\hline
\end{tabular}



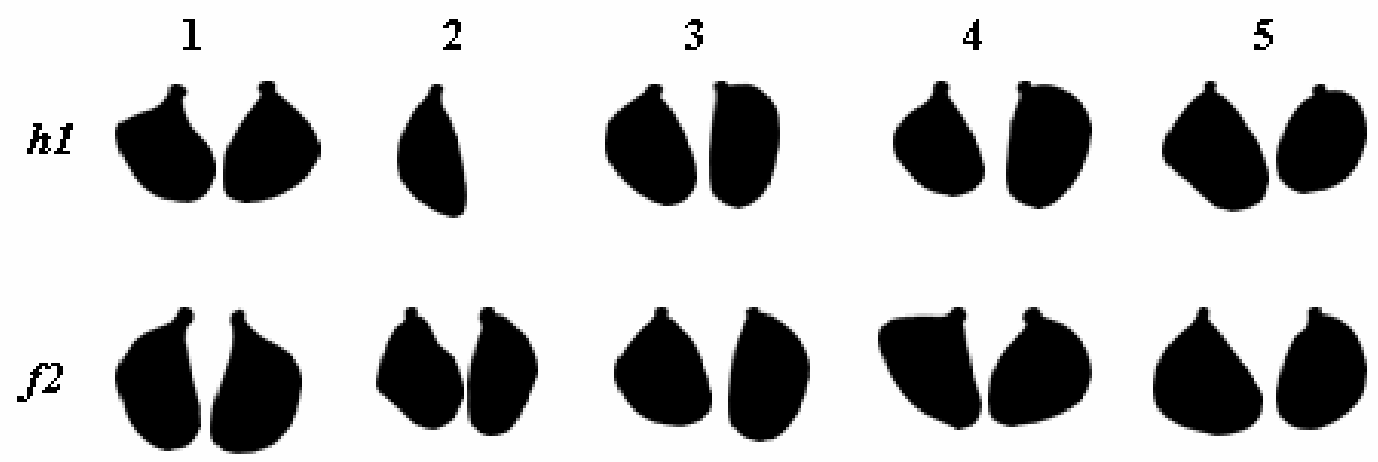

$e^{2}$
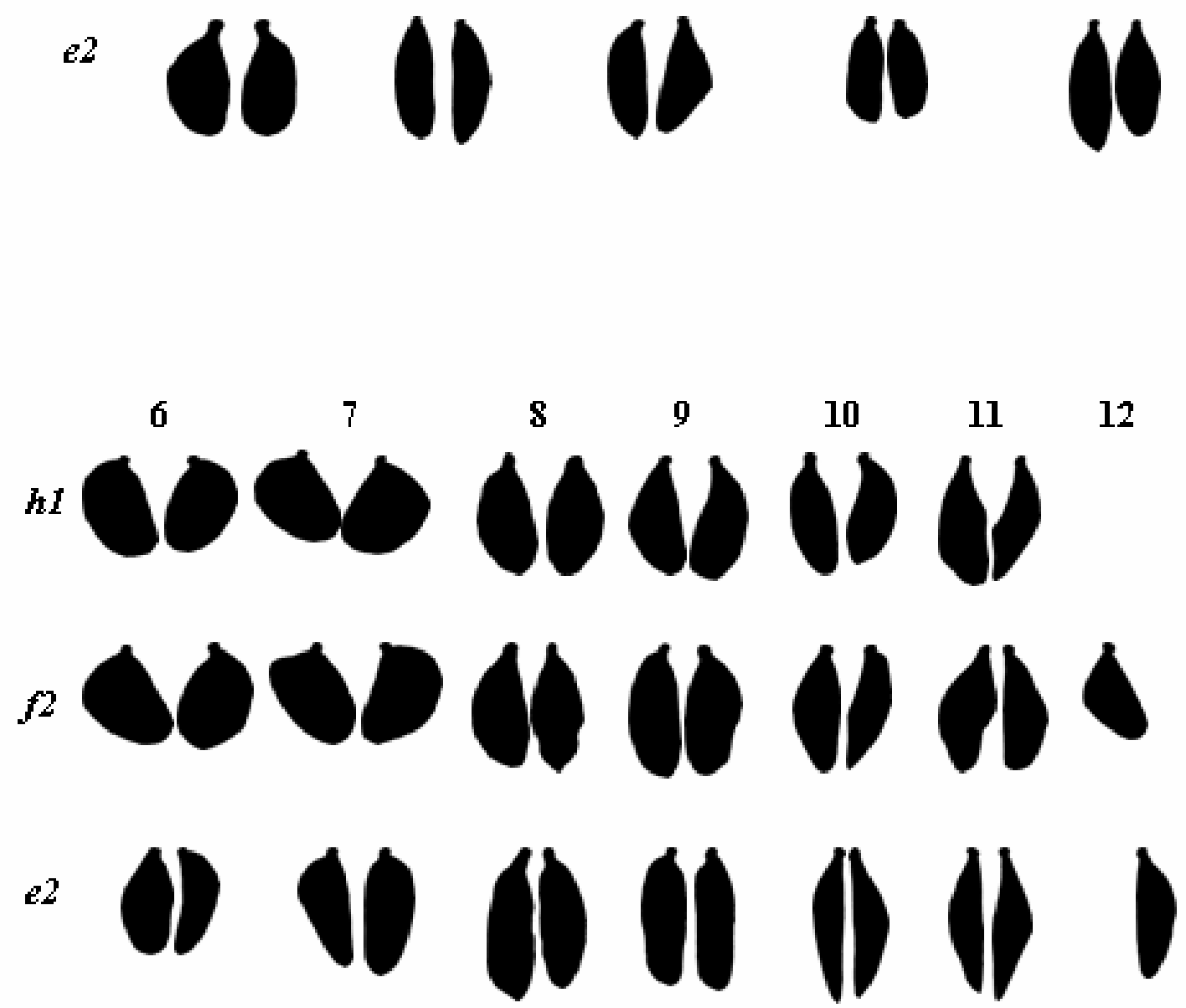

Figura 78. Pares de setas da região posterior do corpo $(h 1, f 2$ e $e 2)$ de espécimes de Stylophoronychus: $1=S$. vannus, parátipo; $2-7=S$. vannus, espécimes coletados na Tailândia; $8=S$. lalli; holótipo; 9= S. lalli, parátipo; 10-12=S. vannus, espécimes coletados em Java. 
Capítulo II - Taxonomia de Aponychus, Paraponychus e Stylophoronychus
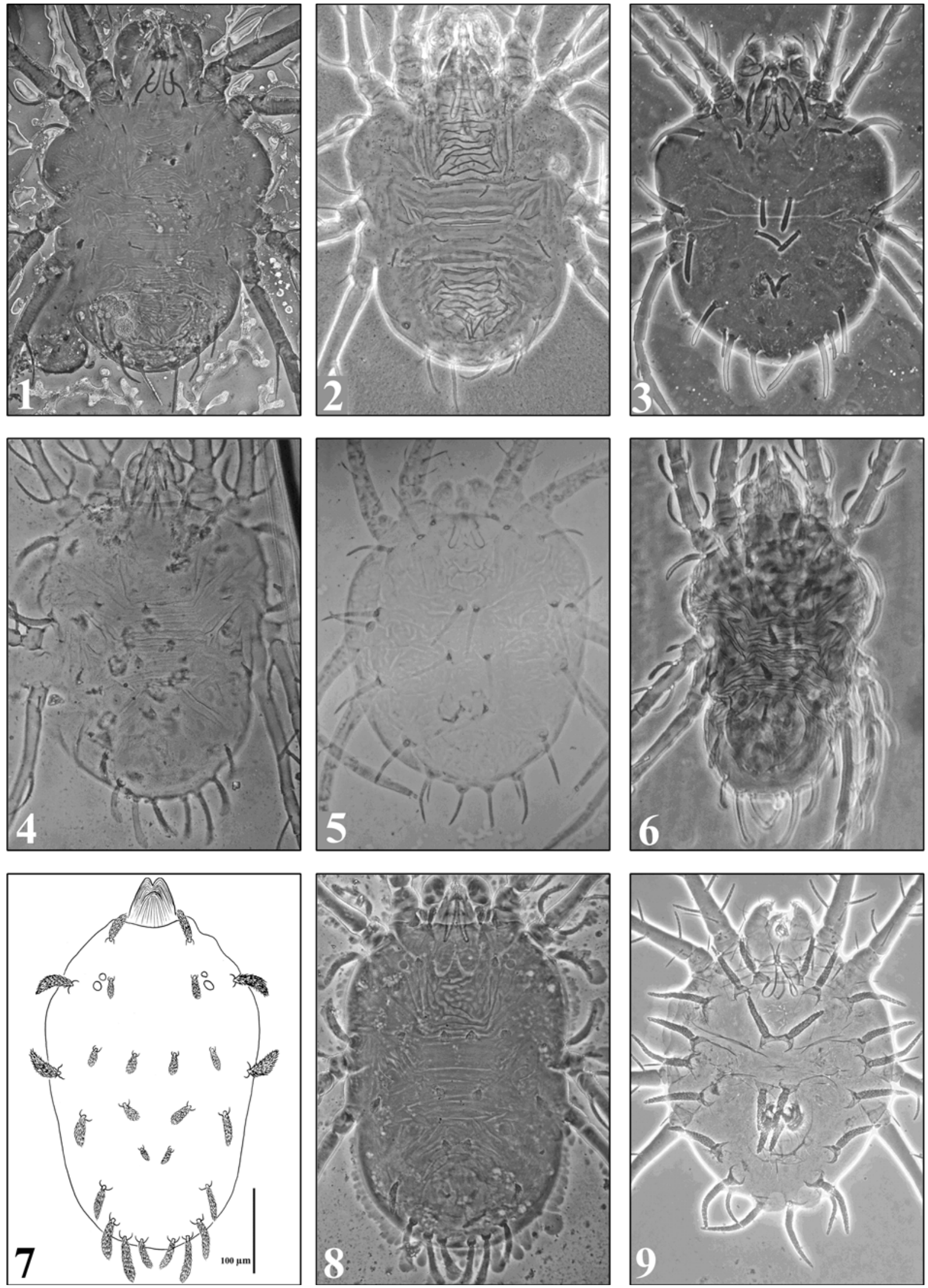

Figura 79. Espécimes e tipo de Aponychus: A. corpuzae $(1=\$ 2=$ coletado em Java), $A$. chiavegatoi (3=), A. expansus (4=\$), A. firmianae $(5=\downarrow)$, A. grandidieri $(6=\downarrow)$, A. imperatus $(7=*)$, A. lupus $(8=\downarrow)$, A. mallotus $(9=\downarrow)(\$=$ holótipo; $\bullet$ parátipo; * = redesenhado a partir de ilustração original). 

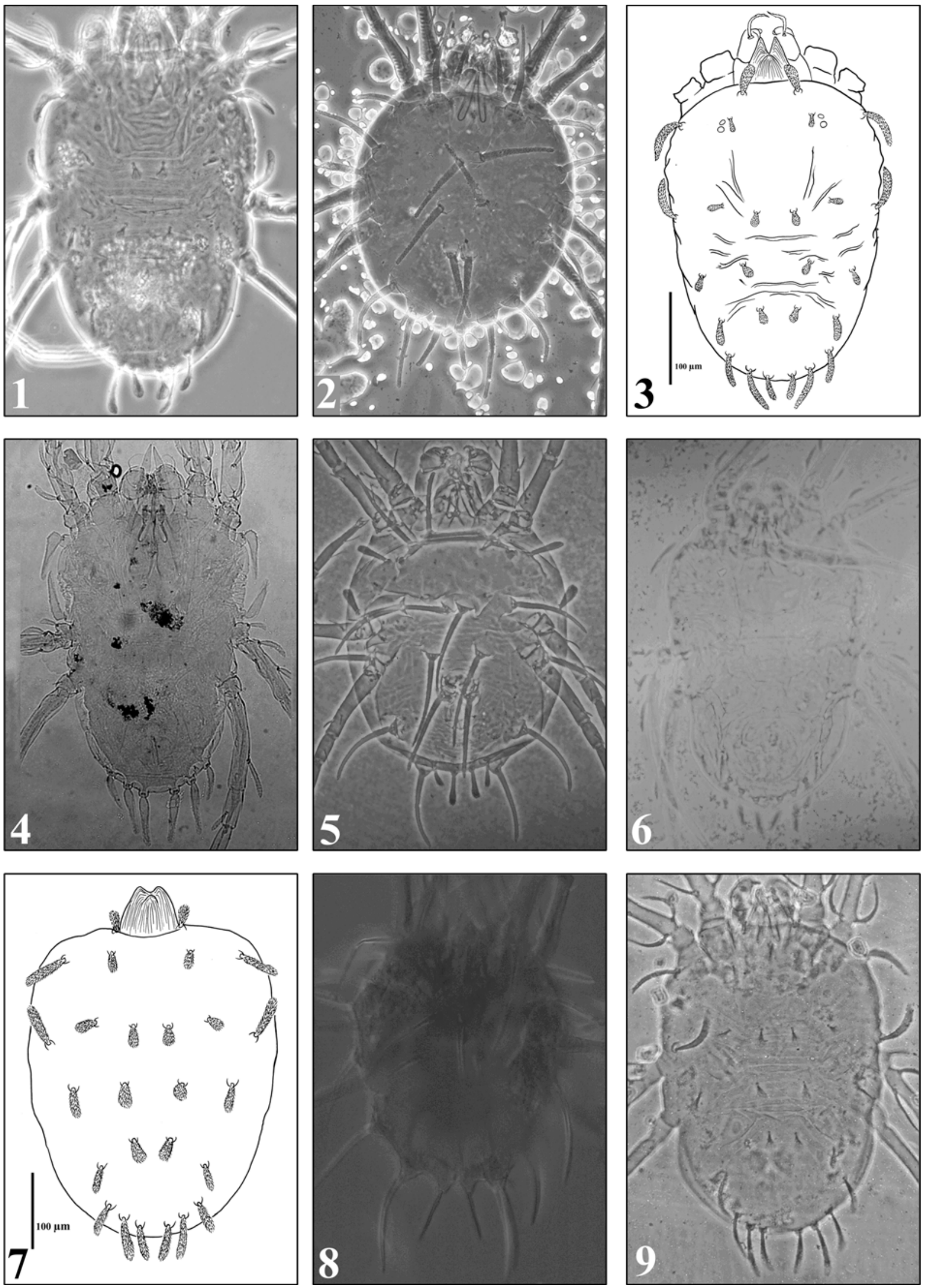

Figura 80. Espécimes e tipo de Aponychus: A. parydrus $(1=\downarrow)$, A. pilipinus $(2=\downarrow)$, A. rarus $(3=*)$, A. sarjui (4=\$), A. schultzi (5), A. siamensis (6=\$), A. solimani (7=*), A. spinosus (8=\$), A. sulcatus $(9=)$. $(\mathbf{=}=$ holótipo; $*$ parátipo; $*=$ redesenhado a partir de ilustração original $)$. 

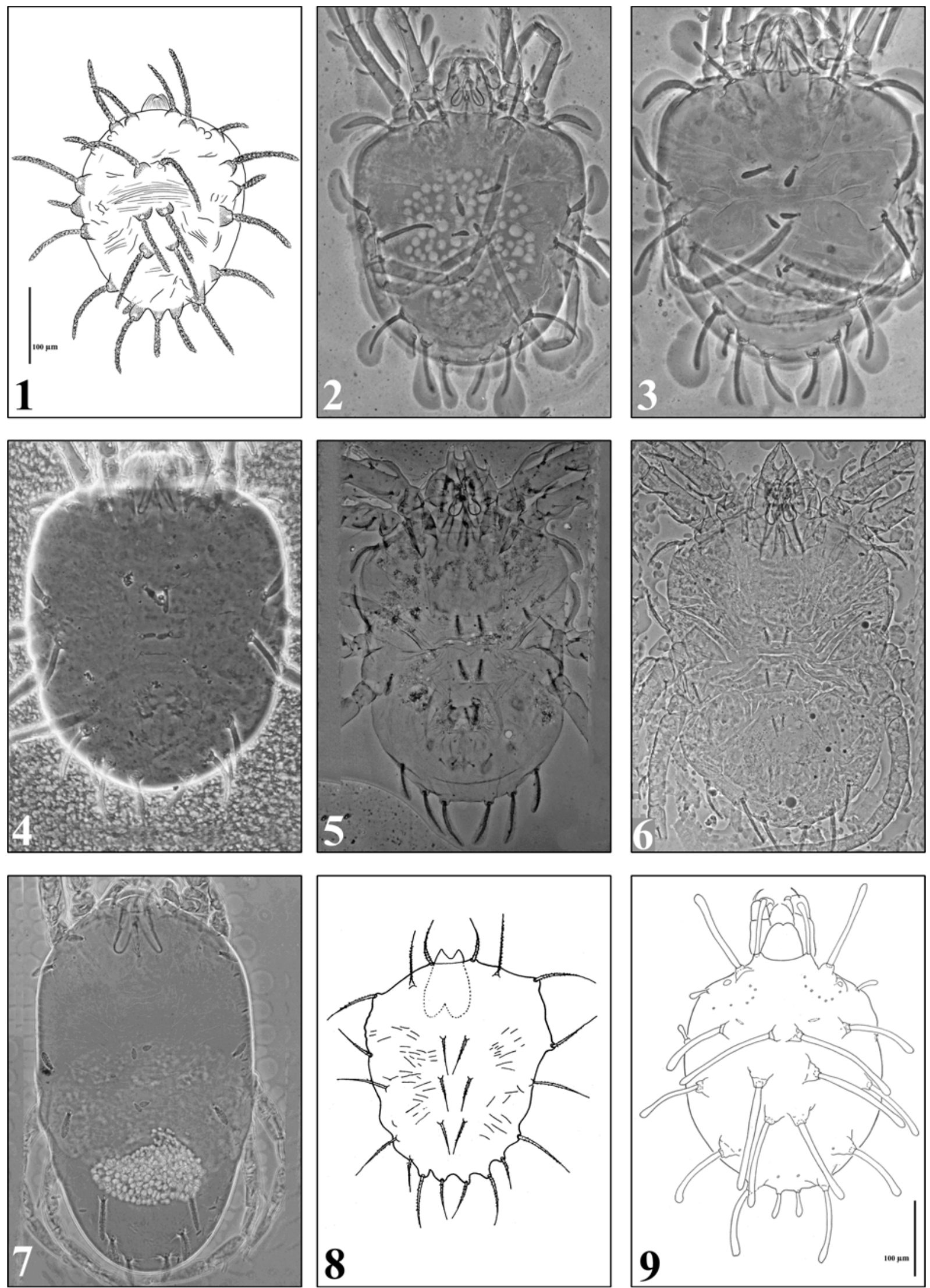

Figura 81. Espécimes tipo de Aponychus, Paraponychus e Stylophoronychus : A. taishanicus $(1=*)$, Paraponychus corderoi $(2=\$ ; 3=\downarrow)$, P. incanus $(4=\downarrow)$, S. baghensis $(5=\$ ; 6=\downarrow)$, P.saundersi $(7=\downarrow)$, P. kodaikanalensis $(8=*)$, S. insularis $(9=*)(\Lambda=$ holótipo; $\bullet=$ parátipo; $*=$ redesenhado a partir de ilustração original). 

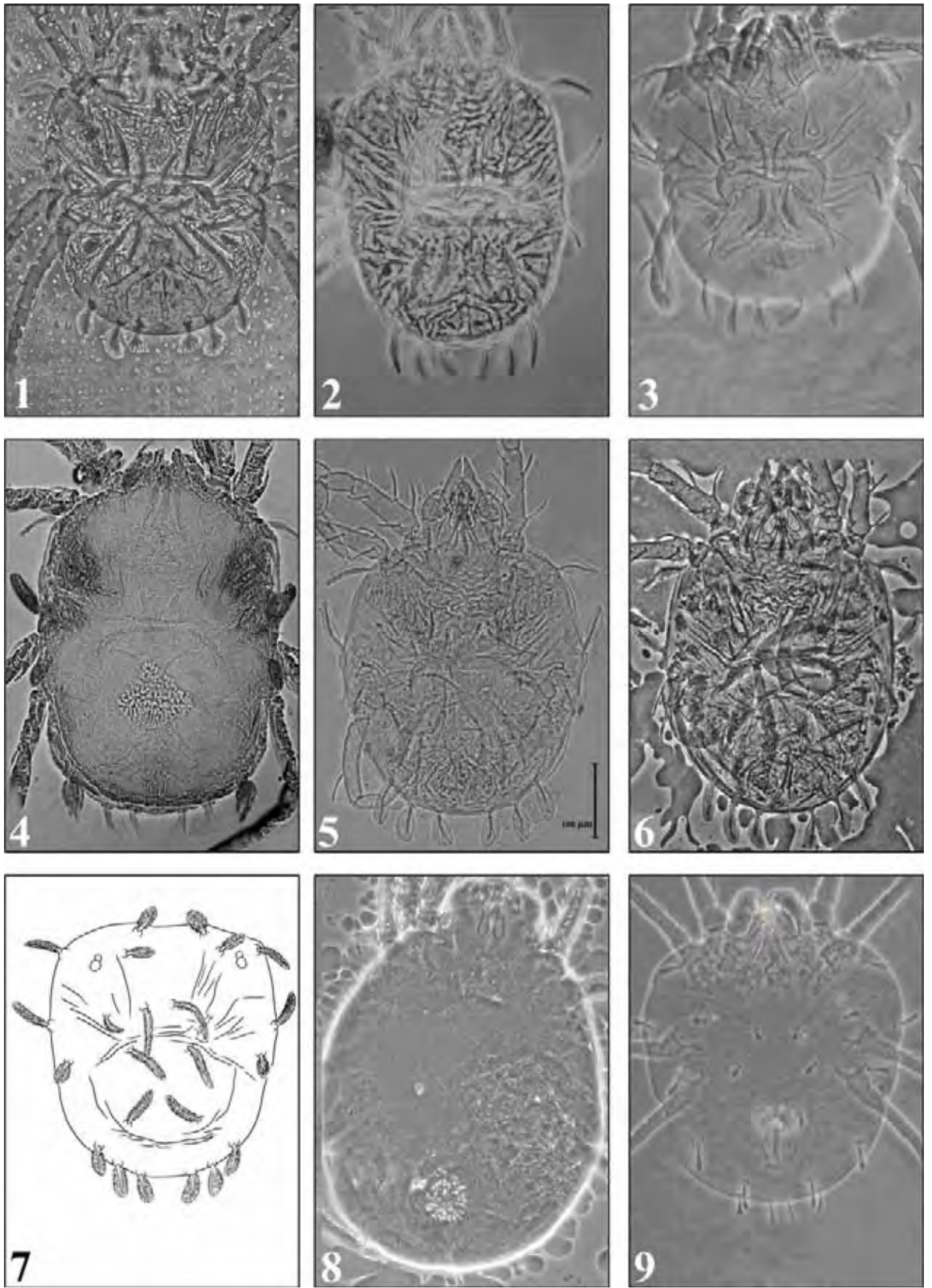

Figura 82. Espécimes tipo de Aponychus e gêneros próximos: Stylophoronychus vannus $(1=\downarrow$; 2=coletado em Java-DZSJRP; $3=$ coletado em Java-OSU), A. bambusae (4=\$), S. lalli (5=\$; 6=\$), S. guangzhouensis (7=*), Meyernychus emeticae (8=^), Eutetranychus banksi (9=coletado em Jaguanum) ( $=$ holótipo; $*$ parátipo; * = redesenhado a partir de ilustração original). 
Tabela VIII. Quetotaxia dos artículos das pernas das espécies de Aponychus, Paraponychus e Stylophoronychus, e das espécies do grupo externo (número de solenídios entre parênteses; setas associadas indicadas por " $d$ ").

\begin{tabular}{|c|c|c|c|c|c|c|}
\hline Espécie & Monoc bambusicola & Mer. emeticae & E. banksi & A. acquilibris & A. chiavegatoi & A. corpuzae \\
\hline Coxa & 2.2 .1 .1 & $2 \cdot 2 \cdot 1-1$ & 2.2 .1 .1 & $2 \cdot 2 \cdot 1.1$ & $2 \cdot 2 \cdot 1-1$ & $2 \cdot 2-1-1$ \\
\hline Trocânter & $1 \cdot 1 \cdot 1 \cdot 0$ & $|-|-1 . \mid$ & $|\cdot| \cdot|\cdot|$ & $\mid-1-1-1$ & $|-| \cdot|-|$ & $\mid-1 \cdot 1 \cdot 1$ \\
\hline Fêmur & $9 \cdot 5-2 \cdot 2$ & $8-6-3-1$ & $6-5 \cdot 2 \cdot 1$. & $7-5-4-2$ & $6-4-2-1$ & $7 \cdot 5 \cdot 4 \cdot 2$ \\
\hline Gềnu & $2 / 3-3-4-4$ & $5 \cdot 5 \cdot 2 \cdot 2$ & $4 \cdot 4 \cdot 2 \cdot 2$ & $3-3-2 \cdot 2$ & $2 \cdot 2-0 \cdot 0$ & $3 \cdot 3 \cdot 2-2$ \\
\hline Tibia & $8(2)-4-3 \cdot 3$ & $9(1)-6-5-6 / 7$ & $9(1)-6-4 \cdot 5$ & $6-3-2-2$ & $4(1) \cdot 3 \cdot 2 \cdot 2$ & $5(1)-3-2-2$ \\
\hline
\end{tabular}

\begin{tabular}{|c|c|c|c|c|c|c|}
\hline Espécie & A. expansus & A. firmianae & A. grandidieri & A. imperatus & A. lupus & A. mallotus \\
\hline Coxa & $2 \cdot 1-1-1$ & $2-1-1-1$ & $2 \cdot 1-1.1$ & $2 \cdot 1-1-1$ & $2 \cdot 1-1-1$ & $2 \cdot 2-1-1$ \\
\hline Trocianter & 1.1 .1 .1 & $\mid-1-1-1$ & $\mid-1-1-1$ & $1-1.1 .1$ & $1-1.1-1$ & $1-1-1-1$ \\
\hline Fêmur & $6-5-3-1$ & $6-4-2-1$ & $6-5-3-1$ & $6-5-3-1$ & $6-5-3-1$ & $7-5 / 4-4-2$ \\
\hline Gênu & $3-3-2 \cdot 2$ & $3-3-1-1$ & $3-3-2-2$ & $3-3-2-2$ & $3-3-2-2$ & $2-2-0-0$ \\
\hline Tibia & $5(1)-3 \cdot 2 \cdot 2$ & $5(1) \cdot 4 \cdot 3 \cdot 3$ & $5(1)-3 / 2-2-2$ & $5(1)-3 \cdot 2 \cdot 2$ & $5(1) \cdot 3 \cdot 2 \cdot 2$ & $5(1)-4-3-4$ \\
\hline Tarso & $14(1)-11(1)-8-8(1)$ & $8(1 a)-7(1 a)-6-6$ & $12(1)-11(1 d)-8.8(1)$ & $12(2) \cdot 12(2)-8.8(1)$ & $14(1)-14(1 \mathrm{~d})-8-8(1)$ & $8(1 a)-5(4)-5(1)-5(1)$ \\
\hline Espécie & A. parydrus & A. pilipinus & A. rarus & A. sarjui & A. schultei $i$ & A. siamensis \\
\hline Coxa & $2 \cdot 1-1 \cdot 1$ & $2 \cdot 2-1 \cdot 1$ & & & $2 \cdot 2 \cdot 1-1$ & $2 \cdot 1 \cdot 1 \cdot 1$ \\
\hline Troeânter & $1-1-1-1$ & $\mid-1-1-1$ & & $|-|-|-|$ & $|-|-|-|$ & $1-1-1-1$ \\
\hline Fêmur & $6-5 \cdot 3-1$ & $6-4-3-1$ & $5-3 \ldots$ & $6-5-4-1$ & $7-4-3-2$ & $6-5-4-1$ \\
\hline Gềnu & $3-3-2-2$ & $3 \cdot 3 \cdot 1-1$ & & $2-2-1-1$ & $3-3-1-1$ & $3 \cdot 3-2 \cdot 2$. \\
\hline Tibia & $5(1)-3-2-2$ & $5(1)-4-3-3$ & $5(1)-2(1) \ldots$ & $5(1) \cdot 3-2$ & $6(1)-5-4-4$ & $5(1)-3-2-2$ \\
\hline Tarso & $12(1 \mathrm{~d})-11(1 \mathrm{~d})-8-8(1)$ & $10(1 d) \cdot 9(1 d)-7(1)-7(1)$ & & $10-10$ & & $11(1)-10(1)-7(1)-7(1)$ \\
\hline
\end{tabular}

\begin{tabular}{|c|c|c|c|}
\hline Espécie & A. solimani & A. spinosus & A. sulcatus \\
\hline Cosa & $2-1-1-1$ & $2-1-1-1$ & $2-1-1-1$ \\
\hline Trocainter & $|-1.1|$. & $|-1 .-1|$. & 1.1 .1 .1 \\
\hline Fêmur & $6-5 \cdot 3-1$ & $6-4-2-1$ & $6-5-3-1$ \\
\hline Gênu & $3-3-2-2$ & $2-2-1-1$ & $3-3-2-2$ \\
\hline Tíbia & $6-3-2$ (rod)-2(rod) & $4(1)-3-2-2$ & $5(1)-3-2 \cdot 2$ \\
\hline Tarso & $14-12-8-8$ & $8(1)$ & $14(1) \cdot 10(1 a) \cdot 7 / 8 \cdot 8(1)$ \\
\hline Espécie & P. Kodaikanalensis & P. saundersi & S. bambusae \\
\hline Coxa & & $3-1-1-1$ & $2.1-1.1$ \\
\hline Trocânter & & $\mid-1-1-1$ & $\mid-1-1-1$ \\
\hline Fềuur & & $6 / 7-4-3-1$ & $6-5-3-1$ \\
\hline Gênu & & $3.3 .1 \cdot 1$ & $|-|-|-|$ \\
\hline Tíbia & $5(1)-2(1)$ & $5(1)-4-3 \cdot 3$ & $3(1)-1-1-1$ \\
\hline Tarso & $8(1)-6(1)$ & $11(1 d-11(1)-6-6(1)$ & $10(1 d)-8(1)-6(1)-6(1)$ \\
\hline Espécie & S. lalli & S. nakaoi & $\boldsymbol{S}$ vannus \\
\hline Coxa & $2.1-1.1$ & $2 \cdot 1-1-1$ & $2 \cdot 1-1.1$ \\
\hline Trocânter & $|-|-|-|$ & $|-|-|-|$ & $|-|-|-|$ \\
\hline Fêmur & $6-5-3-1$ & $6-5-3-1$ & $6-5-3-1$ \\
\hline Gênu & $|-1-1|$. & $2-1-1-1$ & $|-|-|-|$ \\
\hline Tibia & $3(1)-1-1-1$ & $3(1)-2-1-1$ & $3(1)-1-1-1$ \\
\hline Tarso & $10(1 d)-8(1)-6(1)-6(1)$ & $9(1 d)-8(1 d)-6(1) \cdot 6(1)$ & $10(1 d)-8(1)-6(1) \cdot 6(1)$ \\
\hline
\end{tabular}




\section{Chave para auxílio na identificação de fêmeas das espécies de Aponychus, Paraponychus e Stylophoronychus.}

Como observado nas análises filogenética e taxonômica, para algumas espécies não foram encontrados caracteres morfológicos suficientes para permitir sua separação de modo confiável. Nestes casos, elas são referidas no mesmo dicótomo da chave.

1a. estilóforo com acentuadas e pontiagudas projeções bilobadas anteriores.. 2

1b. estilóforo com margem anterior arredondada ou com projeções não pontiagudas. 7

2a. seta $f l$ ausente; eixo central das setas dorsais visível. gênero Stylophoronychus

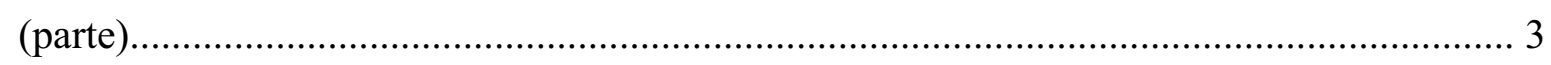

2b. seta $f 1$ presente; eixo central das setas dorsais não visível. 4

3a. grânulos presentes na margem anterior do estilóforo; tegumento dorsal fortemente enrugado; setas dorsais ultrapassando o par subsequente; 1 seta presente no gênu I (d"2 ausente).

A. bambusae, S. guangzhouensis, S. lalli, S. vannus.

3b. grânulos ausentes na margem anterior do estilóforo; tegumento dorsal liso ou fracamente sulcado; setas dorsais curtas, não ultrapassando o par subsequente; 2 setas presentes no gênu I ( $d$ "2 presente). S. baghensis, S. nakaoi.

4a. uma seta na coxa II; seta $v 2$ ausente no fêmur IV (1 seta nesse artículo) 5.

4b. duas setas na coxa II; seta $v 2$ presente no fêmur IV (2 setas nesse artículo). A. corpuzae, A. aequilibris.

5a. um par de ocelos presentes. 6

5b. dois pares de ocelos presentes. A. expansus, $A$. grandidieri, A. imperatus, A. lupus, A. parydrus, A. rarus, A. solimani, A. sulcatus.

6a. seta $f 1$ reduzida. A. sarjui.

6b. seta $f 1$ de comprimento normal, apxoximadamente igual ao das demais setas caudais.

A. siamensis. 
7a. setas dorsais longas, ultrapassando as bases dos pares subsequentes.

7b. setas dorsais curtas, no máximo atingindo as bases dos pares subsequentes.

8a. seta dorsal $f 1$ presente. 9

8 b. seta $f 1$ ausente.

S. insularis.

9a. setas $s c 2$ e $c 3$ reduzidas em relação às demais setas dorsais 10

9 b.setas $s c 2$ e $c 3$ de comprimento semelhante ao das demais setas dorsais.

A. mallotus.

10a. duas setas presentes na coxa II; seta ventro axial $v 3$ presente nos fêmures I e II. 11

10b. uma seta na coxa II; seta ventro axial $v 3$ ausente nos fêmures I e II.

A. spinosus.

11a. seta dorso-antiaxial $d$ " 1 presente no fêmur I

11a. seta dorso-antiaxial $d " 1$ ausente no fêmur I.

A. pilipinus.

12a. seta $v 3$ presente no fêmur II; 6 setas táteis na tíbia I.

A. schultzi.

12b. seta $v 3$ ausente no fêmur II; 5 setas táteis na tíbia I.

A. taishanicus.

13a. seta dorsal $c 2$ presente. Aponychus (parte) 14

13b. seta dorsal $c 2$ ausente. Paraponychus. 15

14a. seta $c 2$ vestigial.

A. chiavegatoi.

14b. seta $c 2$ de comprimento semelhante ao de $c 1$ e $c 3$

A. firmianae.

15a. comprimento das setas dorsocentrais não atingindo as bases dos pares

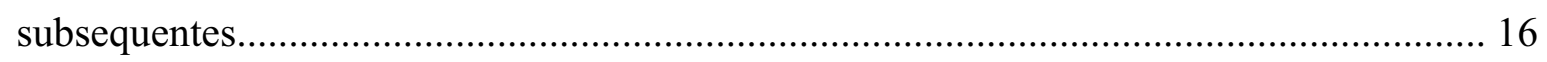

15b. comprimento das setas dorsocentrais atingindo as bases dos pares subsequentes. P. kodaikanalensis.

16a. comprimento do idiossoma duas vezes a largura P. saundersi. 16b. idiossoma aproximadamente 1,5 vez a largura. P. corderoi, P. incanus. 


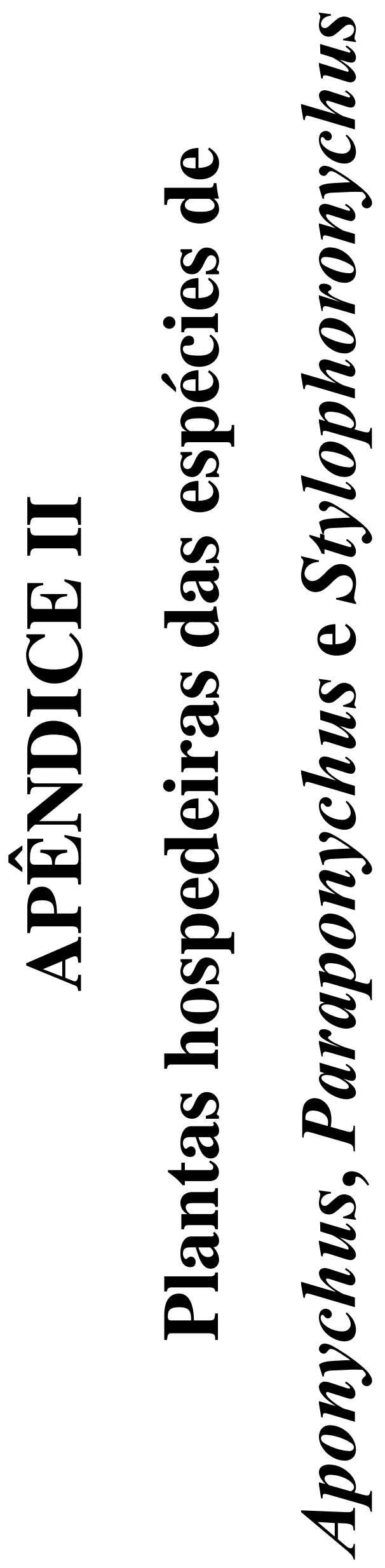




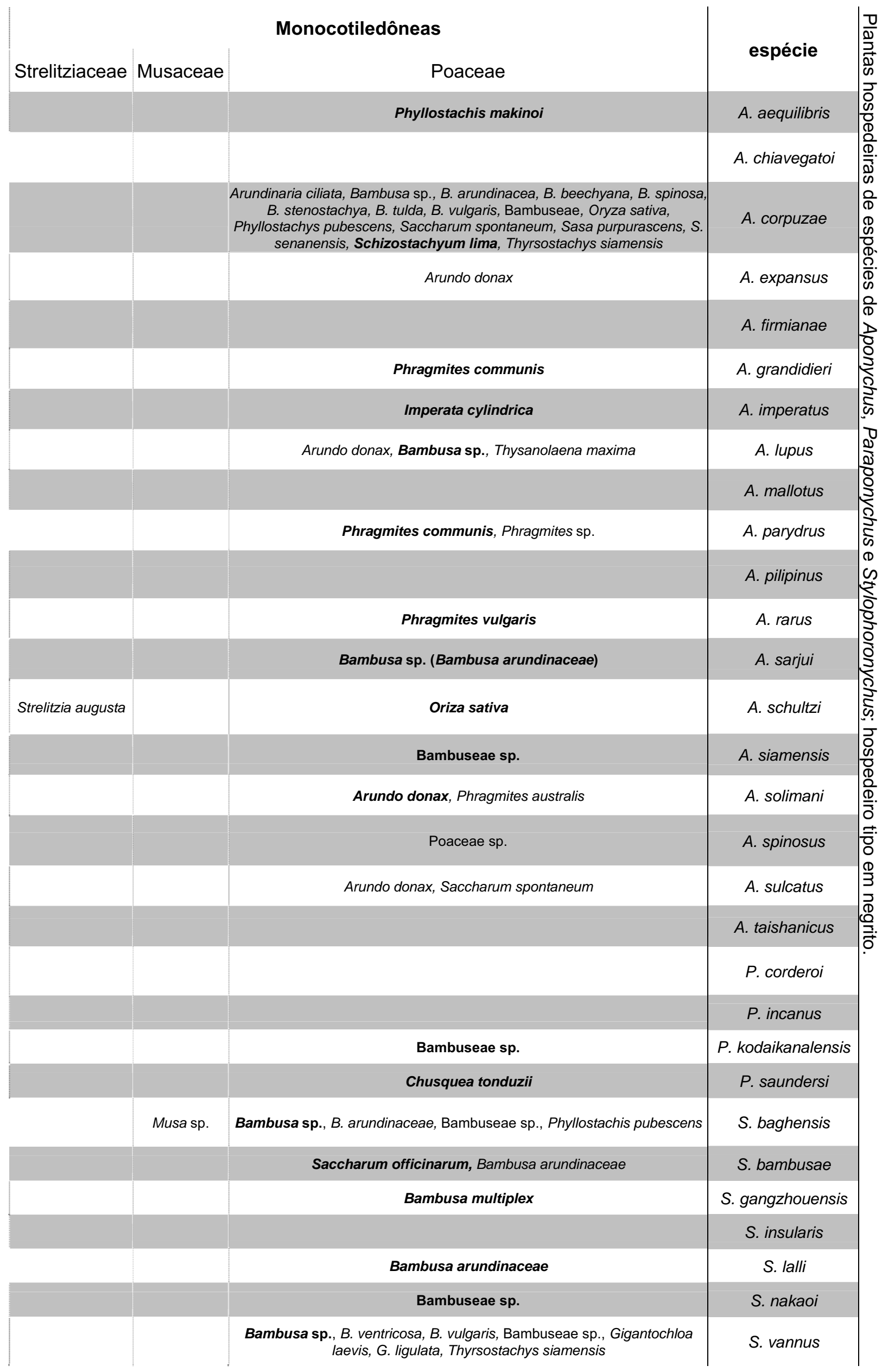




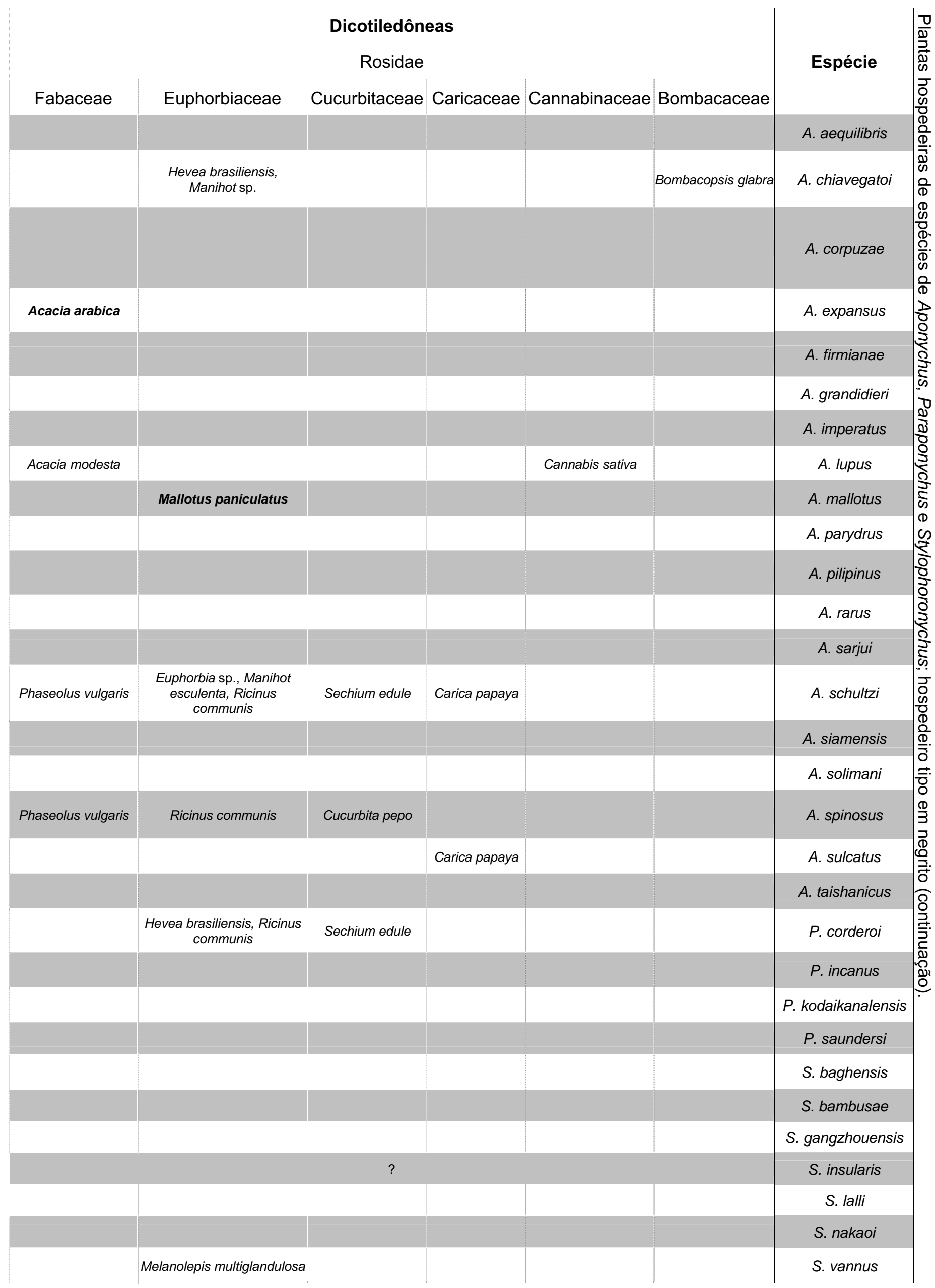




\begin{tabular}{|c|c|c|c|c|c|c|c|c|}
\hline & & & Dic & $\begin{array}{l}\text { cotiledôneas } \\
\text { Rosidae }\end{array}$ & s & & espécie & 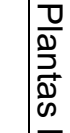 \\
\hline Rutaceae & Rosaceae & Myrtaceae & Moraceae & Meliaceae & Melastomataceae & Malvaceae & & 宓 \\
\hline & & & & & & & A. aequilibris & 总. \\
\hline Citrus sp. & & & & & & $\begin{array}{c}\text { Theobroma } \\
\text { cacao }\end{array}$ & A. chiavegatoi & \begin{tabular}{l}
0 \\
$\infty$ \\
\hdashline \\
\hdashline
\end{tabular} \\
\hline $\begin{array}{l}\text { Feronia } \\
\text { limonia }\end{array}$ & $\begin{array}{c}\text { Fragaria sp., } \\
\text { Pyrus } \\
\text { communis }\end{array}$ & $\begin{array}{l}\text { Syzygium } \\
\text { aqueum }\end{array}$ & & & & & A. corpuzae & 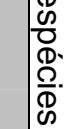 \\
\hline & & & & & & & A. expansus & $\frac{1}{0}$ \\
\hline & & & & & & & A. firmianae & 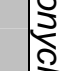 \\
\hline & & & & & & & A. grandidieri & \\
\hline & & & & & & & A. imperatus & $\frac{1}{2}$ \\
\hline & & & Morus alba & & & Malvastrum sp. & A. lupus & $\frac{2}{3}$ \\
\hline & & & & & & & A. mallotus & $\mid \begin{array}{c}3 \\
\frac{3}{2}\end{array}$ \\
\hline & & & & & & & A. parydrus & D \\
\hline & & & & & Memecylon caeruleum & & A. pilipinus & 5 \\
\hline & & & & & & & A. rarus & Sั) \\
\hline & & & & & & & A. sarjui & $\frac{200}{5}$ \\
\hline & & & $\begin{array}{c}\text { Morus sp., } M . \\
\quad \text { nigra }\end{array}$ & $\begin{array}{c}\text { Azadirachta } \\
\text { indica, Melia } \\
\text { azedarach }\end{array}$ & & $\begin{array}{c}\text { Hibiscus sp., H. } \\
\text { rosasinensis, } \\
\text { Sida rhombifolia }\end{array}$ & A. schultzi & 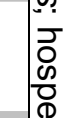 \\
\hline & & & & & & & A. siamensis & D. \\
\hline & & & & & & & A. solimani & 屏 \\
\hline Citrus sp. & $\begin{array}{l}\text { Rubus sp., } R . \\
\text { occidentalis, } \\
\text { R. orientalis }\end{array}$ & & Morus alba & & & $\begin{array}{c}\text { Hibiscus } \\
\text { rosasinensis }\end{array}$ & A. spinosus & $\begin{array}{l}0 \\
\frac{D}{3} \\
3 \\
\end{array}$ \\
\hline & & & & & & & A. sulcatus & \\
\hline & & & & & & & A. taishanicus & $\frac{0}{8}$ \\
\hline & & & & & & & P. corderoi & \\
\hline & & & & & & & P. incanus & 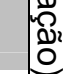 \\
\hline & & & & & & & P. kodaikanalensis & \\
\hline & & & & & & & P. saundersi & \\
\hline & & & & & & & S. baghensis & \\
\hline & & & & & & & S. bambusae & \\
\hline & & & & & & & S. gangzhouensis & \\
\hline & & & & $?$ & & & S. insularis & \\
\hline & & & & & & & S. Ialli & \\
\hline & & & & & & & S. nakaoi & \\
\hline & & & & & & & S. vannus & \\
\hline
\end{tabular}




\begin{tabular}{|c|c|c|c|c|c|c|c|}
\hline & & Dicotiledô & neas & & & & $\frac{0}{2}$ \\
\hline Aster & idae & & & sidae & & Espécie & $\vec{E}$ \\
\hline Caprifoliaceae & Asteraceae & Ulmaceae & Tiliaceae & Sterculiaceae & Salicaceae & & D' \\
\hline & & & & & & A. aequilibris & $\stackrel{0}{\mathbb{Q}}$. \\
\hline & & & & & & A. chiavegatoi & $\begin{array}{l}\infty \\
\frac{\infty}{10}\end{array}$ \\
\hline & & & & & & A. corpuzae & $\frac{\mathrm{o}}{\mathrm{D}}$. \\
\hline & & & & & & A. expansus & \\
\hline & & & & $\begin{array}{c}\text { Firmiana simplex, } F . \\
\text { Platanifolia }\end{array}$ & & A. firmianae & \\
\hline & & & & & & A. grandidieri & \\
\hline & & & & & & A. imperatus & D \\
\hline & & & & & & A. lupus & Sֶ) \\
\hline & & & & & & A. mallotus & \\
\hline & & & & & & A. parydrus & $\stackrel{D}{\infty}$ \\
\hline & & & $\begin{array}{c}\text { Grewia } \\
\text { multiflora }\end{array}$ & & & A. pilipinus & $\frac{2}{8}$ \\
\hline & & & & & & A. rarus & \\
\hline & & & & & & A. sarjui & \\
\hline & & & & & Populus sp. & A. schultzi & ర్ \\
\hline & & & & & & A. siamensis & $\frac{O}{\infty}$. \\
\hline & & & & & & A. solimani & : \\
\hline Lonicera tatarica & Lactuca serriola & $\begin{array}{l}\text { Celtis occidentalis, } \\
\text { UImus sp., U. } \\
\text { americana }\end{array}$ & $\begin{array}{l}\text { Tilia sp., } T \text {. } \\
\text { americana }\end{array}$ & & & A. spinosus & $\begin{array}{l}5 \\
\frac{5}{3} \\
\frac{1}{0} \\
0\end{array}$ \\
\hline & & & & & & A. sulcatus & \\
\hline & & & $\begin{array}{l}\text { Grewia } \\
\text { biloba }\end{array}$ & & & A. taishanicus & $\frac{0}{8}$ \\
\hline & & & & Byttneria aculeata & & P. corderoi & $\vec{c}$ \\
\hline & & & & & & P. incanus & مإِ \\
\hline & & & & & & P. kodaikanalensis & \\
\hline & & & & & & P. saundersi & \\
\hline & & & & & & S. baghensis & \\
\hline & & & & & & S. bambusae & \\
\hline & & & & & & S. gangzhouensis & \\
\hline & & & & $?$ & & S. insularis & \\
\hline & & & & & & S. Ialli & \\
\hline & & & & & & S. nakaoi & \\
\hline & Elephantopus sp. & & & & & S. vannus & \\
\hline
\end{tabular}




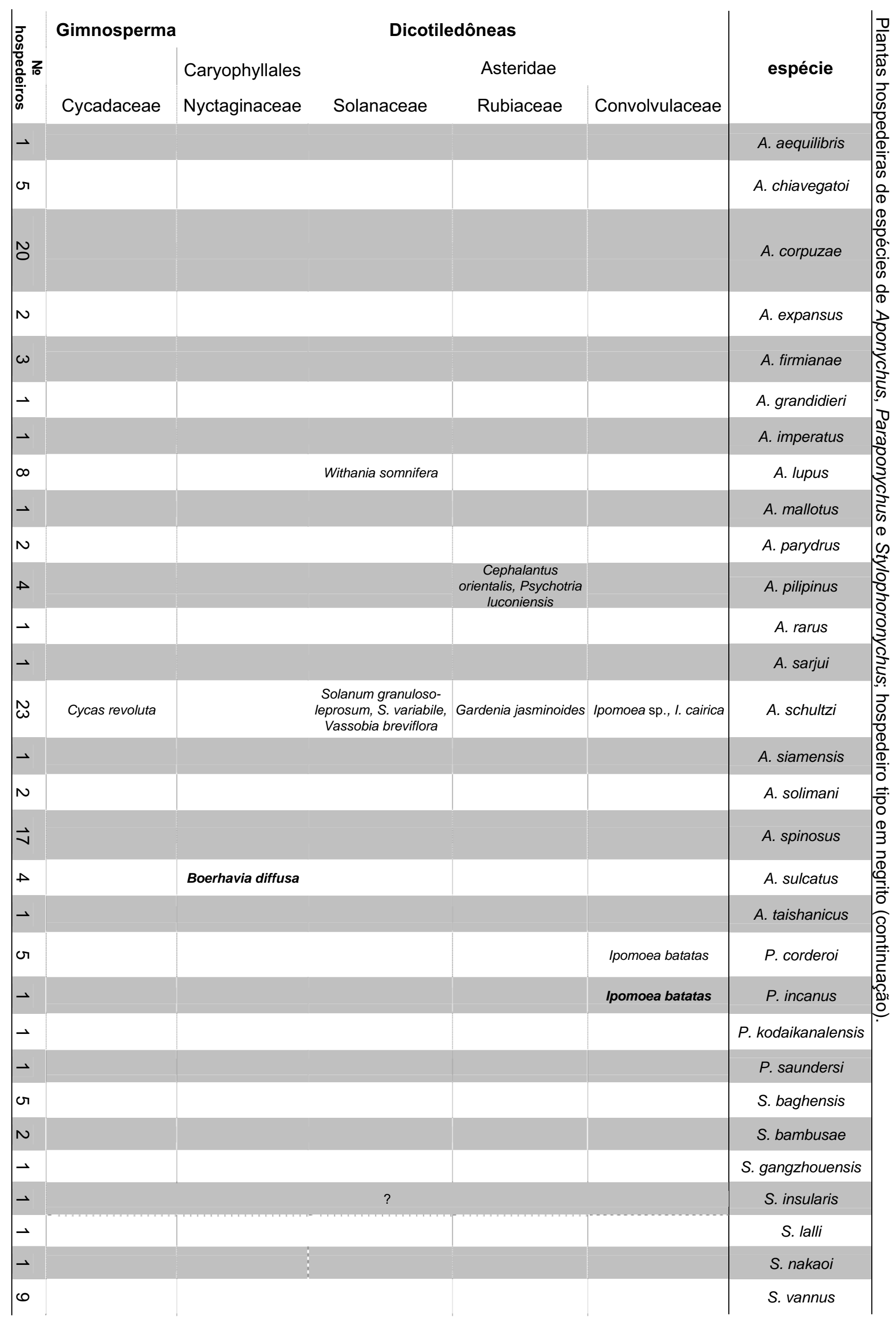




\section{CAPítulo III}

\section{Biogeografia de Aponychus Rimando, Paraponychus González \& Flechtmann e Stylophoronychus Prasad, e associação com hospedeiros}




\section{INTRODUÇÃOO}

Ácaros da família Tetranychidae são estritamente fitófagos (Moraes \& Flechtmann, 2008), registrados na África, Américas, Ásia, Europa e Oceania. Espécies de Aponychus, Paraponychus e Stylophoronychus foram registradas em diversas regiões do mundo, excetuando-se a Antárctica e Australiana. Entretanto, nenhum trabalho até o momento abordou aspectos biogeográficos em função da associação com hospedeiros das espécies desses gêneros.

\section{OBJETIVO}

No presente capítulo, buscou-se obter padrões que expliquem a distribuição das espécies de Aponychus, Paraponychus e Stylophoronychus. Para tanto, são utilizados os resultados obtidos na análise filogenética dessas espécies (capítulo 1), associados com dados de distribuição geográfica e de hospedeiros (capítulo 2), incluindo possíveis casos de sinonímias encontrados nas análises morfológica e filogenética.

\section{MATERIAL E MÉTODOS}

Os dados de ocorrência e distribuição geográfica das espécies foram obtidos principalmente da literatura disponível (Bolland et al., 1998, Migeon \& Flechtmann, 2004, Migeon \& Dorkeld, 2006), sendo incluídos novos registros para algumas espécies. A filogenia dos hospedeiros foi retirada de diversos autores sumarizados por Davies et al. (2004) para as plantas mono e dicotiledôneas, e dos trabalhos de Hilu et al. (1999), Clark et al. (1995, 2007), Giussani et al. (2001) e Hodkinson et al. (2002) para as monocotiledôneas da família Poaceae. Os dados de distribuição geográfica das plantas hospedeiras foram consultados no website do Missouri Botanical Garden (http://www.tropicos.org/).

Considerando-se o fato de que a ocorrência dos ácaros da família Tetranychidae está intimamente associada à distribuição das suas plantas hospedeiras, os domínios biogeográficos considerados no presente capítulo foram utilizados seguindo a composição botânica das regiões da flora mundial, segundo Good (1947) e Takhtajan (1986), sumarizada por Cox \& Moore (2005) (Figura 83, p. 187). 


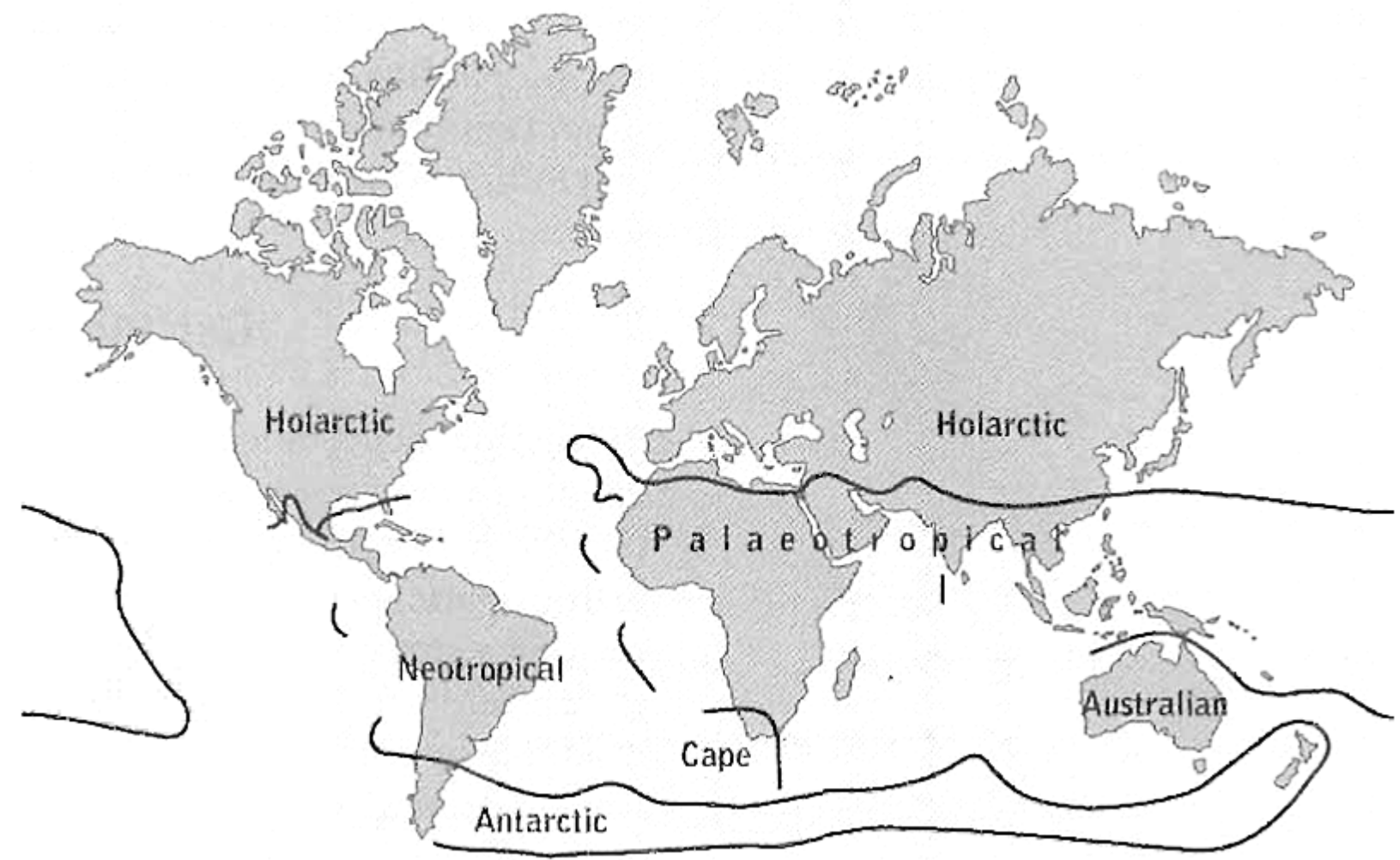

Figura 83. Domínios biogeográficos de flora mundial (retirado de Cox \& Moore, 2005).

\section{RESULTADOS}

\section{Distribuição geográfica}

Com exceção de apenas três espécies, A. schultzi, A. spinosus e A. chiavegatoi, as demais espécies do gênero foram registradas na região Paleotropical. Apenas uma espécie, A. spinosus foi registrada nas regiões Holárctica, Neotropical e Paleotropical, sendo que as demais espécies foram registradas em poucos países de uma mesma região geográfica (Figuras 85, 86, p. 189-190). Das trinta espécies conhecidas, vinte e duas foram registradas somente na região Paleotropical (África, China, Coréia do Sul, Filipinas, Índia, Japão, Madagascar, Malásia, Paquistão e Tailândia), sendo a maioria delas (17) registrada em apenas uma localidade; seis espécie estão restritas à região Neotropical.

Algumas poucas espécies apresentam ampla distribuição geográfica em diversos hospedeiros, como é o caso de A. corpuzae, A. schultzi, A. spinosus e $S$. vannus. Esse também seria o caso de $A$. rarus, caso seja confirmada a sinonímia sênior dessa espécie com outras (ver discussão taxonômica na página 140).

A Índia é o país que apresenta o maior número de espécies desse grupo (7), o que possivelmente está relacionado ao grande número de acarólogos naquele país. Outros países que 
apresentam registros de espécies desse grupo são: China e Filipinas (5 spp. cada), Brasil e Tailândia (4), Paquistão e Taiwan (3), Coréia do Sul, Costa Rica, Egito, Indonésia, Japão, Malásia, Paraguai e Peru (2), África do Sul, Argentina, Canadá, Colômbia, Estados Unidos, Honduras, Madagáscar e Nicarágua (1).

\section{Hospedeiros}

Foram registradas 93 espécies de plantas hospedeiras pertencentes principalmente aos dois grandes grupos de angiospermas: monocotiledôneas (32 spp.) e dicotiledôneas (60 spp.). Apenas uma espécie, Aponychus schultzi, foi registrada sobre uma gimnosperma, Cycas revoluta (Cycadaceae) (Aranda \& Flechtmann, 1971), entretanto, é muito provável que seja um registro acidental. Das 30 espécies acarinas desse grupo, 15 foram encontradas exclusivamente sobre monocotiledôneas (Figuras 84, 85, p. 188-189), em 32 hospedeiros das famílias Poaceae (30 spp.), Musaceae (1 sp.) e Strelitziaceae (1 sp.). Oito espécies foram encontradas somente em dicotiledôneas, em 59 espécies de 24 famílias (Apêndice 2, p. 179); sete espécies foram registradas ocorrendo em ambos os grupos de plantas.

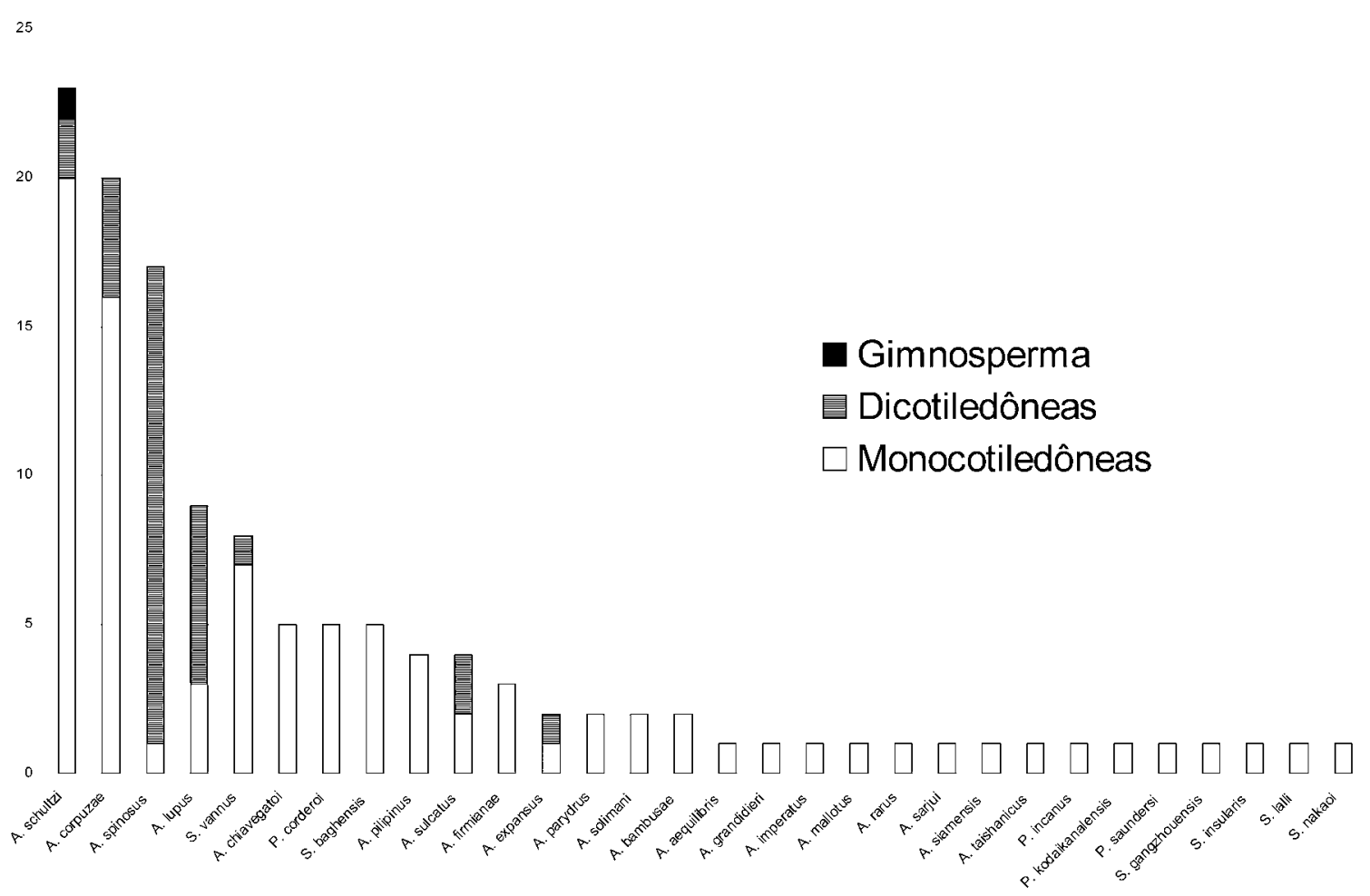

Figura 84. Número e tipo de hospedeiro para cada espécie de Aponychus, Paraponychus e Stylophoronychus. 


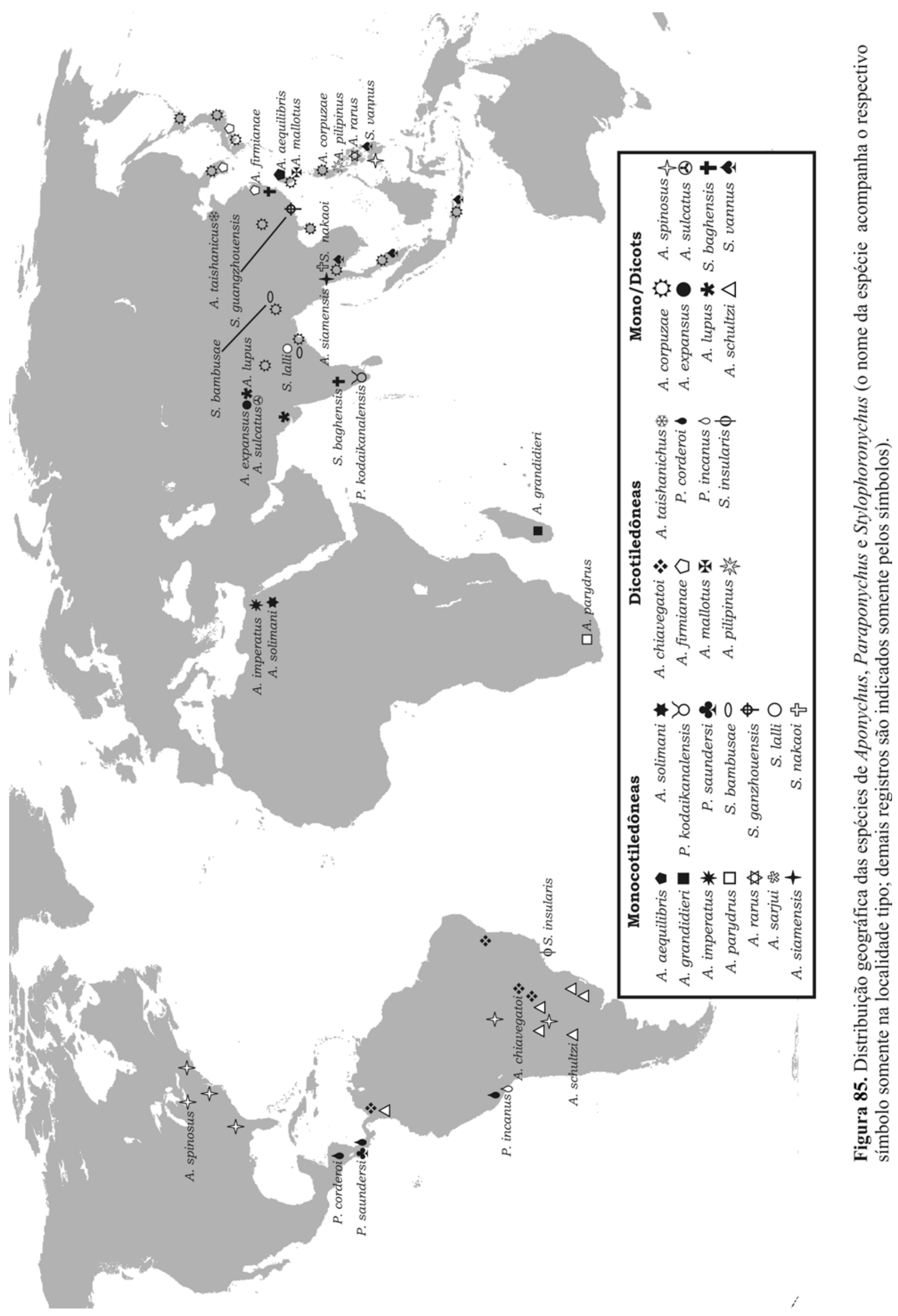


Mesmo nas espécies registradas sobre ambos os grupos vegetais, foi verificada a tendência delas associarem-se pricipalmente a plantas de somente um desses grupos. Assim, 16 dos 20 hospedeiros de A. corpuzae (80\%) e 7 dos 9 hospedeiros de $S$. vannus $(77,8 \%)$ são monocotiledôneas, mais especificamente da família Poaceae. Do mesmo modo, 16 dos 17 hospedeiros de A. spinosus (94\%), 20 dos 23 hospedeiros de A. schultzi (91,3\%) e 6 dos 9 hospedeiros de A. lupus (66,6\%) são dicotiledôneas. Apenas em duas espécies, A. expansus e A. sulcatus (quatro e dois hospedeiros, respectivamente) foi encontrada uma relação de $50 \%$ dos hospedeiros de cada um desses grupos.

Das 32 espécies de monocotiledôneas registradas, 30 (93,8\%) são da família Poaceae. Dessas, 21 são da subfamília Bambusoideae, tribo Bambuseae, que apresenta cerca de 1.400 espécies de bambús verdadeiros, ou "woody bamboos" (Clark et al., 2007). Apesar de Aponychus schultzi, de ocorrência restrita à região Neotropical, já ter sido registrada sobre duas espécies de monocotiledôneas, Oriza sativa (Poaceae) e Strelitzia augusta (Strelitziaceae), ela não colonizou nenhuma espécie da tribo Bambuseae, que hospedam apenas espécies asiáticas de Aponychus e Stylophoronychus.

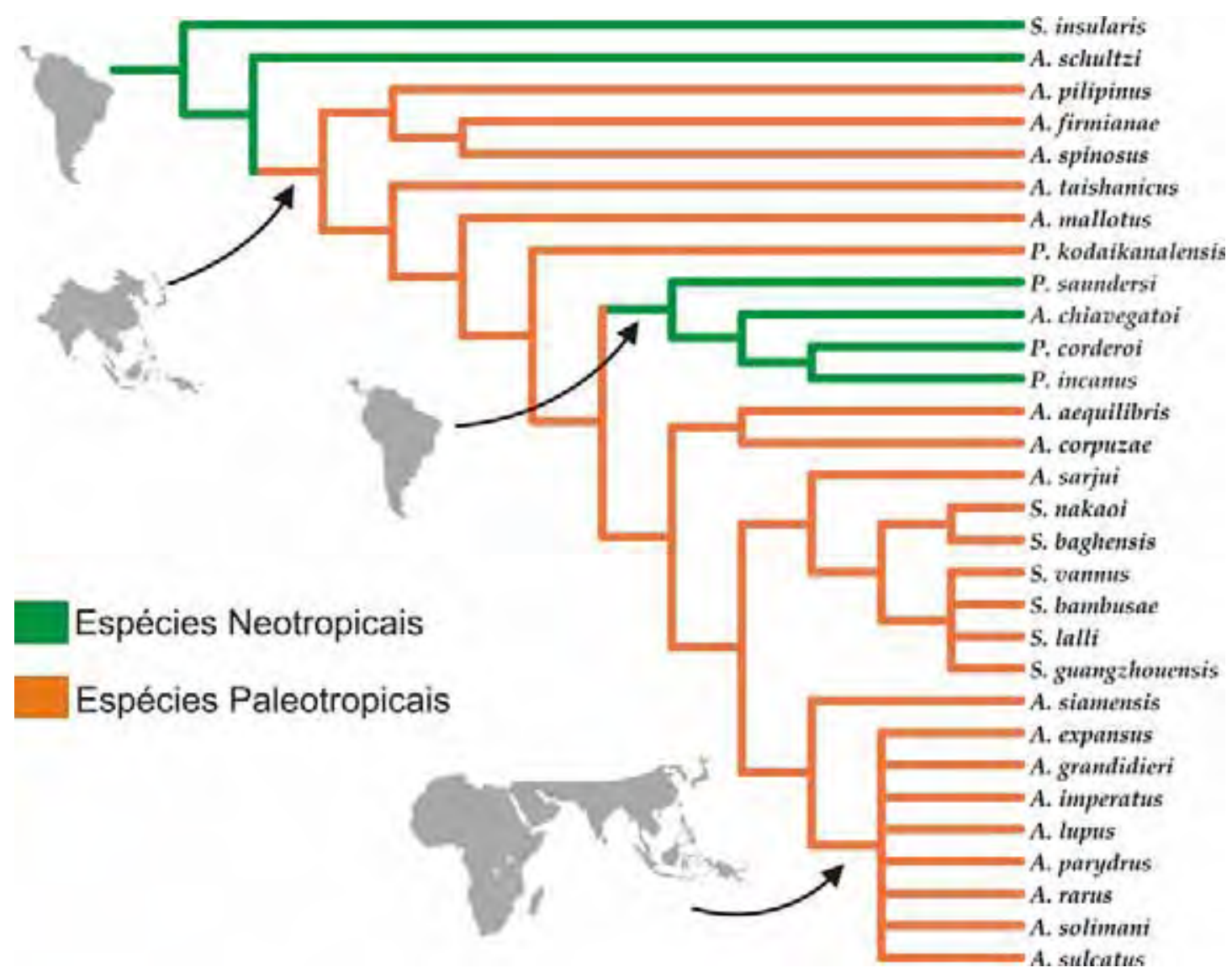

Figura 86. Filogenia e distribuição das espécies de Aponychus, Paraponychus e Stylophoronychus nas regiões Neotropical e Paleártica. 
Aponychus corpuzae foi registrada principalmente em monocotiledôneas da família Poaceae, sendo que em dicotiledôneas ela ocorreu somente em espécies da subclasse Rosidae. Stylophoronychus vannus ocorre principalmente em monocotiledôneas da família Poaceae, subfamília Bambusoideae, com apenas um registro em uma dicotiledônea da família Asteraceae.

São reportadas novas ocorrências e hospedeiros para A. chiavegatoi e A. schultzi. A primeira apresenta, de acordo registros atuais, distribuição restrita à América do Sul, associada a dicotiledôneas da subclasse Rosidae: Hevea brasiliensis (Euphorbiaceae) e Theobroma cacao (Malvaceae) em Ituberá, BA, Manihot esculenta (Euphorbiaceae), Departamento de Córdoba, Colômbia; Bombacopsis glabra (Bombacaceae) em Campinas, SP. Aponychus schultzi, de ocorrência também restrita à América do Sul, é aqui reportada em diversas localidades da região Sul do Brasil, sobre plantas da família Solanaceae.

\section{DISCUSSÃO}

Foi possível observar uma relação direta entre a distribuição geográfica e a associação com hospedeiros, podendo ser destacados dois grandes grupos de espécies: um de ocorrência na região Paleotropical (África, Ásia e Oceania) e associado principalmente a monocotiledôneas, e outro de ocorrência nas regiões Neotropical e Holártica, associado principalmente a dicotiledôneas. Assim, das 17 espécies associadas principalmente com monocotiledôneas, com poucos registros sobre dicotiledôneas, a grande maioria (16) ocorre somente na África e Ásia, sendo que a única espécie neotropical associada a uma planta monocotiledônea é Paraponychus saundersi, registrado sobre Chusquea tonduzii (Poaceae) na Costa Rica. As demais espécies (6) registradas nas Américas ocorrem principalmente sobre dicotiledôneas.

A maioria das espécies ocorre principalmente em regiões tropicais ou equatoriais, sendo que, das 30 espécies desse grupo, apenas três delas já foram registradas em latitudes superiores a 40 graus: A. spinosus no Canadá, A. corpuzae e A. firmianae no Japão. Essas duas primeiras espécies apresentam diversos registros sobre monocotiledôneas e dicotiledôneas, respectivamente, o que sugere que são adaptadas ao clima dessas regiões e hospedeiros. Nota-se também que espécies desse grupo não ocorrem em regiões desérticas (Figura 85, p. 189).

O gênero Stylophoronychus, com exceção de S. insularis, apresenta distribuição endêmica à região Paleotropical, com seis espécies associadas a monocotiledôneas na Índia, Tailândia, China, Filipinas, Malásia e Java. A posição taxonômica de $S$. insularis permanece questionável 
(Zhang et al., 2000), sendo provável que essa espécie, descrita a partir de uma única fêmea coletada sobre uma dicotiledônea, no Rio de Janeiro, Brasil, tenha adquirido independentemente o principal caráter diagnóstico desse gênero, a ausência do par de setas histerossomais $f 1$. Os resultados obtidos na análise filogenética (capítulo II) corroboram essa hipótese. Essa espécie apresenta morfologia obviamente distinta das demais espécies do gênero, com setas dorsais bastante longas, e estilóforo convexo anteriormente e sem as marcantes projeções bilobadas. Por outro lado, espécies de Paraponychus foram registradas principalmente na região Neotropical, com apenas uma exceção, P. kodaikanalensis, descrita do sul da Índia. Essa espécie apresenta morfologia atípica para o gênero, com as extremidades das setas dorsais afiladas e estilóforo fortemente bilobado. É possível que nessa espécie possa ter ocorrido a perda dos elementos do par de setas $c 2$, principal caráter diagnóstico para o gênero, independente das demais espécies de Paraponychus.

Aponychus spinosus é a espécie do grupo estudado com a maior amplitude de distribuição geográfica já registrada, descrita da região sudeste do Canadá (Banks, 1909), e já coletada em diversas localidades da América do Sul (Aranda \& Flechtmann, 1971, Paschoal, 1969), América do Norte (Baker \& Tuttle, 1994) e em uma única localidade na Ásia, nas Filipinas (Thewke \& Enns, 1969). Próximo a essa última região, na China, ocorre uma outra espécie bastante semelhante, Aponychus taishanicus Wang, 1980 que também apresenta as setas dorsais bastante longas, com a possibilidade de que o registro de A. spinosus nas Filipinas seja, na realidade, de $A$. taishanicus. Essas duas espécies apresentam grande semelhança morfológica entre si, até mesmo quanto ao edéago. Entretanto, a distinta quetotaxia nos artículos das pernas permite prontamente diferenciá-las.

\section{Origem e dispersão}

Tetraniquídeos são raros no registro fóssil, e pouca informação pode ser extraída a partir dessa fonte (Walter \& Proctor, 1999). O único registro fóssil de um ácaro tetraniquídeo data do período Paleogeno, época Eoceno (44-49 milhões de anos atrás), embora não identificado mais acuradamente (Koch \& Berend, 1854 apud Dunlop \& Selden, 2009). A grande maioria dos representantes acarinos encontrados no registro fóssil são oribatídeos (Acariformes: Oribatida) (Labandeira et al., 1997). Estes ácaros possuem exoesqueleto fortemente quitinizado, e são abundantemente encontrados em folhedo ou em detritos de solo, o que aumenta a chance de serem fossilizados. Tetraniquídeos, por sua vez, apresentam exoesqueleto fracamente quitinizado, e vivem estritamente sobre folhas, o que proporciona, relativamente, menores chances, de serem 
preservados pelo registro fóssil.

Além da precária informação do registro fóssil, algumas outras dificuldades se interpõem frente à elaboração de uma hipótese de origem e dispersão desses ácaros. Como já visto, os registros de ocorrência de algumas espécies de Aponychus e gêneros correlatos são muito deficientes, principalmente para as espécies que possuem registro único, não mais coletadas após sua descrição original. O pequeno número de indivíduos conhecidos de algumas espécies também dificulta uma asserção mais acurada sobre a origem, evolução e diversificação desse grupo.

A dispersão de ácaros da família Tetranychidae ocorre principalmente pelo vento (Kennedy \& Smitley, 1985), o que resulta em um modo casualizado e sem controle sobre a direção da dispersão. Portanto, os ácaros bem sucedidos na colonização de novo habitats dependem somente da disponibilidade de hospedeiros nesses locais que sejam adequados à sua alimentação e desenvolvimento. Mitchell (1970) identificou duas características relacionadas à grande capacidade de dispersão de ácaros tetraniquídeos, que podem ser encontradas na maioria das espécies desse grupo de Eurytetranychini: (1) adaptação a uma grande amplitude de hospedeiros, o que aumenta as chances dos ácaros se dispersarem para uma planta favorável à sua colonização; (2) machos menores e menos numerosos, de modo que a maioria dos espécimes nas folhas sejam fêmeas. Como foi observado, muitas das espécies de Aponychus, Paraponychus e Stylophoronychus apresentam apenas indivíduos fêmea conhecidos, ou pelo menos esse sexo é muito mais comumente encontrado, o que pode ser reconhecido como uma adaptação que favoreça a reprodução, e consequentemente, a dispersão dos indivíduos.

Como visto, espécies de Aponychus e Stylophoronychus são mais abundantemente encontrados na região Paleotropical, principalmente na Índia, leste asiático e região Indo-Malásia. A ausência de ácaros desse grupo na região Australiana pode estar relacionada à quase total ausência de espécies hospedeiras desses ácaros nessa região. Isso pôde ser aferido analisando-se a distribuição de duas espécies amplamente registradas no sudeste asiático, A. corpuzae e S. vannus. A primeira delas já foi registrada sobre 20 espécies de hospedeiros, e dessas, apenas uma, Bambusa arundinacea (Retz.) Willd. ocorre na Austrália, apesar de ocorrer em outras regiões da Oceania, como Singapura e Malásia. Com relação a $S$. vannus, nenhum dos oito hospedeiros dessa espécie ocorrem na Austrália, apesar de ocorrerem em diversas localidades da Oceania. As diferenças na composição florística dessas regiões são conhecidas desde o final do século XIX (Engler, 1879 apud Cox \& Moore, 2005). Próximo a essa região ocorre a linha de Wallace, que marca uma segregação abrupta na composição florística dessas regiões, delimitando a região Australiana da região Paleártica. Apesar de não existir um consenso sobre os limites precisos dessa linha (Cox \& Moore, 2005), essas duas espécies não foram registradas em qualquer localidade ao sul dessa linha, apesar de terem alcançado distâncias relativamente maiores em outras direções. 


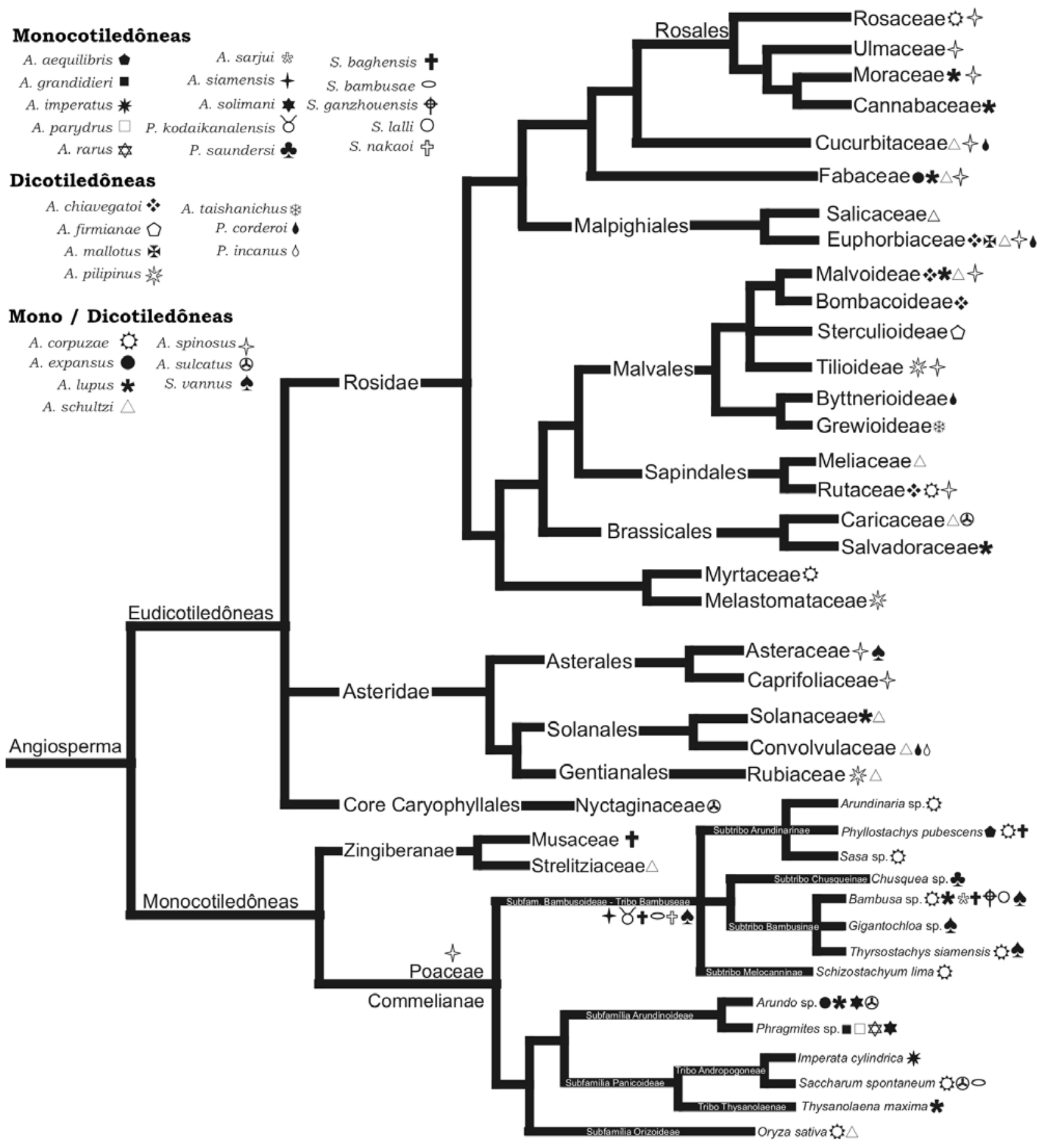

Figura 87. Filogenia das plantas hospedeiras de Aponychus, Paraponychus e Stylophoronychus com distribuição das espécies acarinas nos hospedeiros. 


\section{Conclusões e considerações finais}

Muitas espécies de Aponychus, Paraponychus e Stylophoronychus foram descritas a partir de poucos indivíduos, sendo que sua diagnose específica foi fundamentada, na maioria das vezes, no que se mostrou ser diferenças individuais, inter ou intra-populacionais, e não específicas. Isso pôde ser observado através da comparação entre as descrições e ilustrações originais dos holótipos com os seus respectivos parátipos analisados. Conclui-se, portanto, que essas diferenças, tais como comprimento relativo de algumas setas dorsais, não mais devem ser utilizadas para a diagnose de espécies desse grupo, pelo menos até que se estude um número maior de indivíduos.

Como consequência, algumas dessas espécies até o momento consideradas válidas devem ser sinonimizadas:

- Aponychus corpuzae Rimando, 1966: provavelmente sinônimo sênior de A. aequilibris Tseng, 1990.

- Paraponychus corderoi (Baker \& Pritchard, 1962): provavelmente sinônimo sênior de $P$. incanus Gozalez \& Flechtmann, 1977.

- Stylophoronychus nakaoi (Ehara \& Wongsiri, 1975): provavelmente sinônimo sênior de S. baghensis (Prasad, 1975).

- Stylophoronychus vannus (Rimando, 1968): provavelmente sinônimo sênior de A. bambusae Gupta \& Gupta, 1990, S. lalli (Prasad, 1975) e S. guangzhouensis (Ma \& Yuan, 1980).

- Aponychus rarus Rimando, 1966): provavelmente sinônimo sênior de A. grandidieri (Gutierrez, 1966), A. expansus Chaudhri, 1972, A. lupus Chaudhri, 1972, A. sulcatus Chaudhri, 1972 e A. parydrus (Meyer, 1987).

Algumas espécies não possuem material tipo disponível, sendo que algumas delas possuem identidade duvidosa. Nestes casos, sugerimos que essas espécies devam ser consideradas como species inquirenda, até que novos exemplares sejam coletados nas localidades e hospedeiros tipo, e melhor analisadas.

- Aponychus solimani Zaher, Gomaa \& El-Enany, 1982 possivelmente constitui mais um sinônimo júnior de $A$. rarus.

- Aponychus imperatus Hafez \& Elbadry, 1980 possivelmente também constitui um sinônimo júnior de A. rarus. Na descrição original dessa espécie, nada é mencionado a respeito da designação nem local de deposição dos tipos.

- Stylophoronychus insularis (Flechtmann, 1981), descrita a partir de uma única fêmea, não 
apresenta seu espécime tipo disponível para estudo. Os resultados obtidos pela análise filogenética demonstraram que essa espécie não pertence ao gênero Stylophoronychus. Por essas razões, sugere-se que ela seja mantida como species inquirenda, pelo menos até que novos espécimes sejam coletados e analisados.

Os resultados obtidos na análise filogenética demonstraram que os gêneros Aponychus, Paraponychus e Stylophoronychus, tais como definidos atualmente, são parafiléticos. Alguns caracteres relativos à quetotaxia das pernas mostraram-se bastante úteis para a análise filogenética, por apresentarem um padrão constante de disposição das setas nos artículos. Outros, tradicionalmente utilizados para diagnose genérica (como presença/ausência da seta dorsal $c 2$ utilizada para separação de Aponychus e Paraponychus), tiveram um grande número de passos $(\mathrm{L}=4)$, baixo IC (25) e IR (25).

Algumas espécies foram ilustradas contendo setas nos artículos das pernas somente no lado dorsal, o que já foi utilizado algumas vezes como incorreto diagnóstico comparativo de espécies. Após análise de espécimes tipo, verificou-se a presença de setas na face ventral desses artículos. Portanto, sugerimos que todas as setas presentes nos artículos sejam claramente mencionadas e ilustradas, para se evitar futuros diagnósticos incorretos.

Os dados de distribuição geográfica e filogenia permitem inferir que o local de origem desse grupo foi a América do Sul, e a partir dessa região, teriam se dispersado em direção à Ásia. Um segundo evento de dispersão à região Neotropical teria originado o gênero Paraponychus, incluindo uma espécie de Aponychus que foi aninhada nesse clado, A. chiavegatoi.

É apresentada aqui a primeira hipótese de relacionamento filogenético entre as espécies dos gêneros Aponychus, Paraponychus e Stylophoronychus. Estudos futuros envolvendo caracteres moleculares podem ajudar a melhor definir as relações aqui propostas. 


\section{REFERÊNCIAS BIBLIOGRÁFICAS}

Amorim, D.S. 2002. Fundamentos de Sistemática Filogenética. Ed. Holos, Ribeirão Preto. 156pp.

Aranda, B.R \& Flechtmann, C.H.W. 1971. A report on the Tetranychidae of Paraguay. Proceedings of the Entomological Society of Washington, 73(1): 29-33.

Baker, E.W. 1975. Plant feeding mites of Thailand (Tetranychidae, Tenuipalpidae, and Tuckerellidae). Plant Protection Service Technical Bulletin. Bangkok, Thailand. (35): 50pp.

Baker, E.W. \& Pritchard, A.E. 1962. Arañas rojas de América Central (Acarina: Tetranychidae). Revista de la Sociedad Mexicana de Historia Natural, 23: 309-340.

Baker, E.W. \& Tuttle, D.M. 1994. A guide to the spider mites (Tetranychidae) of the United States. West Bloomfield, USA, Indira Publishing House, 347pp.

Banks, N. 1909. New Canadian mites. Proceedings of the Entomological Society of Washington, 11: 133-143.

Banks, N. 1917. New mites, mostly economic (Arach., Acar.). Entomological News, 28(5): 193199.

Beard, J.J. \& Walter, D.E. 2004. Cryptic false spider mites: a new genus, Austrolinus, and a review of the family Linotetranidae (Acari: Prostigmata: Tetranychoidea). Invertebrate Systematics 18: 593-606.

Blanchard, E.E. 1940. Tres ácaros dañinos para los cultivos argentinos. Revista de la Facultad de Agronomia, 24: 11-18.

Bolland, H.R., Gutierrez, J. \& Flechtmann, C.H.W. 1998. World Catalogue of the Spider Mite Family (Acari: Tetranychidae). Brill Academic Publishers. 384 pp.

Carmona, M.M. \& Dias, J.C.S. 1996. Fundamentos de Acarologia Agrícola. Fundação Calouste Gulbenkian. Lisboa, 423pp.

Chaudhri, W.M. 1972. Three new species of mites of the genus Aponychus from Pakistan. Pakistan Journal of Zoology, 4(2): 161-168.

Chaudhri, W.M., Akbar, S. \& Rasool, A. 1974. Taxonomic studies on the mites belonging to the families Tenuipalpidae, Tetranychidae, Tuckerellidae, Caligonellidae, Stigmaeidae and Phytoseiidae. PL 480 Project on Mites. Lyallpur, Pakistan, University of Agriculture. 250pp.

Clark, L.G., Zhang, W. \& Wendel, J.F. 1995. A phylogeny of the grass family (Poaceae) based on ndhF sequence data. Systematic Botany, 20(4): 436-460.

Clark, L.G., Dransfield, S., Triplett, J., Sánchez-Ken, J.G. 2007. Phylogenetic relationships among the one-flowered, determinate genera of Bambuseae (Poaceae: Bambusoideae). Aliso, 23: 315-332.

Corpuz-Raros, L.A. 1978. New Philippine Tetranychoidea. Kalikasan, Philippine Journal of Biology, 7(3): 211-230. 
Corpuz-Raros, L.A. 1989. Hosts, geographical distribution and predatory mite associations of Philippine phytophagous mites. Philippine Agriculturist, 72(3): 303-322.

Cox, C.B. \& Moore, P.D. 2005. Biogeography: an ecological and evolutionary approach. 7 ed. Wiley-Blackwell Publishing. 440 pp.

Davies, T.J., Barraclough, T.G., Chase, M.W., Soltis, P.S., Soltis, D.E. \& Savolainen, V. 2004. Darwin's abominable mystery: Insights from a supertree of the angiosperms. Proceedings of the National Academy of Sciences, 101(7): 1904-1909.

Dunlop, J.A. \& Selden, P.A. 2009. Calibrating the chelicerate clock: a paleontological reply to Jeyaprakash and Hoy. Experimental and Applied Acarology. 48: 183-197.

Ehara, S. 1966. Some mites associated with plants in the state of São Paulo, Brazil, with a list of plant mites of South America. Japanese Journal of Zoology, 15(2): 129-150.

Ehara, S. 1969. The tetranychoid mites of Taiwan (Acarina: Prostigmata). The Journal of the Faculty of Education, Tottori University, Natural Science, 21(2): 132-141.

Ehara, S. 1980. Two species of spider mites from Japan (Acarina, Tetranychidae). Annotationes Zoologicae Japonenses, 53(3): 203-209.

Ehara, S. 1999. Revision of the Spider Mite Family Tetranychidae of Japan (Acari, Prostigmata). Species Diversity, 4: 63-141.

Ehara, S. \& Tho, Y.P. 1988. Spider mites of the Malay Peninsula (Acarina: Tetranychidae). The Journal of the Faculty of Education, Tottori University, Natural Science, 37(1): 1-24.

Ehara, S. \& Wongsiri, T. 1975. The spider mites of Thailand (Acarina: Tetranychidae). Mushi, 48(13): 149-185.

Engler, A. 1879. Versuch einer Entwicklungsgeschichte der Pflanzenwelt. Leipzig: Engelmann, V.1. apud Cox, C.B. \& Moore, P.D. 2005. Biogeography: an ecological and evolutionary approach. 7 ed. Wiley-Blackwell Publishing. 440 pp.

Feres, R.J.F. 1984. Estudos taxionômicos sobre tetraniquídeos (Acari, Arachnida). Dissertação de Mestrado, IBBMA-UNESP, Botucatu, 73 pp.

Feres, R.J.F. \& Flechtmann, C.H.W. 1988. Aponychus chiavegatoi n. sp. collected from Citrus sp. (Rutaceae) in São Paulo, Brazil (Acari, Tetranychidae, Eurytetranychini). Revista Brasileira de Biologia, 48(4):959-964.

Feres, R.J.F. \& Flechtmann, C.H.W. 1995. Mites (Acari) associated with bamboo (Bambusa sp., Poaceae), in a woody area from Northwestern São Paulo State, Brazil. Revista Brasileira de Zoologia, 12(3): 533-546.

Flechtmann, C.H.W. 1975. Elementos de Acarologia. São Paulo, Livraria Nobel S.A., 344 pp.

Flechtmann, C.H.W. 1981. A small collection of spider mites from Jaguanum Island, Rio de Janeiro, Brazil, with description of Aponychus insularis (Prostigmata: Tetranychidae). 
International Journal of Acarology, 7(1-4): 87-90.

Giussani, L.M., Cota-Shánchez, H., Zuloaga, F.O. \& Kellogg, E.A. 2001. A molecular phylogeny of the grass subfamily Panicoideae (Poaceae) shows multiple origins of C4 Photosynthesis. American Journal of Botany, 88(11): 1993-2012.

Goloboff, P.A. 1999. Analysing large data sets in reasonable time: solutions for composite optima. Cladistics, 15: 415-428.

González, R.H. \& Flechtmann, C.H.W. 1977. Revisión de los ácaros fitófagos en el Peru y descripción de um nuevo género de Tetranychidae (Acari). Revista Peruana de Entomologia, 20(1):67-71.

Good, R. 1947. The Geography of Flowering Plants. Wiley, New York. 3 ed., 518pp. Gupta, S.K. 1976. Contribution to our knowledge of tetranychid mites (Acarina) with descriptions of three new species from India. Oriental Insects, 10(3): 327-351.

Gupta, S.K. 1985. Plant mites of India. Handbook, Zoological Survey of India: 520pp.

Gupta, S.K. 1992. Arachnida: Plant mites (Acari). State Fauna Series 3: Fauna of West Bengal, part 3: 61-211.

Gupta, Y.N. 1980. Some spider mites (Acarina: Tetranychidae) from Andaman and Nicobar Islands with descriptions of three new species. Records of the Zoological Survey of India, 77(1): 111-117.

Gupta, Y.N. 1984. On a collection of tetranychoid mites from Tamil Nadu with description of a new species of Aponychus (Acari: Tetranychidae). Bulletin of the Zoological Survey of India, 6(1-3): 237-245.

Gupta, Y.N. \& Gupta, S.K. 1990. On a collection of tetranychid mites from Arunachal, Pradesh, India with descriptions of two new species. Rec. Zoological Survey of India, 88: 15-22.

Gupta, S.K. \& Gupta, Y.N. 1994. A taxonomic review of Indian Tetranychidae (Acari: Prostigmata) with descriptions of new species, re-descriptions of known species and keys to genera and species. Memoirs of the Zoological Survey of India, 18: 1-196.

Gutierrez, J. 1966. Cinq nouvelles espèces de Tetranychidae de Madagascar. Acarologia, 8(4): 594-610.

Gutierrez, J. 1985. Systematics. In: Helle, W \& Sabelis, M.W. (eds.). Spider mites, their biology, natural enemies and control. Vol. 1A. Elsevier Sci. Publishers, Amsterdam. p. 75-90.

Gutierrez, J. \& Helle, W. 1985. Evolutionary Changes in the Tetranychidae. In: Helle, W. \& Sabelis, M.W. (eds.). Spider mites, their biology, natural enemies and control. Vol. 1A. Elsevier Sci. Publishers, Amsterdam. p. 91-107.

Hafez, S.M. \& El-Badry, E.A. 1980. Life history studies on Aponychus imperatus n. sp. (Acari: Tetranychidae) with description of all developmental stages. Faculty of Agriculture Ain- 
Shams University Research Bulletin, 1225: 1-12.

Hennig,W. 1966. Phylogenetic systematics. University of Illinois Press, Urbana, 263pp.

Hilu, K.W., Alice, L.A. \& Liang, H. 1999. Phylogeny of Poaceae inferred from matK sequences. Annals of the Missouri Botanical Garden, 86(4): 835-851.

Hinomoto, N., Osakabe, Mh., Gotoh, T. \& Takafuji, A. 2001. Phylogenetic analysis of green and red forms of the two-spotted mite, Tetranychus urticae Koch (Acari: Tetranychidae), in Japan, based on mitochondrial cytochrome oxidase subunit I sequences. Applied Entomology and Zoology, 36(4): 459-464.

Ho, C.C. 2003. A new species of Aponychus from Taiwan and a redescription of A. corpuzae (Acariformes: Tetranychidae). Plant Protection Bulletin (Taipei), 45: 343-351.

Hodkinson, T.R., Chase, M.W., Lledó, M.D., Salamin, N. \& Renvoize, S.A. 2002. Phylogenetics of Miscanthus, Saccharum and related genera (Saccharinae, Andropogoneae, Poaceae) based on DNA sequences from ITS nuclear ribosomal DNA and plastid trnL-F intergenic spacers. Journal of Plant Research, 115: 381-392.

Johnston, D.E. \& Flechtmann, C.H.W. 1990. On the genus Aponychus (Acari: Tetranychidae) in Java. International Journal of Acarology, 16(4): 247.

ICZN-International Code of Zoological Nomenclature Third Edition. 1985. International Thrust for Zoological Nomenclature in association with British Museum (Natural History). London. $338 p p$.

Kennedy, G.G. \& Smitley, D.R. 1985. Dispersal. In: Helle, W. \& Sabelis, M.W. Spider mites: their biology, natural enemies and control. Amsterdam, Netherlands, Elsevier Science Publisher. V. 1B: 233-242.

Kitching, I.J., Forey, P.L., Humphries, C.J. \& Williams, D.M. 1998. Cladistics: the theory and practice of parsimony analysis. 2nd Ed. Oxford, Oxford University Press, 228pp.

Koch, C.L. \& Berendt, G.C. 1854. Die im Bernstein befindlichen Myriapoden, Arachniden und Apteren der Vorwelt. In: Berendt, G.C. (ed.) Die in Bernstein Befindlichen Organischen Reste der Vorwelt Gesammelt in Verbindung mit Mehreren Bearbeitetet und Herausgegeben 1. Nicolai, Berlin apud Dunlop, J.A. \& Selden, P.A. 2009. Calibrating the chelicerate clock: a paleontological reply to Jeyaprakash and Hoy. Experimental and Applied Acarology. 48: 183197.

Krantz, G.W. 1970. A manual of acarology. Oregon State University Bookstores, Oregon, 335pp.

Krantz, G.W. \& Walter, D.E. (Eds.) 2009. A Manual of Acarology. Third Edition. Texas Tech University Press. Lubbock, Texas. 807pp.

Labandeira, C.C., Philipps, T.L. \& Norton, R.A. 1997. Oribatid mites and the decomposition of plant tissues in Paleozoic coal-swamp forests. Palaios, 12: 319-353. 
Lee, J.S. 1989. A systematic study on the Tetranychoid mites (Order Acarina) in Korea. Chonju, Chonbuk University, 124pp.

Lindquist, E. E. 1985a. Anatomy, Phylogeny and Systematics - 1.1.1 External Anatomoy. In: Helle, W. \& Sabelis, M.W. (eds.). Spider mites, their biology natural enemies and control. Vol. 1A. Elsevier Sci. Publishers, Amsterdam. p. 3-28.

Lindquist, E. E. 1985b. Diagnosis and Phylogenetic Relationships. In: Helle, W. \& Sabelis, M.W. (eds.). Spider mites, their biology, natural enemies and control. Vol. 1A. Elsevier Sci. Publishers, Amsterdam. p. 63-74.

Ma, E.P. \& Yuan, Y.L. 1965. A new species of the genus Eutetranychus. Acta Zootaxonomica Sinica, 2(3): 247-250.

Ma, E.P. \& Yuan, Y.L. 1980. A new genus and a new species of spider mites from South China (Acarina:Tetranychidae). Acta Entomologica Sinica, 23(4): 442.

Ma, E.P. \& Yuan, Y.L. 1982. A new genus and five new species of Tetranychidae from China (Acari: Tetranychidae). Entomotaxonomia, 4(1-2):109-114.

Ma, E.P., Yuan, Y.L. \& Qian, Y.H. 1984. Spider mites. University, J., Agricultural mites of China, Shanghai, Shanghai Science and Technology Press: 88-164.

McGregor, E.A. 1950. Mites of the family Tetranychidae. American Midland Naturalist, 44(2): 257-420.

Mesa, N.C., Ochoa, R., Welbourn, W.C., Evans, G.A., Moraes, G.J. 2009. A catalog of Tenuipalpidae Berlese of the world (Acari: Prostigmata). Zootaxa, 2098:1-185.

Meyer, M.K.P.S. 1974. A revision of the Tetranychidae of Africa (Acari) with a key to the genera of the world. Entomology Memoir, Department of Agricultural Technical Services, Republic of South Africa, 36: 1-291.

Meyer, M.K.P.S. 1987. African Tetranychidae (Acari, Prostigmata) with reference to the world genera. Technical Communication / Department of Agriculture and Water Supply, Republic of South Africa 69: 1-175.

Meyer, M.K.P.S. \& Vargas, C. 1999. Two new spider mites (Acari: Tetranychidae) from Costa Rica. International Journal of Acarology, 25(2): 111-120.

Migeon, A. \& Dorkeld, F. 2006. Spider Mites Web: a comprehensive database for the Tetranychidae. http://www.montpellier.inra.fr/CBGP/spmweb (última atualização em 15 de junho de 2009).

Migeon, A. \& Flechtmann, C.W.H. 2004. First additions and corrections to the world catalogue of the spider mite family (Acari: Tetranychidae). International Journal of Acarology, 30(2): 143152.

Mitchell, R. 1970. An analysis of dispersal in mites. The American Naturalist. 104(939): 425-431. 
Moraes, G.J. \& Flechtmann, C.H.W. 2008. Manual de Acarologia Agrícola. Acarologia Básica e Ácaros de Plantas Cultivadas no Brasil. 1 ed., v.1. Ribeirão Preto, SP. Holos, Editora Ltda. 288pp.

Navajas, M. \& Gutierrez, J. 1996. Molecular phylogeny in spider mites (Tetranychidae). 5.8: 305308. In: Mitchell, R., Horn, D.J., Needham, G.R. \& Welbourn, W.C. 1996. Proceedings of the IX International Congress of Acarology.

Nixon, K.C \& Carpenter, J.M. 1993. On outgroups. Cladistics, 9: 413-426.

Nixon, C.K. 1999. WinClada ver. 1.0000. published by the author, Ithaca, NY, USA.

Norton, R.A., Kethley, J.A., Johnson, D.E. \& Oconnor, B.M. 1993. Phylogenetic perspectives on genetic systems and reproductive modes of mites 8-99. In: Wrensch, D.L. \& Ebbert, M.A. (eds), Evolution and Diversity of Sex Ratio in Insects andMites. Chapman \& Hall, New York, $630 \mathrm{pp}$.

Paschoal, A.D. 1969. Ácaros encontrados em plantas no Estado de São Paulo. Revista de Agricultura, S.P., 44(2-3): 76-78.

Prasad, V. 1975a. A new species of plant feeding mite from India (Acarina:Tetranychidae). International Journal of Acarology, 1(1):1-5.

Prasad, V. 1975b. Plant feeding mites of India (Acarina: Tetranychoidea): 1. genera Tuckerella and Aponychus. International Journal of Acarology, 1(1):6-11.

Prasad, V. 1987. A decade of Acarology. Indira Publishing House. Michigan. 183 pp.

Pritchard, A.E. \& Baker, E.W. 1955. A revision of the spider mite family Tetranychidae. Pacific Coast Entomological Society Mem. Ser. 2: 1-472.

Rimando, L. 1966. A new subfamily of spider mites with the description of a new genus and two species (Acarina: Tetranychidae: Aponychinae). Philippine Agriculturist, 50: 105-113.

Rimando, L. 1968. The genus Aponychus (Tetranychidae, Acarina). Philippine Entomologist, 1: 610.

Rimando, L. \& Corpuz-Raros, L.A. 1996. A revision of the tribe Eurytetranychini in the Tetranychinae (Tetranychidae, Acari). Philippine Entomologist, 10 (1): 9-14.

Robaux, P. \& Gutierrez, J. 1973. Les phanères des pattes et des palpes chez deux espèces de Tetranychidae: nomenclature et évolution au cours de l'ontogénèse. Acarologia, 15(4): 616643.

Ros, V.I.D. \& Breeuwer, J.A.J. 2007. Spider mite (Acari: Tetranychidae) mitochondrial COI phylogeny reviewed: host plant relationships, phylogeography, reproductive parasites and barcoding. Experimental and Applied Acarology. 42: 239-262.

Sadana, G.L., Chhabra, S.C. \& Kumari, N. 1981. New records of tetranychoid mites of ornamental and medicinal plants and their hosts from the Punjab state. Entomon, 6(4): 325-327. 
Sadana, G.L., Chhabra, S.C. \& Gupta, B.K. 1982. Tetranychid mites infesting fruit trees in the Punjab together with records of some new hosts and description of a new species. Entomon, 7(3): 397-401.

Schuh, R.T. 2000. Biological systematics: principles and applications. Cornell University Press, New York.

Scotland, R.W. \& Pennington, R.T. 2000. Homology in systematics: coding characters for phylogenetic analysis. Taylor and Francis, London. 288p.

Takhtajan, A. 1986. Floristic Regions of the World. London and Berkeley, CA: University of California Press (tradução em inglês de original em russo publicado em 1978).

Thewke, S.E. \& Enns, W.R. 1969. The spider mite complex (Acarina: Tetranychoidea) in Missouri. Museum Contributions, Columbia, Missouri, USA, University of Missouri, Monograph n1, 106pp.

Tseng, Y.H. 1978. Mites of the family Bdellidae from Taiwan (Acarina: Prostigmata). Journal of the Agricultural Association of China, 104: 25-51.

Tseng, Y.H. 1982. Mites of the family Stigmaeidae from Taiwan with key to genera of the world (Acarina: Prostigmata). Phytopathologist and Entomologist of the National Taiwan University. 9: 1-52.

Tseng, Y.H. 1990. A monograph of the mite family Tetranychidae (Acarina: Trombidiformes) from Taiwan. Taiwan Museum Special Publication Series, 9: 1-226.

Tuttle, D.M. \& Baker, E.W. 1968. Spider mites of South Western United States and a revision of the family Tetranychidae. The Arizona Board of Regents, Library of Congress Catalog, U.S.A. $143 p p$.

Walter, D.E. \& Proctor, H.C. 1999. Mites: Ecology, Evolution and Behavior. Wallingford, UK, CAB Int. 322pp.

Wang, H.F. 1981. A new species of Aponychus from China (Acarina: Tetranychidae). Acta Entomologica Sinica, 24(2): 221-222.

Wathrous, L. E. \& Q. D. Wheeler. 1981. The out-group comparison method of character analysis. Systematic Zoology, 30: 1-11.

Xie, L., Miao, H. \& Hong, X-Y. 2006. The two spotted spider mite Tetranychus urticae Koch and the carmine spider mite Tetranychus cinnabarinus (Boisduval) in China mixed in their Wolbachia phylogenetic tree. Zootaxa, 1165: 33-46.

Zaher, M.A., Gomaa, E.A. \& El-Enany, M.A. 1982. Spider mites of Egypt (Acari: Tetranychidae). International Journal of Acarology, 8(2): 91-114.

Zhang, Z-Q, Zhang, Y. \& Lin, J. 2000a. Taxonomic notes on Stylophoronychus (Acari: Tetranychidae) with new data for $S$. baghensis infesting moso bamboo in Fujian, China. 
Systematic \& Applied Acarology Special Publications 4: 37-47.

Zhang, Y., Lin, J., Zhang, Z-Q., Song, M., Ji, J. \& Liu, Q. 2000b. Key factor affecting populations of Schizotetranychus nanjingensis, Aponychus corpuzae and Aculus bambusae in Fujian bamboo forests during different seasons: an analysis using methods of grey sequence. Systematic \& Applied Acarology Special Publications 4: 125-160. 